DEVELOPMENT AND MECHANICAL CHARACTERIZATION OF GLASS/FLAX/EPOXY HYBRID COMPOSITE PLATES FOR FEMUR FRACTURE FIXATION

\author{
by \\ Saeed Manteghi \\ Bachelor of Mechanical Engineering (BEng) \\ Ryerson University, Toronto, 2014 \\ A Thesis \\ Presented to Ryerson University \\ in partial fulfillment of the \\ requirements for the \\ Degree of Master of Applied Science \\ in the Program of Mechanical Engineering
}

Toronto, Ontario, Canada, 2016

(C) Saeed Manteghi, 2016 


\section{Author's Declaration}

I hereby declare that I am the sole author of this thesis or dissertation. This is the true copy of the dissertation, including any required final versions, as accepted by my examiners.

I authorize Ryerson University to lend this dissertation to other institutions or individuals for the purpose of scholarly research.

I further authorize Ryerson University to reproduce this dissertation by photocopying or by other means, in total or in part, at the request of other institutions or individuals for the purpose of scholarly research.

I understand that my dissertation may be made electronically available to the public. 


\title{
Abstract \\ Development and Mechanical Characterization of Glass/Flax/Epoxy Hybrid Composite Plates for Femur Fracture Fixation
}

\author{
Saeed Manteghi \\ Master of Science (MASc) \\ Department of Mechanical and Industrial Engineering \\ Ryerson University \\ 2016
}

The purpose of this study is to investigate the mechanical feasibility of a hybrid Glass/Flax/Epoxy composite material for bone fracture fixation such as fracture plates. These hybrid composite plates have a unique sandwich structure in which the outer layers are made of Glass/Epoxy and the core from Flax/Epoxy. In order to evaluate the mechanical properties of this hybrid composite, static and dynamic tests, Rockwell hardness test as well as water absorption tests were performed. This study confirms that the proposed hybrid composite plates are significantly more flexible axially compared to conventional metallic plates. Furthermore, they have considerably higher ultimate strength in tension, compression and flexion. Such high strength will ensure good stability of boneimplant construct at the fracture site, immobilize adjacent bone fragments and carry clinical-type forces experienced during daily normal activities. Moreover, this sandwich structure with stronger and stiffer face sheets and more flexible core can result in a higher stiffness and strength in bending compared to tension and compression. These qualities make the proposed hybrid composite an ideal candidate for the design of an optimized fracture fixation system with much closer mechanical properties to human cortical bone. 


\section{Acknowledgment}

After an intensive period of two years, writing this acknowledgment is the finishing touch on my thesis. It has been a period of intense learning for me, not only in the scientific arena, but also on a personal level. Working through this project and writing this thesis has had a great impact on me. I would like to reflect on the people who have supported and helped me so much throughout this period.

First and foremost, I would like to express my deepest and sincerest gratitude to my dear supervisors Dr. Habiba Bougherara and my co-supervisor Dr. Zouheir Fawaz. I owe much of this accomplishment to them. Thank you for your guidance, support, and for providing a great learning environment. I would like to thank members of both Material Science lab, Alan Machin, and Aerospace Engineering Frames lab, Dr. Hamid Ghaemi, for their expertise and assistance at all levels of this research project.

I would also like to acknowledge my dear friend Dr. Ziauddin Mahboob who has helped me a lot in developing and manufacturing of the specimens as well as performing experiments especially fatigue tests. Completion of tasks would not have been possible without his guidance and constant support during this study.

A very special thanks goes out to my dear friend Payam Emadi, without whose support and editing assistance, I would not have finished this thesis. Moreover, I thank undergraduate student RAs Cindy Truong and Maryam Nejatian for all their assistance they provided through this study.

Finally, I would like to thank my family and friends for their constant support and motivation. Having caring people around is a blessing to me and I deeply believe this achievement was possible only through their enduring love, guidance and support. 


\section{Table of Contents}

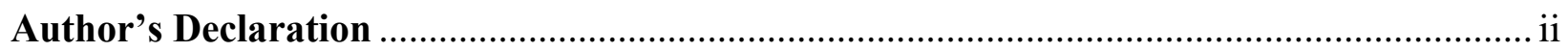

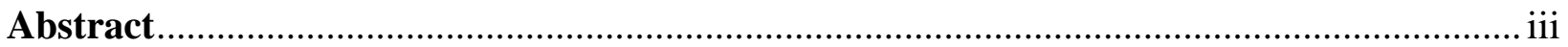

Acknowledgment

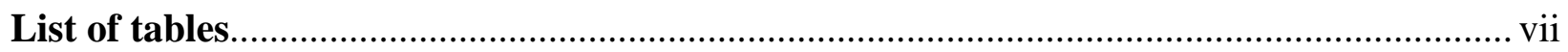

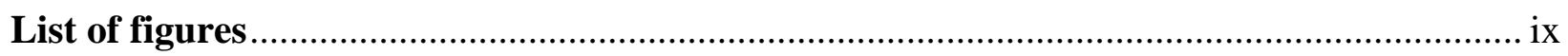

Commonly used terminology ..................................................................................... $\mathrm{xvi}$

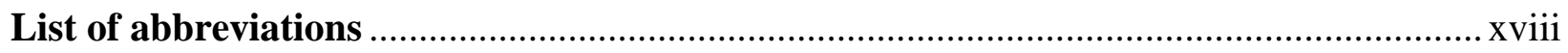

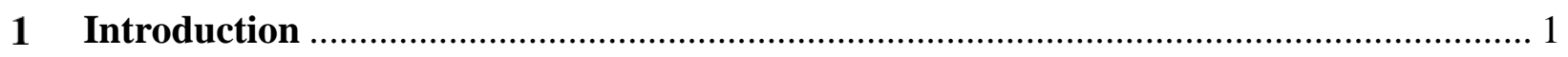

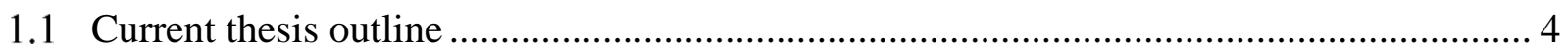

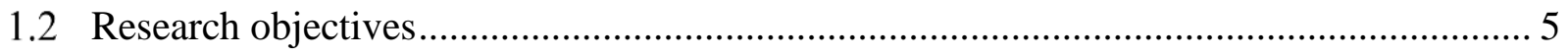

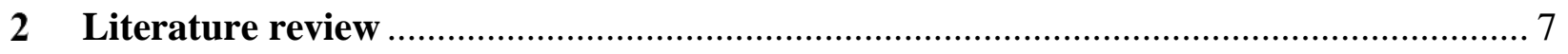

2.1 Human femur ..................................................................................................... 7

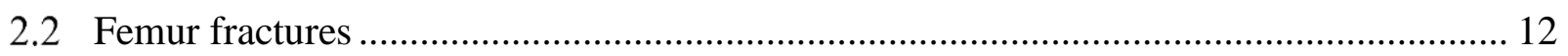

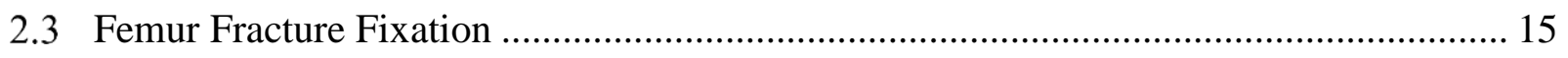

2.4 Stress shielding versus selective stress shielding ........................................................ 25

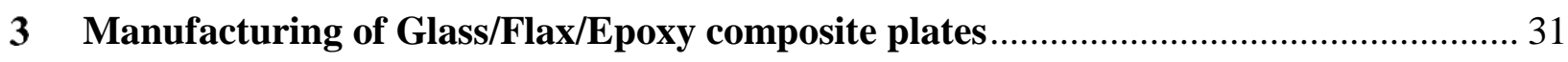

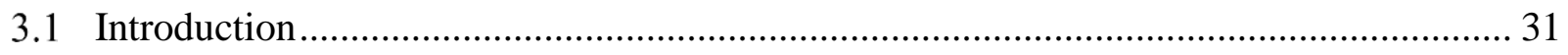

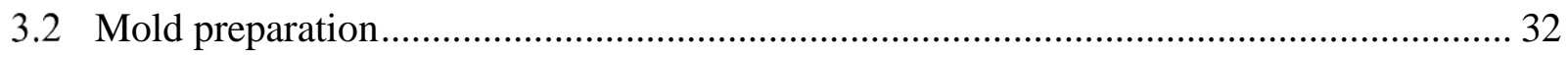

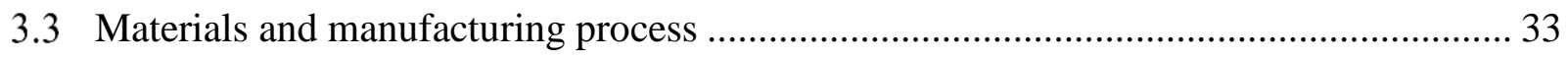

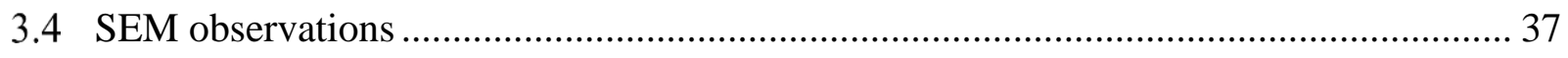

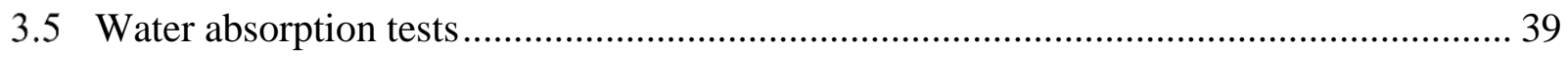

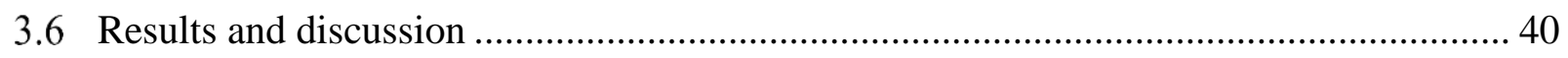

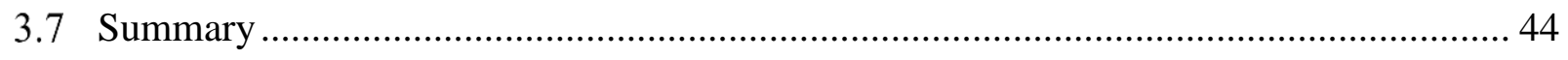




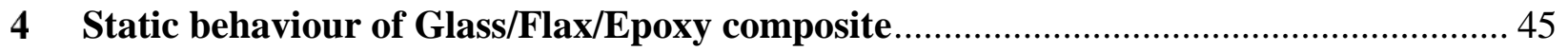

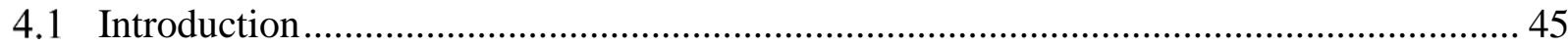

4.2 Materials and manufacturing process of Glass/Flax/Epoxy specimens ......................... 46

4.3 General study design and experimental methods................................................. 47

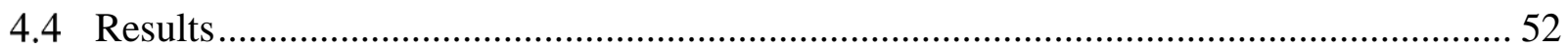

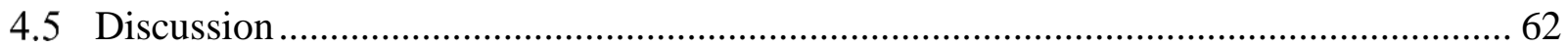

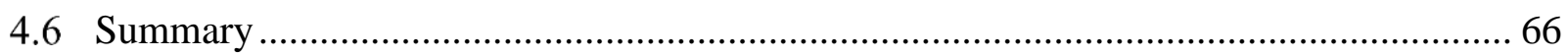

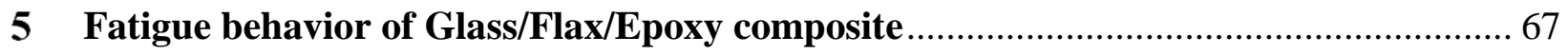

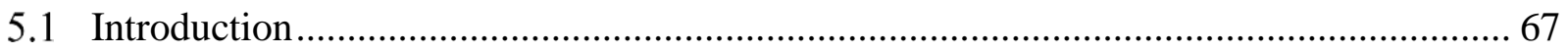

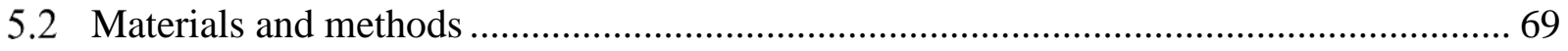

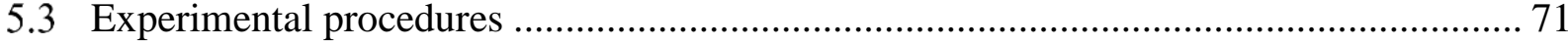

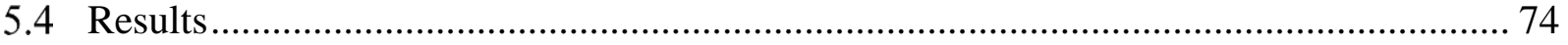

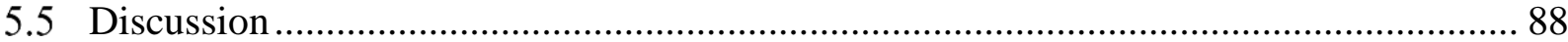

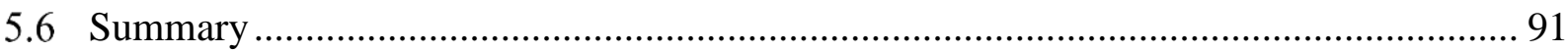

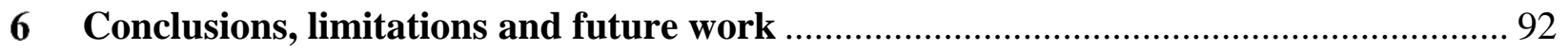

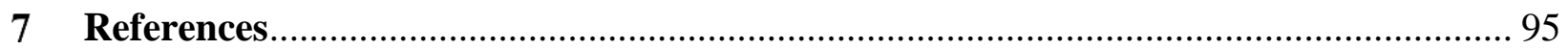




\section{List of tables}

Table 1: Approximate values for the material properties of the human femur; cortical and cancellous bones

Table 2: Mechanical properties of the cortical bone and alloys used in fixation plates

Table 3: Average constituent fraction for $[0 \mathrm{G} 2 / 0 \mathrm{~F} 6] s$ and $[0 \mathrm{G} 2 / \pm 45 \mathrm{~F} 6] s$ samples 41

Table 4: Result of water absorption tests performed in curent study accomponied with results of other composite material reported by prior studies.

Table 5: Overall results of tension test on unidirectional [0G2/0F6]s Glass/Flax/Epoxy composite specimens 52

Table 6: Overall results of tension test on $[0 \mathrm{G} 2 / \pm 45 \mathrm{~F} 6]$ s Glass/Flax/Epoxy composite specimens

Table 7: Overall results of compression test on unidirectional [0G2/0F6]s Glass/Flax/Epoxy composite specimens 56

Table 8: Overall results of compression test on $[0 \mathrm{G} 2 / \pm 45 \mathrm{~F} 6]$ s Glass/Flax/Epoxy composite specimens 57

Table 9: Overall results of bending test on unidirectional [0G2/0F6]s Glass/Flax/Epoxy composite specimens

Table 10: Overall results of bending test on unidirectional [0G2/ $\pm 45 \mathrm{~F} 6] \mathrm{s}$ Glass/Flax/Epoxy composite specimens

Table 11: Comparison of the surface hardness for some material. 61

Table 12: Elastic modulus of the current Glass/Flax/Epoxy composite along with some previously studied material, $\mathrm{E}_{\mathrm{lT}}$ is tensile Young's modulus, $\mathrm{E}_{\mathrm{lC}}$ is compressive Young's modulus and $\mathrm{E}_{\mathrm{f}}$ is flexural modulus 
Table 13: Ultimate strength of the current Glass/Flax/Epoxy composite along with some previously studied material, $\sigma^{\mathrm{TT}} \mathrm{U}$ is ultimate tensile strength, $\sigma^{\mathrm{lC}} \mathrm{U}$ is ultimate compressive strength and $\sigma^{\mathrm{F}} \mathrm{U}$ is ultimate flexural strength

Table 14: Overall results of Compression test on five specimens (SP 1 to SP 5) of unidirectional

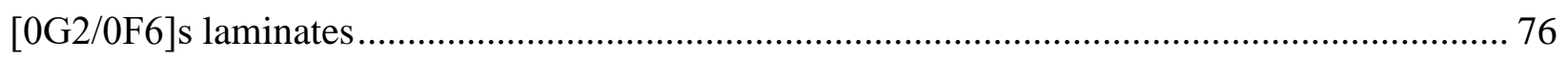

Table 15: Overall results of compression test on five specimens (SP 1 to SP 5) of [0G2/士45F6]s laminates 78

Table 16: Integration parameter $\Phi$ for the $[0 \mathrm{G} 2 / 0 \mathrm{~F} 6] \mathrm{s}$ and $[0 \mathrm{G} 2 / \pm 45 \mathrm{~F} 6] \mathrm{s}$ laminates ................ 87

Table 17: Average, standard deviation and coefficient of variation of $\Phi$ 87

Table 18: Fatigue properties of the current Glass/Flax/Epoxy materials, human femur cortical bone, carbon fiber composite, and flax fiber composites from prior studies 89 


\section{List of figures}

Figure 1: Various applications of composite biomaterials [24] .............................................. 2

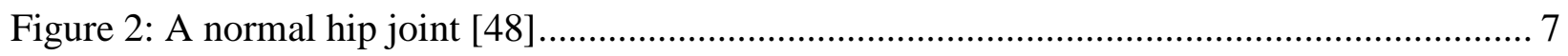

Figure 3: Anatomy of human femoral bone [49] ............................................................ 8

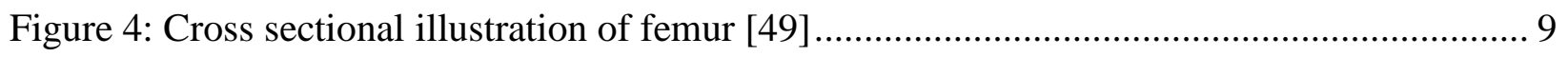

Figure 5: Trabecular system of femoral neck [51] ........................................................ 10

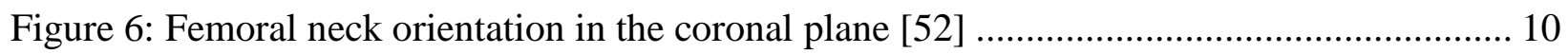

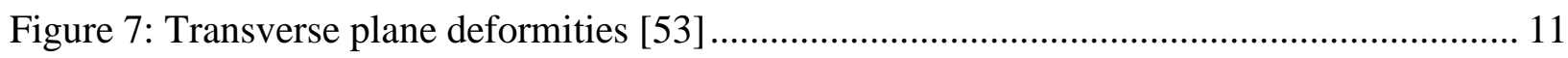

Figure 8: Different types of proximal fractures; a) trochanteric fracture, b) femoral neck fracture,

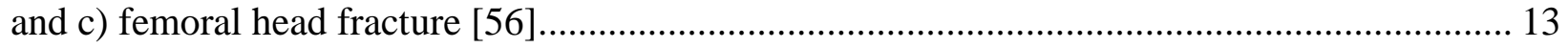

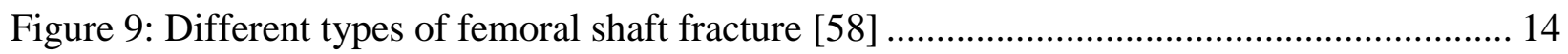

Figure 10: Different types of distal femur fracture: A1-A3) extra-articular, B1-B3) partial articular,

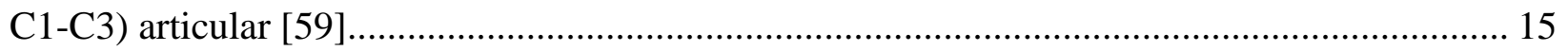

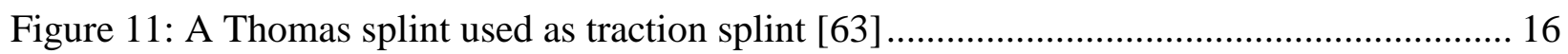

Figure 12: A young child in a hip spica cast to immobilize a femoral shaft fracture [64] .......... 17

Figure 13: A) Wire (on the left), B) Steinman pin (on the right) for traction technique [65] ...... 18

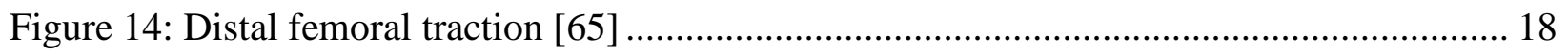

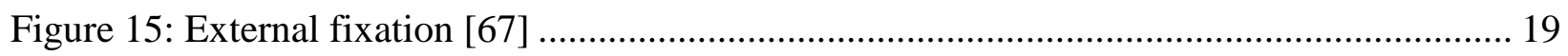

Figure 16: Interamedullary nailing femoral fixation; A and B are antegrade nailing, C and D are

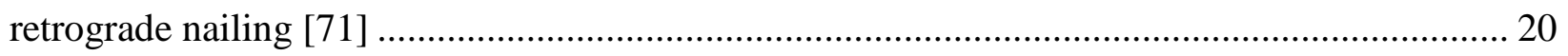


Figure 17: Conventional plating fixation: the green arrows show that the bone is compressed [76]

Figure 18: . Locked screw plating fixation: the plate and screw are rigidly held in place and do not alter the position of bone segments [76] 22

Figure 19: Neutralization plate used in combination with lag screw [77]. 23

Figure 20: Compression plate fixed with screws and pulled by tensioner [77]. 23

Figure 21: Carbon fibre reinforced epoxy fracture plates [24]. 28

Figure 22: X-ray images of a mid-shaft tibial fracture, after plating with a carbon fibre reinforced epoxy bone plate for 37 weeks [24]. 28

Figure 23: Wrapped base plate with silicone tape borders 32

Figure 24: Base plate with peeling membrane. 33

Figure 25: Lineo flax ply sample with yarn strands ratio $0^{\circ}: 90^{\circ}$ equal to $40: 3 \ldots$ 33

Figure 26: Unidirectional E-Glass ply sample with randomly distributed yarns to hold the UD fibers in place. 34

Figure 27: Mold and plate fabrication set up..... 34

Figure 28: Spreading the matrix using a brush and then raking of resin using rigid roller upon fiber Sheets 35

Figure 29: Mold Inside the membrane bag, loaded into the compression molding machine; before and after compression 35

Figure 30: The three stage curing cycle used in specimens manufacturing process 36

Figure 31: A $100 \mathrm{X}$ SEM image of the cross section of a sample showing fiber, matrix, voids and other flaws 37 
Figure 32: Polished sample mounts ready for optical observation; left) [0G2/0F6]s samples, right) [0G2/士45F6]s samples 38

Figure 33: A SEM image at 100X magnification of [0G2/0F6]s samples. 39

Figure 34: Constituent fraction evaluation using Buehler Omnimet software (Unidirectional laminate, image \#14).

Figure 35: A generic results from Buehler Omnimet software for constituents fraction (Unidirectional laminate, image \#14)

Figure 36: A typical SEM image from Glass/Flax layers interface of [0G2/0F6]s sample at 100X magnification

Figure 37: A typical SEM image from Glass/Flax layers interface of [0G2/ $\pm 45 \mathrm{~F} 6] s$ sample at 100X magnification 42

Figure 38: Average weight increase (\%) vs. time for specimens with ply configuration [0G2/0F6]s and $[0 \mathrm{G} 2 / \pm 45 \mathrm{~F} 6] \mathrm{s}$ 43

Figure 39: The novel "sandwich structure" of Glass/Flax/Epoxy plate 46

Figure 40: Tension test set up..... 48

Figure 41: Compression test set up.

Figure 42: Bending test set up 50

Figure 43: Rockwell hardness test set up 51

Figure 44: Tension test results for five test specimens (SP01-SP05) for [0G2/0F6]s laminate ... 52 Figure 45: Tension test results for five test specimens (SP01-SP05) for [0G2/ $\pm 45 \mathrm{~F} 6]$ s laminate53 Figure 46: Catastrophic failure of specimens in tension test; (a) [0G2/0F6]s Laminate, (b) $[0 \mathrm{G} 2 / \pm 45 \mathrm{~F} 6] \mathrm{s}$ laminate 54 
Figure 47: SEM image of failed surface of Flax bundle of a) [0G2/0F6]s and b) [0G2/ $\pm 45 \mathrm{~F} 6] \mathrm{s}$

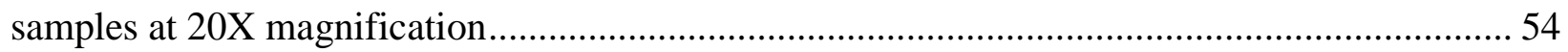

Figure 48: SEM image of failed surface Flax bundle of a) [0G2/0F6]s and b) [0G2/ $\pm 45 \mathrm{~F} 6] \mathrm{s}$ samples at 100X magnification, fiber pull out and shearing can be seen 55

Figure 49: SEM image of failed Flax fiber of a [0G2/0F6]s sample at 2000X magnification; fiber exhibited smooth tensile failure surfaces after being pulled out.................................................... 55

Figure 50: Compression test results for five test specimens (SP01-SP05) for [0G2/0F6]s laminate 56

Figure 51: Compression test results for five test specimens (SP01-SP05) for [0G2/ $445 \mathrm{~F} 6] \mathrm{s}$ laminate 57

Figure 52: Typical failed specimens in compression: a) [0G2/0F6]s, b) $[0 \mathrm{G} 2 / \pm 45 \mathrm{~F} 6] \mathrm{s}$ laminates 58

Figure 53: Bending test results for five test specimens (SP01-SP05) for [0G2/0F6]s laminate... 58

Figure 54: Bending test results for five test specimens (SP01-SP05) [0G2/ $\pm 45 \mathrm{~F} 6]$ s laminate .... 59

Figure 55: A typical failed specimen from bending test; a side view (left) shows the failure on the compression surface of the sample. Matrix cracking, fiber breakage and pull out on the failed surface (right) 60

Figure 56: A specimen in three point bending test loaded until it reached $60 \mathrm{~mm}$ displacement 60 Figure 57: A specimen in three point bending test after being unloaded recover its shape from 60 mm displacement 61

Figure 58: Schematic of fatigue damage developing for a cross-ply laminate [135] ................... 68

Figure 59: The novel "sandwich structure" of Glass/Flax/Epoxy plate. ...................................... 70

Figure 60: A 100mm x 25mm speckled specimen for compression test .................................... 71 
Figure 61: Compression test set up; left) a speckled specimen gripped between hydrolic heads, right) compression test set up with DIC camera capturing images

Figure 62: Compression-compression fatigue test set up; IR camera used in this study is shown in left figure. 73

Figure 63: Force vs. displacement of five tested specimens (SP 1 to SP 5) of [0G2/0F6]s unidirectional laminates 75

Figure 64: Typical stress vs. Strain curve for [0G2/0F6]s unidirectional laminates 76

Figure 65: Force vs. displacement of five tested specimens (SP 1 to SP 5) of [0G2/ $\pm 45 \mathrm{~F} 6] \mathrm{s}$ laminates 77

Figure 66: Typical stress vs. strain for curve [0G2/ $\pm 45 \mathrm{~F} 6]$ s laminates 77

Figure 67: Strain profile $\left(\mathcal{E}_{\mathrm{xx}}\right)$ in longitudinal direction of a DIC image of a [0G2/0F6]s sample; purple represent lower starin level and red represent a higher starin level...... 79

Figure 68: Strain $\left(\mathcal{E}_{\mathrm{xx}}\right)$ profile in \pm 45 direction of a DIC image of a [0G2/ $\left.\pm 45 \mathrm{~F} 6\right] \mathrm{s}$ sample; purple represent lower starin level and red represent a higher starin level. 79

Figure 69: $\mathrm{S}-\mathrm{N}$ curve for the $[0 \mathrm{G} 2 / 0 \mathrm{~F} 6] \mathrm{s}$ laminates; load ratio $\mathrm{R}=0.1$, frequency $=5 \mathrm{~Hz}$, and $\mathrm{UCS}=261.73 \mathrm{MPa}$ 80

Figure 70: S-N curve for the $[0 \mathrm{G} 2 / \pm 45 \mathrm{~F} 6] \mathrm{s}$ laminates; load ratio $\mathrm{R}=0.1$, frequency $=5 \mathrm{~Hz}$, and $\mathrm{UCS}=231.87 \mathrm{MPa}$. 80

Figure 71: Typical stress $(\sigma)$ versus strain $(\varepsilon)$ curve for one plate loaded at $70 \%$ of UCS. 81

Figure 72: Dynamic elastic modulus $E^{*}$ versus normalized number of cycles $\left(\mathrm{N} / \mathrm{N}_{\mathrm{f}}\right)$ in $[0 \mathrm{G} 2 / 0 \mathrm{~F} 6] \mathrm{s}$ unidirectional laminates. $\mathrm{N}=$ number of cycles. $\mathrm{N}_{\mathrm{f}}=$ number of cycles at failure 82

Figure 73: : Dynamic elastic modulus $E^{*}$ versus normalized number of cycles $\left(N / N_{f}\right)$ in [0G2/ $\pm 45 F 6]$ s laminates. $\mathrm{N}=$ number of cycles. $\mathrm{N}_{\mathrm{f}}=$ number of cycles at failure 82 
Figure 74: A typical graph of thermal variation vs. number of cycles of a [0G2/0F6]s plate under stepwise fatigue loading test; every 5000 cycles load increases to next step 83

Figure 75: Temperature distributions at the surface of a [0G2/0F6]s laminate as a function of number of cycles at $75 \%$ of UCS; a) sample at 1000 cycles, b) sample at 2500 cycles an temperature stabilized at $61{ }^{\circ} \mathrm{C}$. 84

Figure 76: Temperature distributions at the surface of a $[0 \mathrm{G} 2 / \pm 45 \mathrm{~F} 6] \mathrm{s}$ laminate as a function of number of cycles at $75 \%$ of UCS; a) sample at 1000 cycles, b) sample at 2500 cycles an temperature stabilized at $34^{\circ} \mathrm{C}$. 84

Figure 77: Average thermal variations versus number of cycles for stepwised applied stress as a fraction $(\%)$ of UCS on the $[0 \mathrm{G} 2 / 0 \mathrm{~F} 6] \mathrm{s}$ laminates 85

Figure 78: Average thermal variations versus number of cycles for stepwised applied stress as a fraction $(\%)$ of UCS on the $[0 \mathrm{G} 2 / \pm 45 \mathrm{~F} 6]$ s laminates 85

Figure 79: Average stabilized temperature versus the applied stress level of [0G2/0F6]s laminates 86

Figure 80: Average stabilized temperature versus the applied stress level of $[0 \mathrm{G} 2 / \pm 45 \mathrm{~F} 6] \mathrm{s}$ laminates 86 


\section{Units used}

$\begin{array}{ll}\mathbf{M P a} & \text { Mega Pascal } \\ \mathbf{G P a} & \text { Giga Pascal } \\ \mathbf{W} / \mathbf{m K} & \text { Thermal Conductivity } \\ \mathbf{k g} & \text { Kilogram } \\ \mathbf{k W} & \text { Kilowatt } \\ \mathbf{N} & \text { Newton } \\ \mathbf{g} / \mathbf{c m}^{\mathbf{3}} & \text { Density } \\ \mathbf{H z} & \text { Hertz (One cycle per second) }\end{array}$




\section{Commonly used terminology}

Anterior Towards the front of the body

Biocompatibility The property of being biologically compatible by not producing a toxic, injurious, or immunological response in living tissue

Cancellous bone Sponge bone tissue contained in inner space of bone

Condyle A rounded prominence at the end of a bone, most often for articulation with another bone

Contralateral Taking place or originating in a corresponding part on an opposite side

Cortical bone The compact bone of the shaft of a bone that surrounds the marrow cavity

Diaphysis The shaft of a long bone, between the epiphyses

Distal Situated farthest from the centre, median line, or point of attachment or origin

Femur The longest thickest bone of the human skeleton, articulating with the pelvis above and the knee below

Intercondylar Between two condyles

Lateral Situated or extending away from the median plane of the body

Medial Situated toward the median plane or midline of the body or a structure

Metaphysis The wider part at the end of a long bone, adjacent to the epiphyseal disk

Osteopenia $\quad$ Reduced bone mass due to a decrease in the rate of osteoid synthesis to a Level insufficient to compensate for normal bone lysis

Osteoporosis A disease characterized by decrease in bone mass and density

Physiologic Relating to the way that living things function, rather than to their shape or structure

Posterior Towards the rear of the body

Prosthesis An artificial substitute for a missing body part, such as an arm, leg, eye, or tooth; used for functional or cosmetic reasons or both 
Proximal

Resorption

Trochanter
Nearest to a point of reference, as to a center or median line or to the point of attachment or origin

The loss of substance or bone by physiologic or pathologic means, such as the reduction of the volume and size of the residual ridge of the mandible or maxillae

A broad, flat process on the femur, at the upper end of its lateral surface, or a short conical process on the posterior border of the base of its neck 


\section{List of abbreviations}

MTT

CF

BMP

CAD

PMMA

HCFS

CA

BW

FEA

IR

IRT

TSA

MRI

CT

HA

UCS

UFS

UTS

SEM
Methyl tetrazolium

Carbon fiber

Bone morphogenetic protein

Computer aided design

Poly methyl methacrylate

High cyclic fatigue strength

Contact angle

Body weight

Finite element analysis

Infrared

Infrared thermography

Thermoelastic stress analysis

Magnetic resonance imaging

Computerized tomography

Hydroxyapatite

Ultimate compressive strength

Ultimate flexural strength

Ultimate tensile strength

Scanning electron microscopy 


\section{Introduction}

The term " advanced engineering composite material"' refers to the combination of a soft (matrix) and a strong (reinforcement) constituent that are combined together in order to facilitate the production process, enhance the properties of the matrix and assist in transferring load between the stiff and strong reinforcements [1]. Composite materials due to their significant physical, mechanical and thermal properties, corrosion resistance and dimensional stability are being extensively used in our day-to-day life as an important category of material properties for designing structural components in engineering applications such as aerospace, automotive and biomechanical application [2]. These outstanding mechanical properties depending on the end use of the composite can be tailored by altering the type of the fibrous reinforcements and their placement orientation in the composite structure $[1,3]$.

In recent years, composite materials have been considered for biomedical applications (i.e. fracture fixation mechanism such as plates and IM nails) since they have mechanical and biological similarities to the human tissue as well as having the potential to be manipulated to have combinations of properties that cannot be obtained by conventional materials $[4,5,6]$. Composite implants have some advantages compared to metal implants such as radiolucency (i.e. they appear dark on exposed radiographic film), compatibility with modern medical imaging like MRI (magnetic resonance imaging) and CT (computerized tomography) scans making clinical monitoring easier [7, 8]. However, there some complications facing composite materials such as degradation of the properties over time even under low amplitude cyclic loading [1], diminution of the properties in bodily humid atmosphere, and risk of implant breakage [2,9] . In addition, some of these composite materials may generate of wear debris, which will in turn trigger inflammation (i.e. soft tissue thickening), osteolysis (i.e. bone cell resorption), and cytotoxicity (i.e. slowed or halted bone cell proliferation), which may eventually lead to implant loosening and/or failure $[10,11,12]$.

The applications of composite materials in orthopaedics can be traced back to the 1980s, when they were initially used for fracture fixation and joint replacement in cases of trauma $[13,14,15]$. Studies have considered composite materials for various biomedical applications: spinal cage for 
degenerative discs [16, 17], filling bone defects for anchoring into bone [18, 19], and orthopaedic trauma implants [6].

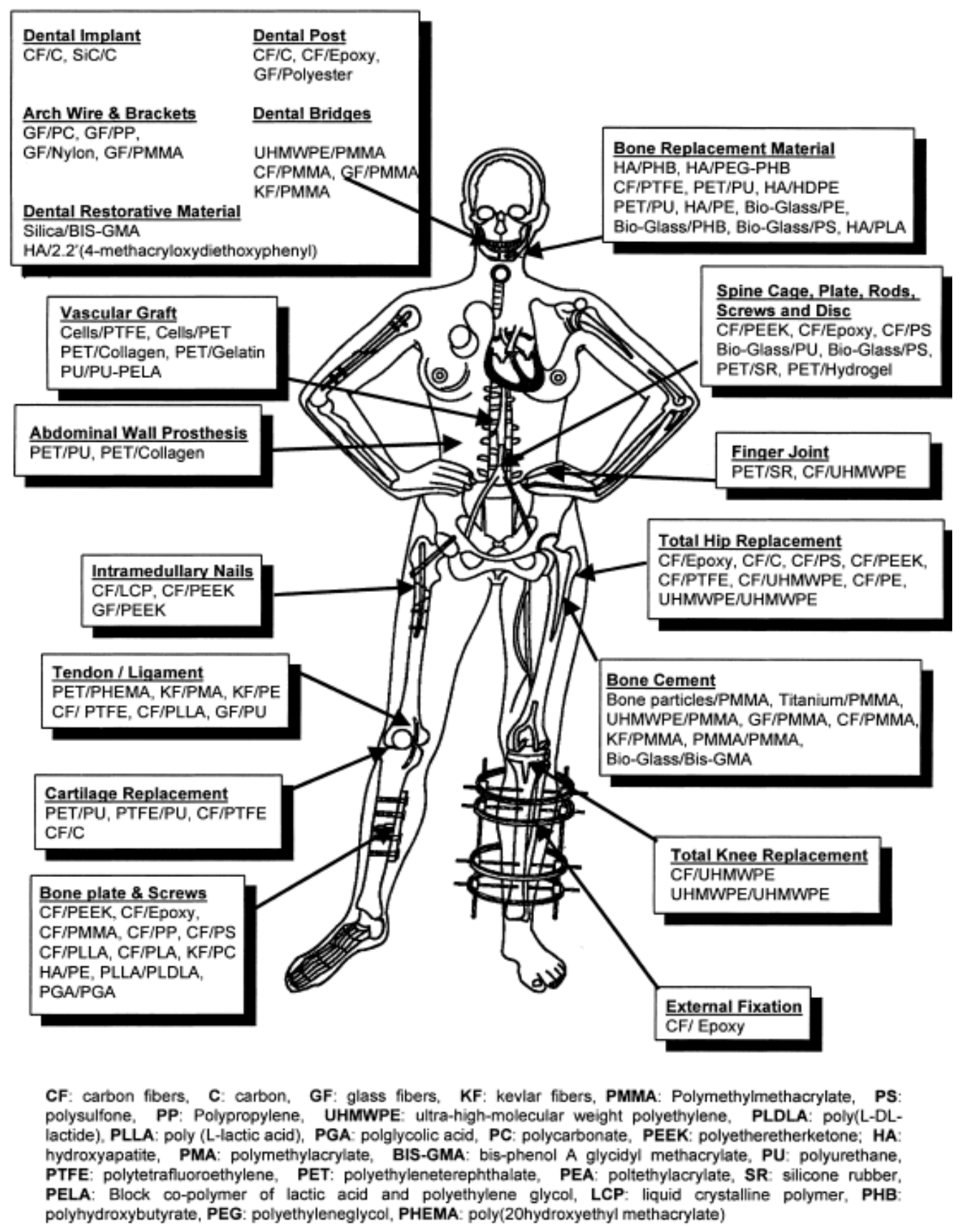

Figure 1: Various applications of composite biomaterials [20]

A fracture of a long bone can be treated using various methods (i.e. surgical or non-surgical) depending on the location of the fracture and severity of the fracture. According to the American Academy of Orthopaedic Surgeons, depending on the physical condition of the patient, healing 
can begin to occur as early as 6 weeks. However, an average required time for a fractured femur to heal fully is about 3 to 6 months [7]. Such a long healing period leads to a high chance of misalignment. Therefore, the fractured femur requires an aid to enhance its healing process and to provide proper alignment [21]. An efficient fixation device must have mechanical properties close to the bone plate [22] in order to allow some levels of axial movements between fracture ends while stabilizing the fracture site by minimizing the unfavourable fragments' motions [23]. Therefore, the fixation mechanism must fully tolerate the torsional and bending loads (high bending and torsional stiffness) while being axially flexible [24].

The focus of the present study is to investigate the possibility of using a new composite material in designing fracture plates commonly used in long bone fractures such as femoral shaft fractures. Although, the conventional metallic plates made of titanium (Ti)-alloys or stainless steel can provide appropriate stability at the fracture site because of their high bending and torsional stiffnesses [25]. However, their axial stiffness are much higher compared to human cortical bone and they can result in removal of normal stress from the bone, known as "stress shielding" effect [26], causing the bone to adapt by reducing its density which can slow the healing process or lead to re-fracture $[23,27]$. Therefore, to address these drawbacks, any material that could promote selective stress shielding would be favorable in order to reduce the axial stiffness while maintaining the adequate bending and torsional stiffnesses [24]. The composite fixation mechanism significantly increase the load levels on the surrounding bone while remaining stiff [14] and strong enough to stabilise the fracture site and withstand physiologic loading [24]. Moreover, due to customizability of the composite material, a composite plate with similar geometry to conventional plates can be optimized by manipulating fiber orientation or the stacking sequence of plies to yield desired stiffness and strength in different directions [18, 24].

Significant research have been done to develop polymer based fibre reinforced composite materials for bone fracture plate applications [18]. Among them, those reinforced with natural fibers such as Roselle, banana, and sisal [28, 29], or the ones reinforced with synthetic fibers. This includes, unidirectional lamina [30], discontinuous short fiber [31], glass fiber reinforce composite implants [18], bio active glass composite [32, 33, 34], Coir/ biopolymers and Coir/Bioepoxy green natural fiber composites [35], fiber reinforced PEEK [36] and braided fibers [37]. In addition, other investigations have focused on hybrid composites, which were made from a combination of both 
synthetic and natural fibres [38]. Despite all well-known advantages of natural fibres-based composites, there are still some limitations, which will require further improvement. These limitations include moisture absorption due to hydrophobicity [39], dimensional stability, poor wettability, low thermal stability during processing and poor adhesion with synthetic fibres [40]. Therefore, in order to overcome these limitations, a combination of two or more natural and synthetic fibres into a single matrix has led to the development of hybrid composites [41, 42] which can provide a desired set of mechanical properties with acceptable performance in different directions which cannot be achieved by one single type of fiber [41, 43].

Since, limited number of studies have considered hybrid composites for bone fracture plate applications [7, 42], we propose to develop new and unique hybrid Glass/Flax/Epoxy composite plates having a sandwich structure with potential use for long bone fracture plate fixation.

\subsection{Current thesis outline}

The main objective of this research is to characterize the mechanical properties of a new Glass/Flax/Epoxy composite plate to evaluate its potential for clinical application such as long bone fracture fixation mechanism (i.e. fracture plates). For that reason, this study was divided into five main chapters, which provide an inclusive information about the manufacturing process and experimental procedures used to accomplish the research objectives.

Chapter 1 and chapter 2 include a comprehensive literature review including an introduction to the anatomy of femoral bone, clinical and biomechanical aspects of femur fracture, commonly used methods for femur fracture fixation including various type of surgical and non-surgical methods and a summary of the studies proposed less-rigid materials for manufacturing bone plates.

Chapter 3 will discuss the material and manufacturing process of the Glass/Flax/Epoxy plates. The material quality will be determined in terms of void, fiber and matrix fractions. Finally, the water absorption rate will be examined.

Chapter 4 will focus on the experimental procedures to characterize the static mechanical properties of the developed composite plate. The mechanical effectiveness of the developed composite material for fracture plate fixation will be examined considering its mechanical properties such as modulus of elasticity and ultimate strength when experiencing tension, 
compression and three-point bending loading condition. In addition, Rockwell hardness test is conducted to evaluate the surface quality of this material in comparison with conventional material used for biomedical application specifically fracture plate mechanism.

Chapter 5 will analyze the compression-compression fatigue behaviour of the developed composite material. First, mechanical properties such as longitudinal and transverse modulus of elasticities, poison ratio, as well as ultimate compression strength (UCS) will be determined. Then using the calculated UCS, fatigue characterization of the composite plates will be investigated. In particular, this chapter explores the compression-compression fatigue properties of the composite plate using conventional fatigue experiments and thermography techniques.

Chapter 6 concludes the important practical implementations of the current study. In addition, it addresses the main limitations of this work. Finally, future required works and studies related to this study (i.e., Glass/Flax/Epoxy composite materials for bone fracture plate applications) would be suggested.

\subsection{Research objectives}

The main purpose of this thesis is to develop a new Glass/Flax/epoxy hybrid composite material and to contribute to the existing body of knowledge about this material for long bone fracture fixation plates. Thus, two configurations of Glass/Flax/Epoxy composites layup namely, $\left[0_{\mathrm{G} 2} / 0_{\mathrm{F} 6}\right]_{\mathrm{S}}$ and $\left[0_{\mathrm{G} 2} / \pm 45_{\mathrm{F} 6}\right]_{\mathrm{S}}$ were manufactured using a compression molding facility. The static and dynamic mechanical properties of these two configurations were investigated in order to determine the adequate overall stiffness in repairing and healing of bone, while allowing the bone to absorb greater stresses (i.e. less “stress shielding") to achieve strong union at fracture site. These mechanical properties will be compared to those of conventional clinical metallic plates. To achieve the main objective, therefore, the following tasks were carried out:

a. An in-depth literature review on previous studies covering bone plate fixation

b. Manufacturing two configurations of Glass/Flax/Epoxy composite plates:

- Configuration \#1: $\left[0_{\mathrm{G} 2} / 0_{\mathrm{F} 6}\right]_{\mathrm{S}}$, with unidirectional plies

- Configuration \#2: $\left[0_{\mathrm{G} 2} / \pm 45_{\mathrm{F} 6}\right]_{\mathrm{S}}$ with unidirectional outer glass plies and inner $\pm 45^{\circ}$ angled flax plies. 
c. Evaluate the void content and water absorption rate

d. Static evaluation of the mechanical properties of these Glass/Flax/Epoxy composite plates using:

- Axial tension test

- Axial compression test

- Three-point bending test

- Rockwell hardness test

e. Dynamic evaluation of the expected failure life of the composite material under various loading condition and develop the S-N (Stress vs. Number of cycles) curve:

- Step loading compression-compression fatigue test for thermographic study

- Compression-compression fatigue test at various load; $60 \%$ - 90\% of UCS using conventional fatigue analysis

- Compression-compression fatigue test at various load; $60 \%-90 \%$ of UCS using thermography techniques

f. Comparing the results obtained from aforementioned tests with results reported by prior studies. 


\section{Literature review}

\subsection{Human femur}

The femur, commonly known as thighbone, has a cylindrical shape and is the longest and strongest bone in the human body (Figure 3). The distal end of the femur forms the femoral part of the knee joint, and the proximal end forms the femoral part of the hip joint [44]. The hip joint is a ball and socket joint, which composed of the round femoral head and the acetabular cup (Figure 2).

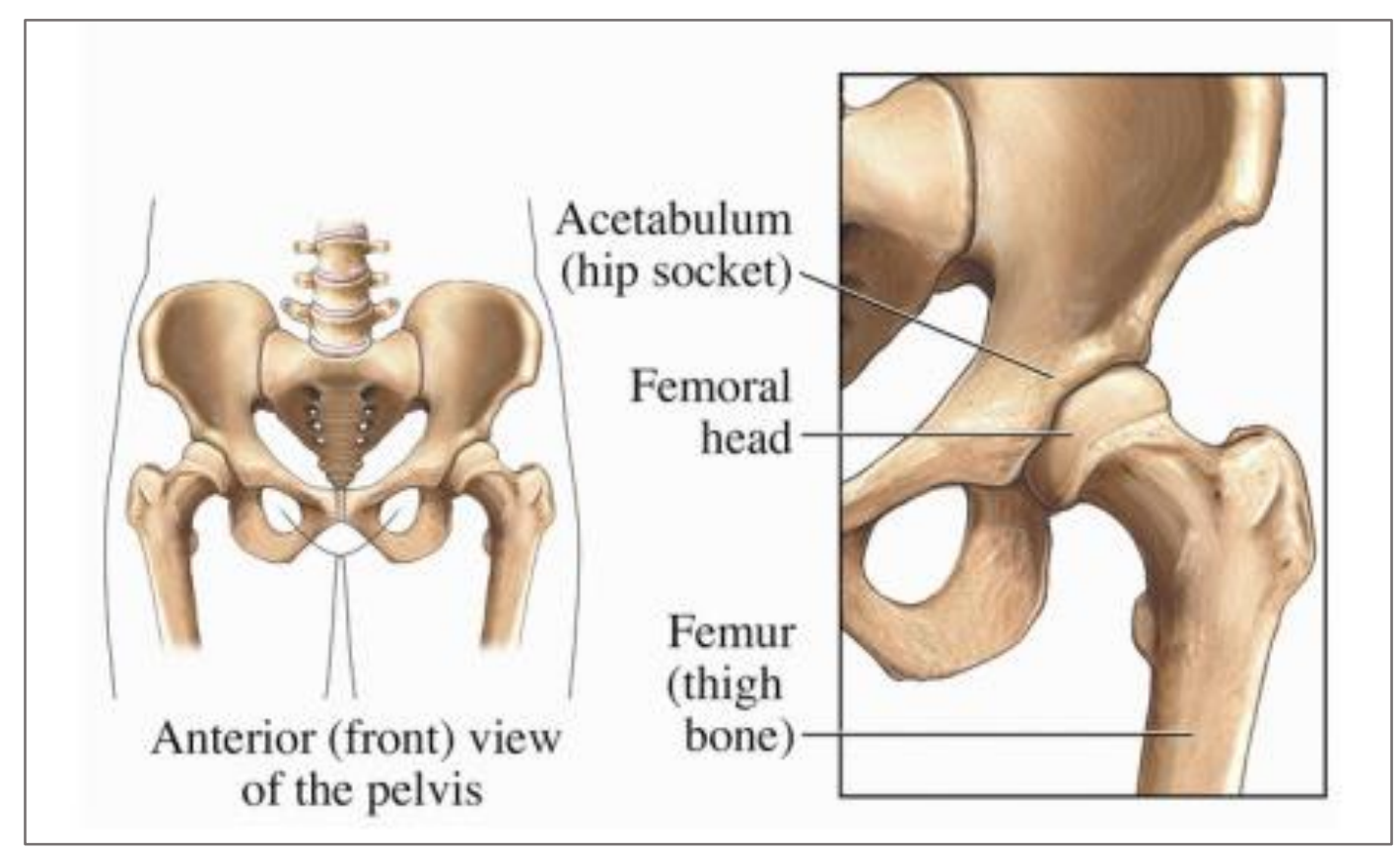

Figure 2: A normal hip joint [45]

The approximate diameter and length of a femur in an average healthy adult male are $23.4 \mathrm{~mm}$ and $480 \mathrm{~mm}$ respectively. This bone is capable of enduring two times the weight of an adult body. The width of the pelvis, which separates the knee joints at the distal end of opposing femurs, influence the degree of femur's inclination. Hence, the increased inclination in female is due to the greater length of the pelvis [44].

As illustrated in Figure 3, the proximal end of femur is composed of head, greater trochanter, and lesser trochanter. The medial and lateral condyles are located at the distal end, which form the superior part of the knee joint. The ends of the femur are connected through a long bone, known as femoral shaft [44]. 


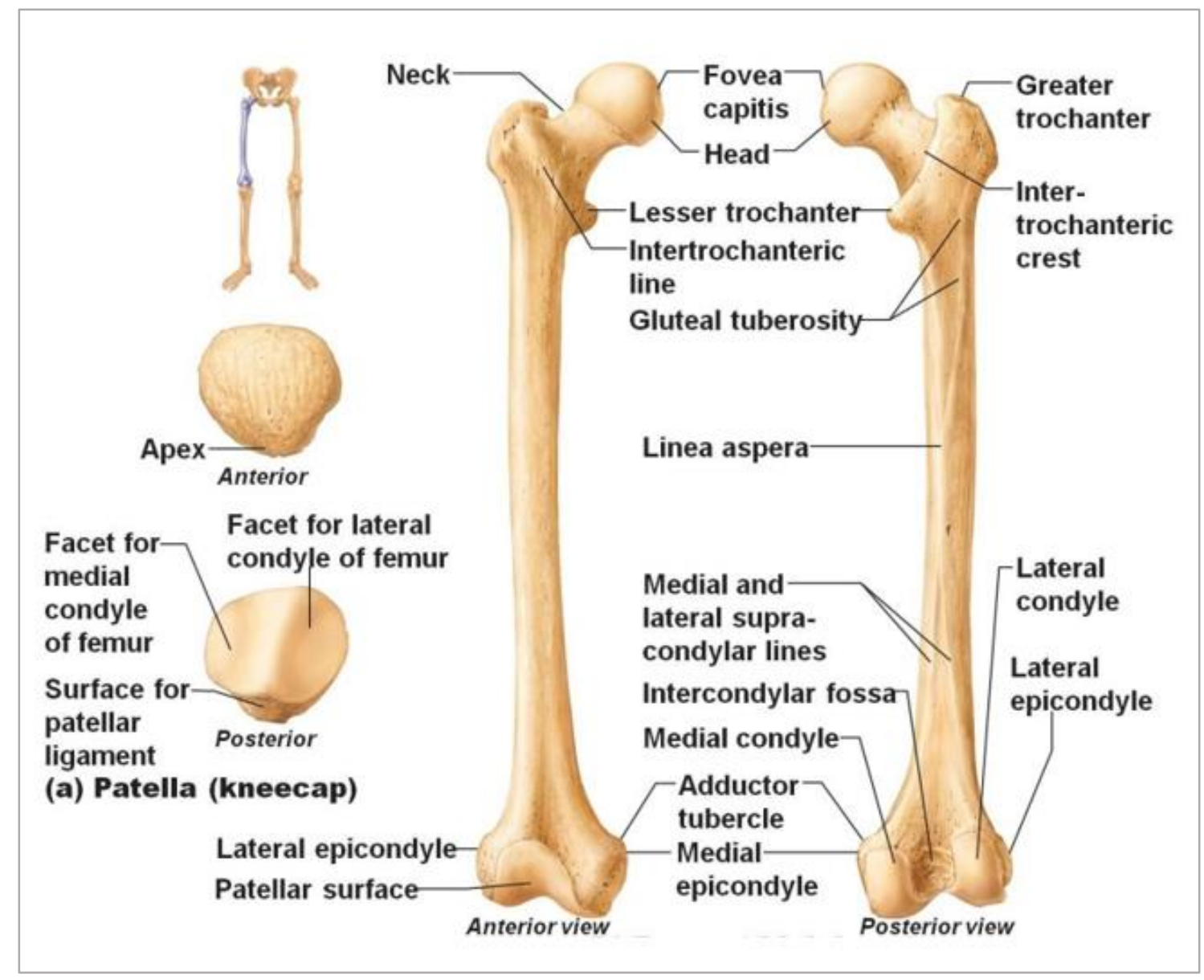

Figure 3: Anatomy of human femoral bone [46]

As illustrated in Figure 4, the innermost region of the femur, medullary cavity, is a hollow tube, which contains the yellow marrow. The distal end is fairly cuboid and larger in comparison with the proximal region. The shaft of the femur, also known as diaphysis, is made of cortical or compact bone. The two ends of the femur, epiphysis, are composed of spongy or trabecular bone. Spongy bone has a porous structure, which results in a softer and weaker structure compared with cortical bone. The transitional region from cortical bone to epiphysis is known as the metaphysis [47]. 


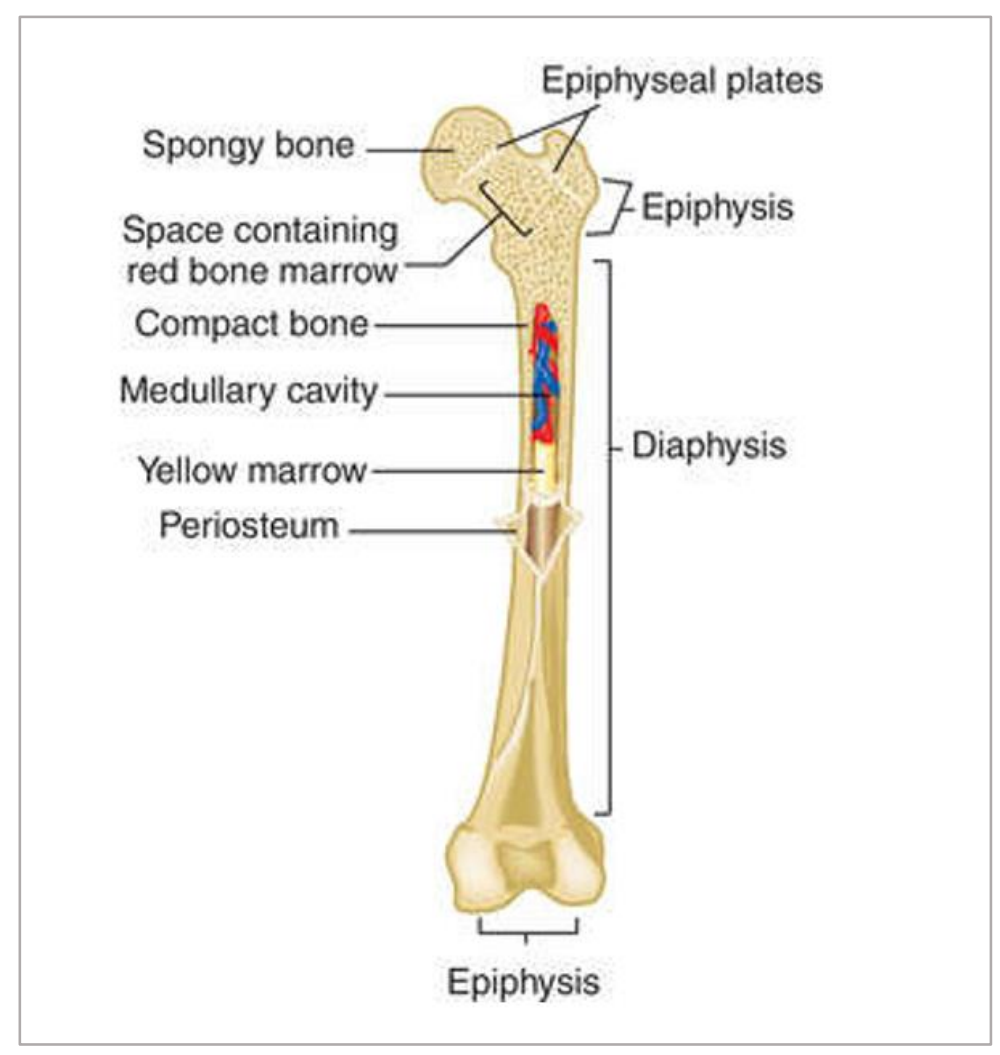

Figure 4: Cross sectional illustration of femur [46]

\subsubsection{Femoral head}

The femoral head is a medially positioned spherical bone that is located at the proximal region of the femur. This bone is connected to the stem through the femoral neck, which is directed upwards and slightly forwards. The cartilaginous surface of the head articulates with the hip through the acetabular cup. The medial-central area of the head's surface is covered with thicker cartilaginous layer to endure the increased applied load to the central lunate. Therefore, there are differences in stiffness and strength throughout the head's surface. [44, 46]

\subsubsection{Femoral neck}

Referring to Figure 5, femoral head and neck are mostly made of spongy or trabecular bone. Trabecular systems arrange in the direction of loading to provide supporting for the applied forces. The red and green lines in Figure 5 represent the trabecular system the femoral neck, which support the compressive and tensile loads applied to this region [48]. 


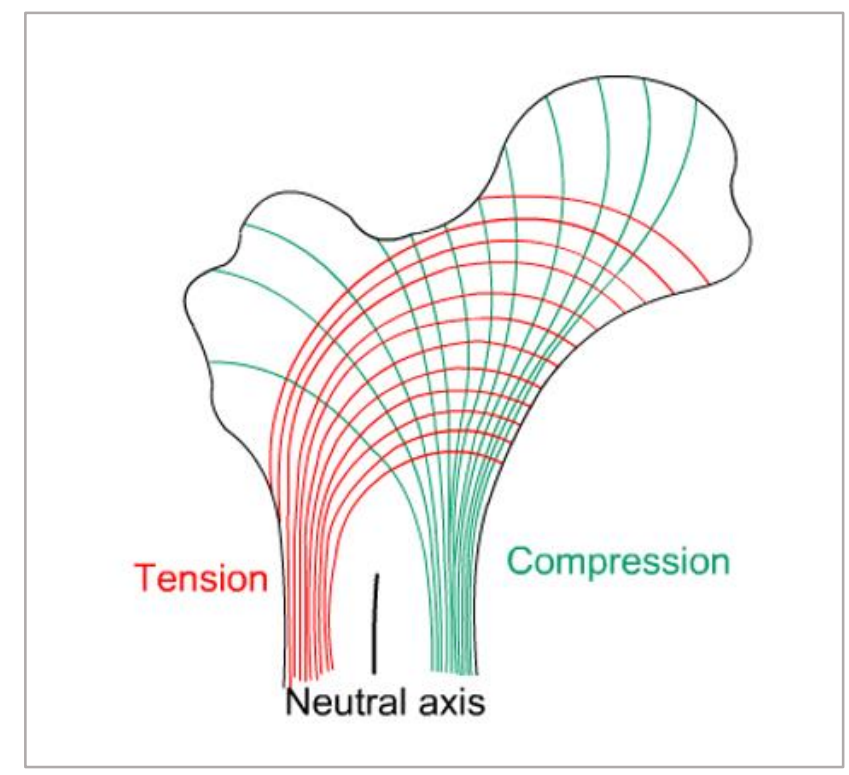

\section{Figure 5: Trabecular system of femoral neck [48]}

The positioning of femoral neck effects the loading on the knee and hip joints. As shown in Figure 6 , the inclination angle between the femoral neck and the femoral axis is approximately $125^{\circ}$ in normal bodies. In coxa vara or coxa valga situations, where the angle is smaller or larger than $125^{\circ}$, the force applied by the head to the joint is different from normal joint.

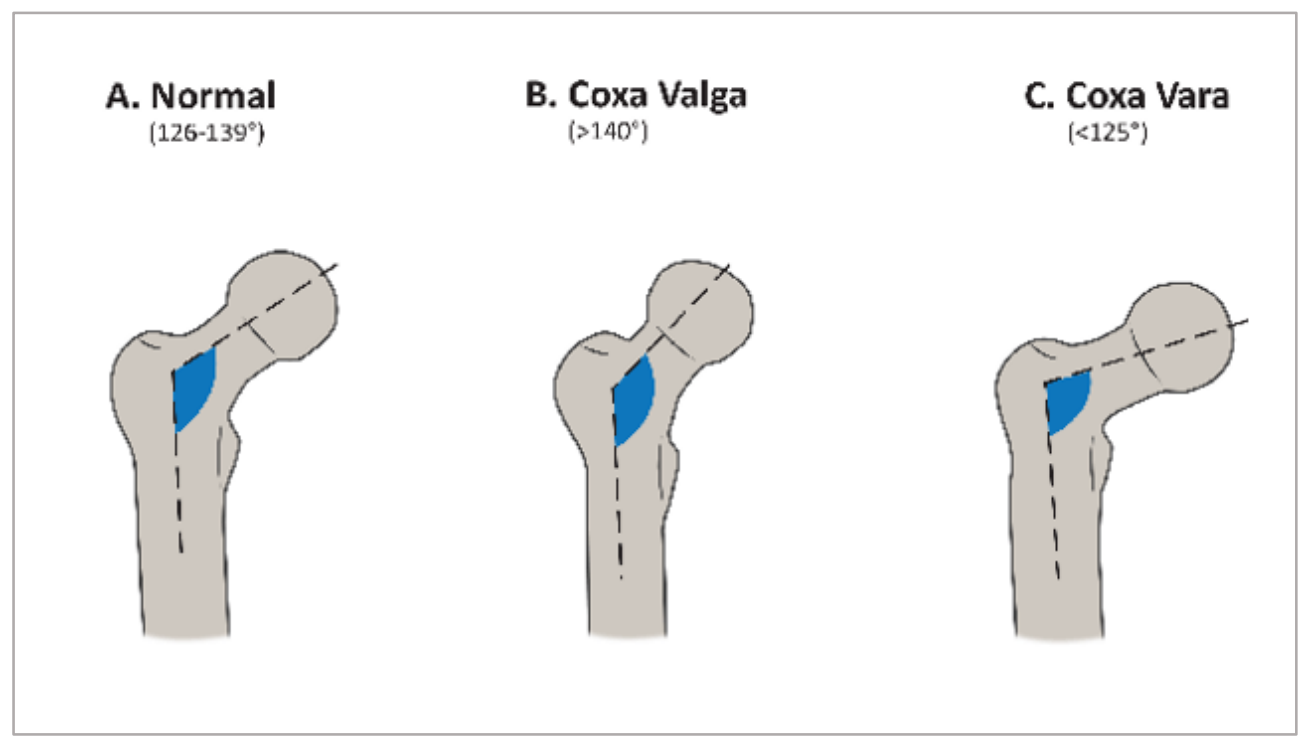

Figure 6: Femoral neck orientation in the coronal plane [49]

The transverse angle is the angle between the projection of femoral head and the transverse axis of the femoral condyles. This angle is approximately $12^{\circ}-15^{\circ}$ in normal adults. Referring to Figure 
7 , anteversion occurs in conditions where the angle is greater than $12^{\circ}$, and retroversion occurs when the angle is less than $12^{\circ}$.

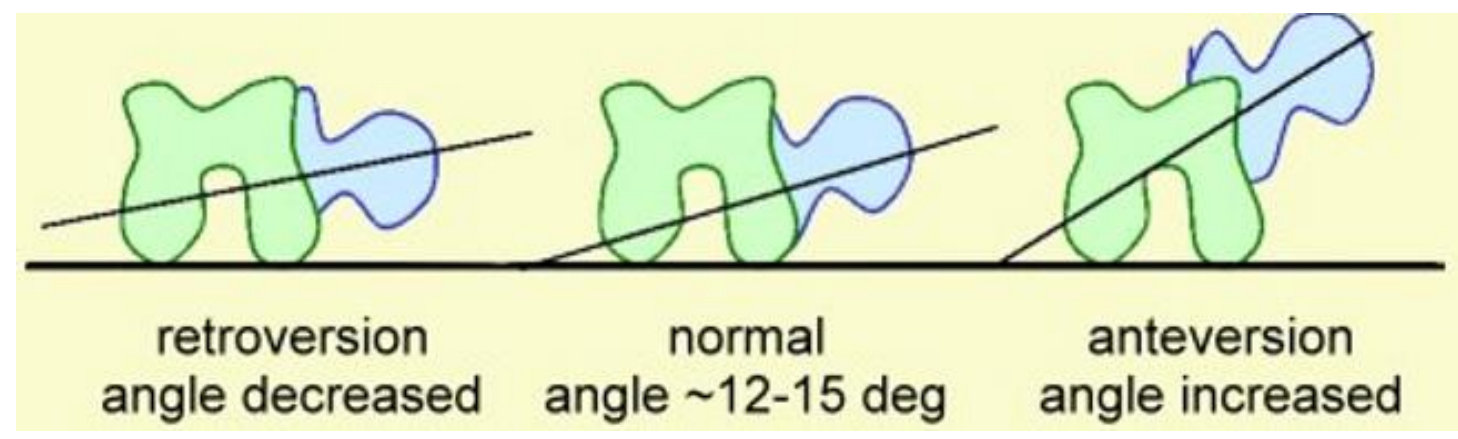

Figure 7: Transverse plane deformities [50]

\subsubsection{Material properties of femur}

Due to the arrangement of trabecular system in the femoral bone, it shows an anisotropic characteristic and its response is different when the direction of applied load is changed. Therefore, it is able to withstand higher loads in the longitudinal direction and lower loads applied in transverse direction. On the other hand, the bone's response depends on the amount and location of the applied load due to viscoelastic property of femoral bone.

Table 1: Approximate values for the material properties of the human femur; cortical and cancellous bones

\begin{tabular}{|c|c|c|c|c|}
\hline $\begin{array}{c}\text { Bone } \\
\text { type }\end{array}$ & Direction and load type & $\begin{array}{c}\text { Density } \\
\left(\mathrm{g} / \mathrm{cm}^{3}\right)\end{array}$ & $\begin{array}{c}\text { Ultimate Strength } \\
(\mathrm{MPa})\end{array}$ & $\begin{array}{c}\text { Modulus of } \\
\text { Elasticity (GPa) }\end{array}$ \\
\hline \multirow{4}{*}{ Cortical } & Longitudinal tension & 1.85 & 133 & 17.7 \\
\cline { 2 - 5 } & $\begin{array}{c}\text { Longitudinal } \\
\text { compression }\end{array}$ & 1.85 & 193 & 17.7 \\
\cline { 2 - 5 } & Longitudinal Shear & 1.85 & 68 & 3 \\
\hline \multirow{4}{*}{ Cancellous } & Transverse tension & 1.85 & 51 & 12.8 \\
\cline { 2 - 5 } & Transverse compression & 1.85 & 33 & 12.8 \\
\cline { 2 - 5 } & Compression & 0.31 & 6 & 0.76 \\
\hline
\end{tabular}

Table 1 shows, that cortical bone has higher ultimate strength and modulus of elasticity; therefore, it is more suitable for providing structural support. On the other hand, cancellous bone is less dense due to its porous structure; thus, it acts as a shock absorber and distributes the load. The composition of cortical and cancellous bone provides the best support for the applied longitudinal load. The table shows that the ultimate compressive strength is much larger in longitudinal 
direction. This indicates that the structure of femoral bone provides more support in compression compared with tension [51].

\subsection{Femur fractures}

As the femur is one of the strongest bones in body, fracture occurs when a considerable amount of compressive load is applied to the femur. These fractures lead to hospitalization, and in some cases, they cause severe blood loss due to disrupted blood supply from the femur [51, 52]. Osteoporosis is one of the common causes of femoral fracture. This disease is caused by reduced bone mineral density (BMD) and disruptions in the bone remodelling process due to different factors such as menopause, aging, malnutrition, lack of exercise, genetics, illnesses or medications. Therefore, the weak structure of femoral bone in osteoporotic patients leads to a lower ultimate compressive strength [52].

Generally, femoral fractures are classified into three categories including proximal, shaft and distal fractures based on the location, pattern, and skin or muscle injuries caused by the fracture. In addition, femoral fractures could be transverse, oblique, spiral, comminuted, or open [52].

\subsubsection{Femoral proximal fractures}

Proximal fractures, femoral fractures closer to the hip joint, are very common in osteoporotic patients. Figure 8 show different types of femoral proximal fractures. Intertrochanteric fracture, illustrated in Figure 8.a, occurs in between the greater and lesser trochanteric region. Subchanteric femur fracture, as the least common proximal fracture, occurs below the lesser trochanter and may sometime extend down to the femoral shaft [53]. Figure 8.b shows three different categories of femoral neck fracture, which are known as: subcapital, transcervical, and basicervical neck fracture. Subcapital fracture occurs exactly on the line that connects the femoral head to the neck and caused by stress riser regions resulted by sharp reduction in the cross sectional area. Transcervical fracture occurs on the body of the femoral neck where it has smaller cross sectional area, which results in high mechanical stresses [52]. Finally, basicervical neck fracture takes place along the plane that connects greater and lesser trochanter. 


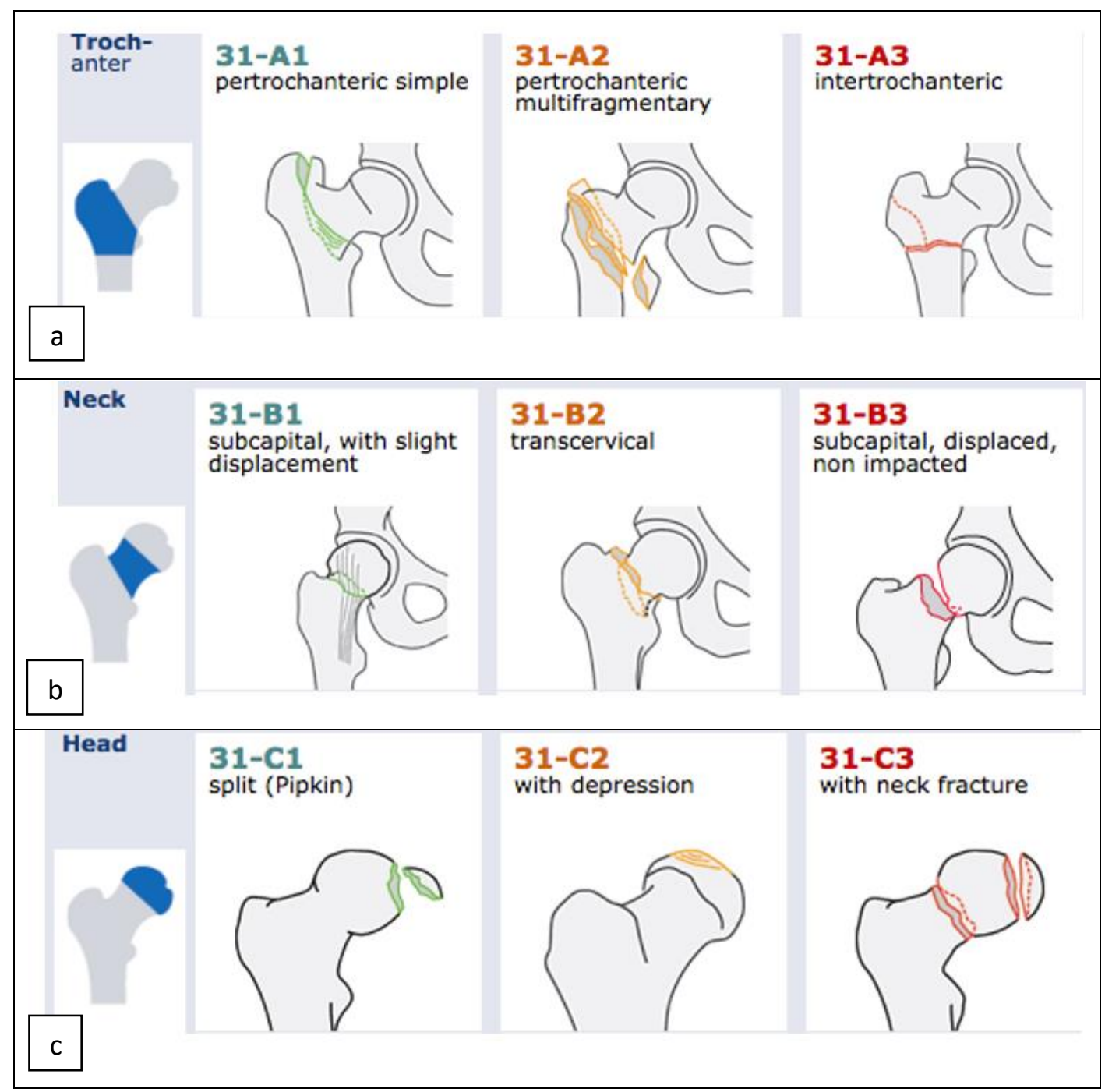

Figure 8: Different Types of proximal fractures; a) trochanteric fracture, b) femoral neck fracture, and c) femoral head fracture [53]

\subsubsection{Femoral shaft fractures}

Usually, fractures below the lesser trochanter are considered as femoral shaft fracture. These fractures may occur due to applying sudden amount of high force to the bone or mal-positioning of orthopedic implants that increase the stress on the bone. Since the shaft is almost cylindrical, different types of loading result in different forms of fracture. The figure below shows fractures resulted by possible types of loading, such as tensile, compressive, torsional, bending and a combination of bending and compressive [54]. 

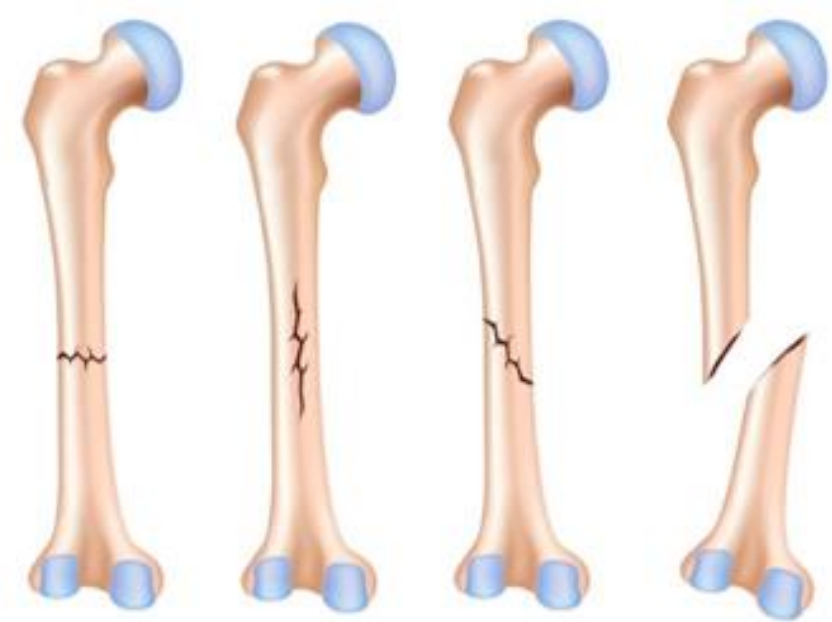

Transverse

Oblique,

\begin{abstract}
Linear
\end{abstract}
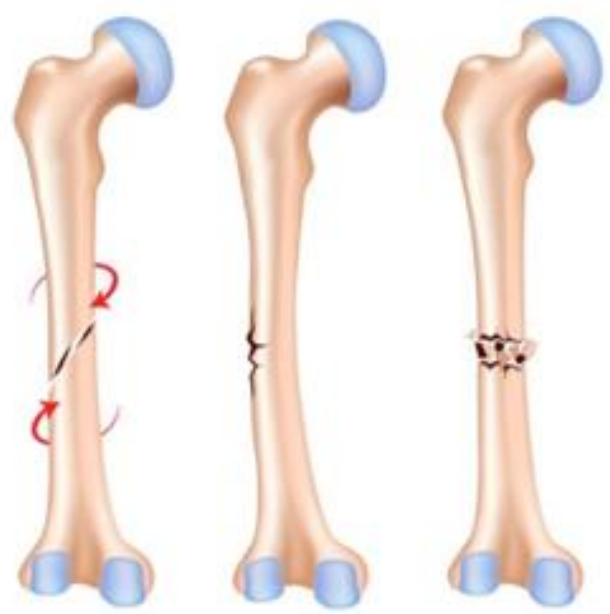

Spiral

Greenstick Comminuted nondisplaced displaced

Figure 9: Different types of femoral shaft fracture [55]

Applying the same amount of ultimate tensile force on both ends of the femur cause a transverse fracture normal to the force's plane, which is illustrated in the leftmost diagram of Figure 9. Oblique fractures are usually caused by applying high amount of compressive stress on both ends of the femur. Applying torsional forces can cause oblique spiral fractures, which initiate on the surface of the femoral shaft parallel to the axis of the specimen in the plane with the highest torsional stress and continues to grow through the bone in a spiraling manner within the planes where tensile stress exists. Bending force applies both compressive and tensile force; thus, the fracture pattern is a butterfly, which is a combination of bending and compressive force. The fracture pattern produced by the combination of bending and compressive forces would be something similar to that for compressive force alone. However, the butterfly fragment would involve more than $50 \%$ of the cortex, thus the contact between distal and proximal fragments would be less than $50 \%$. In this case, increasing compressive force would produce more than one butterfly fragments. 


\subsubsection{Femoral distal fractures}

Fractures at the bottom of the femur are known as distal femur fractures. Receiving a sudden amount of high stress on this region can lead to fracture. In addition, patients with total knee replacement are susceptible to distal femur fracture when exposed to low-energy stresses. This is mainly due to mal-positioning of the knee prosthesis components. Osteoporosis is another factor that may lead to distal femur fracture, because demineralized bone is less able to provide support for bearing low energy stresses. Distal femoral fractures are divided to three main types based on femur's anatomy: extra-articular, partial articular, and articular fractures. As discussed in previous sections, the distal and proximal ends of femur are covered with articular cartilage to enhance lubrication and wear resistance. The first type of fracture does not involve the articular region of the distal femur. In partial articular fracture, a part of the articular surface is involved in the fracture. Articular fractures occur when both condyles are detached from the diaphysis. Figure 10 is an illustration of different distal femur fractures.

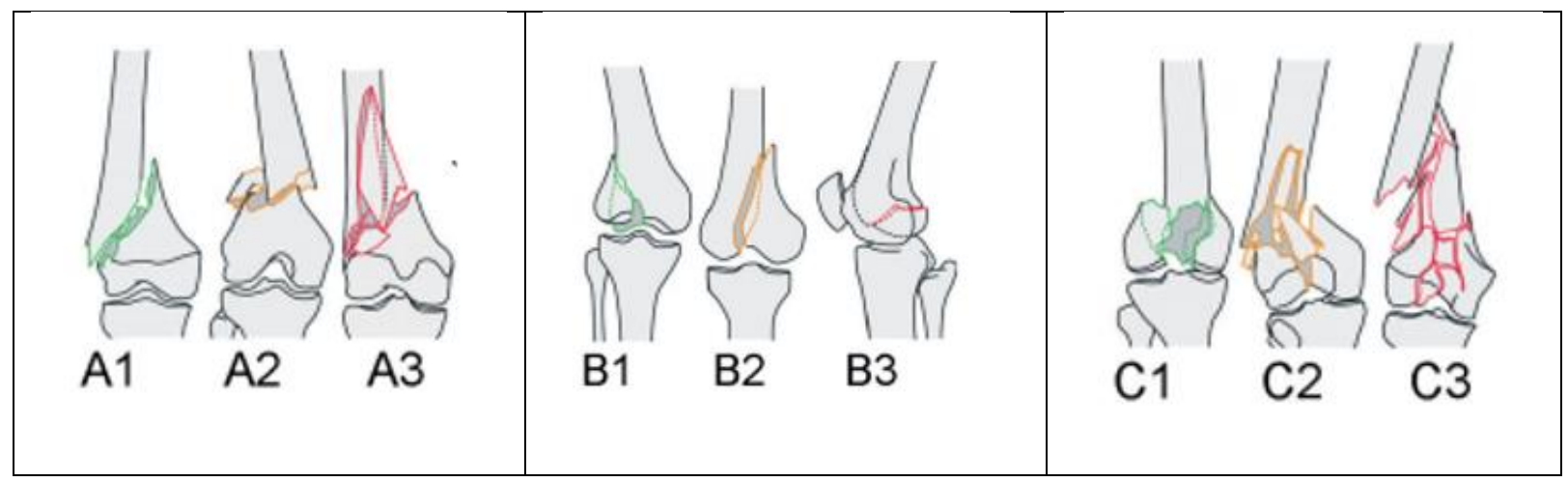

Figure 10: Different types of distal femur fracture: A1-A3) extra-articular, B1-B3) partial articular, C1-C3) articular [56]

\subsection{Femur fracture fixation}

Currently, there are several methods that are used for the fixation of a fractured femur. Choosing the best method for the fixation mostly depends on location and the severity of the fracture as well as the characteristics of the patient (old or young, male or female, etc.). Femur fracture can be repaired either with non-surgical or surgical techniques, which depends on the maturity degree of the patients' skeletal system, the amount of displacement at the fracture site, fracture type and the existence of the associated injuries [57]. Commonly known non-surgical treatments are casting 
and tracing, whereas external fixations, intramedullary nailing and plating are known as the most popular methods for surgical treatments.

\subsubsection{Non-surgical methods of femur fracture fixation}

\subsubsection{Splinting}

A splint is an inexpensive, easy and quick to apply device used for support or immobilization of a limb or the spine [58]. It can be used in multiple situations, including temporary immobilization of potentially broken bones or damaged joints and support for joints during activity. For femur fractures, using a splint that applies consistent traction has several benefits. First, a traction splint stretches out the powerful muscles of the thigh (and the surrounding fascia), which compresses blood vessels embedded in the muscles and holds the bone ends in place. This helps to reduce bleeding. Second, it prevents the broken bone ends from driving further into the surrounding soft tissue, which helps ease the pain. Third, in conjunction with supporting bands around the leg, the traction splint tends to align the broken bone ends within the limb [59]. However, it is not possible to obtain good three-point immobilization of distal femoral fractures with any splint. The conical shape of the thigh will not allow for close apposition of the splint [58].

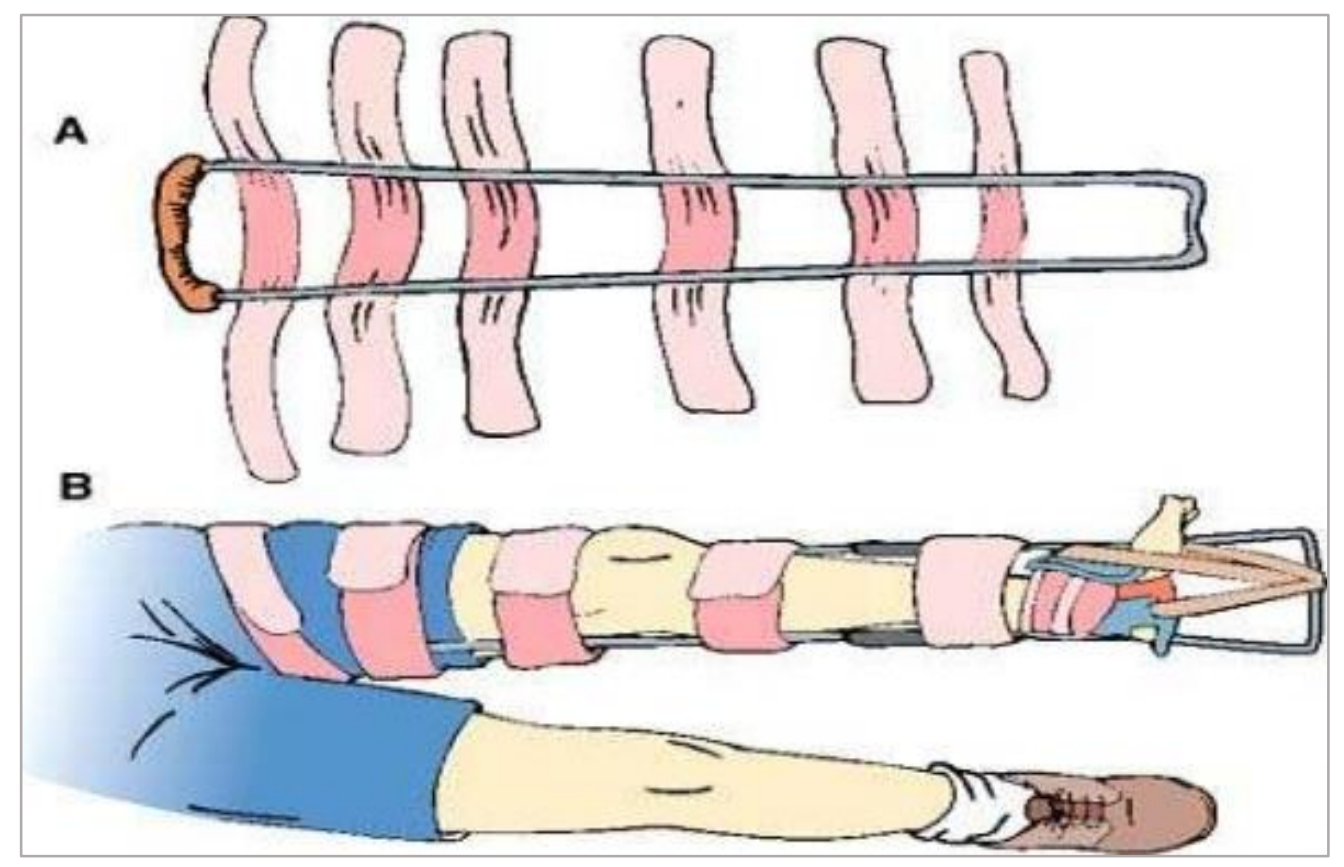

Figure 11: A Thomas splint used as traction splint [60] 


\subsubsection{Casting}

Casting is a common non-surgical technique for femur fracture fixation. Patients treated by casting method should be lighter than 50-60 Ibs, as casting cannot withstand any of the body's weight of heavier bodies. This requirement restricted the age of the patients who can be treated by casting method to 8 years or younger as the elderly people would be heavier than the specified body's weight. Moreover, this type of treatment is not applicable for more complicated fractures produced any comminution because casting cannot remove the fragments from the injured site, thus this can add more complication due to the infection introduced at the fracture site [1].

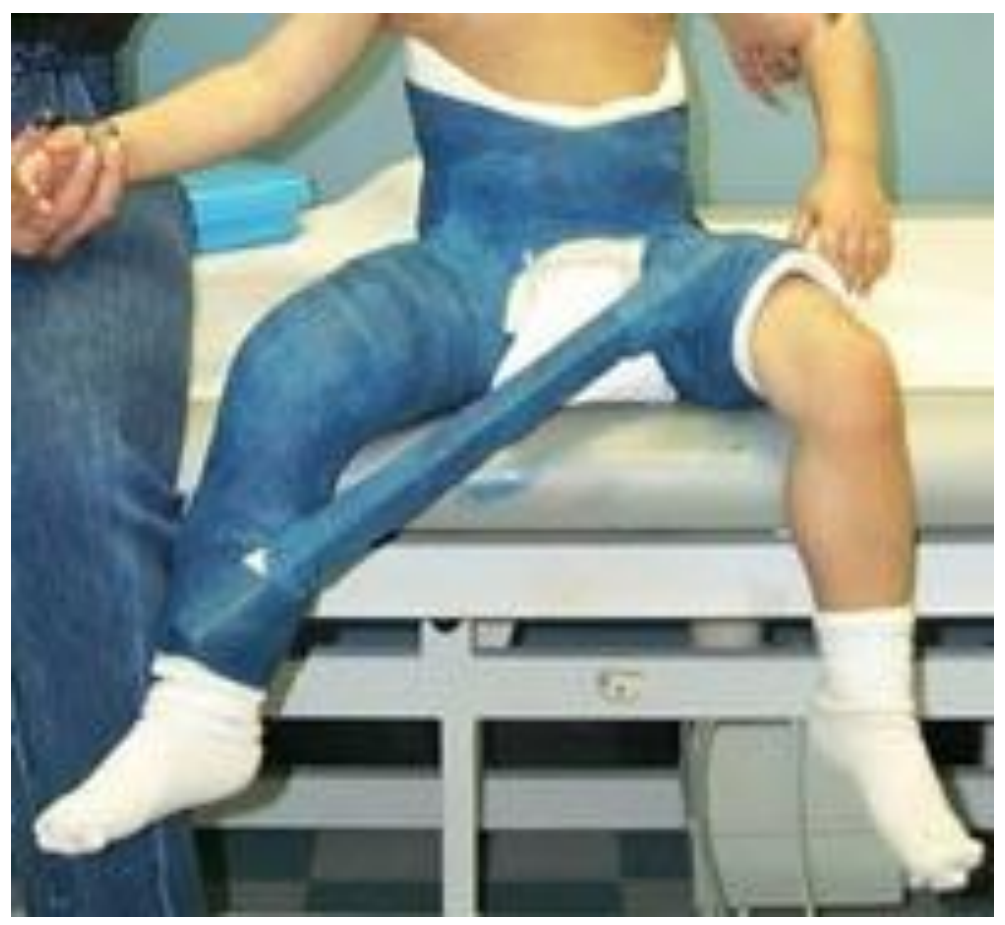

Figure 12: A young child in a hip spica cast to immobilize a femoral shaft fracture [61]

\subsubsection{Traction}

This method is a traditional treatment for non-surgically fixing fractures. Traction provides constant controlled force for initial stabilization of long bone fractures. In more severe cases, which surgery is required, it helps in reduction process during the operation. The first step of traction is placing the fractured limb inside a cast. Then, wire or Steinman pins are inserted into the cast reaching the fractured bone under local anesthesia (Figure 13). 


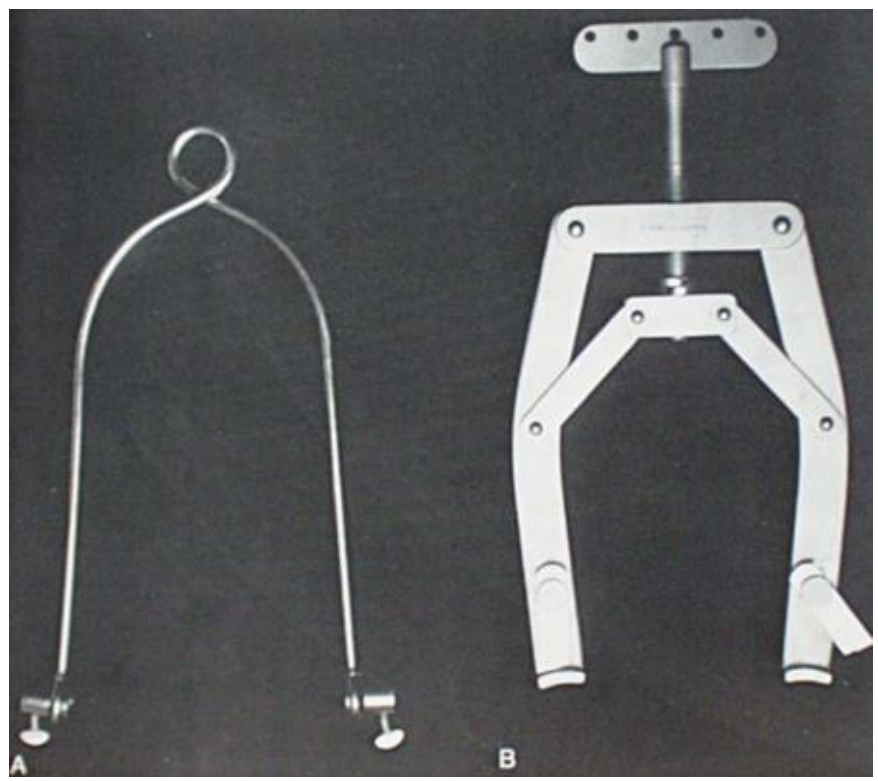

Figure 13: A) Wire (on the left), B) Steinman pin (on the right) for traction technique [62]

The pins are connected to a series of weight, which may pull up to $20 \%$ of body's weight [62]. This method is highly preferred for lower extremities, such as long bone, pelvic, and acetabular fractures. Traction is a timely process and requires monitoring consistently. In this method, the healing process of the bone should be closely monitored to make adjustment necessary for acceptable alignment. Therefore, surgeons usually prefer to use faster healing methods.

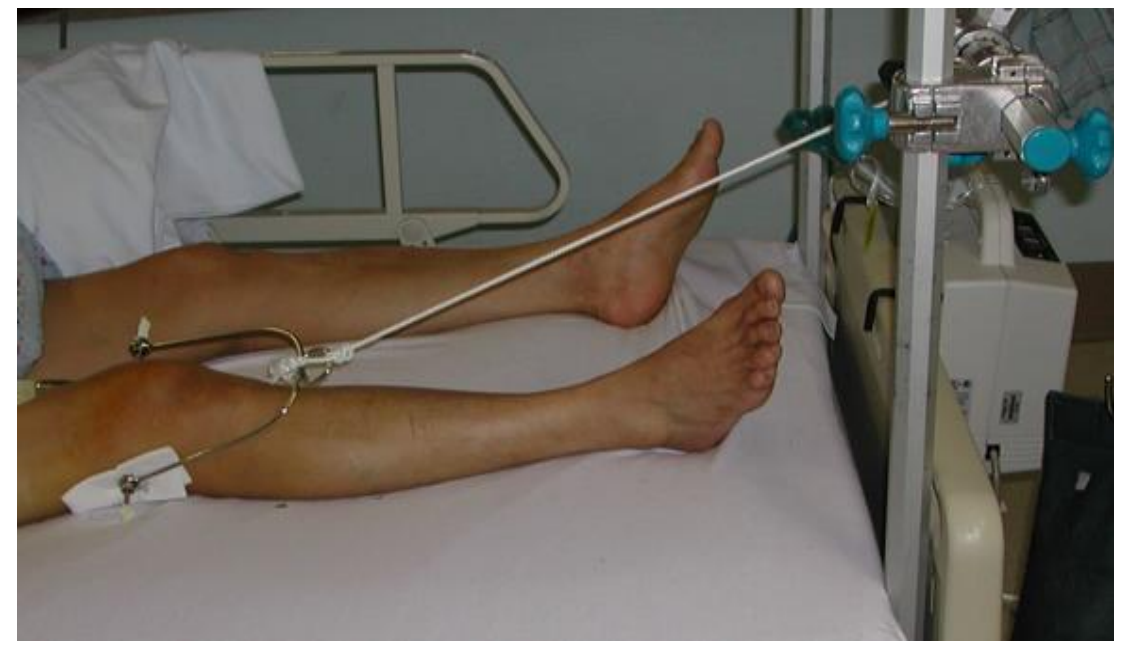

Figure 14: Distal femoral traction [62]

Figure 14 is an example of distal femoral traction [62]. This method is mainly used for acetabular and proximal femur fractures. Also, in cases where the knee ligament is injured, traction is used on the distal femur rather than the proximal tibia. 


\subsubsection{Surgical treatment methods for femur fracture fixation}

External Fixation, intramedullary nailing (IM) and plating are three common surgical methods used for femur fracture fixation. These surgical approaches are chosen based on the type of fracture and the implant [56]. Physicians intend to choose nailing or plating unless the patient is expected to have a serious complication during operation or at non-ambulatory status.

\subsubsection{External fixation}

In this method, a splinting tool such as a bar or a ring-shaped frame is attached to the bone using a pin or a wire (Figure 15). The fractured pieces of bone are held in position using metal pins or screws that are entered through small incisions in the skin and muscle. The pins are connected to the frame, and adjusted in proper locations and positions. Usually, external fixation is used prior to a major surgery, where temporary treatment is required to hold the fracture in place. In some cases, this device may be used to keep the fractured pieces in place until the healing process is complete. This technique does not cause major wounds and is beneficial for patients with soft tissue injuries and irritations [63].

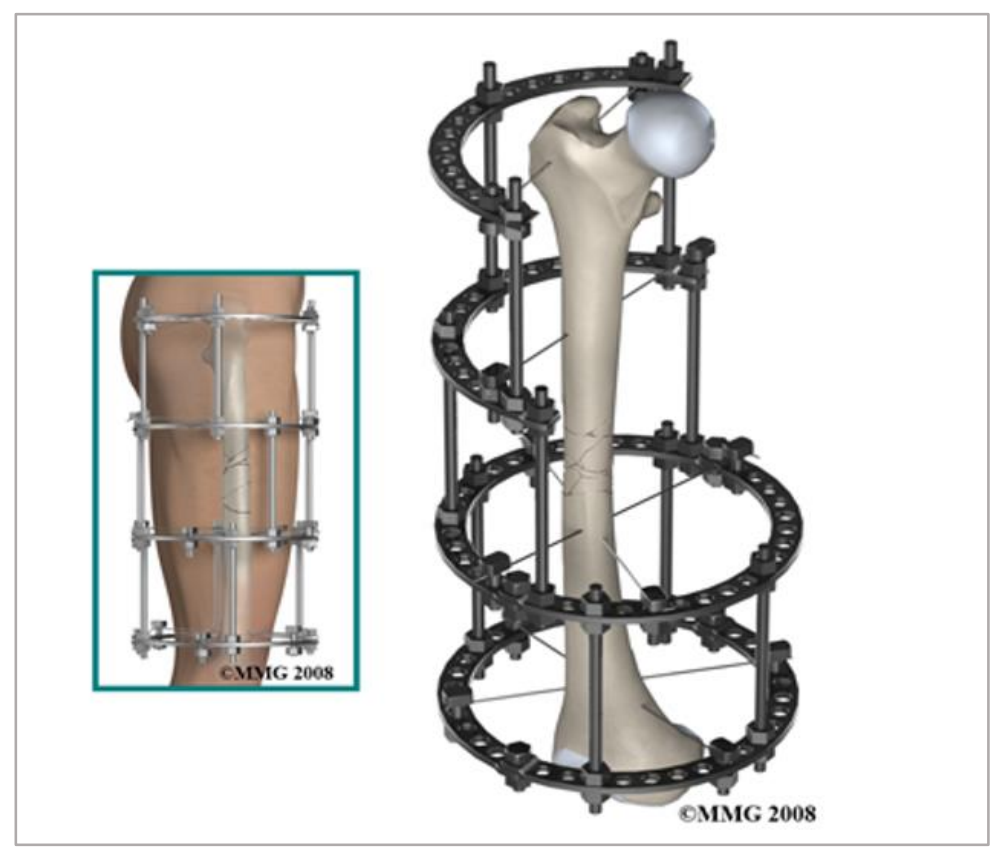

Figure 15: External fixation [64]

Almost all fractures treated with external fixation experience inflammation and infection due to tissue's exposure to hardware. Therefore, this process requires adequate preoperative education 
and patient's compliance. In addition, the ring frames are complicated to assemble and require professional training. External fixations limit the patients' movement and restrict their daily activities. Thus, they may cause stiffness and joint discomforts, which may be solved using physiotherapy. Another possible problem of this treatment is neurovascular injuries, which may occur due to misplacement of the pins or growth of nerves in the area due to lengthening of the procedure [65].

\subsubsection{Intramedullary nailing fixation}

Intramedullary fixation is one of the standard femoral fracture treatments with a high success rate. This technique has produced more favorable results in diaphyseal portions of the femur compared to the periarticular region. Therefore, intramedullary fixation of these fractures are less traumatic and generate a better outcome [66]. This treatment is invasive and involves in carving a canal through the proximal or distal end of the femur. Then, a rod is placed inside the canal using a guidewire and fixed using lateral screws. The rate of malunion and infection is very small in patients with intramedullary femoral fixation [67]. Figure 16 is an illustration of Intramedullary Nailing femoral fixation surgery.

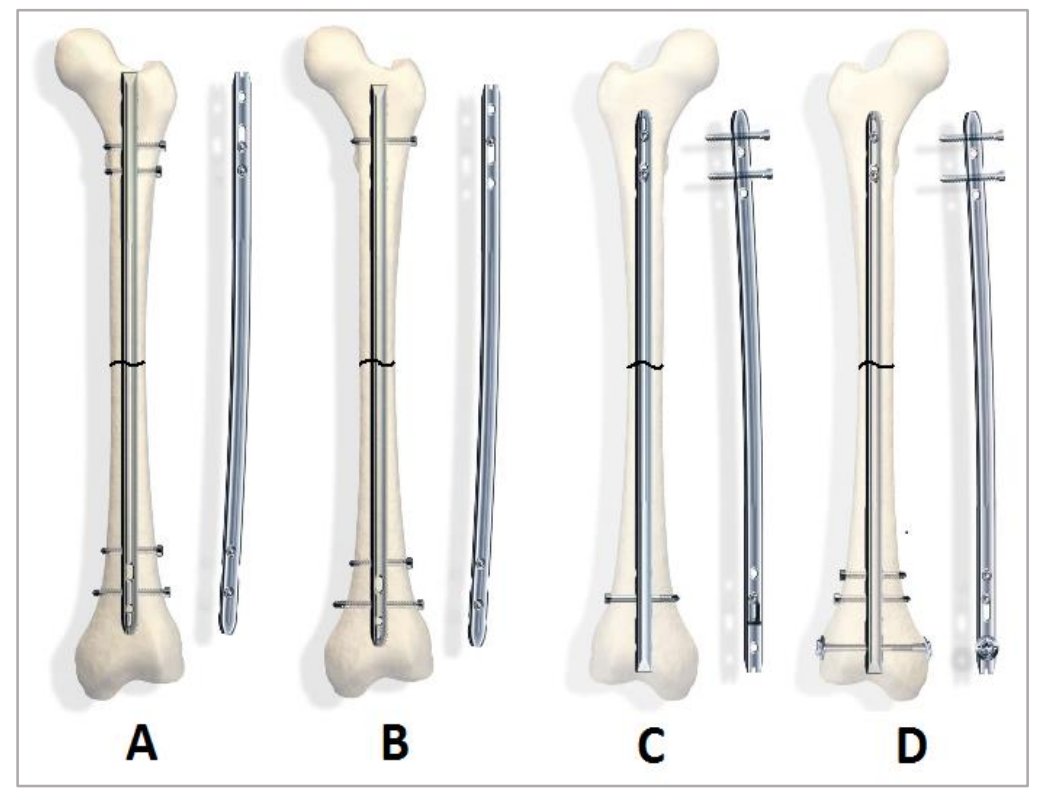

Figure 16: Interamedullary nailing femoral fixation; $A$ and $B$ are antegrade nailing, $C$ and $D$ are retrograde nailing [68] 
The insertion of intramedullary nail is categorized to two groups of retrograde and antegrade nailing, depending on the type and location of the fracture. Retrograde nailing is commonly recommended for patients with proximal or shaft femoral fractures. In this technique, the femur is reamed from the medial condyle of the distal femur and the canal extends to the proximal femur. Since the distal femur is more accessible for initiating the canal, this method is used in majority of the cases. In antegrade nailing, the canal is initiated from the greater trochanter of the proximal femur. The proximal femur is not as accessible as the distal femur; thus, this method is more complicated than retrograding. However, both methods have the same infection rate, healing process, and success rates [69]. Antegrading is used for fixing fractures below the lesser trochanter and about $7 \mathrm{~cm}$ above the knee joint. In general, intramedullary nailing is recommended for adults with mature bones, since nailing process may damage the growth plate of the femur.

Despite having a high rate of success and healing, intramedullary nailing has its own disadvantages. In rare cases, studies have shown that intramedullary nailing of the femur can cause embolism. However, cautious clearing of the intramedullary canal diminishes the chance of embolism. Thus, doctors must be extremely careful to avoid technical or operative errors. Rod insertion, especially for antegrade nailing, is one of the most complicated steps of this process, and may cause fracture at the insertion point or the femoral neck. In addition, the diameter of the medullary cavity is non-uniform; therefore, the narrow regions are reamed in order to provide unity. Usually, this may cause more damage to the bone, and may result in further fractures or revascularization failure [70]. Another complication of this technique is rotational deformity, which occurs as the nail is passed through the cavity to keep contact between the fractured components. In addition, nailing cannot be used for severe injuries, and it may generate more fractured bone segments. Furthermore, some cases may require an additional surgery after the nailing treatment in order to adjust the length of the shortened femur [71].

\subsubsection{Plating fixation}

Plating has been one of the common method used to fix femoral fractures for more than 100 years. In this technique, the injured area is surgically opened and the plate is laid on the fractured bone. Screws, cables, or both are used to fix the plate to the bone [72]. There are two types of plating methods, known as conventional (non-locked) plating and locked plating. In conventional plating, the plate is stabilized and held in place by the friction created between the screw and bone. Thus, 
the screws must be tight enough in order to avoid alterations in the position of the fractured segments. Locked screw plating is more advantageous since tightening the screws lock the plate the stabilized the fractured segments without compressing the bone. Therefore, there will be no alterations in the position of the fractured segments [73]. Figure 17 and Figure 18 illustrate the conventional and locked screw plating.

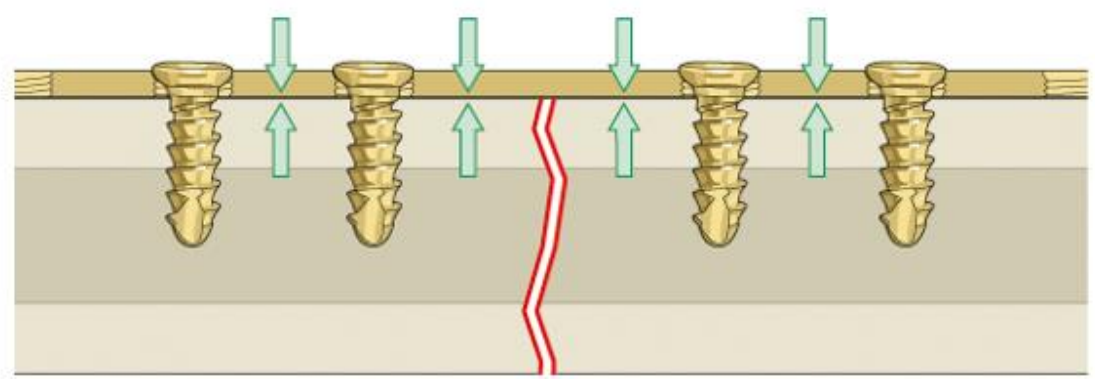

Figure 17: Conventional plating fixation: the green arrows show that the bone is compressed [73]

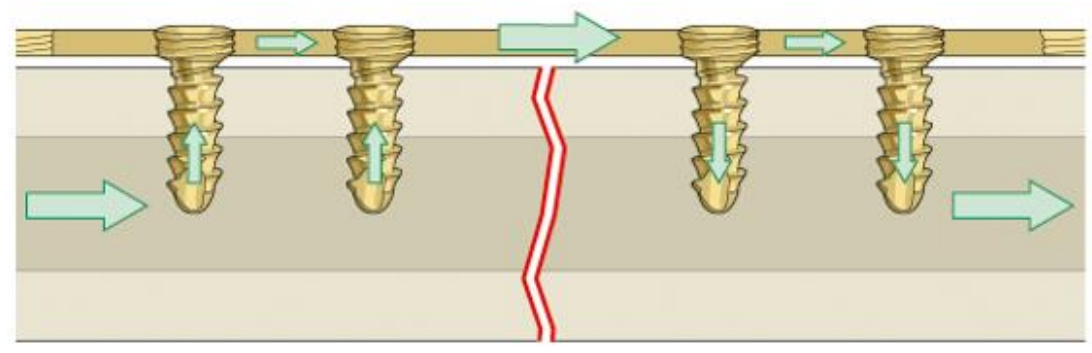

Figure 18: . Locked screw plating fixation: the plate and screw are rigidly held in place and do not alter the position of bone segments [73]

Mainly, there are two types of bone plate systems known as the neutralization plate and compression plate. Neutralization is used to fix short oblique fractures (butterfly fractures) and mild fractures. In this technique, the plate is laterally placed over the fractured region without applying preload to the site. Lag screws are screws that could also be used to connect the oblique fractured segments. Figure 19 shows a neutralization plate that is used in combination with lag screw to connect the oblique fracture [70]. 


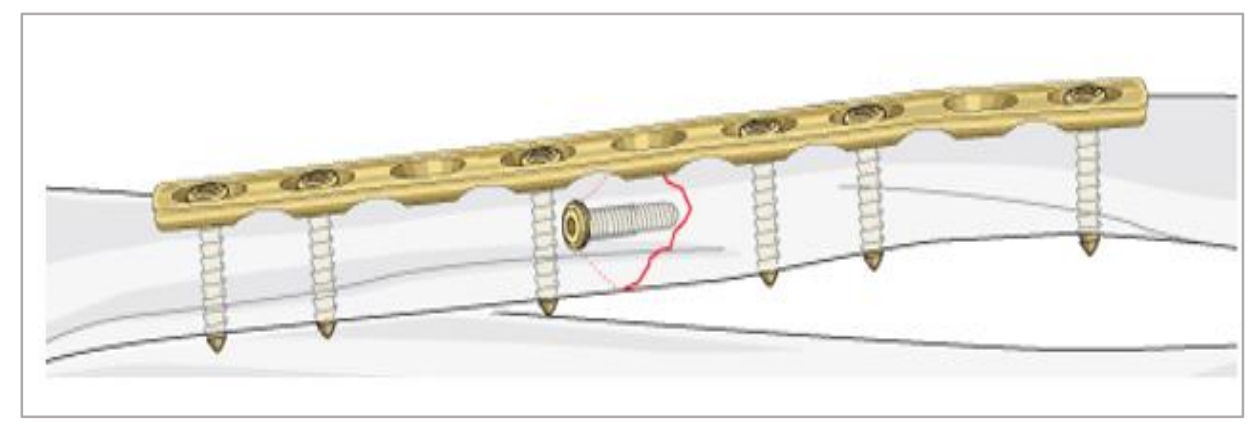

Figure 19: Neutralization plate used in combination with lag screw [74].

On the other hand, dynamic compression plating (DCP) or compression plating applies compressive loading to the fractured region (Figure 20). The compressive force prevents the fractured pieces from loosening and avoids further inter-fragmentary fractures caused by torsional or shear loading. In this technique, the plate is first fixed to one side of the fracture, and then pulled to the other side using external tensile loading. The external force is removed after attaching the plate to the other side of the fracture using screws. In the end, this loading will connect the pieces of the fractured bone.

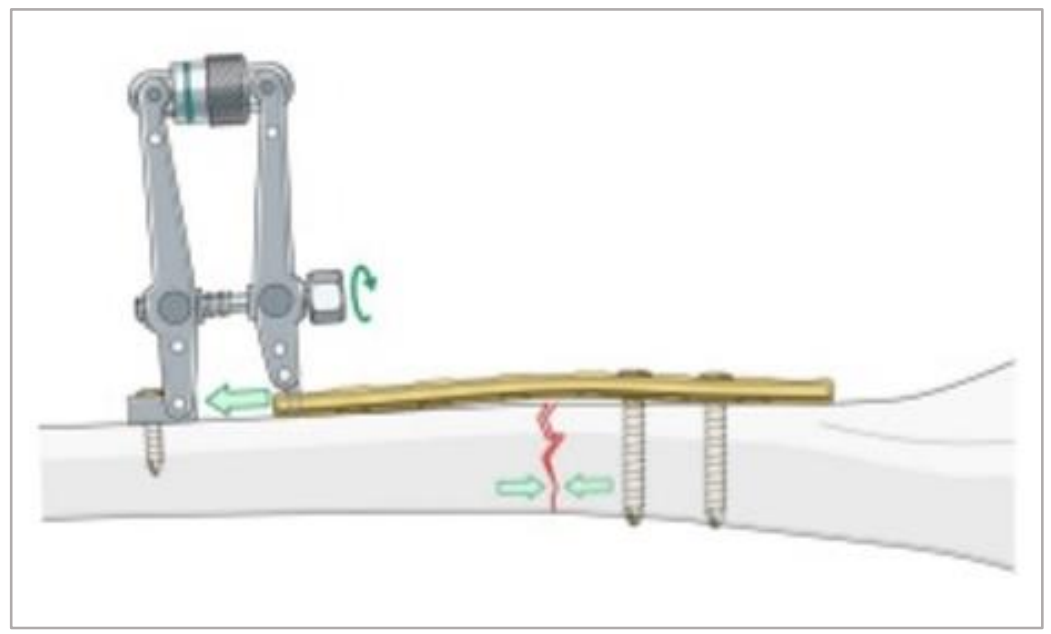

Figure 20: Compression plate fixed with screws and pulled by tensioner [74].

Bone plating is a good substitute when intramedullary nailing can not be used to fixed the bone. For instance, complicated cases such as post-hip arthroplasty fractures at the proximal region of the femur can be treated using plates. Also, bone plates are suitable for comminuted or severe fractures with many bone segments. An outstanding advantage of plating is that it maintains the appropriate distance between the fractured segment; thus, it does not lead to alteration in the size 
of the femur. Unlike IM, plates are directly attached to over the fractured surface and do not cause any lateral rotation or deformities. Overall, plating is preferred over IM nailing, because is does not require the removal of the epiphysis and bone tissue.

Fixation plates hold the fracture site in position and reduce the fracture gaps; therefore, the bone healing process occurs without no interruption. Although the plate and screw system prevent tensile loadings applied to the fracture site, it provides compressive loading to reduce the fracture and accelerate healing. Commonly, the fixation plates are made of Stainless Steel, Cobalt Alloys, Aluminum Alloys, or Titanium Alloys due to their biocompatibility and mechanical properties. These material are stiffer than the cortical bone; thus, they are able to carry the majority of the load when they are used in combination with the bone [29]. Table below shows the mechanical properties of each alloy, as well as the cortical bone.

Table 2: Mechanical properties of the cortical bone and alloys used in fixation plates

\begin{tabular}{|c|c|c|c|}
\hline Material & $\begin{array}{c}\text { Density } \\
\left(\mathrm{g} / \mathrm{cm}^{3}\right)\end{array}$ & $\begin{array}{c}\text { Ultimate Strength } \\
(\mathrm{MPa})\end{array}$ & $\begin{array}{c}\text { Modulus of Elasticity } \\
(\mathrm{GPa})\end{array}$ \\
\hline Stainless Steel [75] & 7.81 & 870 & 190 \\
\hline Titanium Alloys [76] & 4.5 & 220 & 116 \\
\hline Cobalt Alloys [77] & 8.80 & 225 & 211 \\
\hline Cortical Bone [78] & 1.85 & 133 & 17.7 \\
\hline
\end{tabular}

Mature bone tissue undergoes bone remodeling, the process of mineral deposition or absorption, depending on the amount of loading applied to the bone. Regions of the bone that carry a higher amount of loading undergo more mineral deposition rather than absorption [79]. An ideal fixation plate should allow the bone to carry enough load. If the loading applied to the bone is less than the normal amount, the bone will undergo mineral absorption and becomes weaker. Thus, it is important to use material stiff enough to hold the fracture site in position and allow the bone to carry the necessary amount load [70]. Failures of the plates and screws can cause further fractures and misalignments. One of the weaknesses of plating fixation is maintaining the necessary compression required for bone healing process. Normally, a few days after the surgery the compressive force is eliminated from the bone. Thus, the healing process will be disrupted and the fractured region will not receive the required amount of compressive force to be held in place. Furthermore, this may lead to bone weakness and joint problems. Additionally, studies have shown that plating method can cause post-operative infections due to the use of external apparatus such 
as plates and screws. Thus, professional have to ensure that the equipment and material are thoroughly sterilized. In general, long term implant stability and immediate fracture union are the main purposes of periprosthetic femoral fracture treatment and the ideal surgical repair method and the most suitable treatment are still controversial. Although, many researchers have tried to qualitatively and quantitatively investigated the mechanical behaviour of clinically used fixation mechanism. But, still having high tensile, flexural and torsional stiffness's to provide maximum stability at the fracture site and allow the non-fractured sites of bone to be stressed under normal compressive loading conditions for fracture reduction are the main objectives for designing an optimal fracture fixation mechanism.

\subsection{Stress shielding versus selective stress shielding}

As mentioned in the previous sections, prolonged use of stiff fixation plates can lead to bone injuries such as misalignments or bone loss. Several studies on various plastic plates showed that this material is not a clinically acceptable choice due to lack of sufficient strength [80]. An ideal material must be able to shield bending, tensile and torsional stresses, provide sufficient compression for fracture reduction, and transfer enough stress to the bone in order to maintain normal loading. The elastic modulus of alloys shown in Table 2 are much greater than that of cortical bone; thus, this phenomenon causes unfavorable stress shielding by the plate. Furthermore, the chance of bone fracture due to disrupted bone remodeling will increase [19].

The conventional bone fracture fixation plates are made of metallic materials, which have a 5-10 stiffer than cortical bone. Thus if such a plate is attached to a fractured bone, the plate will be superior load bearing component compared to the underlying bone, leading to phenomena known as "stress-shielding". Consequently, stress shielding result in localized osteopenia of cortex beneath the plate, changes the diameter of the cortex, prohibits normal bone remodeling, and then increases the possibility of bone refracture during loading and unloading [19]. Moreover, these metallic materials appear white in color during the post-surgical monitoring process of the injured bone using X-ray radiography, which limits the visibility of bone that also appears white in color. Also, they are not compatible with magnetic resonance imaging (MRI) and obscuring the details in computerized tomography (CT) scanning by causing streaking line in the images. Finally, in case of fatigue cracks when protective oxide layers are removed from the surface of the metallic implant, the rate of repassivating of the unprotected crack regions extensively effect the fatigue 
strength of the materials. The inability of metallic implants to repassivate quickly exposes unprotected regions to corrosion fatigue, which can lead to a significant drop in fatigue endurance limit - one of the main reason of the metallic implants failure [81, 82]. As a result, researchers are focusing on new concepts such as stress-relaxation or less-stiff devices to eliminate "stress shielding" effect in stimulation of stress at the fracture site [83]. The concept of a stress-relaxation bone plate was introduced by applying minimal alteration in traditional rigid fixation mechanisms [84] such as developing sliding plates made of stainless steel [85], insertion of a silicon rubber between plate and surface of the bone $[86,87]$, and using coelastic washers capable of creep in the screw holes [88]. On the other hand, stiffness-graded materials (SGMs) were developed for manufacturing of the fracture fixation plates and preliminary compression tests were conducted between stainless steel plates and SGMs plates for bone healing using finite element analysis [39]. These studies reported that bone away from the fracture site were able to take more stress in SGM plates compared to stainless steel plates. Moreover, new plate consisting of a combination of lowstiffness metal plate with low Young's modulus and stainless steel plate with high stiffness were developed. The finite element analysis showed that the low-stiffness metal plate applied more compressive load to newly formed callus, as a result accelerating callus formation compared to titanium alloy plates and stainless steel plates [89].

However, using metallic implant for biomedical application is controversial due to their intrinsic drawbacks such as corrosion fatigue and radiopaquecy [81, 82] which needs to be addressed in developing biomaterials. Therefore, a new generation of biomaterials, i.e. composite materials has been introduced and received substantial attention due to their natural advantageous of flexibility, non-corrosiveness, tailorability and radiolucency [90, 83]. A composite material can be defined as a combination of a matrix and a reinforcement (fiber), which when combined gives properties superior to the properties of the individual components. The reinforcement (fibres) is used to fortify the matrix (resin) in terms of strength and stiffness. The matrix keeps the reinforcement in the desired orientation and protects the reinforcement from chemical and environmental attack, and it bonds the reinforcement so that applied loads can be effectively transferred [20]. By altering the type, size, orientation and distribution of the reinforcement constituent of the composite, it is possible to tailor a wide range of mechanical and biological properties to optimize the composite structure in order to improve their interaction with surrounding ambient regarding to their application. In addition, using composite materials in orthopaedics promotes other potential 
advantages including the possibility of reinforcing failure-prone conventional materials such as bone cement and bearing materials to improve their durability, incorporating bioactive phases to improve the fixation of implants, and the use of resorbable phases that allow incorporation of the material into the bone [20].

The use of composite materials allows many new design possibilities for various biomedical applications particularly orthopedics, but this freedom of design requires a clearer understanding of the objectives and constraints on the design process i.e. biocompatibility. The interaction of composite materials with the body is more complex than that of the conventional metallic materials, and the prediction of their long-term mechanical performance presents many intractable difficulties. Moreover, the testing of composite components also presents many challenging problems, which are not adequately addressed by existing standards developed for testing conventional monolithic materials. However, despite all these challenges composite materials are very attractive solution and likely to prove invaluable for various biomedical applications particularly in development of orthopaedics [20]. This possibility led to widespread interest in using composite materials for various non-load bearing and load bearing orthopaedic applications. This includes spinal cage for degenerative discs [17], filling bone defects for anchoring into bone for dental implants $[18,91]$, intramedullary implants for fixing subtrochanteric defects [92], long bone fracture repair plates [37, 93], high tibial osteotomy [91], and total hip replacements [92].

Woo et al [84] introduced carbon fiber reinforced composite materials for bone fracture fixation plate. These plates were more flexible than comparable metallic components, and would allow the bone to take more stress on the fractured site resulting in faster healing process and promote fracture union without the complication of osteopenia.

As it was mentioned earlier, composite materials can be designed to achieve a wide range of mechanical and biological properties, and so their design presents far more complex problems than that of conventional monolithic materials due to the large number of additional design variables that must be considered. Consequently, in orthopaedic applications, it is essential that the design of composite components have a firm theoretical basis if it is not to create new problems whilst attempting to solve existing ones [20]. 


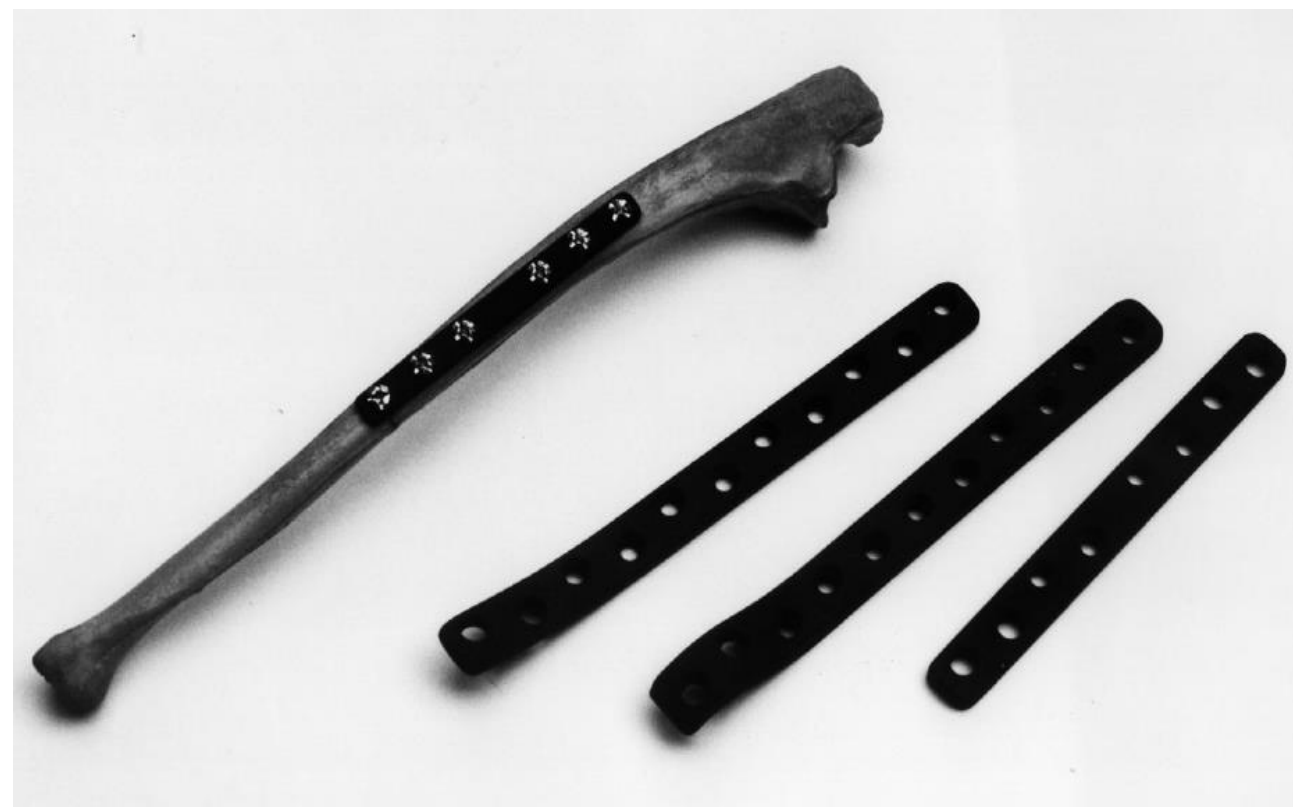

Figure 21: Carbon fibre reinforced epoxy fracture plates [20].

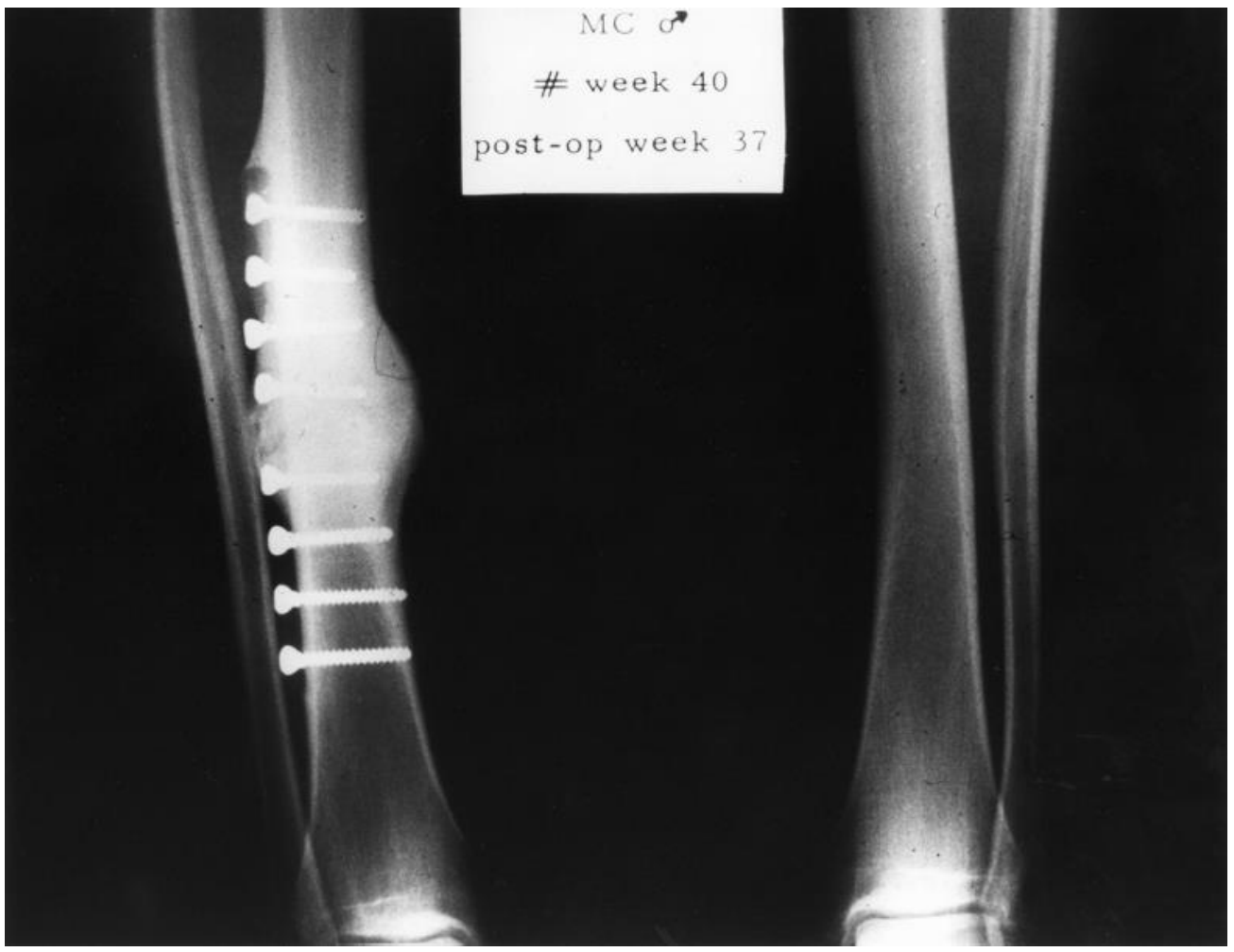

Figure 22: X-ray images of a mid-shaft tibial fracture, after plating with a carbon fibre reinforced epoxy bone plate for 37 weeks [20]. 
There are three interdependent factors that must be considered in the design of a composite implant. First, the selection of appropriate matrix and reinforcing materials, second, the choice of appropriate fabrication and processing methods, and third, the internal and external design of the device itself [20]. The new materials proposed for bone fracture plate applications need to have proper stiffness with adequate fatigue strength comparable to those of stainless steel material. As bone would experience high cyclic loading during daily normal activities, the amount of strain inserted to the fracture site should be minimized by bone plate to avoid subsequent non-union or misalignment.

Composite materials that have been suggested for bone fracture plate application can be mainly grouped to non-resorbable, partially-resorbable and fully-resorbable. Non-resorbable composite materials could be considered either as thermoset and thermoplastic polymer composite. Although thermoplastic polymer composite showed biocompatibility and durability, it was very difficult to fabricate long fiber reinforced composite using thermoplastic polymers with sufficient strength for load-bearing applications earlier. Another benefit of using thermoplastic composite materials for manufacturing bone fracture plate is that, similar to metallic implants, they could be formed in certain condition to adopt the curved geometry of femur. Thermosetting polymers such as epoxy resins have more variable biocompatibility and durability characteristics and so have not been so popular in orthopaedics, although they have found some successful commercial application in fracture fixation [6] Some few examples of thermoset polymer composite materials are CF/epoxy and Glass/epoxy composite [10]. Although some evidence of toxicity exists in composite materials with partially cured epoxy, composite materials with properly processed epoxy resin showed not only excellent biocompatibility but also the capability to be manufactured with a very sophisticated geometry [20].

In general, the mechanical properties, i.e. stiffness, of the thermoset composite biomaterials stay intact in-vivo condition. It is desired to see a degree of slow stiffness degradation for fracture bone plate applications as bone heals. Therefore, resorbable materials have gained considerable attention for use in applications such as fracture fixation. These partially resorbable polymers are capable of promoting stiffness and strength degradation overtime and accordingly would allow the underlying bone to carry a greater portion of load during healing process. Several studies have suggested partially-resorbable composite which was consisted of resorbable polymers reinforced with non-resorbable fibers including carbon fiber [94], and polyamide fibers [95]. In addition, 
Tormala et al. [96] and Choueka et al. [97] proposed the use of fully resorbable composites consisting of resorbable polymers such as calcium phosphate based glass fibers and poly L-lactic acid (PLLA) fibers as reinforcing and polyhydroxybutyrate (PHB) [98, 99], and collagen as matrix [100]. Although, Resorbable materials have significant potential in designing fracture fixation mechanism where a fully resorbable implant might eliminate the necessity for a second surgical operation to remove the device after the fracture has healed [20]. Nevertheless, achieving desirable mechanical properties especially strength and stiffness was complicated and therefore their application was limited to non-load bearing purposes. Moreover, they only could retain their properties only for few weeks which limit their use for certain event requiring short healing period. On the other hand, it was reported that synchronizing the degradation rate of such composites with healing rate would not feasible since healing process may vary from one person to another [30].

The strength and durability requirements for loadbearing implants are remarkably high and they must be determined by the use of applicable test methods. In addition, the use of composite materials must allow enhanced mechanical compatibility with the neighbouring tissues, and more stability as long-term fixation. Amongst aforementioned studies, only a few of them reached to pre-clinical or clinical stages because the developed composites have introduced new problems while attempting to resolve the existing one. In addition, composite biomaterials may break, especially in severe bending loading condition normally exists in vicinity of bone gap at the fracture site. Furthermore, long-term durability under cyclic loading condition is one of the most challenging aspect in designing and testing of the composite implants. Unlike many metallic biomaterials, the static strength of most composite materials does not correlate well with their fatigue performance, and their static strength and stiffness give very limited indication of their performance under prolonged cyclic loading [101]. It is still hard to convince surgeons to use composite biomaterials sine there is lack in their clinical data and in-vivo stability, whereas metallic biomaterials have been used for this purpose for quite long time with sufficiently strong clinical background. Thus, there is still a need to develop new composite material and optimize their design for various biomedical applications. 


\section{Manufacturing of Glass/Flax/Epoxy composite plates}

The purpose of this chapter is to describe the process used in this study in manufacturing of the composite plates and to evaluate the quality of the developed Glass/Flax/Epoxy plate's sandwich structure as per ASTM requirements for mechanical experiments. First, the constituent's fraction of plates as well as void contents were measured to ensure they are in acceptable range based on standards and project hypothesis. Then, scanning electron microscopy (SEM) observation was conducted on the Glass/Flax layers' interface to determine the quality of interface bonding between these two different types of fibers, which is a key factor in propagation of cracks, and initiation of delamination when the material is mechanically loaded.

\subsection{Introduction}

Composite materials due to their significant physical, mechanical and thermal, corrosion resistance and dimensional stability are being extensively used in our day to day life as an important category of material properties for designing structural components in engineering applications such as aerospace, automotive and biomechanical application [102]. These outstanding mechanical properties depending on the end use of the composite can be tailored by altering the type of the fibrous reinforcements and their placement orientation in the composite structure [1,103]. Despite the high performance of synthetic fibers such as glass and carbon, drawbacks including nonrenewability, non-recyclability, and high-energy consumption requirements to manufacture, have shifted interests towards natural fibers in recent years. When compared to synthetic fibres, natural fibres present important advantages such as low density, low cost, non-toxicity, availability, renewability, ease of production, low process energy, non-abrasive, good acoustic properties, and appropriate stiffness and strength [29, 43]. Moreover, they are recyclable and biodegradable [35].

In recent years, composite materials have been considered for biomedical applications (i.e. fracture fixation mechanism such as plates and IM nails) since they have mechanical and biological similarities to the human tissue $[5,6,19]$. Since, only a limited number of studies have considered hybrid composites for bone fracture plate applications [7, 42], a new and unique hybrid Glass/Flax/Epoxy composite plate with sandwich structure with potential for long bone fracture plate application has been developed. The reason of considering sandwich structure, with flexible flax fibers as the core material and strong carbon fibers at the external faces, was to mimic the 
structure of bone with soft cancellous bone at its core and rigid cortical bone at its surfaces. The experiments on this composite material were designed in a way to characterize its biological and mechanical properties as well as its biomechanical performance to figure out how it can act in comparison with a clinically used metal plate with actual clinical use for the same purpose. The main purpose of this chapter is to discuss the material and process used in manufacturing of the Glass/Flax/Epoxy hybrid composite plates.

\subsection{Mold preparation}

The mold consists of two $375 * 375 \mathrm{~mm}$ aluminum plates, high temperature resistant membrane, high temperature resistant tape, high temperature resistant sealant silicone tape, and high temperature resistant peeling membrane. The aluminum plates were wrapped with the high temperature membrane (green membrane) and sealed with the heat resistant tape to protect it from potential resin leaking out during the compression process. A 300x300 mm square was then drawn in the center of the base plate to mark the placement location of the fiber sheets. On the perimeter of this drawn square, the silicone sealant tape was layered in a basic weave pattern to create a border (Figure 23).

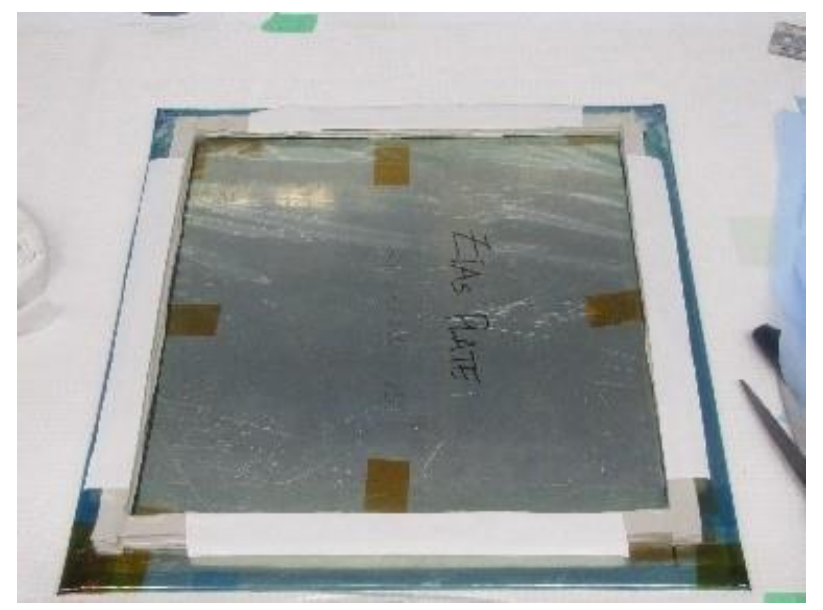

Figure 23: Wrapped base plate with silicone tape borders

This border would serve as a house to keep the Fiber/Matrix in place during the compression process as well as mitigate resin leakage. The height of this border is dependent upon the number of layers being used to form the plate. The silicone sealant tape border is then sealed in the corners using a silicone paste to further increase its stability and resistance to leaking. The final step in 
preparing the mold is to cut two $300 * 300 \mathrm{~mm}$ of the peeling plies (the blue ply shown in Figure 24). This material is utilized so that the finished plate can be easily extracted from the mold.

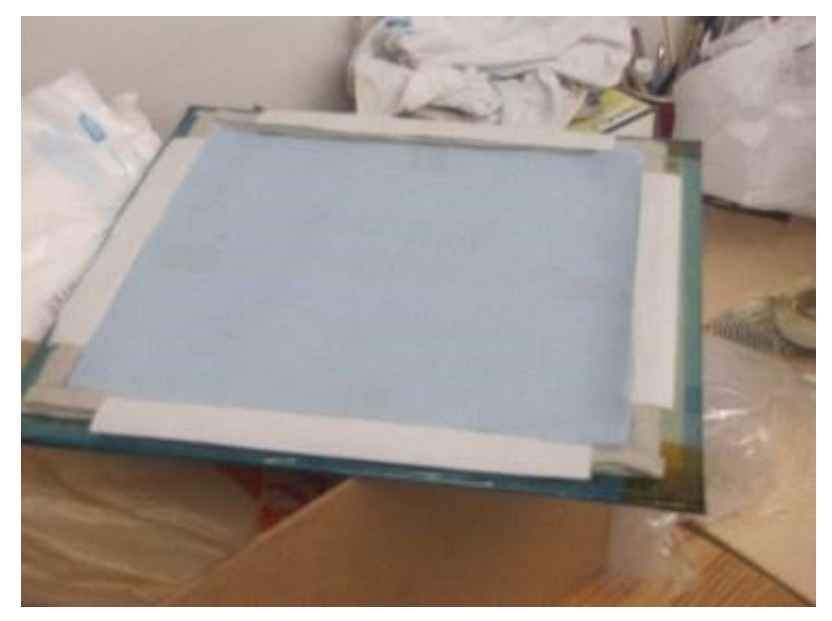

Figure 24: Base plate with peeling membrane

\subsection{Materials and manufacturing process}

Manufacturing of the Glass/Flax/Epoxy composite plates was done using 12 layers of Flax fiber (Lineo Flax ply) and 4 layers of Glass fiber (two layer in each side) in $\left[0_{\mathrm{G} 2} / 0_{\mathrm{F} 6}\right]_{\mathrm{S}}$ and $\left[0_{\mathrm{G} 2} / \pm 45_{\mathrm{F} 6}\right]_{\mathrm{S}}$

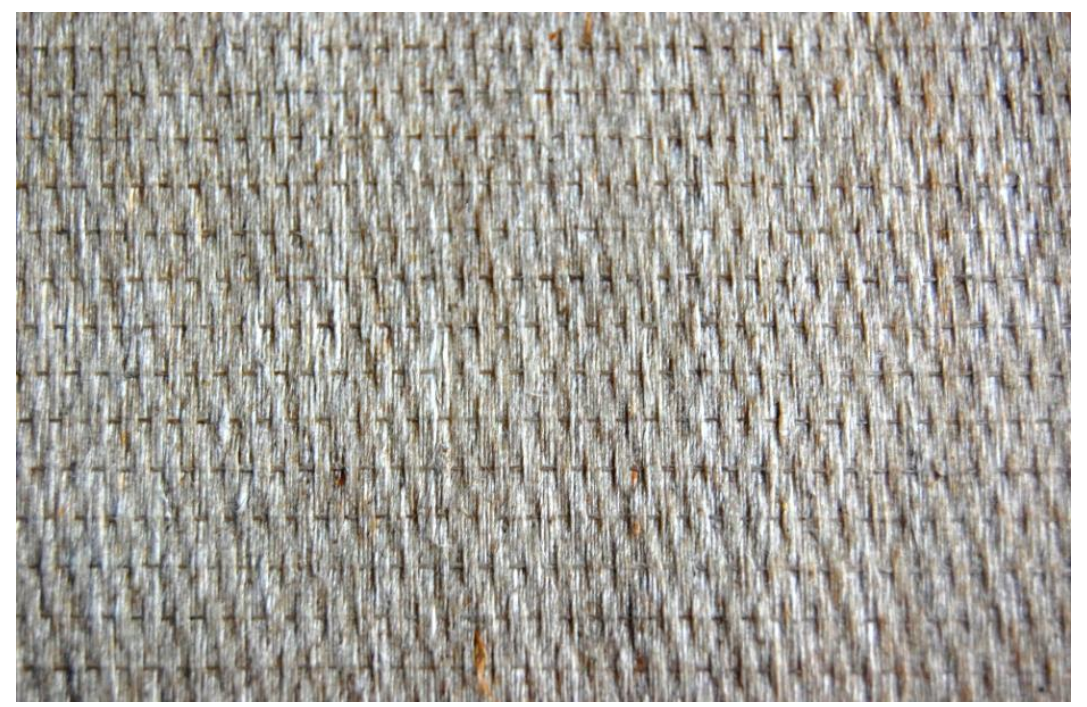

Figure 25: Lineo flax ply sample with yarn strands ratio $0^{\circ}: 90^{\circ}$ equal to $40: 3$ 


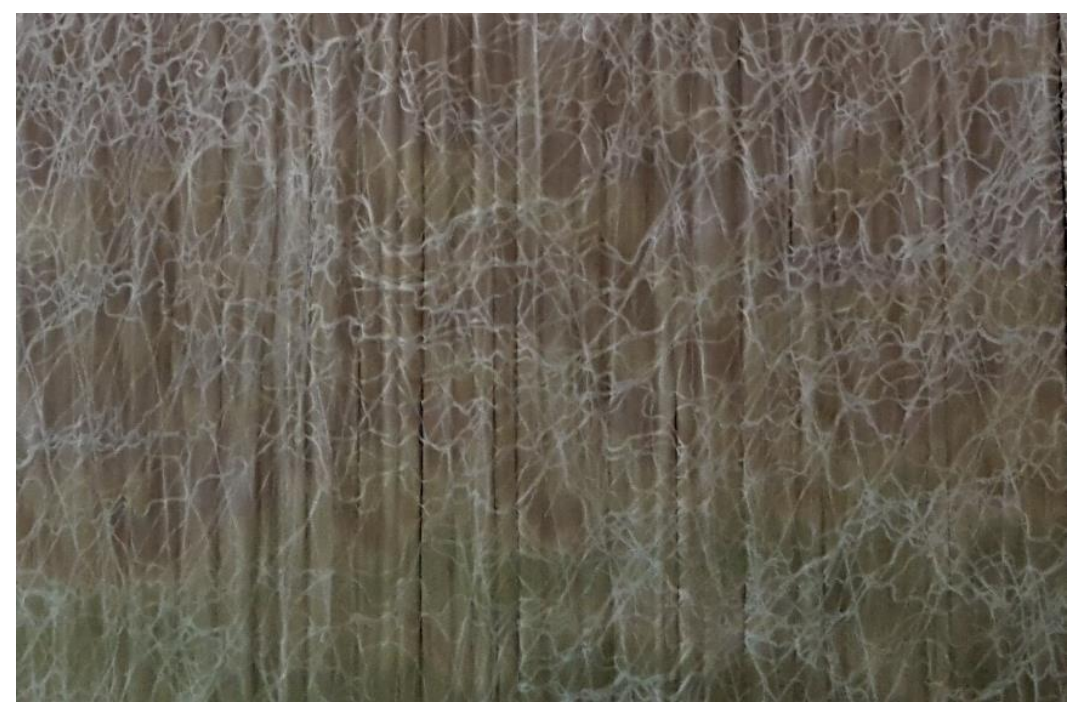

Figure 26: Unidirectional E-Glass ply sample with randomly distributed yarns to hold the UD fibers in place

stacking arrangement where mixture of Araldite LY 564 low viscosity epoxy and Aradur 22962 hardener polyamine with weight percentage ratio of $4: 1$ was used as binding matrix in the composite as shown in Figure 27.

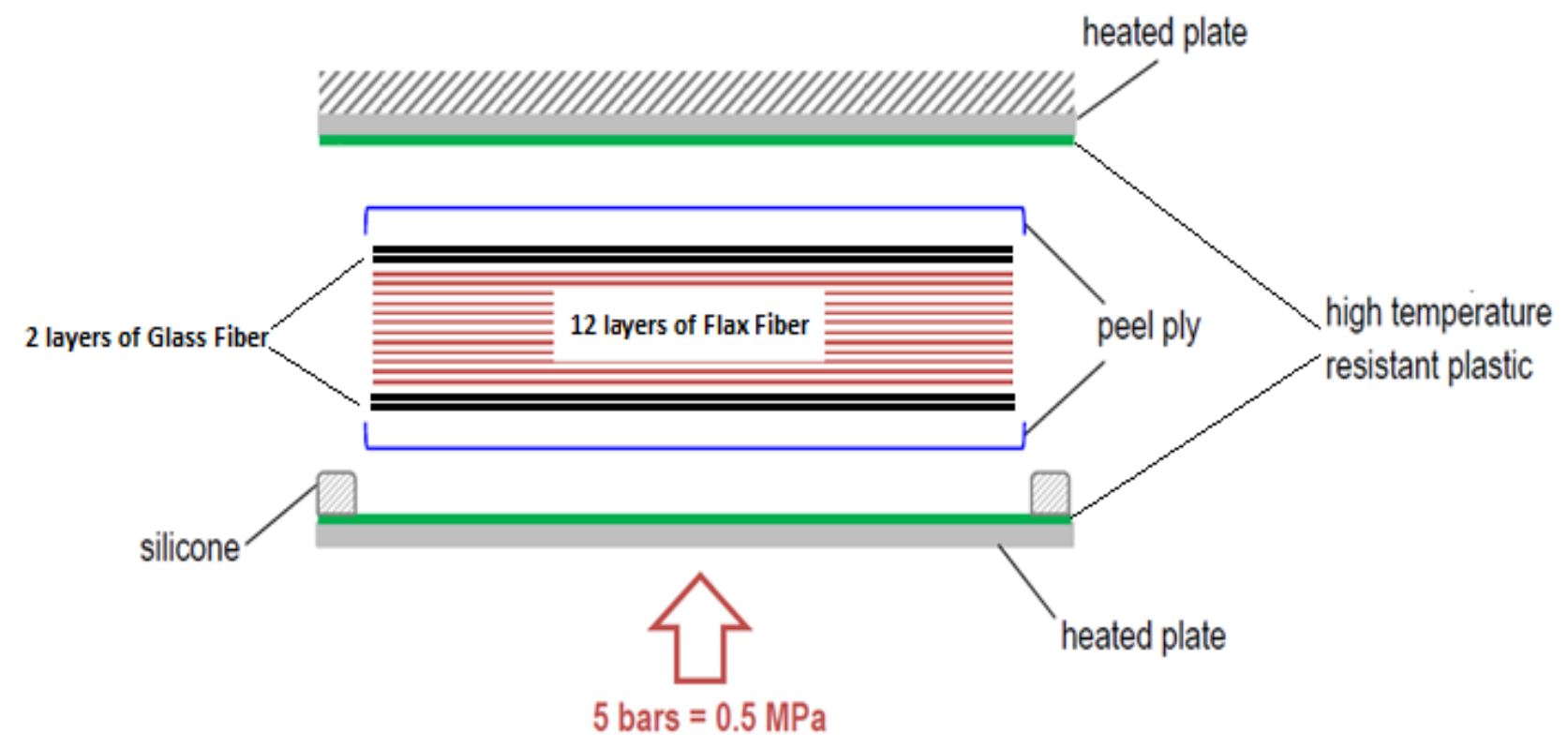

Figure 27: Mold and plate fabrication set up

In between each layer of fiber, the resin mixture was evenly spread using a brush, and then raked with a ridged roller to create small ridges to aid in adhesion (Figure 28). 

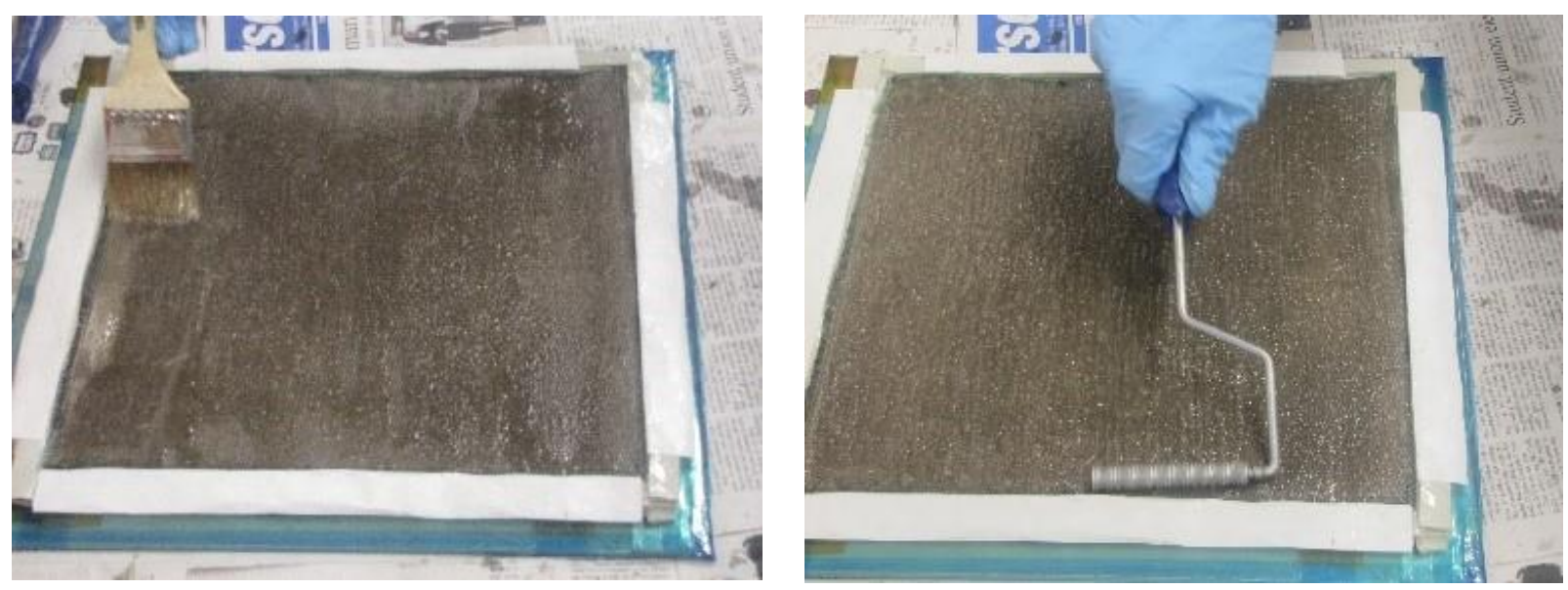

Figure 28: Spreading the matrix using a brush and then raking of resin using rigid roller upon fiber Sheets

To close the mold, the second wrapped aluminum plate was placed upon the base which housed the layered fiber sheets. Before commencing the laminate forming stage of the manufacturing process, a bag is created using the high temperature resistant membrane and heat resistant tape. The purpose of this bag is to contain the laminate plate during the compression molding process, as well as collecting the excess resin that escapes the mold. This protects the machine from the leaking fluid. The mold was then placed within the bag, which had already been installed inside the machine and the bag was then sealed using the heat resistant tape (Figure 29).
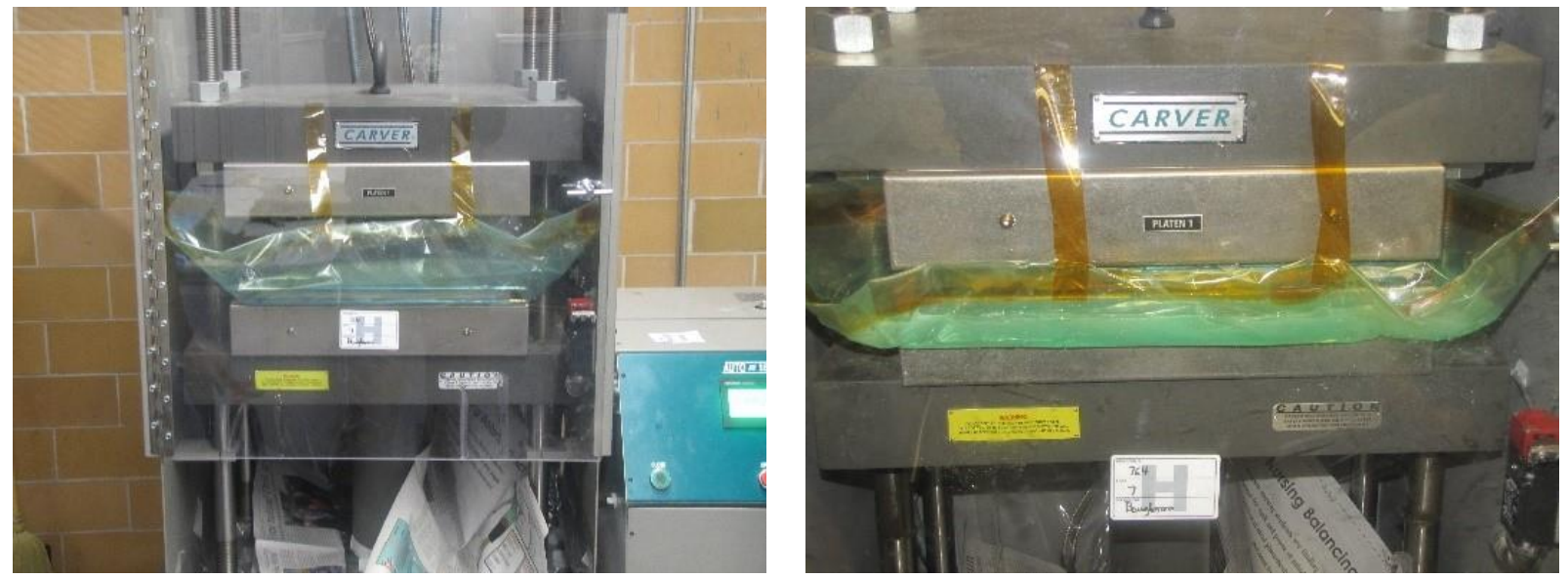

Figure 29: Mold Inside the membrane bag, loaded into the compression molding machine; before and after compression 
A compression molding machine was used (Carver Press, Wabash, IN, USA) to cure the material in a three stage curing cycle was used to cure the sandwich plates in a three stage curing cycle at elevated temperature (Figure 30).

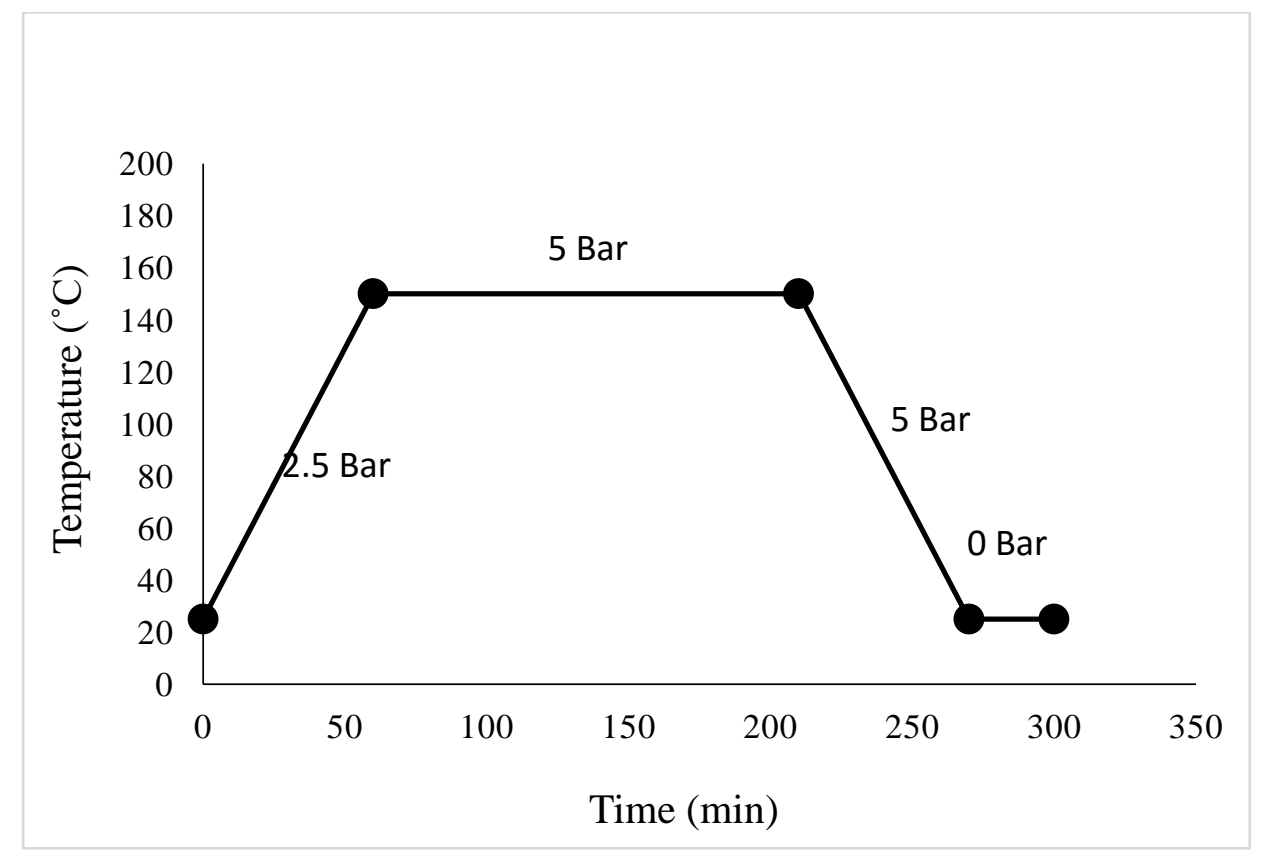

Figure 30: The three stage curing cycle used in specimens manufacturing process

Initially, the plates were heated up from room temperature to $150{ }^{\circ} \mathrm{C}$ at half load pressure of 2.5 bar (heating stage). Then at this temperature $\left(150{ }^{\circ} \mathrm{C}\right)$, the pressure was increased to 5 bar and plates were kept in this condition for 2.5 hours to cure fully (curing stage). Finally, the plates were cooled down from $150{ }^{\circ} \mathrm{C}$ to room temperature at 5 bar pressure (cooling stage). The final manufactured plate in each batch was $300 * 300 \mathrm{~mm}$ in size, and average thickness of $4 \mathrm{~mm}$. These composite plates were cut using a table saw to fabricate plates with a length of $250 \mathrm{~mm}$ and a width of $25 \mathrm{~mm}$ in order to be used in future with required specimen sizes based on the recommended dimensions from ASTM standards for different test to determine the mechanical properties of polymer matrix composite materials under different loading conditions.

Several trial and errors in changing manufacturing parameters such as time, pressure and temperature were conducted in order to achieve a volume fraction of approximately $50 \%$ of fiber in final product with an acceptable void content of less than $3 \%$. 


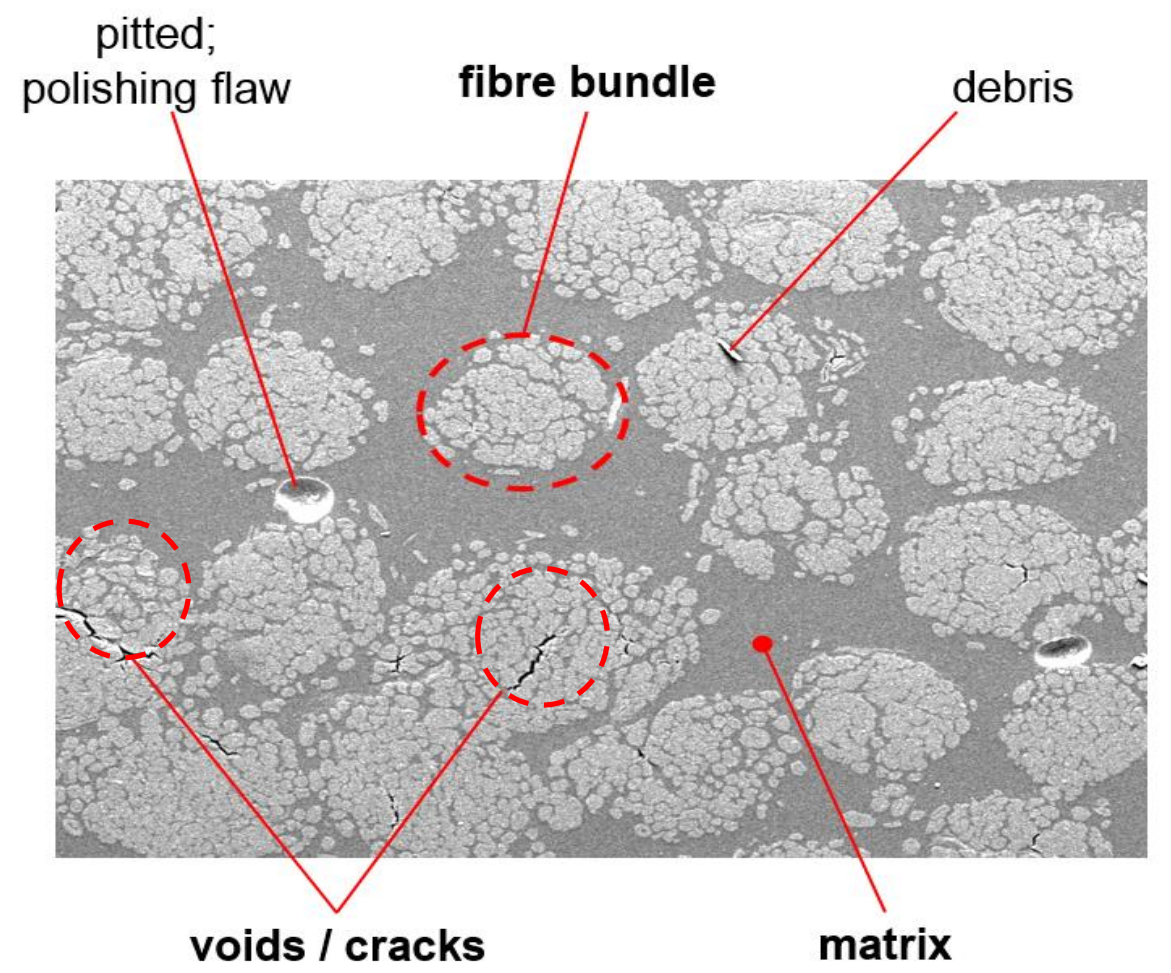

Figure 31: A 100 X SEM image of the cross section of a sample showing fiber, matrix, voids and other flaws

The Glass fiber were added to the composite structure in order to enhance the overall axial and bending mechanical properties of the material as well as reducing the water absorption rate. The aforementioned stacking arrangement result in a unique sandwich structure composite compared to previous studies performed for orthopaedic bone plate applications $[5,7,10,24,28,30,31,37$, $104,105]$.

\subsection{SEM observations}

\subsubsection{Evaluating the void, fiber and matrix contents}

The effect of voids on the mechanical properties of composite material has been widely studied. The matrix-dominated properties such as interlaminar shear strength [106], bending properties [107], compressive strength and modulus [108], fatigue [109] are influenced by voids, while the fiber-dominated mechanical properties are not significantly influenced by voids [110]. Although it is well stablished that mechanical properties decrease as the void content increases, the magnitude of the effect of void content on the mechanical properties of composites is different [111]. Moreover, majority of researcher studied the effect of voids in the literature by quantifying 
voids by content (\%) but in recent studies it was realized that this approach is too simplistic. The microstructure (shape and size) and location of voids are important as through their stress effect they can influence whether or not a crack emanates from voids and propagates and finally result in failure of the composites.

In this study, the author focused on void content as a limiting measure for validating the results from conducted mechanical experiments. Therefore, the goal in the manufacturing process was to achieve void content in the range of $\leq 3 \%$ in order to minimize its impact on the overall mechanical behaviour of the composite material. For each stacking sequence, five samples from five different plates were cold mounted using fast dry epoxy resin. Then, the mounted samples were etched and polished for SEM observation.
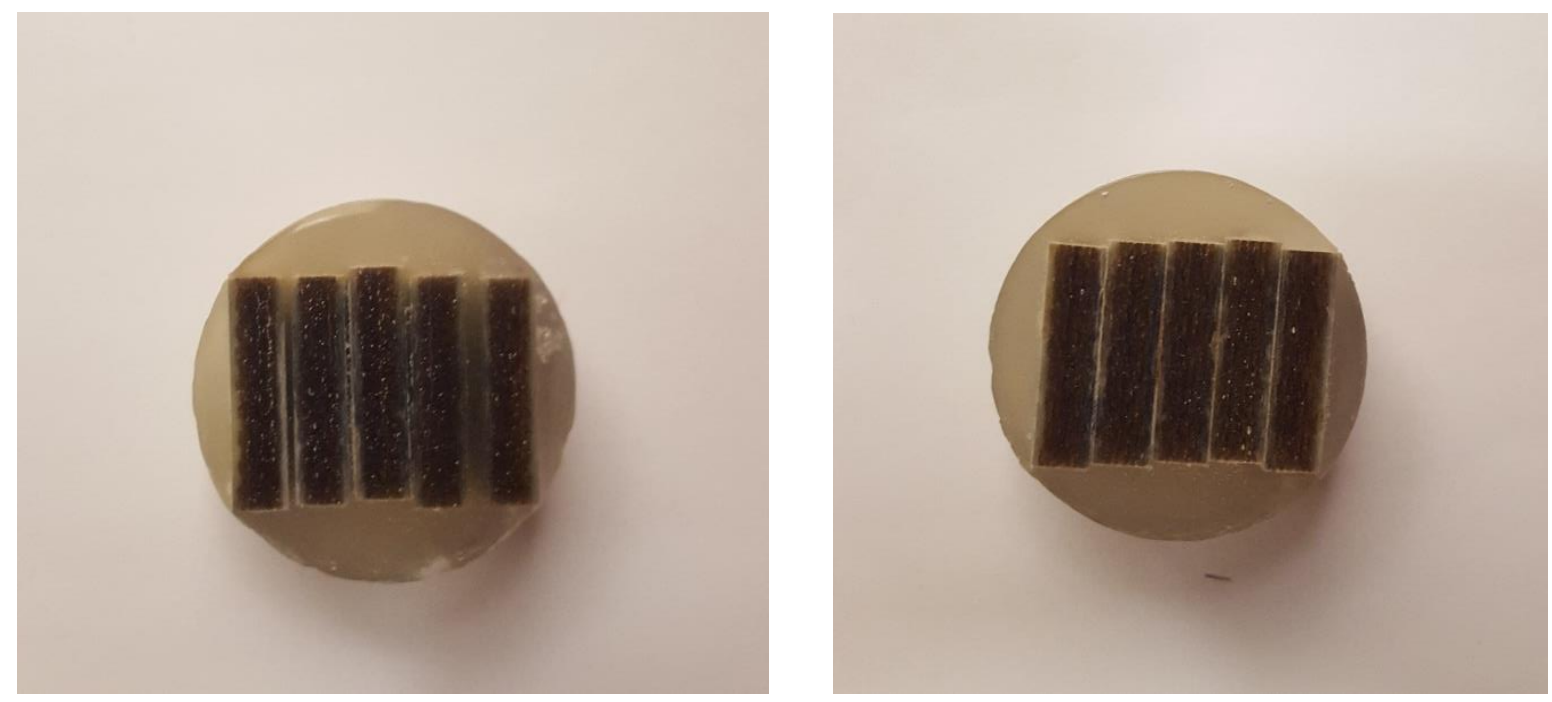

Figure 32: Polished sample mounts ready for optical observation; left) $\left[0_{\mathrm{G} 2} / \mathbf{0}_{\mathrm{F} 6}\right]_{S}$ samples, right) $\left[0_{\mathrm{G} 2} / \pm 45_{\mathrm{F} 6}\right]_{S}$ samples

Three images (Figure 33) from different section of each sample were taken. This resulted in collecting of fifteen images for each type of plates. Finally, these images were analyzed and tabulated results are provided in Table 3. 


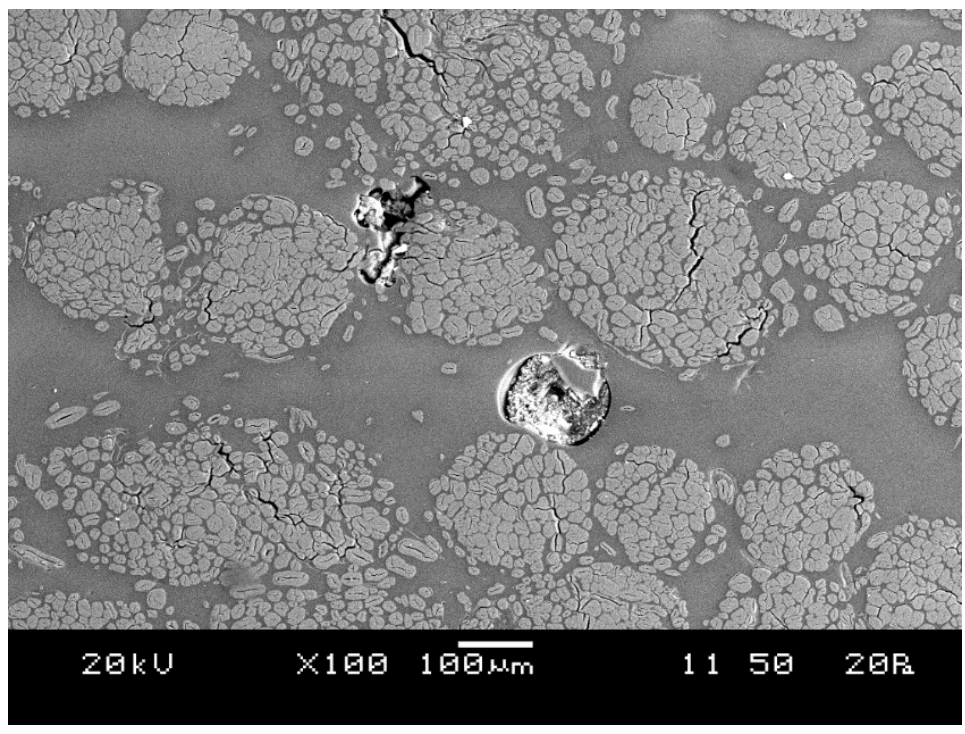

Figure 33: A SEM image at 100X magnification of $\left[0_{\mathrm{G} 2} / 0_{\mathrm{F} 6}\right]_{S}$ samples

\subsubsection{Evaluating the Glass/Epoxy and Flax/Epoxy layers' interface bonding}

Since the fibers (Glass/Flax) used in the manufacturing of the plates have different mechanical properties such as moduli of elasticity and ultimate strength, it is anticipated that failure will initiate with propagation of cracks in matrix at Glass/Flax layers' interface resulting in further delamination of these layers. Therefore, it was necessary to examine the quality of Glass/Flax layers' interface bonding to assure the results from mechanical testing are valid based on ASTM standards. In total ten images of the Glass/Flax layers' interface were taken randomly from each samples mount (two image from each sample) and were analyzed to evaluate the quality of the interface bonding.

\subsection{Water absorption tests}

Considering to the favorable performance characteristics, composite materials have been gaining wide use in commercial, military, aerospace and biomedical applications. There are some concerns however; that the mechanical properties of such materials may suffer when exposed to moisture for long periods of time $[112,113,114]$. Therefore, in order to utilize the full potential of composite materials, their response to moist environments must be known [115]. The objective of water absorption tests was to determine the moisture absorption rate as a function of time when 
the material is fully submerged in water (i.e. implant inside the body is in contact with bodily liquid constantly for relatively long time).

In this study, the standard saturated water absorption tests were conducted in accordance with ASTM standard (ASTM D570-98) [116]. Five specimens from each stacking sequence (i.e., unidirectional and angle ply) were cut. The specimens were dried in an oven for 1 hour at $110 \mathrm{C}$ and immediately weighed to the nearest $0.001 \mathrm{gr}$ using a precision balance (Sartorius M-prove series, Sartorius Inc., NY, USA). After that, they were entirely immersed in distilled water maintained at room temperature. At the end of every 24 hours' period, the specimens were removed from the water and wiped off one at a time with a low lint cloth and weighed immediately to the nearest $0.001 \mathrm{gr}$ and then placed in the water again. The percentage of the weight increase during immersion was calculated to the nearest $0.01 \%$ as follows [116]

$$
\text { Increase in weight } \%=\frac{\text { wet weight }- \text { conditioned weight }}{\text { conditioned weight }} * 100 \quad \text { (Eq. 1) }
$$

\subsection{Results and discussion}

\subsubsection{Evaluating the void, fiber and matrix contents}

The SEM images were analyzed using Buehler Omnimet software to evaluate the average constituent fraction of each types of plates. As it shown in Figure 34, software was utilized in order to designate specific color/contrast to each element presented in the row image in order to measure the corresponding area fraction of each constituent.

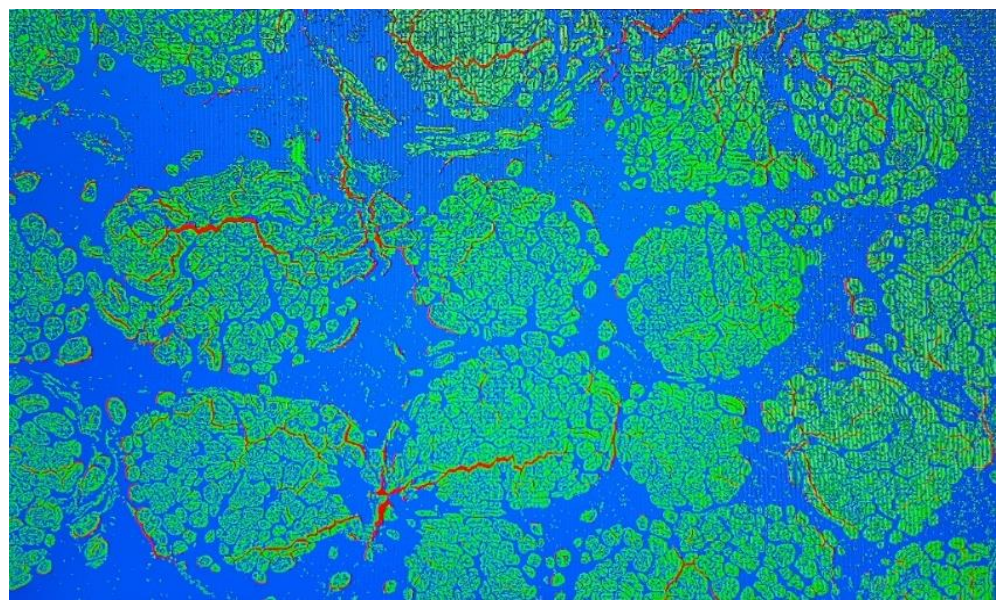

Figure 34: Constituent fraction evaluation using Buehler Omnimet software (Unidirectional laminate, image \#14) 


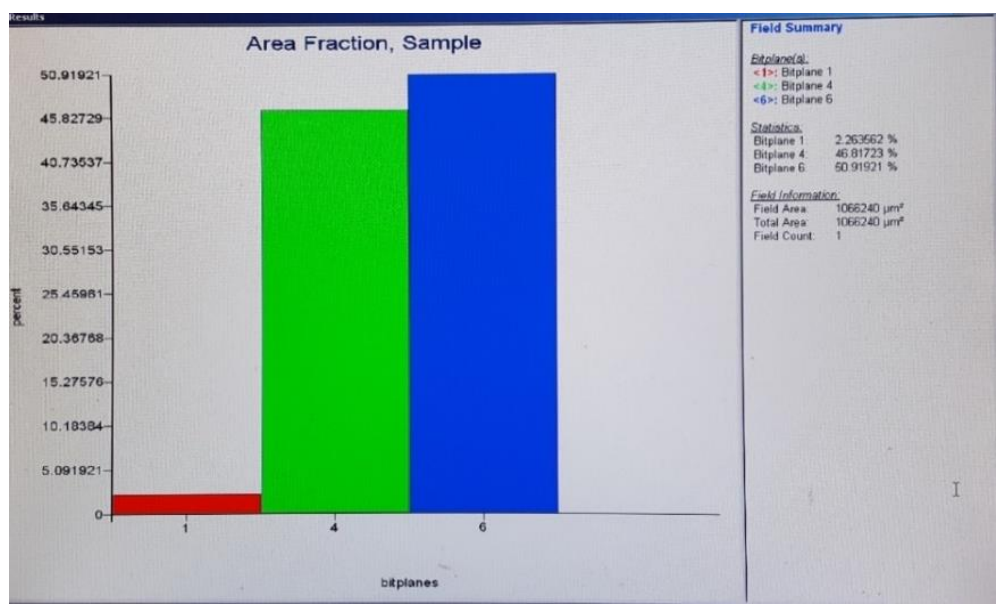

Figure 35: A generic results from Buehler Omnimet software for constituents fraction (Unidirectional laminate, image \#14)

The overall average constituent fraction of both stacking arrangements used in this study can be found in the Table 3. Since, the expected volume average fraction for fibre and matrix were assumed to be $50 \%$ with an acceptable range of void contents of 3-5\%. As it can be seen in Table 3, the results are in acceptable range and the manufacturing process was successful.

Table 3: The average constituent fraction for $\left[0_{\mathrm{G} 2} / 0_{\mathrm{F} 6}\right]_{S}$ and $\left[0_{\mathrm{G} 2} / \pm 45_{\mathrm{F} 6}\right]_{S}$ samples

\begin{tabular}{|c|c|c|c|}
\hline Sample & Void $\%$ & Fiber $\%$ & Matrix \% \\
\hline$\left[0_{\mathrm{G} 2} / 0_{\mathrm{F} 6}\right]_{S}$ & 2.7 & 45.9 & 51.4 \\
\hline$\left[0_{\mathrm{G} 2} / \pm 45_{\mathrm{F} 6}\right]_{S}$ & 2.1 & 46.1 & 51.2 \\
\hline
\end{tabular}

\subsubsection{Glass/Epoxy and Flax/Epoxy layers' interface bonding}

SEM images in Figure 36 and Figure 37, showed the strong bonding at the interface of Glass/Epoxy and Flax/Epoxy adjacent layers for both $\left[0_{\mathrm{G} 2} / 0_{\mathrm{F} 6}\right]_{S}$ and $\left[0_{\mathrm{G} 2} / \pm 45_{\mathrm{F} 6}\right]_{S}$, as no debonding or delamination between these adjacent layers occurred. This ensures that loading condition will be the only cause for occurrence of the delamination during mechanical testing and manufacturing process of the plates was successful. 


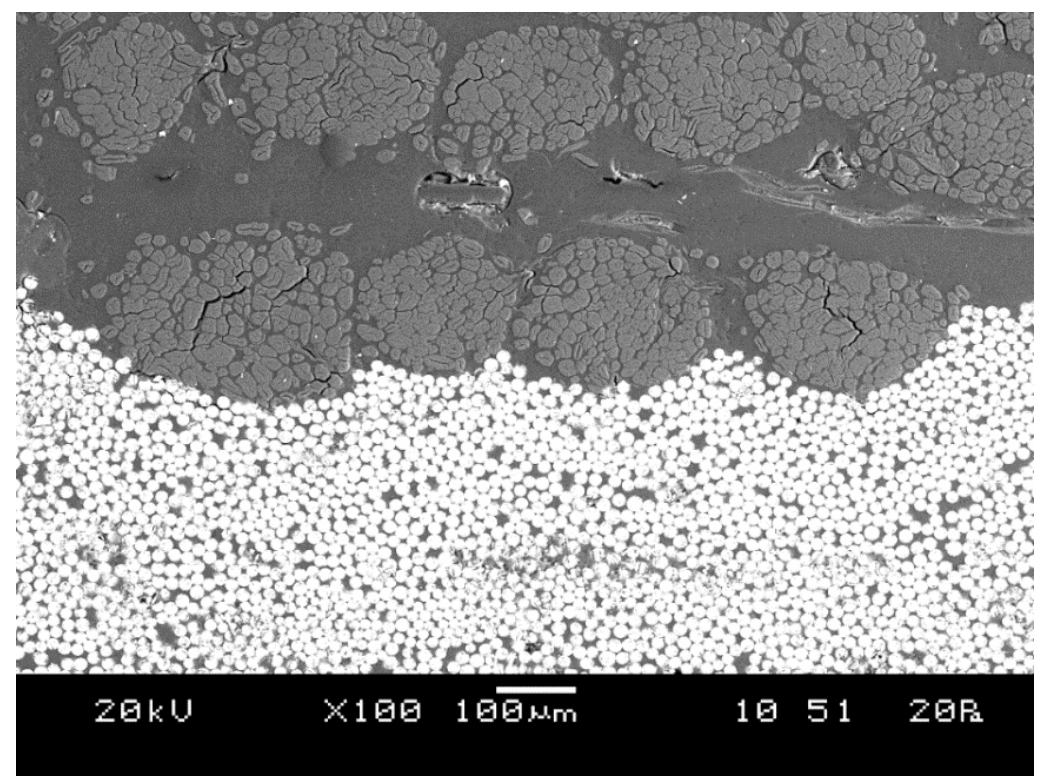

Figure 36: A typical SEM image from Glass/Flax layers interface of $\left[0_{\mathrm{G} 2} / \mathbf{0}_{\mathrm{F} 6}\right]_{S}$ sample at 100X magnification

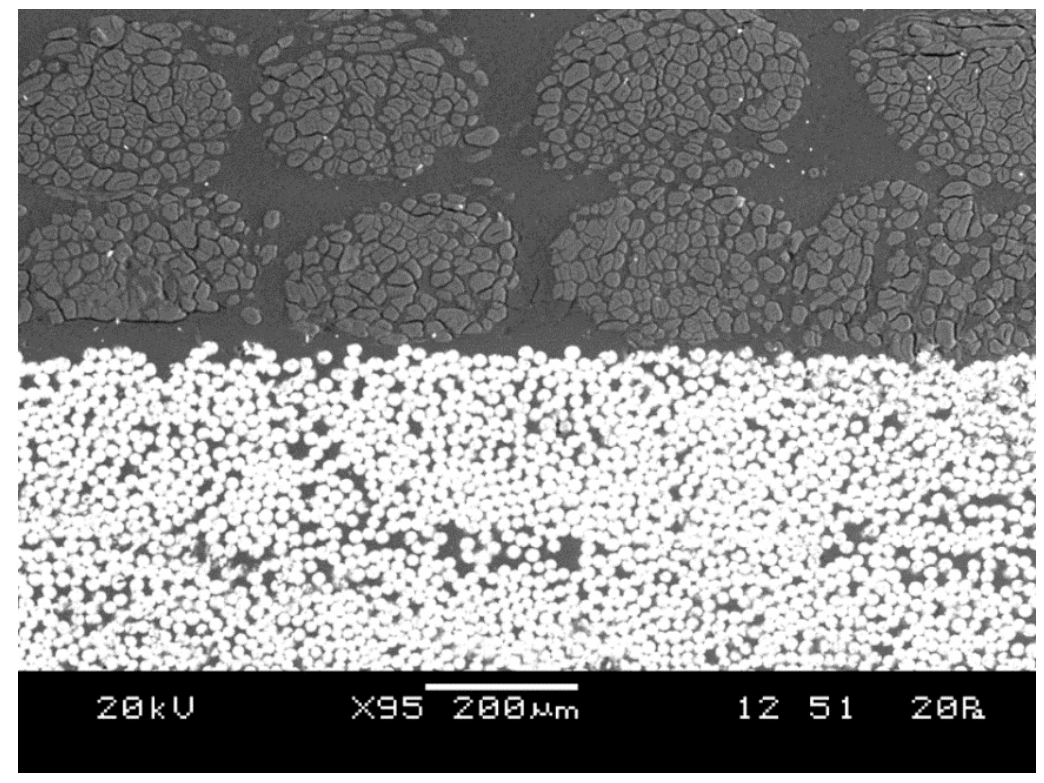

Figure 37: A typical SEM image from Glass/Flax layers interface of $\left[0_{\mathrm{G} 2} / \pm 45_{\mathrm{F} 6}\right]_{S}$ sample at 100X magnification

\subsubsection{Water absorption test}

The results of water absorption tests for unidirectional $\left[0_{\mathrm{G} 2} / 0_{\mathrm{F} 6}\right]_{\mathrm{S}}$ and angle ply $\left[0_{\mathrm{G} 2} / \pm 45_{\mathrm{F} 6}\right]_{\mathrm{S}}$ plates were shown in Figure 38. The measured weight of the composite plates reached a steady state after 
about 40 days and was found to be $6.03 \pm 0.174 \%$ for $\left[0_{\mathrm{G} 2} / \pm 45_{\mathrm{F} 6}\right]_{\mathrm{S}}$ specimens and $4.61 \pm 0.217 \%$ for $\left[0_{\mathrm{G} 2} / 0_{\mathrm{F} 6}\right]_{\mathrm{S}}$ unidirectional specimens.

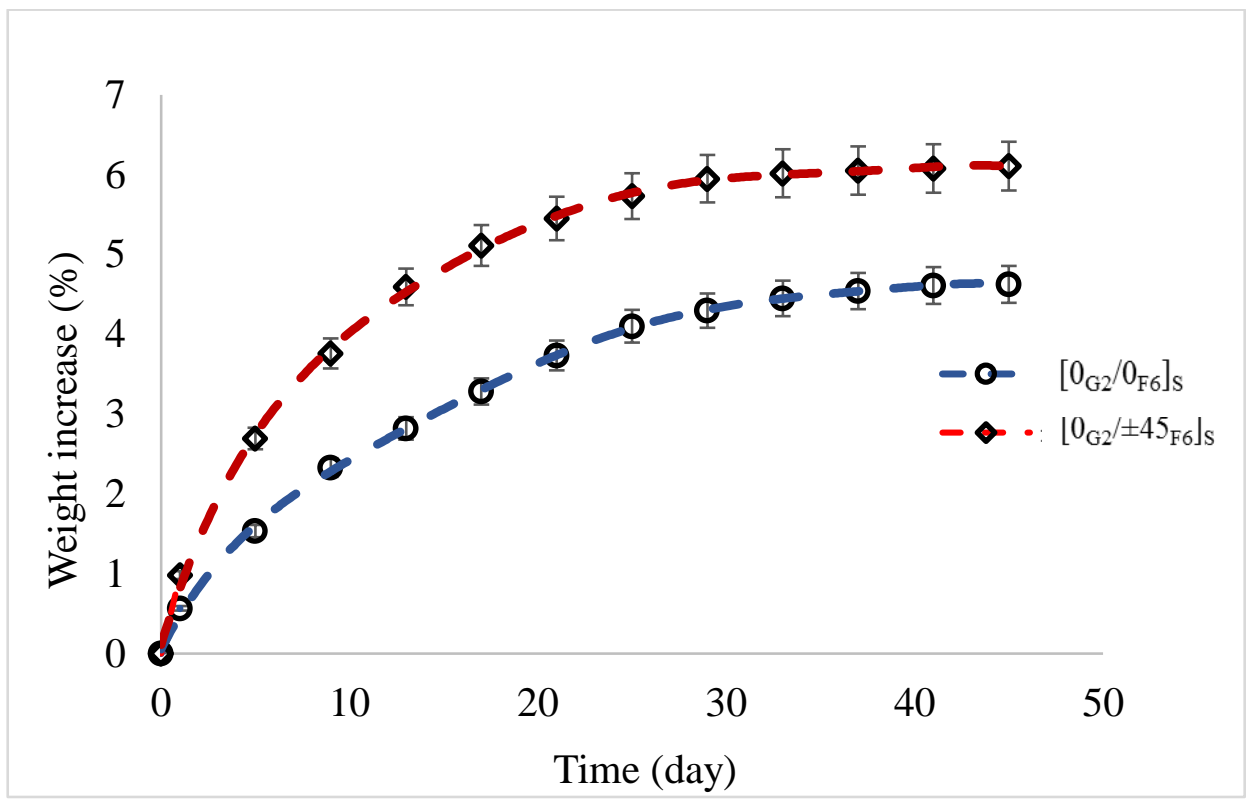

Figure 38: Average weight increase $(\%)$ vs. time for specimens with ply configuration $\left[0_{\mathrm{G} 2} / \mathbf{0}_{\mathrm{F} 6}\right]_{\mathrm{S}}$ and $\left[0_{\mathrm{G} 2} / \pm 45_{\mathrm{F} 6}\right]_{\mathrm{S}}$

For comparison purposes, the results from this study are tabulated along with those from previous studies in Table 4. It can be seen from these results that the addition of two external layers of glass fiber significantly improved (by more than 180\%) the water absorption of the pure flax/epoxy composite. Also, changing the orientation of the flax fibers from $0^{\circ}$ to $\pm 45^{\circ}$ considerably increase the rate of water absorption by more than $30 \%$.

Table 4: Result of water absorption tests performed in curent study accomponied with results of other composite material reported by prior studies

\begin{tabular}{|c|c|c|}
\hline Material & Water Absorption $(\%)$ & Reference \\
\hline Flax/Epoxy & 17.2 & {$[7]$} \\
\hline Current $\left[0_{\mathrm{G} 2} / \pm 45_{\mathrm{F} 6}\right]_{\mathrm{S}}$ & $6.035 \pm 0.174$ & - \\
\hline Current $\left[0_{\mathrm{G} 2} / 0_{\mathrm{F} 6}\right]_{\mathrm{S}}$ & $4.608 \pm 0.217$ & {$[7]$} \\
\hline $\mathrm{CF} / \mathrm{Flax} /$ Epoxy & 8.3 & {$[7]$} \\
\hline $\mathrm{CF} /$ Epoxy & 1.25 & - \\
\hline
\end{tabular}




\subsection{Summary}

This chapter confirms that the manufacturing process of the Glass/Flax/Epoxy composite plates successfully result in average volume fraction of fiber close to $50 \%$ and void content are in acceptable range of $\leq 3 \%$. Moreover, the developed Glass/Flax/epoxy composite material has shown a strong bonding at Glass/Flax layers' interface which proves that adding the glass layers as a stronger and stiffer reinforcement fiber in order to enhance the overall mechanical properties of the composite was successes. Finally, the addition of two external layers of glass fiber significantly improved (by more than 180\%) the water absorption compared to pure flax/epoxy composite, resulting in a more biocompatible composite. 


\section{Static behavior of Glass/Flax/Epoxy composite}

The purpose of this chapter is to investigate the mechanical feasibility of a Glass/Flax/Epoxy hybrid composite material for long bone fracture fixation mechanism such as fracture plates. These hybrid composite plates have a "sandwich structure" in which two layers of Glass/Epoxy were attached to each side of Flax/Epoxy core. This resulted in a unique structure compared to prior structure proposed for similar clinical applications. In order to evaluate the static mechanical properties of this material, the uniaxial tension, compression, three-point bending and Rockwell Hardness tests were conducted to simulate the main loads experienced by orthopedic femur fracture plates.

This chapter confirms that the proposed hybrid composite plates are significantly more flexible axially compared to conventional metallic plates. Furthermore, they have considerably higher ultimate strength in tension, compression and flexion. Such high strength will ensure good stability of bone-implant construct at the fracture site, immobilize adjacent bone fragments and carry clinical-type forces experienced during daily normal activities. Moreover, this sandwich structure with stronger and stiffer face sheets and more flexible core can result in a higher stiffness and strength in bending compared to tension and compression. These qualities make the proposed hybrid composite an ideal candidate for the design of an optimized fracture fixation system with much closer mechanical properties to human cortical bone.

\subsection{Introduction}

The focus of the present study is to investigate the possibility of using a new composite material in designing fracture plates commonly used in long bone fractures such as femoral shaft fractures. Although several studies proposed composite materials for bone fracture plates, yet there is not enough confident to use this material in clinical trial study in human body which indicates there is a vast opportunity for researcher for further investigation on the composite materials for biomedical applications. Furthermore, the hybrid composite with "sandwich structure" reinforced by glass and flax fibers has never been considered for bone fracture plate applications. Therefore, in the current study, a new Glass/Flax/Epoxy composite plate with potential biomedical application as a long bone fracture plate was manufactured. The glass fiber was chosen due to its great tensile and compressive strength. In addition, sandwich structure with stronger and stiffer fibers (glass 
fibers) in outer layers and flexible flax fibers as the core material was considered to mimic the structure of bone with soft cancellous bone at its core and rigid cortical bone at its surfaces which will face higher stress (tension/compression) when it is under loading condition. In this chapter, it was hypothesized that the Glass/Flax/Epoxy composite would have properties similar to that of human cortical bone and have potential for biomechanical application such as long bone fracture plate. In order to evaluate the static mechanical properties of this material, uniaxial tension, uniaxial compression and three-point bending were conducted to simulate the main loads experienced by orthopaedic femur fracture plates. In addition, Rockwell hardness tests were performed in order to compare surface hardness of this material with the conventional metal used for the same application.

\subsection{Materials and manufacturing process of Glass/Flax/Epoxy specimens}

Manufacturing of the Glass/Flax/Epoxy composite plates was done using 12 layers of Flax fiber and 4 layers of UD Glass fiber (two layer in each side) (Lineo Flax ply) in $\left[0_{\mathrm{G} 2} / 0_{\mathrm{F} 6}\right]_{\mathrm{S}}$ and $\left[0_{\mathrm{G} 2} / \pm 45_{\mathrm{F} 6}\right]_{\mathrm{S}}$ stacking arrangement where mixture of Araldite $®$ LY 564 low viscosity epoxy and Aradur® 22962 hardener polyamine was used as binding matrix in the composite as shown in Figure 39. Several trial and errors in changing manufacturing parameters such as time, pressure and temperature was conducted in order to achieve a volume fraction of approximately $50 \%$ of fiber in final product with an acceptable void content of less than $3 \%$.

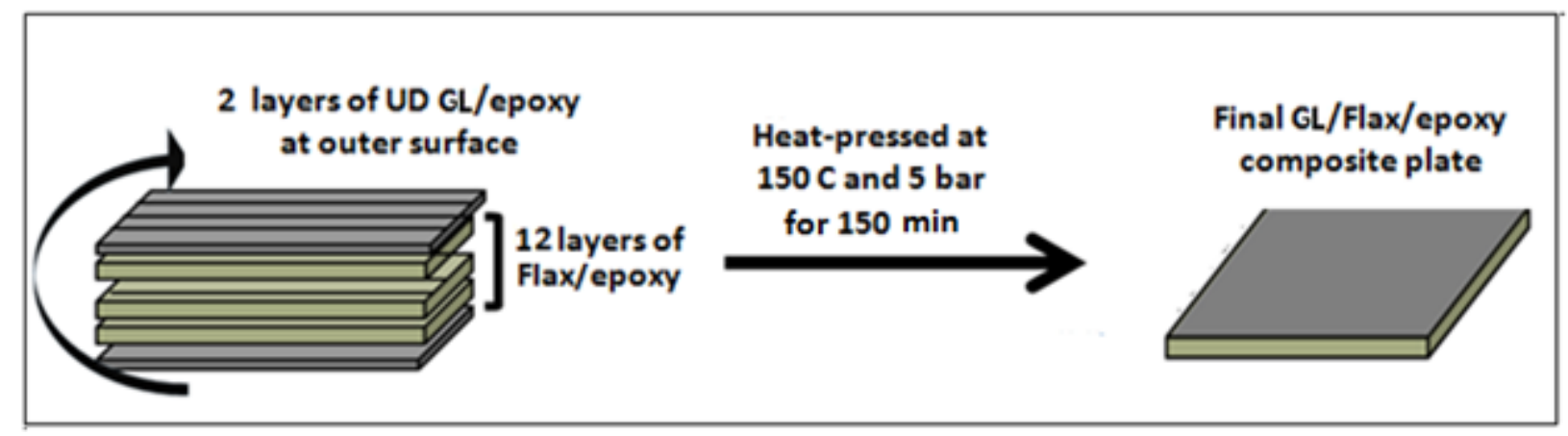

Figure 39: The novel "sandwich structure" of Glass/Flax/Epoxy plate

A compression molding machine was used (Carver Press, Wabash, IN, USA) to cure the material in a three stage curing cycle was used to cure the sandwich plates. Initially, the plates were heated up from room temperature to $150{ }^{\circ} \mathrm{C}$ at half load pressure of 2.5 bar (heating stage). Then at this 
temperature $\left(150^{\circ} \mathrm{C}\right)$, the pressure was increased to 5 bar and plates were kept in this condition for 2.5 hours to cure fully (curing stage). Finally, the plates were cooled down from $150{ }^{\circ} \mathrm{C}$ to room temperature at 5 bar pressure (cooling stage). The final manufactured plate in each batch was $300 * 300 \mathrm{~mm}$ in size, and average thickness of $4 \mathrm{~mm}$. These composite plates were cut using a table saw to fabricate plates with a length of $250 \mathrm{~mm}$ and a width of $25 \mathrm{~mm}$ in order to be used in future with required specimen sizes based on the recommended dimensions from ASTM standards for different test to determine the mechanical properties of polymer matrix composite materials.

\subsection{General study design and experimental methods}

The current study is the first to assess the basic static mechanical properties of a new Glass/Flax/Epoxy hybrid composite for potential biomechanical application as a long bone fracture plate. This composite material has mechanical properties that make it attractive for bone fracture plates experiencing clinical-type axial loading or bending. Mechanical testing, include tension, compression, three-point bending, and Rockwell hardness tests, were performed on Glass/Flax/ Epoxy composite specimens to define its mechanical properties, such as longitudinal strength, Young's modulus, flexural strength, flexural modulus, and surface hardness. The objective was to determine the mechanical properties of the composite plate and the strength of bonding at the interface of Glass/Epoxy and Flax/Epoxy laminae under clinical-type axial and bending loading conditions. In addition, the failure mechanism of the specimens was characterized using optical observation and Scanning Electron Microscopy (SEM).

\subsubsection{Tension tests}

Tensile test experiments were conducted based on ASTM standard (ASTM D3039/D3039M-14, 2008b) [117] from each stacking sequence (SP01 to SP05). A tensile test machine (STM series, United Calibration Corp., Huntington Beach, CA), with a testing speed of $2 \mathrm{~mm} / \mathrm{min}$ and a maximum $50 \mathrm{kN}$ load cell. An extensometer (United Calibration Corp., Huntington Beach, CA, USA) placed at the center of the specimens was used to measure elongation. The specimens were

positioned in the grips with the long axis in-line with the force direction (Deluxe-Action Wedge Grips, United Calibration Corp., Huntington Beach, CA, USA) so that $60 \mathrm{~mm}$ of the samples at each end was gripped. The test specimens were loaded to failure under quasi-static tensile loading conditions. 

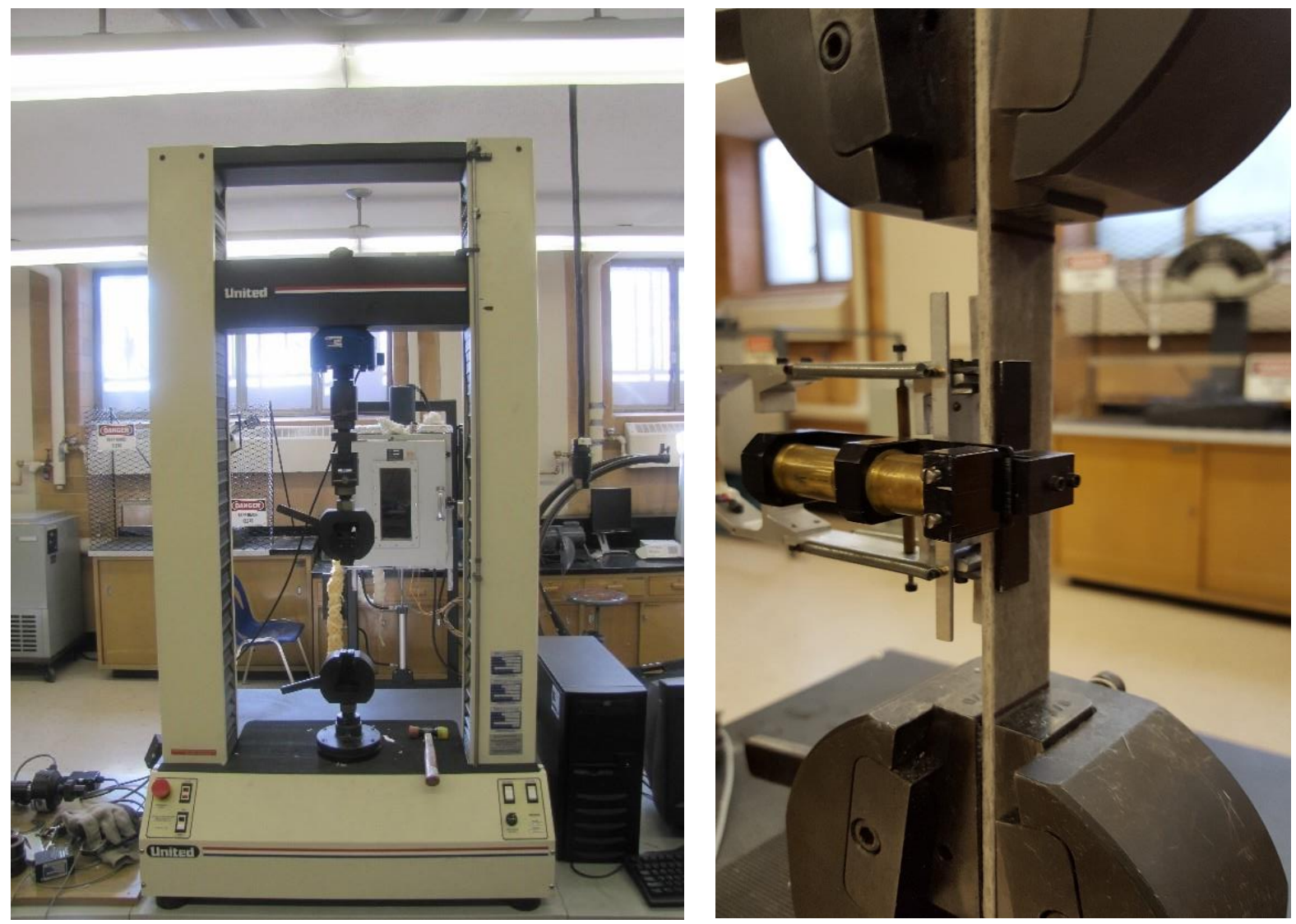

Figure 40: Tension test set up

The ultimate strength and ultimate strain were measured just before the failure. The modulus of elasticity was determined by applying linear regression to the linear domain of the experimental stress-vs-strain curve. Mean value and standard deviation of the obtained were then calculated.

\subsubsection{Compression tests}

Compression tests were performed on specimens in accordance with ASTM standard (ASTM D695-10, 2010a) for compressive properties of rigid plastics [118]. The experiments were conducted on a compression machine (MTS 322 Test Frame, MTS Systems Corporation, Eden Prairie, MN, USA), with a testing speed of $2 \mathrm{~mm} / \mathrm{min}$ and a maximum $100 \mathrm{kN}$ load cell. Five specimens from each stacking sequence were cut in $100 \mathrm{~mm}$ long and $25 \mathrm{~mm}$ wide and were positioned in the hydraulic grips with the long axis in-line with the force direction so that $40 \mathrm{~mm}$ of the samples at each end was gripped with 100 bar gripping pressure. 


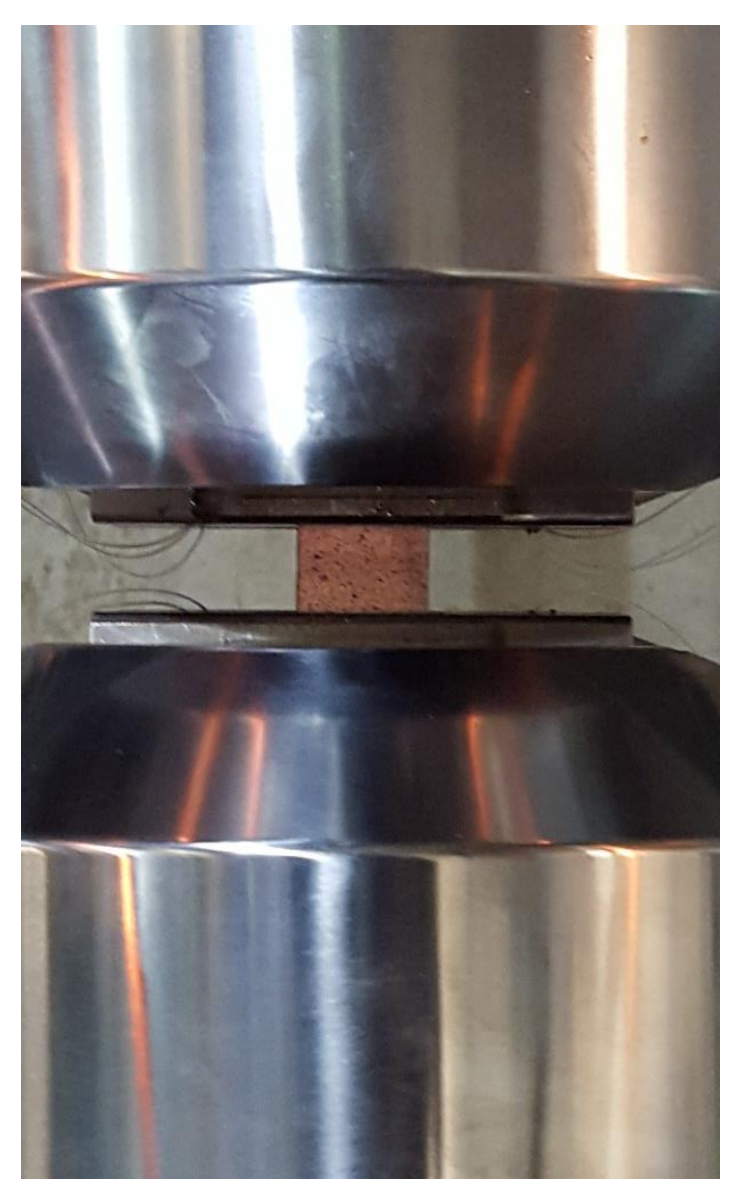

Figure 41: Compression test set up

The test specimens were loaded to failure under quasi-static compressive loading conditions. The ultimate strength and ultimate strain were measured just before the failure (i.e. occurrence of the buckling). The modulus of elasticity (i.e. slope of the curve) was obtained by applying linear regression to the linear domain of the experimental stress-vs-strain curve.

\subsubsection{Bending tests}

The three-point bending tests were performed on 5 specimens from each stacking sequence with a length of $250 \mathrm{~mm}$ and a width of $25 \mathrm{~mm}$ based on the recommended dimensions from the ASTM standard (ASTM D7264/D7264M- 07, 2015) for bending properties of polymer matrix composite materials [119]. All specimens were loaded to failure under quasi-static loading conditions. The experiments were conducted on the same testing machine used for tension tests, in which a fixture having $200 \mathrm{~mm}$ span length was used to support each specimen. A large span-to-thickness ratio 
was chosen in order to minimize the effect of out-of-plane shear in calculation of bending properties [119].

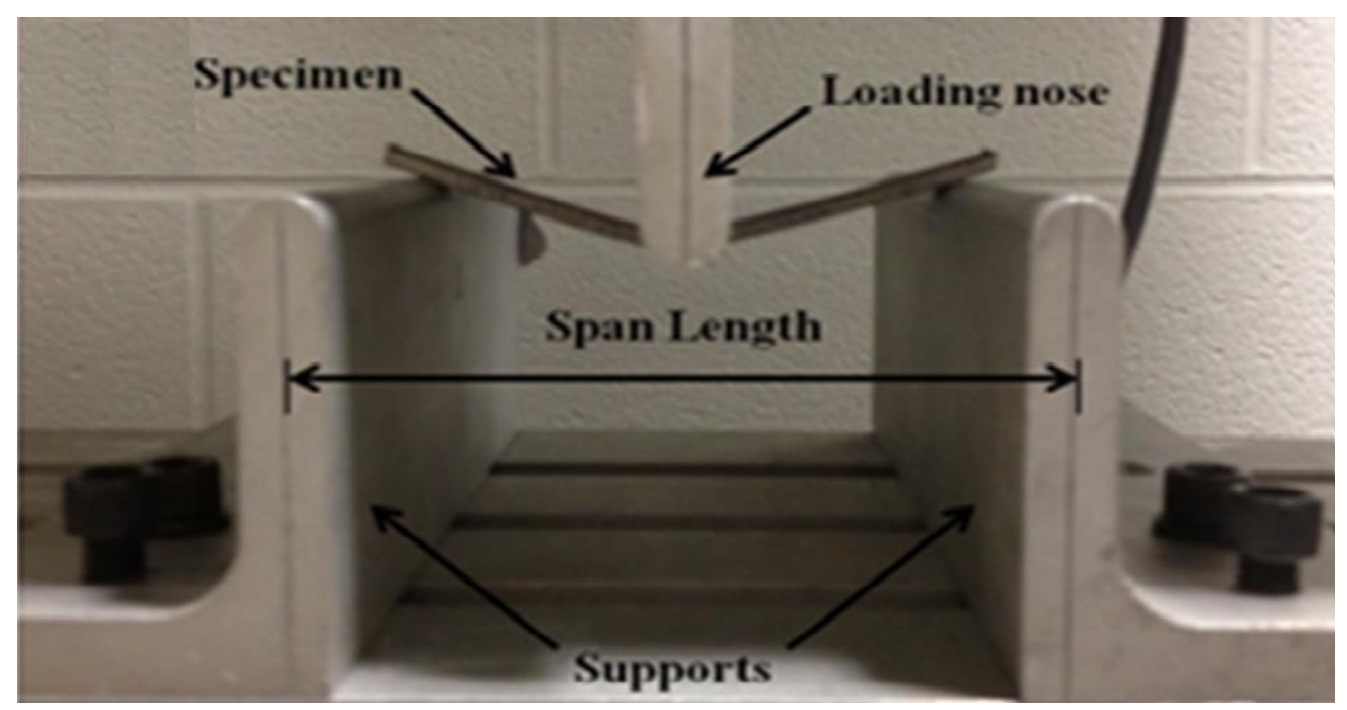

Figure 42: Bending test set up

Both loading nose and supports had circular contact surfaces of $3 \mathrm{~mm}$ radius. The testing speed was $10 \mathrm{~mm} / \mathrm{min}$, and a $50 \mathrm{KN}$ load cell was used in all tests. Using the beam theory, the ultimate strength and ultimate strain were measured just before the failure. Also, the flexural modulus of elasticity, which is the ratio of stress to strain at any point on the stress-vs-strain curve, was calculated using following equations [119],

$$
\begin{aligned}
& E_{f}=\frac{M L^{3}}{4 b h^{3}} \\
& \sigma_{f}=\frac{3 P_{f} L}{2 b h^{2}}
\end{aligned}
$$

Where $\mathrm{E}_{\mathrm{f}}$ is the flexural modulus of elasticity $(\mathrm{MPa}), \sigma_{\mathrm{f}}$ is the ultimate flexural stress $(\mathrm{MPa}), \mathrm{P}_{\mathrm{f}}$ is the maximum load $(\mathrm{N}), \mathrm{L}$ is the support span $(\mathrm{mm}), \mathrm{b}$ is the width of the beam $(\mathrm{mm}), \mathrm{h}$ is the thickness of beam (mm), $M$ is the slope of the force-vs-deflection curve $(\mathrm{N} / \mathrm{mm})$.

\subsubsection{Rockwell hardness tests}

Rockwell E hardness tests were performed on 5 square-shaped specimens from each stacking arrangement of manufactured plates based on the recommended dimensions in the ASTM standard 
(ASTM D785-08, 2008b) for Rockwell hardness test of plastics and electrical insulating materials [120] as there is no ASTM standard specifically for testing the hardness of polymer-matrix composite materials.

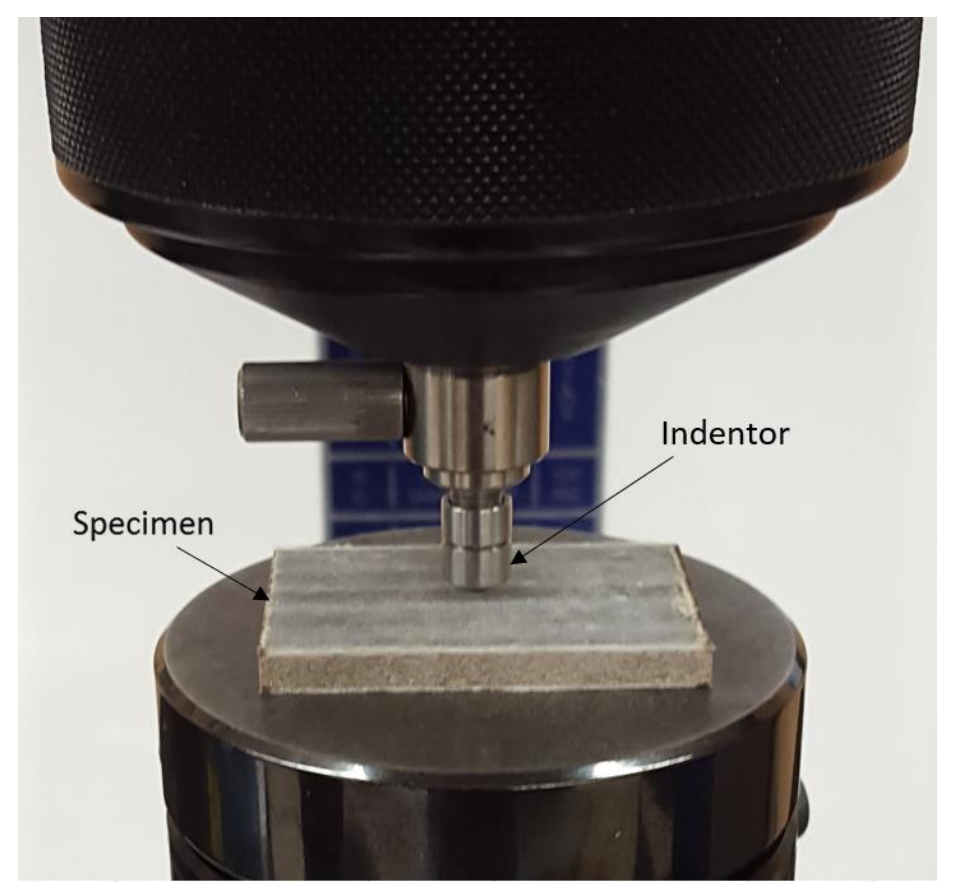

Figure 43: Rockwell hardness test set up

All test specimens were visually examined for parallel flat surfaces to eliminate deflection caused by poor contact between samples and the anvil of the hardness tester machine. A large steel ball (rather than a cone-shaped indenter) was chosen in order to distribute the load more evenly, since fibers may influence the penetration of the indenter and could result in variations in data [120]. Tests were done at ambient room temperature using a Rockwell hardness tester (LR300TD, LECO Corporation, St. Joseph, MI, USA), which forced a steel sphere with a 1/16-inch diameter at a load of $100 \mathrm{~kg}$ (HRE). The total time taken from the initial indentation, to load dwell time, and finally to the recording of the measurement was 10 seconds, which was controlled entirely by the hardness tester. For each sample, 3 readings were made directly from the testing device, and the mean value of these readings was reported as the hardness of this material. 


\subsection{Results}

\subsubsection{Tension test}

The tensile behavior of the five specimens for each configuration used in this study are shown by plotting load vs. displacement in Figure 44 and Figure 45 where SP01-05 refers to five specimens used in this experiment (i.e. SP01 is specimen \#5). All specimens experienced brittle fracture with linear behavior up until failure. From analysing the data recorded during the test, the mean values with standard deviations ( \pm SD) for Young's modulus and ultimate strength were $31.97 \pm 2.97$ $\mathrm{GPa}$ and $408.25 \pm 51.36 \mathrm{MPa}$ for $\left[0_{\mathrm{G} 2} / 0_{\mathrm{F} 6}\right]_{\mathrm{S}}$ unidirectional specimen and 16.51 $0.68 \mathrm{GPa}$ and $301.87 \pm 62.77 \mathrm{MPa}$ for $\left[0_{\mathrm{G} 2} / \pm 45_{\mathrm{F} 6}\right]_{\mathrm{S}}$ specimen respectively (Table 5 and Table 6 ).

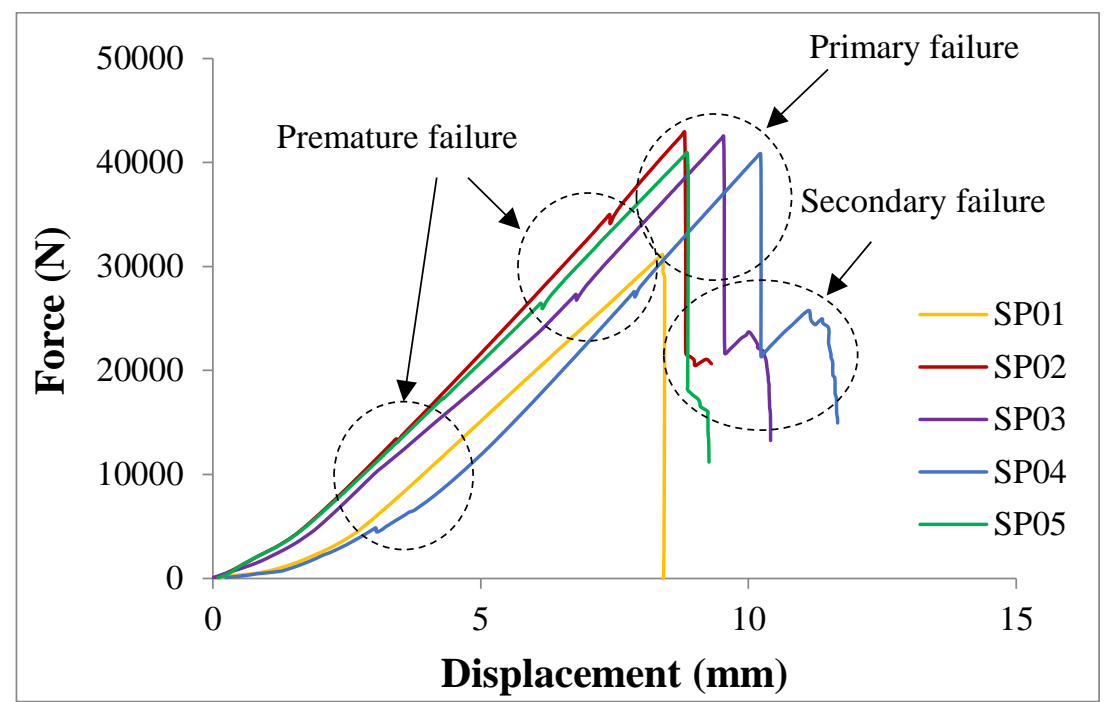

Figure 44: Tension test results for five test specimens (SP01-SP05) for $\left[0_{\mathrm{G} 2} / 0_{\mathrm{F} 6}\right]_{\mathrm{S}}$ laminate

Table 5: Overall results of tension tests on unidirectional $\left[0_{\mathrm{G} 2} / \mathbf{0}_{\mathrm{F} 6}\right]_{\mathrm{S}}$ Glass/Flax/Epoxy composite specimens

\begin{tabular}{|c|c|c|c|}
\hline Sample \# & E (MPa) & EA (MN) & UTS (MPa) \\
\hline SP01 & 35.94 & 3.65 & 307.01 \\
\hline SP02 & 27.00 & 2.70 & 429.61 \\
\hline SP03 & 31.28 & 2.96 & 450.08 \\
\hline SP04 & 33.79 & 3.25 & 424.66 \\
\hline SP05 & 31.83 & 3.03 & 429.88 \\
\hline Mean & $\mathbf{3 1 . 9 7}$ & $\mathbf{3 . 1 2}$ & $\mathbf{4 0 8 . 2 5}$ \\
\hline SD & $\mathbf{2 . 9 7}$ & $\mathbf{0 . 3 2}$ & $\mathbf{5 1 . 3 6}$ \\
\hline CV (\%) & $\mathbf{9 . 3 1}$ & $\mathbf{1 0 . 2 4}$ & $\mathbf{1 2 . 5 8}$ \\
\hline
\end{tabular}




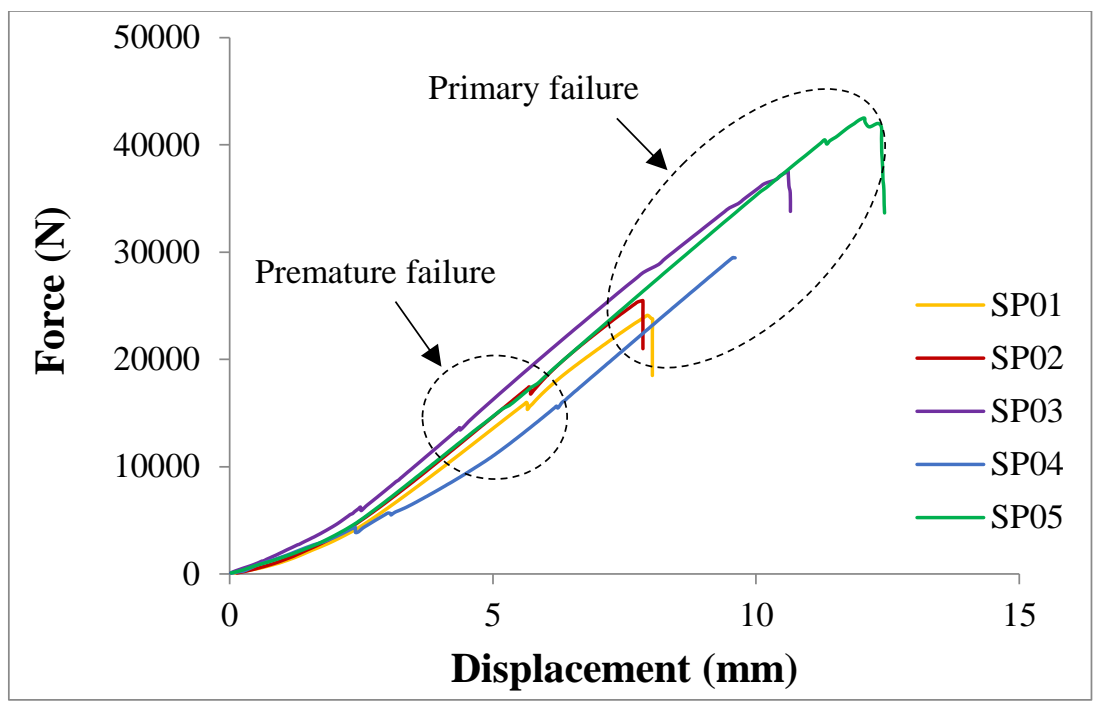

Figure 45: Tension test results for five test specimens (SP01-SP05) for $\left[0_{G 2} / \pm 45_{F 6}\right]_{S}$ laminate

Table 6: Overall results of tension tests on $\left[0_{\mathrm{G} 2} / \pm 45_{\mathrm{F} 6}\right]_{\mathrm{S}}$ Glass/Flax/Epoxy composite specimens

\begin{tabular}{|c|c|c|c|}
\hline Sample \# & E (MPa) & EA (MN) & UTS (MPa) \\
\hline SP01 & 16.08 & 1.66 & 233.14 \\
\hline SP02 & 17.63 & 1.82 & 246.75 \\
\hline SP03 & 15.60 & 1.65 & 354.32 \\
\hline SP04 & 16.64 & 1.75 & 279.96 \\
\hline SP05 & 16.62 & 1.79 & 395.19 \\
\hline \hline Mean & $\mathbf{1 6 . 5 1}$ & $\mathbf{1 . 7 4}$ & $\mathbf{3 0 1 . 8 7}$ \\
\hline SD & $\mathbf{0 . 6 8}$ & $\mathbf{0 . 0 7}$ & $\mathbf{6 2 . 7 7}$ \\
\hline CV $(\%)$ & $\mathbf{4 . 1 0}$ & $\mathbf{3 . 8 5}$ & $\mathbf{2 0 . 7 9}$ \\
\hline
\end{tabular}

Catastrophic failure accompanied by an abrupt decrease in the load after reaching a peak value occurred in all the specimens. All of the specimens showed edge delimitation or long splitting in their glass layer in both sides of the specimen (Figure 46). The inner bundle of the flax fiber laminate stayed intact up until final failure. In addition, premature failures have occurred due to early initiation of cracks in matrix or fiber tearing in few specimens which affected the ultimate strength drastically. Specimens without presence of premature failure have shown higher ultimate strength or strain at primary failure. 

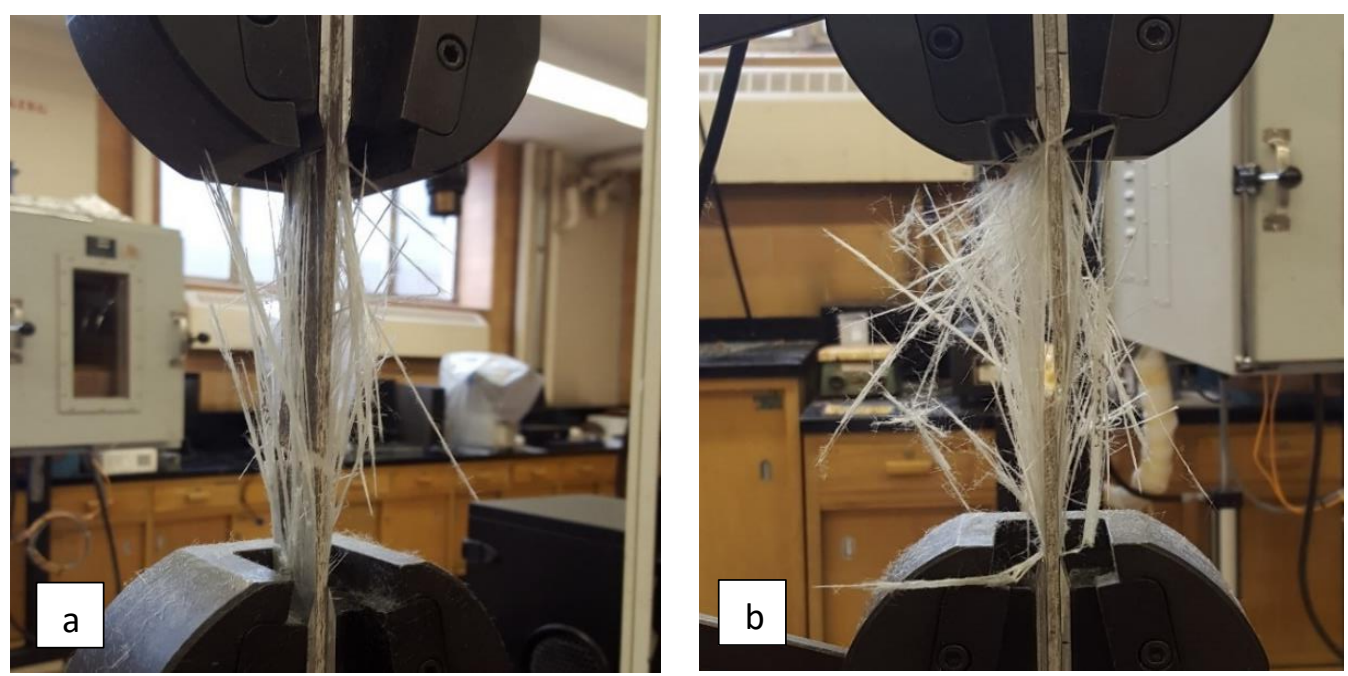

Figure 46: Catastrophic failure of specimens in tension test; (a) $\left[0_{\mathrm{G} 2} / 0_{\mathrm{F} 6}\right]_{\mathrm{S}}$ laminate, (b) $\left[0_{\mathrm{G} 2} / \pm 45_{\mathrm{F} 6}\right]_{\mathrm{S}}$ laminate

The SEM images showed fiber breakage along with fiber bundle and/or fiber pull-out at the fractured surface (Figure 47). Most fibers exhibited smooth tensile failure surfaces caused by the propagation of the crack in the composite.
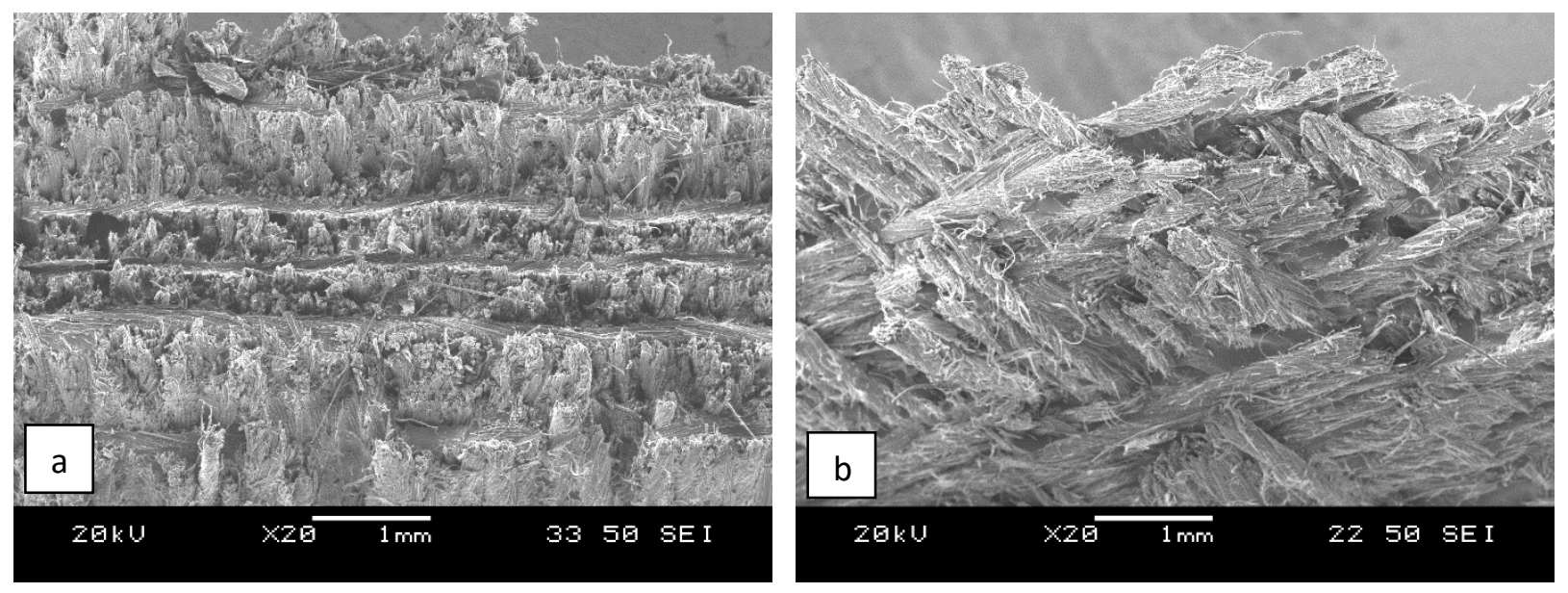

Figure 47: SEM image of failed surface of flax bundle of a) $\left[0_{G 2} / 0_{F 6}\right]_{S}$ and $\left.b\right)\left[0_{G 2} / \pm 45_{F 6}\right]_{S}$ samples at 20X magnification 

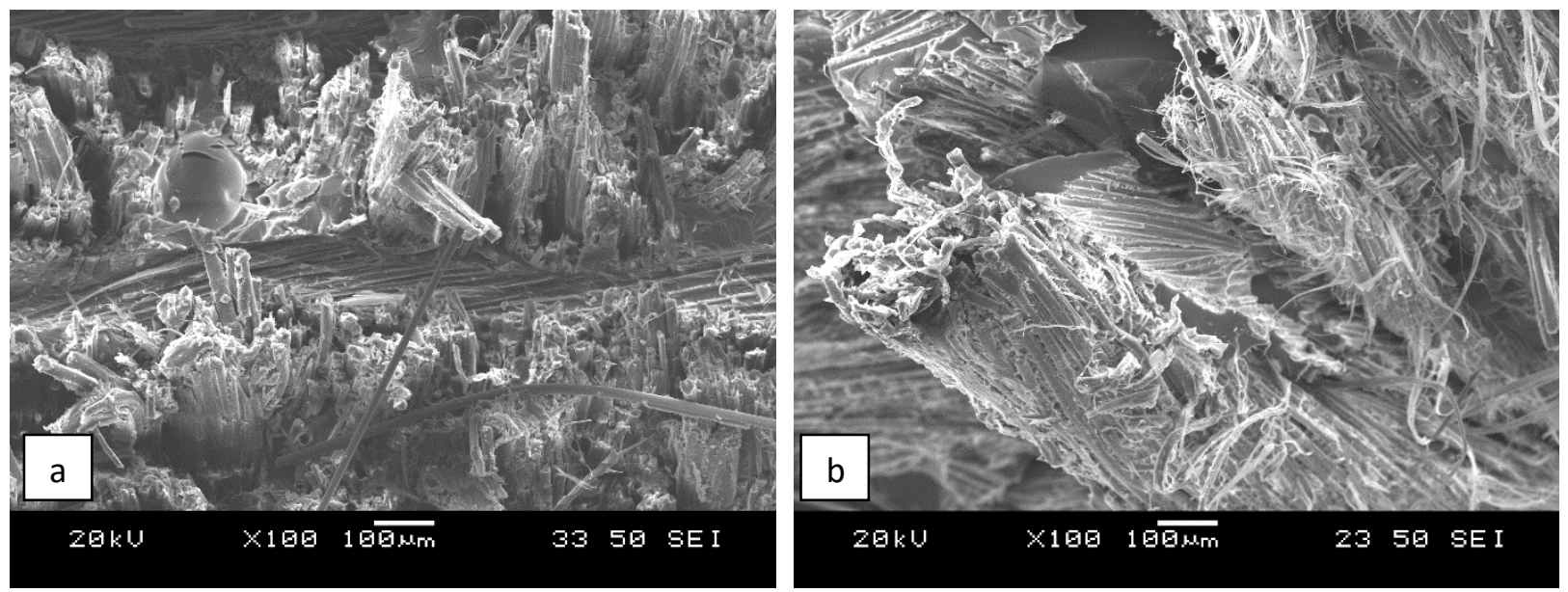

Figure 48: SEM image of failed surface flax bundle of a) $\left[0_{\mathrm{G} 2} / 0_{\mathrm{F} 6}\right]_{\mathrm{S}}$ and b) $\left[0_{\mathrm{G} 2} / \pm 45_{\mathrm{F} 6}\right]_{\mathrm{S}}$ samples at 100X magnification, fiber pull out and shearing can be seen

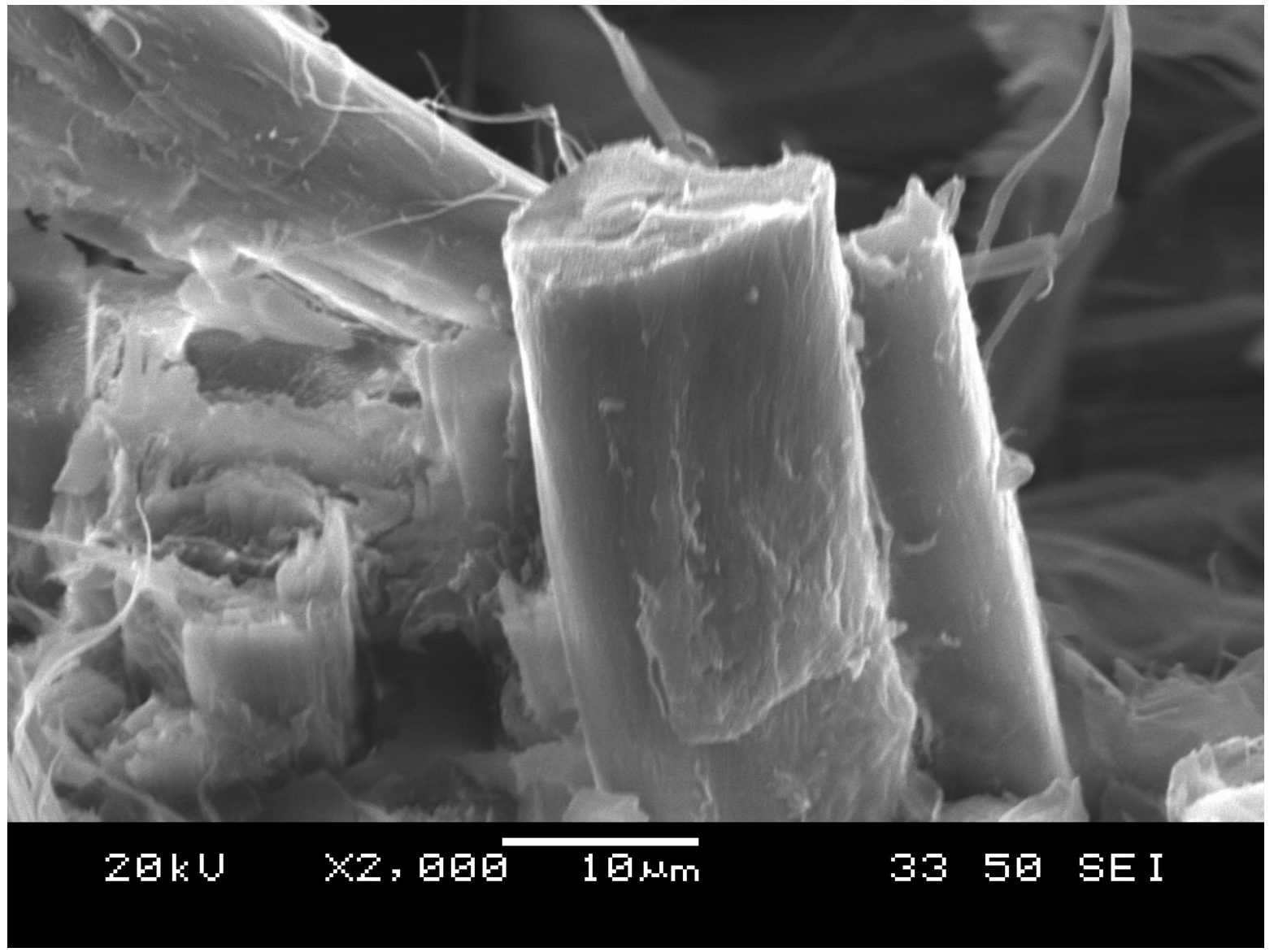

Figure 49: SEM image of failed flax fiber of a $\left[0_{\mathrm{G} 2} / 0_{\mathrm{F} 6}\right]_{\mathrm{S}}$ sample at $2000 \mathrm{X}$ magnification; fiber exhibited smooth tensile failure surfaces after being pulled out 


\subsubsection{Compression test}

The compressive behaviour of the specimens are shown by plotting force vs. displacement in Figure 50 and Figure 51 where SP01-05 refers to five specimens used in this experiment (i.e. SP01 is specimen \#5). The Young's modulus and ultimate strength were 18.26 $\pm 1.02 \mathrm{GPa}$ and 261.21 $\pm 21.93 \mathrm{MPa}$ for $\left[0_{\mathrm{G} 2} / 0_{\mathrm{F} 6}\right]_{\mathrm{S}}$ unidirectional samples and $10.52 \pm 0.37 \mathrm{GPa}$ and $233.25 \pm 7.89 \mathrm{MPa}$ for $\left[0_{\mathrm{G} 2} / \pm 45_{\mathrm{F} 6}\right]_{\mathrm{S}}$ samples, respectively (Table 7 and Table 8 ). As it can be seen in Figure 50 and Figure 51, catastrophic failure accompanied by an abrupt decrease in load after reaching a peak value occurred in all samples.

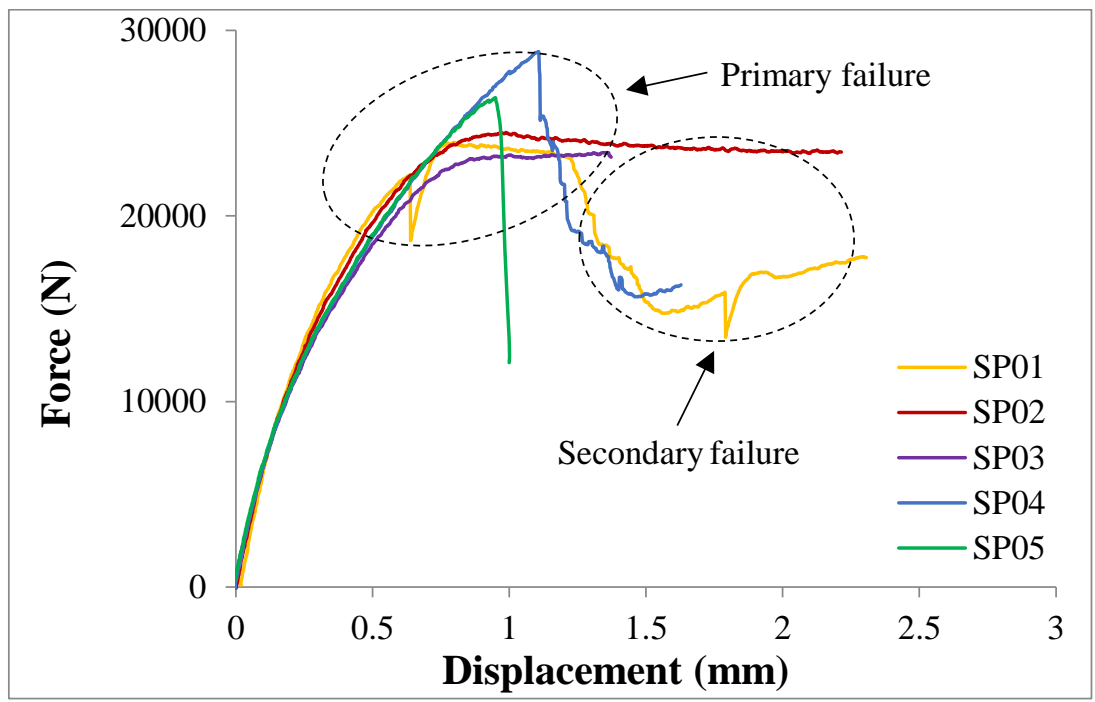

Figure 50: Compression test results for five test specimens (SP01-SP05) for $\left[0_{\mathrm{G} 2} / \mathbf{0}_{\mathrm{F} 6}\right]_{\mathrm{S}}$ laminate

Table 7: Overall results of compression tests on unidirectional $\left[0_{\mathrm{G} 2} / 0_{\mathrm{F} 6}\right]_{\mathrm{S}}$ Glass/Flax/Epoxy composite specimens

\begin{tabular}{|c|c|c|c|}
\hline Sample \# & E (MPa) & EA (MN) & UCS (MPa) \\
\hline SP01 & 19.73 & 1.95 & -242.74 \\
\hline SP02 & 17.58 & 1.80 & -238.83 \\
\hline SP03 & 18.31 & 1.71 & -250.92 \\
\hline SP04 & 16.78 & 1.64 & -295.45 \\
\hline SP05 & 18.90 & 1.79 & -278.09 \\
\hline \hline Mean & $\mathbf{1 8 . 2 6}$ & $\mathbf{1 . 7 8}$ & $\mathbf{- 2 6 1 . 2 1}$ \\
\hline SD & $\mathbf{1 . 0 2}$ & $\mathbf{0 . 1 0}$ & $\mathbf{2 1 . 9 3}$ \\
\hline CV $(\%)$ & $\mathbf{5 . 6 1}$ & $\mathbf{5 . 8 3}$ & $\mathbf{8 . 4 0}$ \\
\hline
\end{tabular}




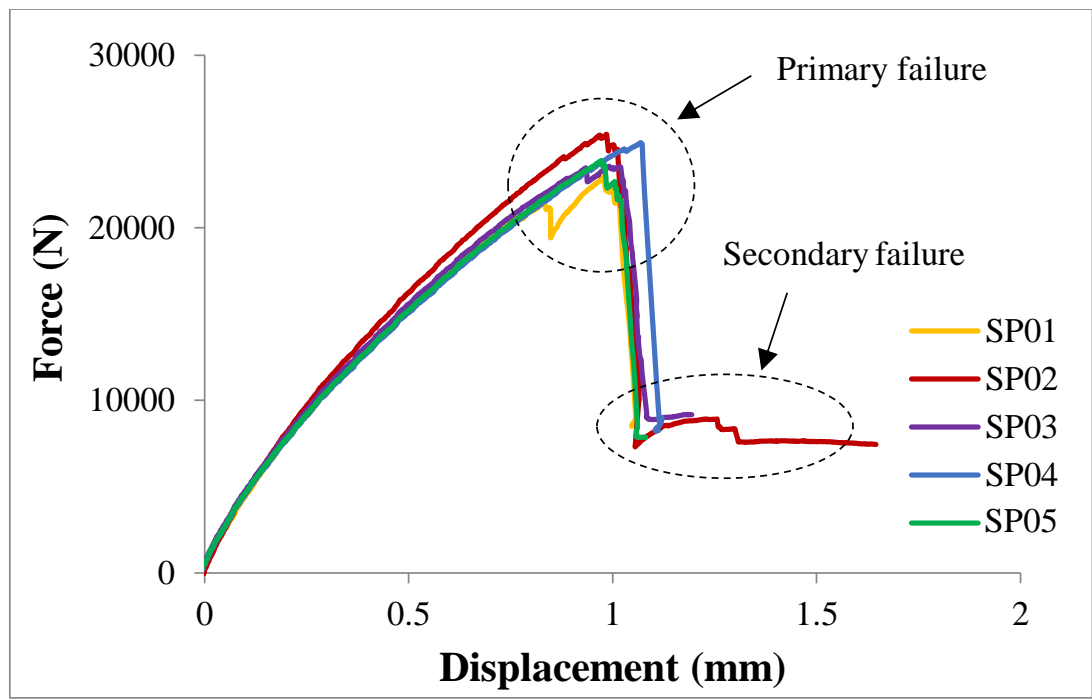

Figure 51: Compression test results for five test specimens (SP01-SP05) for $\left[0_{\mathrm{G} 2} / \pm 45_{\mathrm{F} 6}\right]_{\mathrm{S}}$ laminate

Table 8: Overall results of compression tests on $\left[0_{\mathrm{G} 2} / \pm 45_{\mathrm{F} 6}\right]_{\mathrm{S}}$ Glass/Flax/Epoxy composite

\begin{tabular}{|c|c|c|c|}
\hline Sample \# & E (MPa) & EA (MN) & UCS (MPa) \\
\hline SP01 & 10.34 & 1.05 & -225.54 \\
\hline SP02 & 11.24 & 1.16 & -245.54 \\
\hline SP03 & 10.39 & 1.09 & -224.58 \\
\hline SP04 & 10.28 & 1.08 & -238.26 \\
\hline SP05 & 10.32 & 1.06 & -232.35 \\
\hline \hline Mean & $\mathbf{1 0 . 5 2}$ & $\mathbf{1 . 0 9}$ & $\mathbf{- 2 3 3 . 2 5}$ \\
\hline SD & $\mathbf{0 . 3 7}$ & $\mathbf{0 . 0 4}$ & $\mathbf{7 . 8 9}$ \\
\hline CV (\%) & $\mathbf{3 . 4 7}$ & $\mathbf{3 . 6 6}$ & $\mathbf{3 . 3 8}$ \\
\hline
\end{tabular}

As illustrated in Figure 52, all tested specimens experienced a brittle failure due to delimitation in the adjacent surface of the glass plies and flax plies accompanied with local compressive barreling of the outermost glass plies. This failure can be referred as primary failure in Figure 50 and Figure 51. The inner flax bundle showed minor delamination but buckled drastically under compressive load. This happened due to crack initiation and propagation in the matrix and fiber interface resulting in matrix degradation. Hence, under compression the matrix plays a major roll as load bearing constituent in the composite, failure of the matrix result in delamination of the flax plies and buckling of the inner flax bundle which can be seen as secondary failure in Figure 50 and Figure 51. 

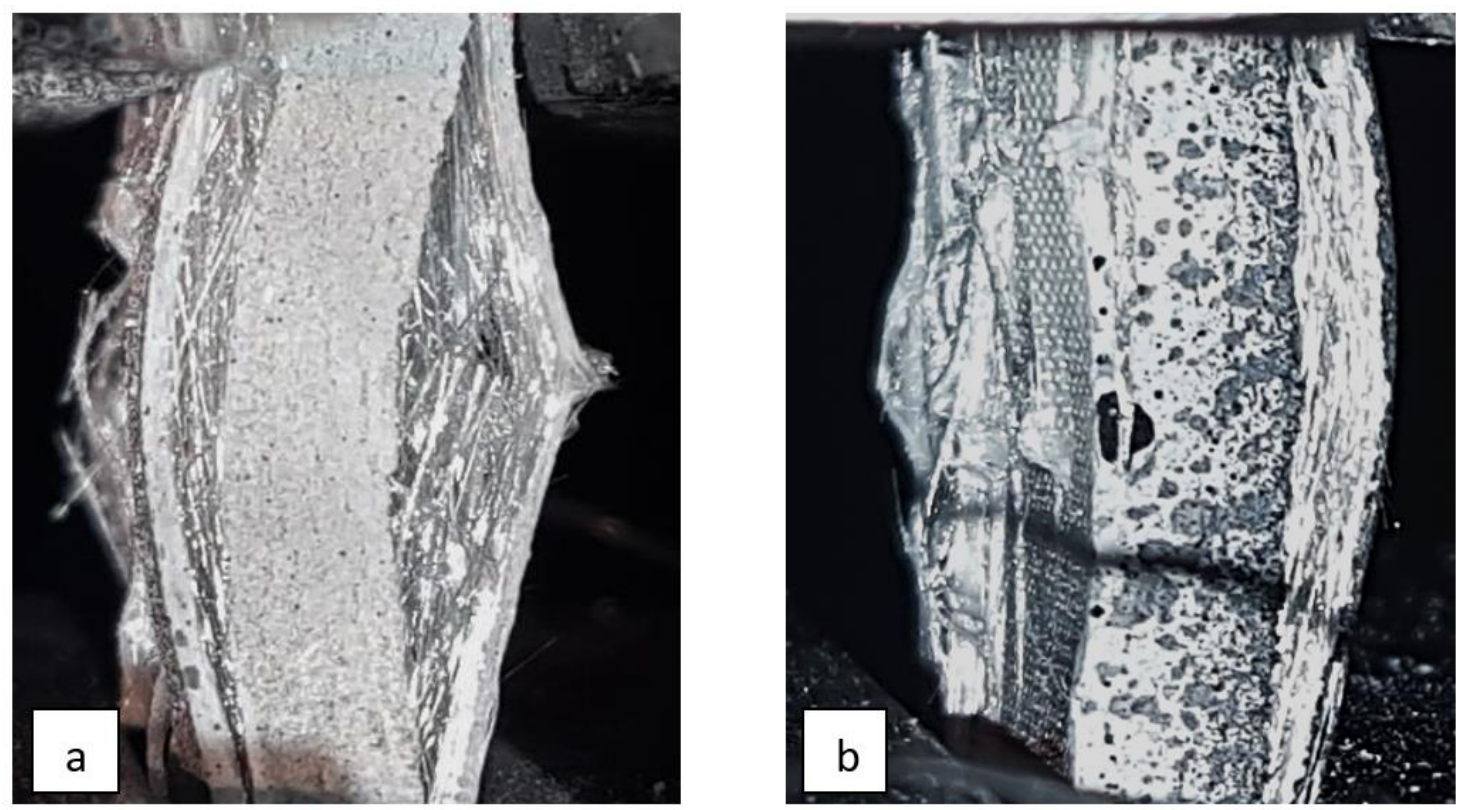

Figure 52: Typical failed specimens in compression: a) $\left[0_{\mathrm{G} 2} / 0_{\mathrm{F} 6}\right]_{\mathrm{S}}$, b) $\left[0_{\mathrm{G} 2} / \pm 45_{\mathrm{F} 6}\right]_{\mathrm{S}}$ laminates

\subsubsection{Bending test}

The behavior of the specimens in the bending test are shown by plotting force vs. displacement in Figure 53 and Figure 54, where SP01-05 refers to five specimens used in this experiment (i.e. SP01 is specimen \#1). All specimens showed linear behavior in the force-vs-displacement curve up until failure occurrence.

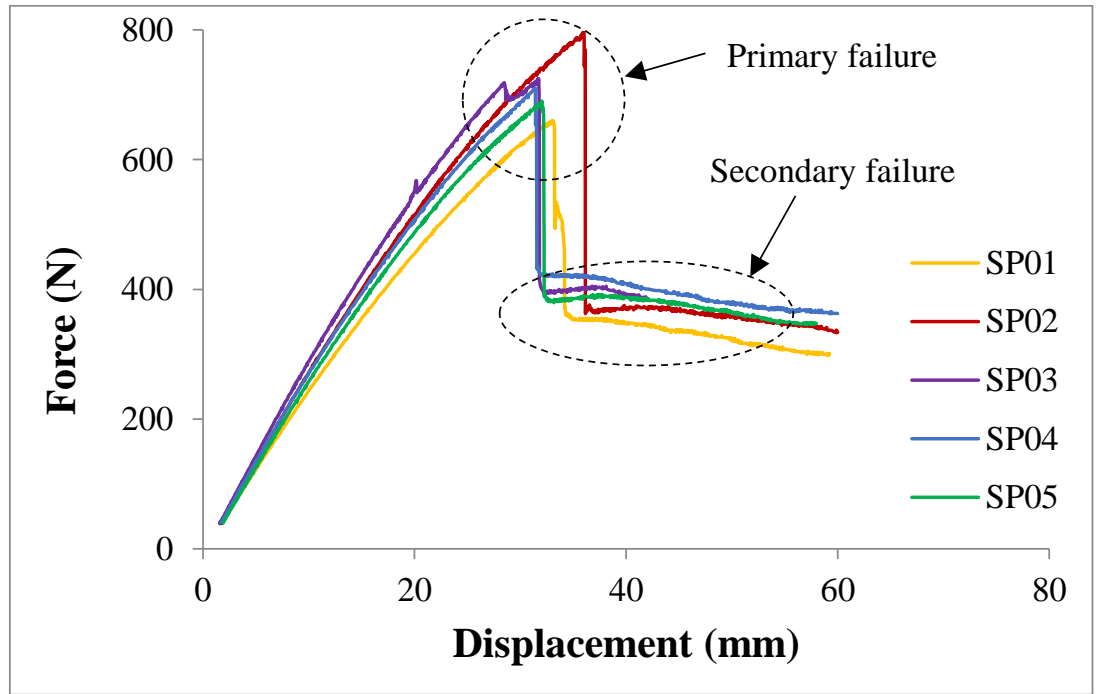

Figure 53: Bending test results for five test specimens (SP01-SP05) for $\left[0_{\mathrm{G} 2} / 0_{\mathrm{F} 6}\right]_{\mathrm{S}}$ laminate 
Table 9: Overall results of bending tests on unidirectional $\left[0_{\mathrm{G} 2} / 0_{\mathrm{F} 6}\right]_{\mathrm{S}}$ Glass/Flax/Epoxy composite specimens

\begin{tabular}{|c|c|c|c|}
\hline Sample \# & E (GPa) & UFS $(\mathbf{M P a})$ & EI $\left(\mathbf{N}^{-m^{2}}\right)$ \\
\hline SP01 & 40.53 & 589.76 & 4.10 \\
\hline SP02 & 39.22 & 635.94 & 4.72 \\
\hline SP03 & 41.45 & 584.58 & 4.99 \\
\hline SP04 & 38.30 & 564.43 & 4.68 \\
\hline SP05 & 39.69 & 581.55 & 4.51 \\
\hline Mean & $\mathbf{3 9 . 8 4}$ & $\mathbf{5 9 1 . 2 5}$ & $\mathbf{4 . 6 0}$ \\
\hline SD & $\mathbf{1 . 0 8}$ & $\mathbf{2 3 . 9 0}$ & $\mathbf{0 . 2 9}$ \\
\hline CV (\%) & $\mathbf{2 . 7 1}$ & $\mathbf{4 . 0}$ & $\mathbf{6 . 4}$ \\
\hline
\end{tabular}

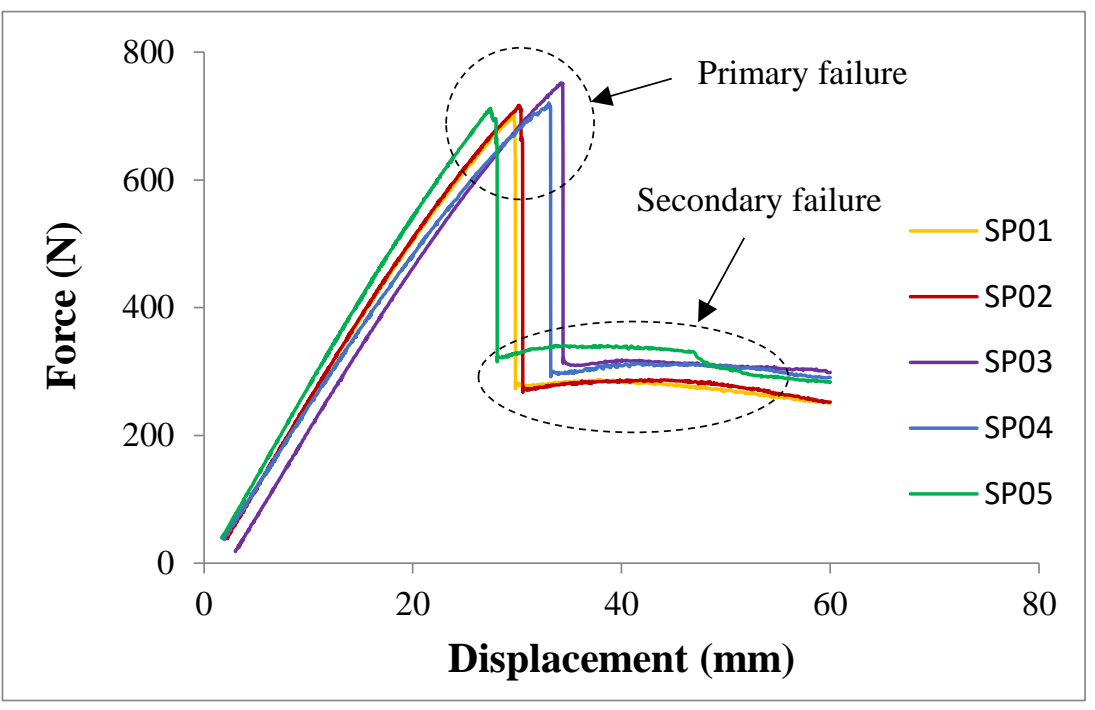

Figure 54: Bending test results for five test specimens (SP01-SP05) $\left[0_{\mathrm{G} 2} / \pm 45_{\mathrm{F} 6}\right]_{\mathrm{S}}$ laminate

Table 10: Overall results of bending tests on unidirectional $\left[0_{\mathrm{G} 2} / \pm 45_{\mathrm{F} 6}\right]_{\mathrm{S}}$ Glass/Flax/Epoxy composite specimens

\begin{tabular}{|c|c|c|c|}
\hline Sample \# & E $($ GPa $)$ & UFS (MPa) & EI $\left(\mathbf{N . m}^{2}\right)$ \\
\hline SP01 & 30.30 & 490.99 & 4.50 \\
\hline SP02 & 29.74 & 488.81 & 4.57 \\
\hline SP03 & 29.57 & 519.21 & 4.45 \\
\hline SP04 & 30.44 & 524.45 & 4.25 \\
\hline SP05 & 30.11 & 476.45 & 4.75 \\
\hline Mean & $\mathbf{3 0 . 0 3}$ & $\mathbf{4 9 9 . 9 8}$ & $\mathbf{4 . 5 0}$ \\
\hline SD & $\mathbf{0 . 3 3}$ & $\mathbf{1 8 . 5 9}$ & $\mathbf{0 . 1 6}$ \\
\hline CV (\%) & $\mathbf{1 . 0 9}$ & $\mathbf{3 . 7}$ & $\mathbf{3 . 6}$ \\
\hline
\end{tabular}


From analysing the data recorded during the test, the average for flexural modulus and ultimate flexural strength were $39.84 \pm 1.08 \mathrm{GPa}$ and $591.25 \pm 23.9 \mathrm{MPa}$ for $\left[0_{\mathrm{G} 2} / 0_{\mathrm{F} 6}\right]_{\mathrm{S}}$ samples and 30.03 $\pm 0.33 \mathrm{GPa}$ and $499.98 \pm 18.59 \mathrm{MPa}$ for $\left[0_{\mathrm{G} 2} / \pm 45_{\mathrm{F} 6}\right]_{\mathrm{S}}$ samples, respectively (Table 9 and Table 10). As can be seen in Figure 53 and Figure 54, a catastrophic failure accompanied by a sudden decrease in load after reaching a peak value occurred in all the specimens. The inner bundle of the flax fiber laminate stayed intact until the test reached in to its limit in displacement. A typical failed specimen in three-point bending is illustrated in Figure 55.

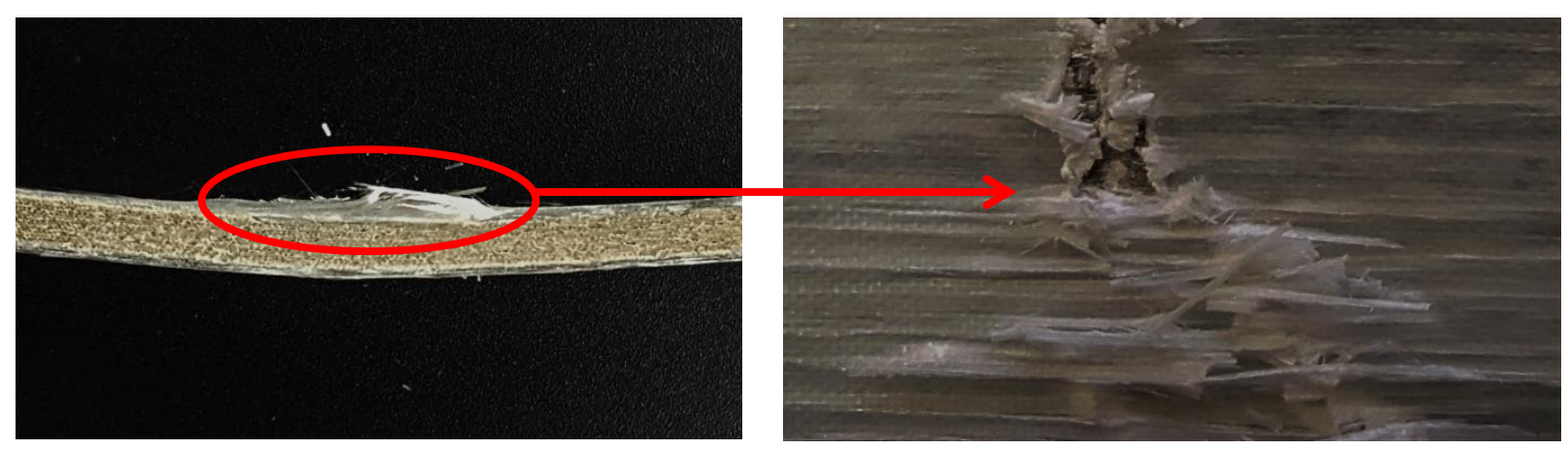

Figure 55: A typical failed specimen from bending test; a side view (left) shows the failure on the compression surface of the sample. Matrix cracking, fiber breakage and pull out on the failed surface (right)

In all specimens, failure occurred at the inner surfaces due to matrix cracking and fiber breakage along the compressed surfaces (primary failure) followed by progressive delamination of the glass plies and buckling of flax plies (secondary failure).

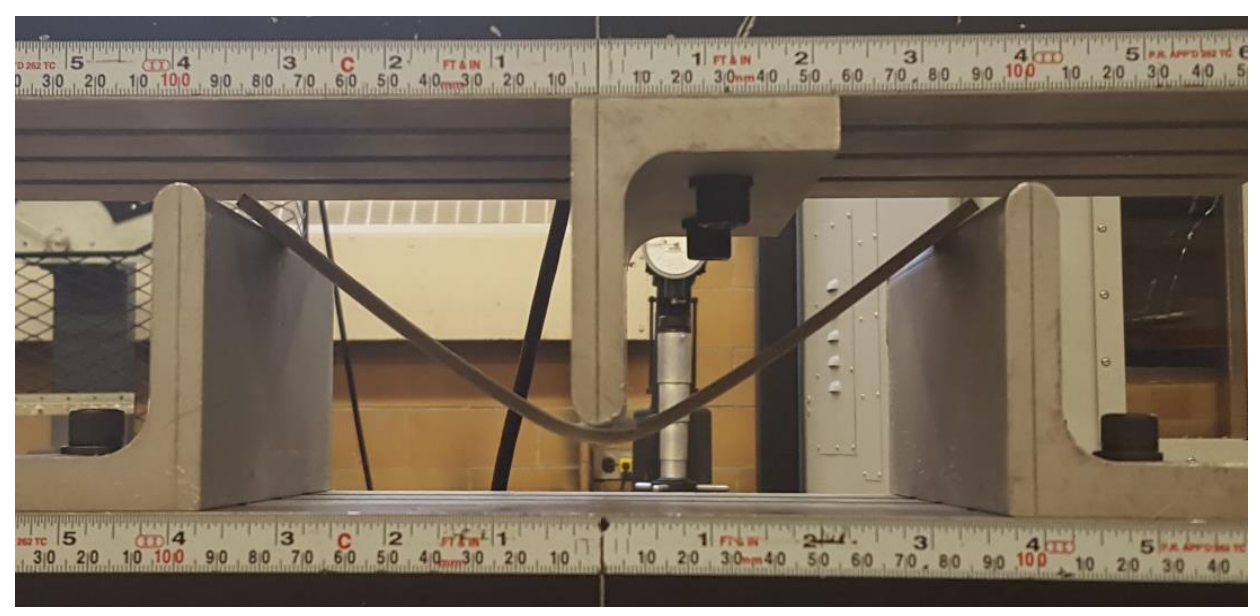

Figure 56: A specimen in three point bending test loaded until it reached $60 \mathrm{~mm}$ displacement 


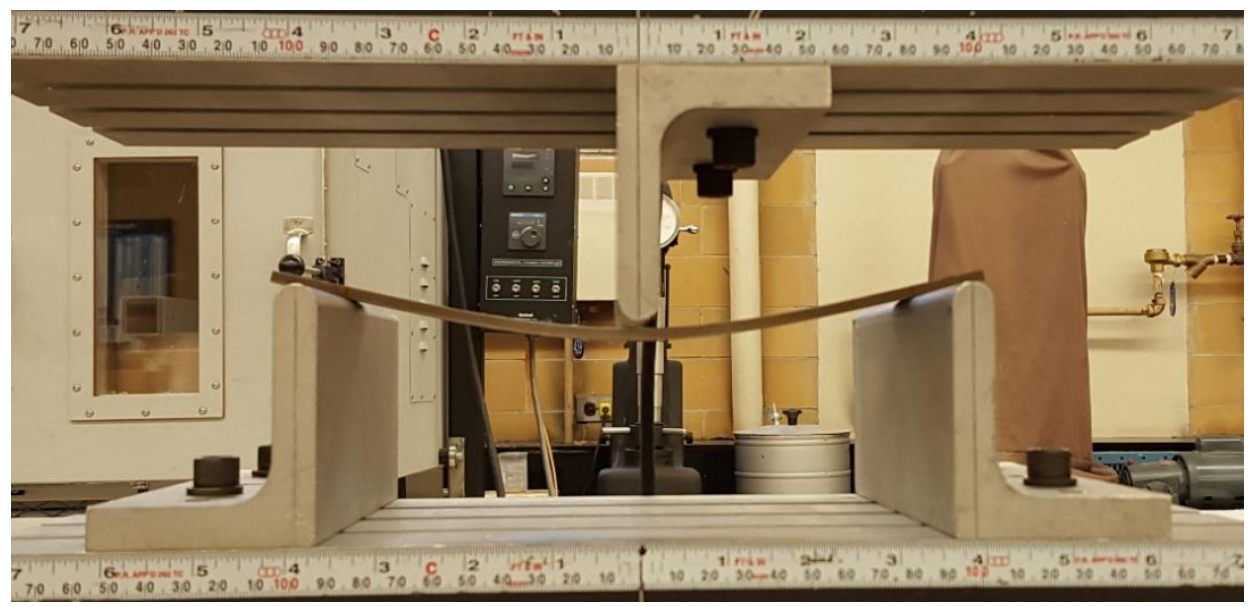

Figure 57: A specimen in three point bending test after being unloaded recover its shape from $60 \mathrm{~mm}$ displacement

Comparing the Figure 56 and Figure 57, it can be determined that the specimens did not failed $100 \%$ plastically and relatively were able to recover their shape by flattening after being unloaded.

\subsubsection{Rockwell hardness test}

The overall average for Rockwell hardness of the Glass/Flax/Epoxy composite were 82.17 \pm 1.18 $\mathrm{HRE}$ for $\left[0_{\mathrm{G} 2} / 0_{\mathrm{F} 6}\right]_{\mathrm{S}}$ unidirectional samples and $85.09 \pm 1.07 \mathrm{HRE}$ for $\left[0_{\mathrm{G} 2} / \pm 45_{\mathrm{F} 6}\right]_{\mathrm{S}}$ samples. All specimens showed circular-shaped indentations at their tested surfaces (molded surfaces), perpendicular to the testing direction (parallel to the molding pressure). A comparison of some materials used in biomedical applications particularly those used for femoral fracture fixation is shown in Table 11.

Table 11: Comparison of the surface hardness for some material

\begin{tabular}{|l|c|c|}
\hline \multicolumn{1}{|c|}{ Material } & Surface Hardness & Reference \\
\hline Current $\left[0_{\mathrm{G} 2} / \pm 45_{\mathrm{F} 6}\right]_{\mathrm{S}}$ & $85.09 \pm 1.07 \mathrm{HRE}$ & - \\
\hline Current $\left[0_{\mathrm{G} 2} / 0_{\mathrm{F} 6}\right]_{\mathrm{S}}$ & $82.17 \pm 1.18 \mathrm{HRE}$ & - \\
\hline $\mathrm{CF} / \mathrm{Flax} /$ Epoxy & $72.43 \pm 3.87 \mathrm{HRE}$ & {$[7]$} \\
\hline
\end{tabular}




\subsection{Discussion}

\subsubsection{General findings}

The current study is the first to investigate the mechanical properties of the Glass/Flax/Epoxy hybrid composite for structural application specifically orthopedic application such as bone plating for femoral bone fracture fixation. A strong bonding has been observed at the interface of Glass/Epoxy and Flax/Epoxy adjacent layers, as no de-bonding or delamination has occurred between these adjacent layers prior to failure. As shown in the static tests, the majority of the tested specimens have exhibited primary failure with abrupt change in the load level after reaching a peak value occurred due to matrix crack propagation followed by delamination at glass/epoxy and flax/epoxy adjacent interface followed by glass fiber rupture. The initiation of glass fiber tearing was followed secondary failure due to completion of the glass fibers breakage and flax fiber bundle tearing/buckling. In the case of tension test, the flax plies bundle has shown sudden rupture at the very end of the experiment. Fiber breakage along with fiber bundle and/or fiber pull-out at the fractured surface were observed in the SEM images of failed specimen from tension test (Figure 47). Most fibers exhibited smooth tensile failure surfaces caused by propagation of the crack in the composite (Figure 48). In the case of compression test, due to matrix degradation, the inner flax fiber bundles have shown interface delamination between flax plies and buckling as secondary. In the case of three-point bending test, the inner flax fiber bundles stayed intact until the test reached in to its limit in displacement and have shown minor interface delamination and buckling as secondary failure; these bundles had enough elasticity to recover their shape to relatively flat after being unloaded. In general considering the overall results from different experiments shown in Table 12 and Table 13, this new hybrid composite material have shown significant mechanical properties that make it very attractive for several structural applications, especially for bone fracture plates which are experiencing clinical-type axial loading and bending.

\subsubsection{Comparison to prior studies}

There are scattered results in the literature on the mechanical properties of composites reinforced by natural fibers and carbon fiber. The results of some prior studies on fiber composites, flax fiber composites, and hybrid composites reinforced by natural fibers and carbon fiber are summarized in comparison to the present study (Table 12 and Table 13). The results of the current study are within the range reported in the literature; however, they do not correlate perfectly due to different 
orientation of the fibers used, dissimilar fiber or matrix volume fraction, and various manufacturing methods. Our results compare favorably with those reported by Moritz et al. [121] using glass fiber composite with respect to flexural strength. However, the flexural modulus is 2 times higher in the current study. When compared to human cortical bone, the current hybrid composite material matches the elastic modulus of the cortical bone, yet 2 to 3 times stronger. Compared to pure Flax/Epoxy, the present hybrid composite is much stronger and stiffer. This confirms that the addition of layers of glass fibers in the outer surface will enhance the mechanical properties of the flexible Flax/epoxy core, which was one of the main objectives of this study. Moreover, the proposed Glass/Flax/Epoxy is less stiff but comparably strong when compared to Carbon/Flax/Epoxy composites (Bagheri et al., 2013) [122]. This quality makes this material a more attractive candidate for an optimized structure for bone fracture fixation systems.

Table 12: Elastic modulus of the current Glass/Flax/Epoxy composite along with some previously studied material, $E_{I T}$ is tensile Young's modulus, $E_{I C}$ is compressive Young's modulus and $E_{f}$ is flexural modulus

\begin{tabular}{|l|c|c|c|c|}
\hline \multicolumn{1}{|c|}{ Material } & $\mathrm{E}_{1 \mathrm{~T}}(\mathrm{GPa})$ & $\mathrm{E}_{1 \mathrm{C}}(\mathrm{GPa})$ & $\mathrm{E}_{\mathrm{f}}(\mathrm{GPa})$ & Reference \\
\hline Current $\left[0_{G 2} / 0_{F 6}\right]_{S}$ & $31.97 \pm 2.97$ & $18.26 \pm 1.02$ & $39.84 \pm 1.08$ & - \\
\hline Current $\left[0_{G 2} / \pm 45_{F 6}\right]_{S}$ & $16.51 \pm 0.68$ & $10.52 \pm 0.37$ & $30.03 \pm 0.33$ & - \\
\hline Flax/Epoxy & 20 & - & - & {$[123]$} \\
\hline Flax/Epoxy & $20-30$ & - & - & {$[124]$} \\
\hline Flax/Epoxy & 12.98 & - & - & {$[125]$} \\
\hline Carbon/Flax/Epoxy & $41.7 \pm 1.6$ & - & $57.4 \pm 1.8$ & {$[7]$} \\
\hline Human Cortical Bone & $7-25$ & & - & {$[90]$} \\
\hline UD CF/Epoxy & $50-300$ & - & - & {$[9]$} \\
\hline CF/Flax/Epoxy & $5.09-6.48$ & - & $14.41-23.84$ & {$[126]$} \\
\hline Sisal/CF/polyester & $1.99-2.78$ & - & $6.52-11.33$ & {$[38]$} \\
\hline $\begin{array}{l}\text { Glass/BisGMA/TEGDMA } \\
\text { Resin (UF-BG) }\end{array}$ & - & - & $17.0 \pm 3.3$ & {$[115]$} \\
\hline $\begin{array}{l}\text { Glass/BisGMA/TEGDMA } \\
\text { Resin (UFS-BG) }\end{array}$ & - & - & $15.3 \pm 1.8$ & {$[115]$} \\
\hline
\end{tabular}


Table 13: Ultimate strength of the current Glass/Flax/Epoxy composite along with some previously studied material, $\sigma^{\mathrm{IT}} \mathrm{U}$ is ultimate tensile strength, $\sigma^{\mathrm{IC}} \mathrm{U}$ is ultimate compressive strength and $\sigma^{\mathrm{F}} \mathrm{U}$ is ultimate flexural strength

\begin{tabular}{|l|c|c|c|c|}
\hline \multicolumn{1}{|c|}{ Material } & $\sigma^{1 \mathrm{~T}}(\mathrm{MPa})$ & $\sigma^{1 \mathrm{C}}{ }_{\mathrm{u}}(\mathrm{MPa})$ & $\sigma_{\mathrm{u}}^{\mathrm{F}}(\mathrm{MPa})$ & Reference \\
\hline Current $\left[0_{G 2} / 0_{F 6}\right]_{S}$ & $408.25 \pm 51.36$ & $261.21 \pm 21.93$ & $591.25 \pm 23.9$ & - \\
\hline Current $\left[0_{G 2} / \pm 45_{F 6}\right]_{S}$ & $301.87 \pm 62.77$ & $233.25 \pm 7.89$ & $499.98 \pm 18.59$ & - \\
\hline Flax/Epoxy & 200 & - & - & {$[123]$} \\
\hline Flax/Epoxy & 148.1 & - & - & {$[125]$} \\
\hline Carbon/Flax/Epoxy & $399.8 \pm 8.2$ & - & $510.6 \pm 66.3$ & {$[7]$} \\
\hline Human Cortical Bone & $50-150$ & - & - & {$[90]$} \\
\hline CF/Flax/Epoxy & $172.4-288.3$ & - & $85-160.42$ & {$[126]$} \\
\hline Sisal/CF/polyester & $84.44-107.51$ & - & $140.89-169.14$ & {$[38]$} \\
\hline $\begin{array}{l}\text { Glass/BisGMA/TEGDMA } \\
\text { Resin (UF-BG) }\end{array}$ & - & - & $802.0 \pm 112.7$ & {$[115]$} \\
\hline $\begin{array}{l}\text { Glass/BisGMA/TEGDMA } \\
\text { Resin (UFS-BG) }\end{array}$ & - & - & $602.0 \pm 81.6$ & {$[115]$} \\
\hline
\end{tabular}

As can be seen in above tables, the composite material used in this study shows higher mechanical properties compared to the previously studied Flax/Epoxy composites, which means improvement of the structure by adding the layers of the Glass fiber was successful. However, more improvement and optimization still is required in order to reach to a confident ground for clinical application of this new hybrid composite.

\subsubsection{Practical implications}

As indicated before, metallic implants promote negative "stress shielding" and reduce fracture healing due to high axial stiffness of the metallic materials used $[30,37,126]$. Therefore, an improved fracture healing can be obtained by designing of fracture fixation mechanism with lower axial stiffness to allow the underlying bone to carry a considerable amount of applied load, while having sufficient bending stiffness to prevent gross motion at the fracture site [26]. As shown in Table 12 and Table 13, the current Glass/Flax/Epoxy composite, with axial tensile modulus of elasticity $31.97 \mathrm{GPa}$ and axial compressive modulus of elasticity $18.26 \mathrm{GPa}$ for $\left[0_{\mathrm{G} 2} / 0_{\mathrm{F} 6}\right]_{\mathrm{S}}$ unidirectional specimens and axial tensile modulus of elasticity $16.5 \mathrm{GPa}$ and axial 
compressive modulus of elasticity $10.52 \mathrm{GPa}$ for $\left[0_{\mathrm{G} 2} / \pm 45_{\mathrm{F} 6}\right]_{\mathrm{S}}$ specimens, give the hope of achieving an optimal design much closer to that of cortical bone (7-25 GPa) [26, 90]. This material will allow more load sharing compared to titanium $(\mathrm{E}=110 \mathrm{GPa})[127]$ and stainless-steel $(\mathrm{E}=$ $220 \mathrm{GPa}$ [128] plates and will help to minimize the stress shielding effect.

The present ultimate tensile strength (408.25 MPa), ultimate compressive strength (261.21 MPa) and ultimate flexural strength $(510.6 \mathrm{MPa})$ for $\left[0_{\mathrm{G} 2} / 0_{\mathrm{F} 6}\right]_{\mathrm{S}}$ unidirectional laminates and ultimate tensile strength (301.87 MPa), ultimate compressive strength (233.25 MPa) and ultimate flexural strength (499.98 MPa) for $\left[0_{\mathrm{G} 2} / \pm 45_{\mathrm{F} 6}\right]_{\mathrm{S}}$ laminates are high enough to avoid poor stability on fracture site, immobilize adjacent bone fragments and carry clinical-type loads, for example, on the human femur (2.5 to 3 times body weight) [26].

Theoretically, if the effects of geometry were fully accounted for using the current ASTM standards, it is expected that the material used in this study should have yielded same values for flexural and tensile properties, however, these value are not the same in this study. It is known that flexural properties of composite materials depend on the stacking-sequences of each lamina and overall symmetry of the structure, while the tensile properties are more instinct of the material and independent of stacking-sequence [117, 119]. Thus, superior flexural properties compared to tensile and compressive properties of the current Glass/Flax/Epoxy composite were caused by the "sandwich structure effect", where the flexible core material of Flax/Epoxy were embedded between two stronger and stiffer Glass/Epoxy layers on each side of the structure. These outer layers mainly experienced tension and compression during bending tests, whereas the entire composite structure (inner and outer layers) uniformly experienced almost the same stress load during uniaxial tension/compression tests. Therefore, it can be concluded that a hybrid composite sandwich structure containing stronger and stiffer fiber in outer layers and more flexible fiber in the inner layers can result in an optimal stiffness and strength (Axial, Shear and Bending). Such sandwich structure is an ideal candidate for designing of long bone fracture fixation mechanism such as plates, as they can provide selective stress shielding and demonstrate lower axial stiffness and adequate shearing and bending stiffnesses concurrently. 


\subsection{Summary}

This chapter confirms that the developed composite material used in this study shows higher mechanical properties compared to the previously studied Flax/Epoxy composites, which means improvement of the structure by adding the layers of the Glass fiber was successful. In addition, the proposed composite structure has higher stiffness in bending compared to tension. This phenomenon can be explained due to "sandwich structure effect". In fact, using the stronger Glass/Epoxy laminae as outer layers and more flexible Flax/Epoxy laminae as the inner core of the structure resulted in advanced bending properties. Moreover, this material has shown high enough ultimate strength in tension, compression and bending to carry clinical-type forces as occur on femur bone during daily normal activities. Therefore, the proposed composite in this study is an ideal candidate for specific applications where selective stress shielding is required such as long bone fracture plates. 


\section{Fatigue behavior of Glass/Flax/Epoxy composite}

The purpose of this chapter was to investigate the fatigue damage and fatigue behaviour of the developed Glass/Flax/Epoxy composite with both infrared (IR) thermography analysis and conventional experimental fatigue analysis under compression-compression cyclic loading condition. Two configurations of Glass/Flax/Epoxy composites layup were studied namely, $\left[0_{\mathrm{G} 2} / 0_{\mathrm{F} 6}\right]_{\mathrm{S}}$ unidirectional ply orientation and $\left[0_{\mathrm{G} 2} / \pm 45_{\mathrm{F} 6}\right]_{\mathrm{S}}$. First, using Digital Image Correlation

(DIC) analysis the static compressive modulus of elasticities and ultimate compressive strength for both sacking configurations were obtained. These results were in accordance to the results of compression test obtained in previous chapter. Also, the average poison ratios were measured to be 0.37 for $\left[0_{\mathrm{G} 2} / 0_{\mathrm{F} 6}\right]_{\mathrm{S}}$ unidirectional sample and 0.58 for $\left[0_{\mathrm{G} 2} / \pm 45_{\mathrm{F} 6}\right]_{\mathrm{S}}$ samples. The high cycle fatigue strength was determined using a thermographic criterion developed in a previous study $[129,130]$. The fatigue strength obtained by the thermographic criterion measured to be around $55 \%$ of UCS and was confirmed by the results obtained through conventional experimental fatigue methods (i.e., Stress level versus Number of cycles to failure).

\subsection{Introduction}

Fatigue failure occurs due to the application of fluctuating stresses that are much lower than the stress required to cause failure during a single application of stress (Static ultimate stress). It has been estimated that fatigue contributes to approximately $90 \%$ of all mechanical service failures [131]. Most engineering materials exhibit a safe zone for the stress below which failure never occurs, even for an indefinitely large number of loading cycles. This safe stress is called the endurance limit or the fatigue limit. For metallic materials, this stress level can be clearly defined [132]. However, fiber-reinforced polymer matrix composites do not typically have a fatigue limit. It is known that the complex damage patterns observed in composite materials consist of matrix cracks, fiber fractures, fiber-matrix interface de-bonding, inter-ply delamination cracks as well as the various interactions between these damage patterns. This has caused a number of researchers to focus on relating the observed damage or a damage parameter to the mechanical properties of the laminates [133]. This damage accumulation process takes place during the entire life of the material and eventually leads to failure even at low applied stresses (Figure 58) [1, 134], therefore the concept of high cycle fatigue strength (HCFS) in composites is used instead of fatigue limit. 


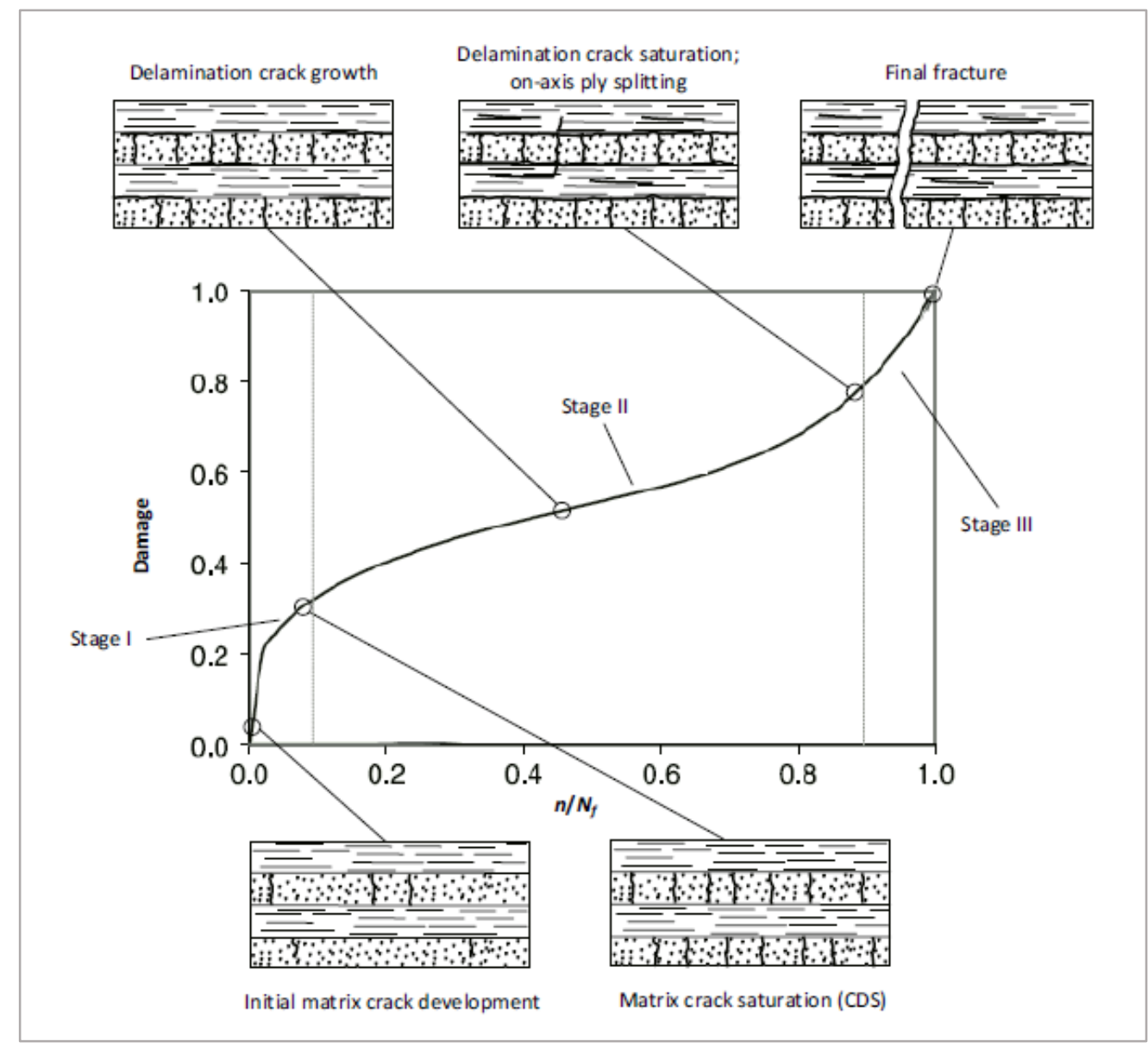

Figure 58: Schematic of fatigue damage developing for a cross-ply laminate [135]

Conventional methods for evaluating the fatigue limit or HCFS are very expensive as the case may require the use of a large number of samples. As a consequence of recent progress in the development of high-resolution infrared detectors for infrared (IR) thermographic cameras, the application of theoretical concepts of thermo-elasticity has been made possible [136, 137]. Thermoelastic stress measurements are based on small temperature variations of the order of $0.001^{\circ} \mathrm{C}$ that occur when a material is subject to a change in elastic strain. The IR thermography technique has been proven to be a reliable non-destructive and nonintrusive technique for the rapid evaluation of fatigue damage and fatigue limit of metallic materials [137, 145, 146].

In studies related to composite materials, the IR thermography technique has been extensively used as a tool for qualitative monitoring of damage evolution. For instance, researchers have used this technique to investigate the notch sensitivity of various glass fiber reinforced polymers(GFRP) laminates [138]. Also, this technique was used to determine the glue infiltration, water ingress, 
and disbands on a blade of a wind turbine made of composite materials [139]. On the other hand, limited number of studies have used this method for rapid evaluation of fatigue limit of fiberreinforced composite materials. Montesano et al. [129] have successfully applied the IR techniques for the identification of the fatigue limit of a braided carbon fiber polyimide composite. El Sawi et al. investigate the damage mechanism and fatigue life of flax fiber reinforced composites. Kamara et al. studied the damage evolution and determined the fatigue limit of a woven carbon fiber-reinforced polymer material using IR thermography technique [140].

In addition, compared to the abundance of studies on fatigue behaviour of synthetic fiberreinforced polymers, the limited number of studies on the fatigue behaviour of natural fiber or hybrid of natural and synthetic fiber reinforced polymers result in a lack of information and understanding about these materials $[141,142,143]$. Furthermore, limited amount of research was done on flax fibers; only a single piece of work was found to deal with the fatigue behaviour and endurance of this type of plant fiber $[19,137,153]$ and no research has investigated the application of IR thermography for the determination of the fatigue limit of Glass/Flax reinforced polymer composites. Therefore, the aim of this study is to investigate the fatigue performance of Glass/Flax fiber-reinforced composites using IR thermography techniques for characterization of damage and fatigue life prediction of this material during mechanical testing under cyclic loading condition.

\subsection{Materials and methods}

\subsubsection{General approach}

The application of thermography analysis has been proven as a reliable non-destructive technique for quick determination of the fatigue strength for metals [144, 145, 146]. However, only a few studies considered this technique for composite materials, and not one has utilized this method to determine the fatigue life of composite materials for medical application [19, 136, 157]. It should be noted that composite materials, unlike most metallic materials, do not have a clear fatigue limit or endurance limit. Thus, the concept of high cycle fatigue strength (HCFS) in composite materials conveys the same meaning as the fatigue limit in metallic materials, but while also considering the damage accumulation process during the entire fatigue life of the composite material.

In this study, fatigue tests were performed on Glass/Flax/epoxy composite plates to determine the fatigue strength using both the conventional S-N (Stress-Number of Cycles) approach and thermography analysis. The purpose was to evaluate the fatigue strength of the composite plate 
under cyclic loading conditions which simulates the clinical loading conditions. It was hypothesized that the composite plate would have a high cycle fatigue strength (HCFS) much higher than the main loads experienced by a femur bone fracture plate during normal daily activities, such as running and walking.

\subsubsection{Composite materials structure}

Manufacturing of the Glass/Flax/Epoxy composite plates was done using 12 layers of Flax fiber and 4 layers of UD Glass fiber (two layer in each side) (Lineo Flax ply) in $\left[0_{\mathrm{G} 2} / 0_{\mathrm{F} 6}\right]_{\mathrm{S}}$ and $\left[0_{\mathrm{G} 2} / \pm 45_{\mathrm{F} 6}\right]_{\mathrm{S}}$ configuration where mixture of Araldite® LY 564 low viscosity epoxy and Aradur® 22962 hardener polyamine was used as binding matrix in the composite as shown in Figure 59.

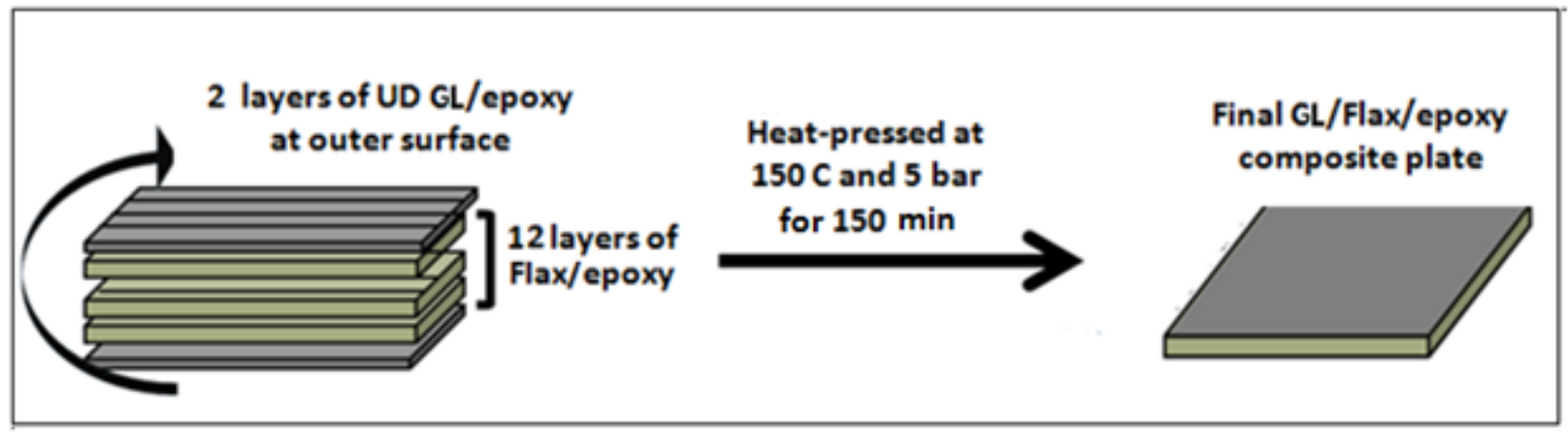

Figure 59: The novel "sandwich structure" of Glass/Flax/Epoxy plate.

Several trials were conducted, changing manufacturing parameters such as time, pressure and temperature, in order to achieve a volume fraction of approximately $50 \%$ of fiber in final product with an acceptable void content of $\leq 3 \%$. A compression molding machine was used (Carver Press, Wabash, IN, USA) to cure the sandwich material in a three stage curing cycle. Initially, the plates were heated up from room temperature to $150{ }^{\circ} \mathrm{C}$ at half load pressure of 2.5 bar (heating stage). Then at this temperature $\left(150{ }^{\circ} \mathrm{C}\right)$, the pressure was increased to 5 bar and plates were kept in this condition for 2.5 hours to cure fully (curing stage). Finally, the plates were cooled down from $150^{\circ} \mathrm{C}$ to room temperature at 5 bar pressure (cooling stage). The final manufactured plate in each batch was $300 \times 300 \mathrm{~mm}$ in size, and average thickness of $4 \mathrm{~mm}$. These plates were cut using a table saw to fabricate specimens with a length of $250 \mathrm{~mm}$ and a width of $25 \mathrm{~mm}$, in compliance with ASTM standards for testing. The combination of two types of natural and synthetic fibers (i.e. Flax and Glass) for the fabrication of the current composite, as well as its "sandwich 
structure", make this composite unique compared to what has been done previously for orthopaedic bone plate applications.

\subsection{Experimental procedures}

\subsubsection{Static compression tests using digital image correlation (DIC)}

Compression tests were performed on specimens in accordance with ASTM standard (ASTM D695-10, 2010a) for compressive properties of rigid plastics [118]. The experiments were conducted on a compression machine (MTS 322 Test Frame, MTS Systems Corporation. Eden Prairie, MN, USA), with a testing speed of $2 \mathrm{~mm} / \mathrm{min}$ and a maximum $100 \mathrm{kN}$ load cell. Five specimens from each stacking sequences were cut measuring $100 \mathrm{~mm}$ x $25 \mathrm{~mm}$. As shown in Figure 60, a speckled pattern was imprinted on each specimen using three different color spray paint (white, black and gray) to facilitate accurate displacement measurement using DIC camera.

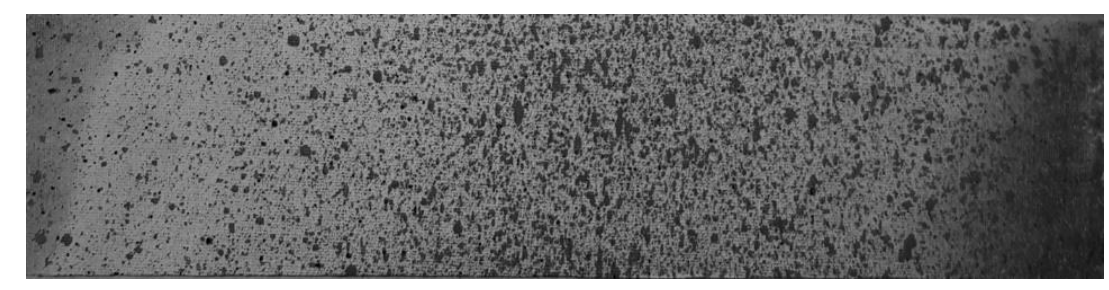

\section{Figure 60: A 100mm x 25mm speckled specimen for compression test}

The specimens were positioned in the hydraulic grips with the long axis in-line with the force direction so that $37.5 \mathrm{~mm}$ at each end was gripped with 100 bar gripping pressure (Figure 61). The static tests were performed in accordance with ASTM standard, at a displacement rate of $2 \mathrm{~mm} / \mathrm{min}$ on the specimens, to failure, under compressive loading conditions. The ultimate strength and ultimate strain were measured just before the failure (i.e. prior to occurrence of the buckling). Both longitudinal and transverse elongation of material were evaluated using the data from DIC camera. Finally, the Poisson's ratio for both ply configurations were determined using the following equation,

$$
v=-\frac{\varepsilon_{\text {Trans. }}}{\varepsilon_{\text {Long. }}}
$$



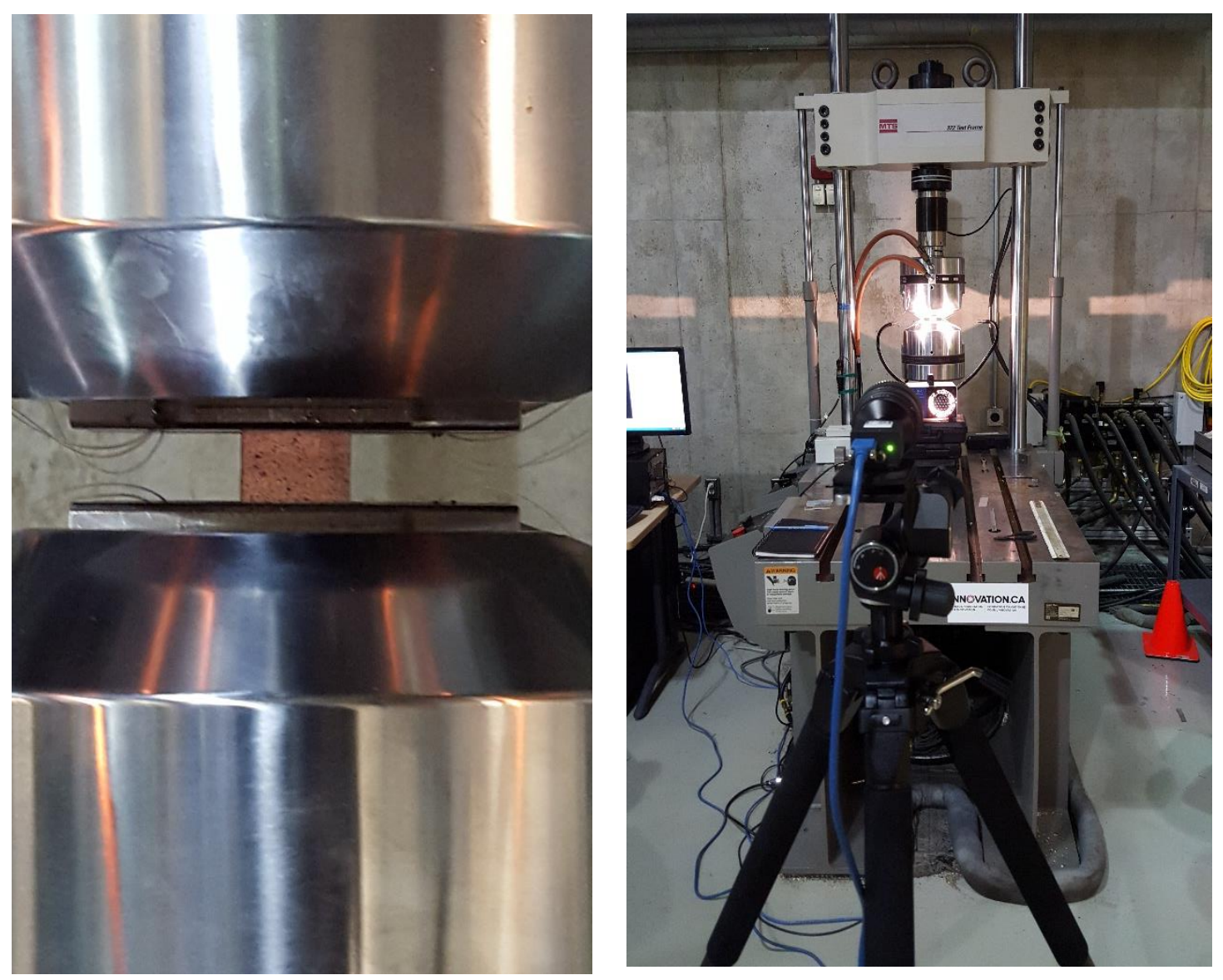

Figure 61: Compression test set up; left) a speckled specimen gripped between hydrolic heads, right) compression test set up with DIC camera capturing images

\subsubsection{Conventional compression-compression fatigue tests}

The compression-compression fatigue tests were conducted on a servo-hydraulic testing system (Model 322.21, MTS System Corporation, Eden Prairie, MN USA), with $100 \mathrm{kN}$ load cell capacity. The specimens were mounted in the hydraulic grips (Model 2743-402, Illinois Tool Works Inc (ITW), Norwood, MA, USA) with the long axis in-line along the force direction such that $37.5 \mathrm{~mm}$ at each end was gripped with a 100 bar gripping pressure. Cyclic loading levels ranging from $60 \%$ to $90 \%$ of UCS with $5 \%$ incremental increase were applied up until failure or at one million cycles. Minimum of three specimens with dimensions $100 \mathrm{~mm}$ by $25 \mathrm{~mm}$ were tested as shown in Figure 62 . The testing span was considered to be $25 \mathrm{~mm}$ in order to minimize buckling and avoid out of plane deflection under compressive load. All fatigue tests were conducted in accordance with the ASTM standard ASTM D695-10 [118] at room temperature $\left(25^{\circ} \mathrm{C}\right)$ and under load control with a minimum to maximum stress ratio of $R=0.1\left(R=S_{\min } / S_{\max }\right)$ and with a 
constant sinusoidal wave form at a frequency of $5 \mathrm{~Hz}$. The results were used to develop the S-N curve corresponding to each stacking sequence.
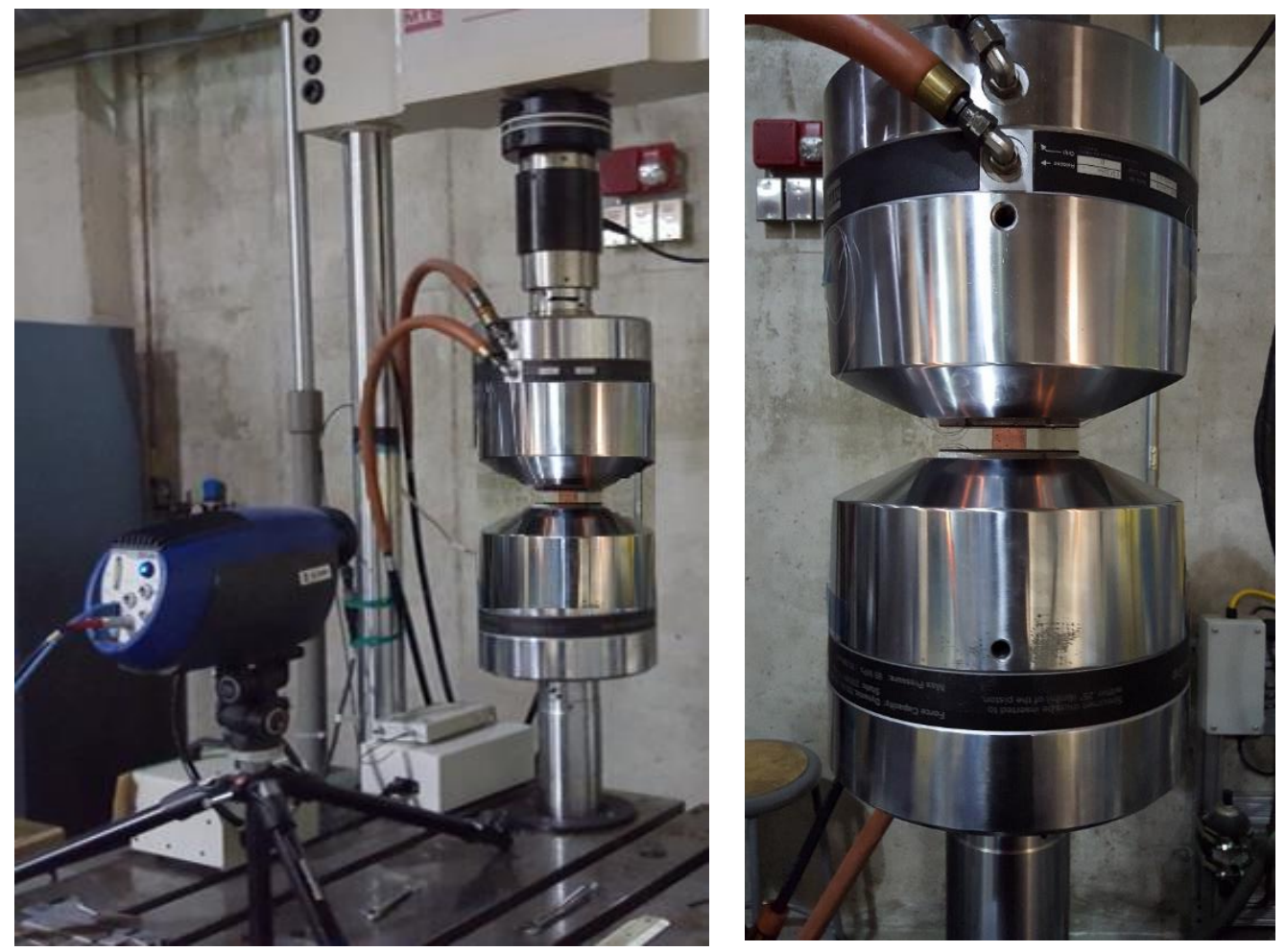

Figure 62: Compression-compression fatigue test set up; IR camera used in this study is shown in left figure.

\subsubsection{Thermography analysis}

The thermographic approach is a non-destructive technique based on thermoelasticity, in which thermal stresses are induced by small variations of temperature. When a material is in its elastic region, this technique can be used to more rapidly determine the fatigue strength. This nondestructive method represents a substitute for conventional fatigue tests, which are time consuming and require a large number of specimens [129, 130, 147].

Three samples from each stacking configuration were tested starting from $20 \%$ of UCS (Ultimate Compression Strength) as the minimum applied stress amplitude. The plates were subjected to cyclic loading for 5000 cycles in order to reach the steady state temperature $[129,130]$. The applied stress amplitude was incremented stepwise with 5\% of UCS load interval, up until failure. The overall rise in the specimen's surface temperature was recorded for each cyclic load level using an 
infrared thermography camera (Silver 420, FLIR Systems Canada, Burlington, ON, Canada) with a spatial resolution of $320 \times 240$ pixels and a temperature resolution of $20 \mathrm{~m}^{\circ} \mathrm{C}$. The camera was synchronized to the controller of the test machine in order to capture 5 frames per second, to eliminate the effect of temperature fluctuations due to any possible reversible thermoelastic heating $[129,130]$. The temperature versus applied cyclic load curves were constructed in order to determine HCFS for each ply configuration and the results were compared with conventional fatigue tests.

Fargione et al. [146] used IR thermography to determine the fatigue S-N curve of metallic materials. The author's hypothesis permits to establish a direct correlation between the temperature increase during a certain stress level and the number of cycles to failure at the same level of stress as shown in equation 5 .

$$
\emptyset=\Delta \mathrm{T}_{\mathrm{i}} * \mathrm{~N}_{\mathrm{f}}
$$

Where $\mathrm{N}_{\mathrm{f}}$ is the total number of cycle until failure at stress level $\sigma_{\mathrm{i}}$, and $\Delta T_{i}$ is the corresponding temperature difference between the room temperature and the stabilized temperature at that stress level. The parameter $\emptyset$ is a constant that is directly proportional to heat dissipation of the material and was defined to be the integral of the function $\Delta T_{i}=f(N)$ extended over the entire number of cycles $\mathrm{N}_{\mathrm{f}}$.

It is hypothesized that IR thermography can provide relatively enough information to develop the S-N curve of composite laminates. Montesano et al. [129] found that the integration function $\emptyset$ is only a constant when multiplying the thermal change $\left(\Delta T_{i}\right)$ by the logarithm of the number of cycles $\left(\mathrm{N}_{\mathrm{f}}\right)$. Consequently, the aforementioned equation (Eq.5) was modified to fit their thermal and fatigue experimental data on carbon fiber-reinforced polyimide composite.

$$
\varnothing=\Delta \mathrm{T}_{\mathrm{i}} * \log \mathrm{N}_{\mathrm{f}} \quad \text { (Eq.6) }
$$

The thermal variations data $\left(\Delta T_{i}\right)$ from thermographic tests and fatigue data $\left(\mathrm{N}_{\mathrm{f}}\right)$ from conventional fatigue tests for each corresponding stress level are used to calculate the integration parameter $\emptyset$ using equation 6. 


\subsection{Results}

\subsubsection{Quasi static compression test using DIC technique}

The compressive behaviour of the composite specimens is shown in Figure 63 and Figure 65 catastrophic failure accompanied by an abrupt decrease in load after reaching a peak value was observed in most of the specimens. As shown in Table 14, the average Young's modulus for $\left[0_{\mathrm{G} 2} / 0_{\mathrm{F} 6}\right]_{\mathrm{S}}$ laminates were calculated to be $24.37 \pm 1.18 \mathrm{GPa}$ and ultimate compression was determined to be $261.73 \pm 23.81 \mathrm{MPa}$. Respectively, Table 15 presents the average Young's modulus to be $14.73 \pm 0.75 \mathrm{GPa}$ and ultimate compression strength to be $231 \pm 7.56$ MP for $\left[0_{\mathrm{G} 2} / \pm 45_{\mathrm{F} 6}\right]_{\mathrm{S}}$ laminates.

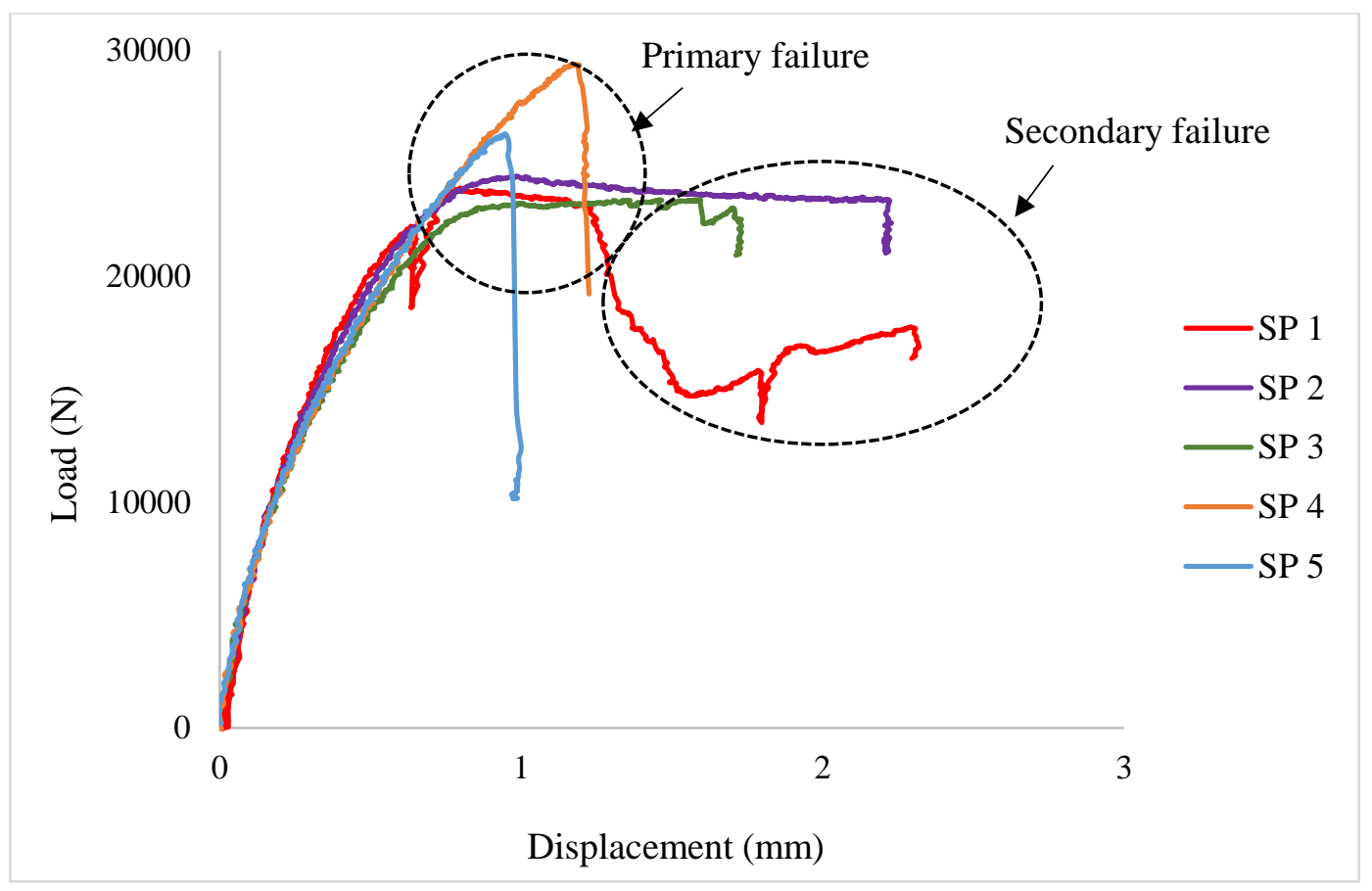

Figure 63: Force vs. displacement of five tested specimens (SP 1 to $S P$ ) of $\left[0_{\mathrm{G} 2} / 0_{\mathrm{F} 6}\right]_{\mathrm{S}}$ unidirectional laminates 


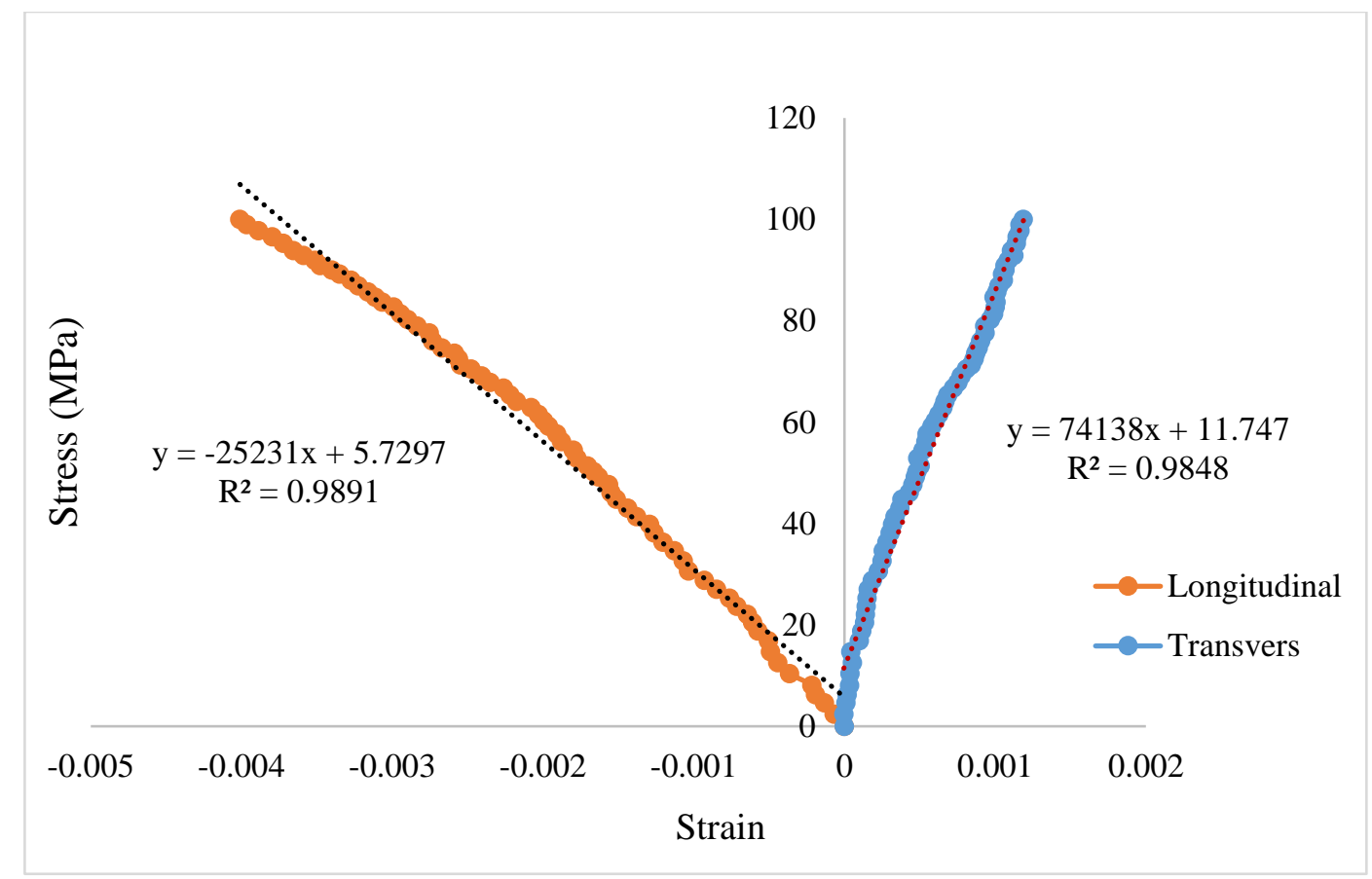

Figure 64: Typical stress vs. strain curve of $\left[0_{\mathrm{G} 2} / 0_{\mathrm{F} 6}\right]_{\mathrm{S}}$ unidirectional laminates

Table 14: Overall results of Compression tests on five specimens $\left[0_{\mathrm{G} 2} / \mathbf{0}_{\mathrm{F} 6}\right]_{\mathrm{S}}$ laminates

\begin{tabular}{|c|c|c|c|}
\hline Sample \# & ELong. $_{\text {(GPa) }}$ & $\mathbf{v}$ & UCS (MPa) \\
\hline SP 1 & 25.305 & 0.37 & 242.13 \\
\hline SP 2 & 23.23 & 0.37 & 238.21 \\
\hline SP 3 & 25.23 & 0.34 & 250.22 \\
\hline SP 4 & 25.42 & 0.40 & 300.73 \\
\hline SP 5 & 22.66 & 0.36 & 277.36 \\
\hline Mean & $\mathbf{2 4 . 3 7}$ & $\mathbf{0 . 3 7}$ & $\mathbf{2 6 1 . 7 3}$ \\
\hline SD & $\mathbf{1 . 1 8}$ & $\mathbf{0 . 0 2}$ & $\mathbf{2 3 . 8 1}$ \\
\hline CV (\%) & $\mathbf{4 . 8 4}$ & $\mathbf{5 . 1 2}$ & $\mathbf{9 . 1 0}$ \\
\hline
\end{tabular}




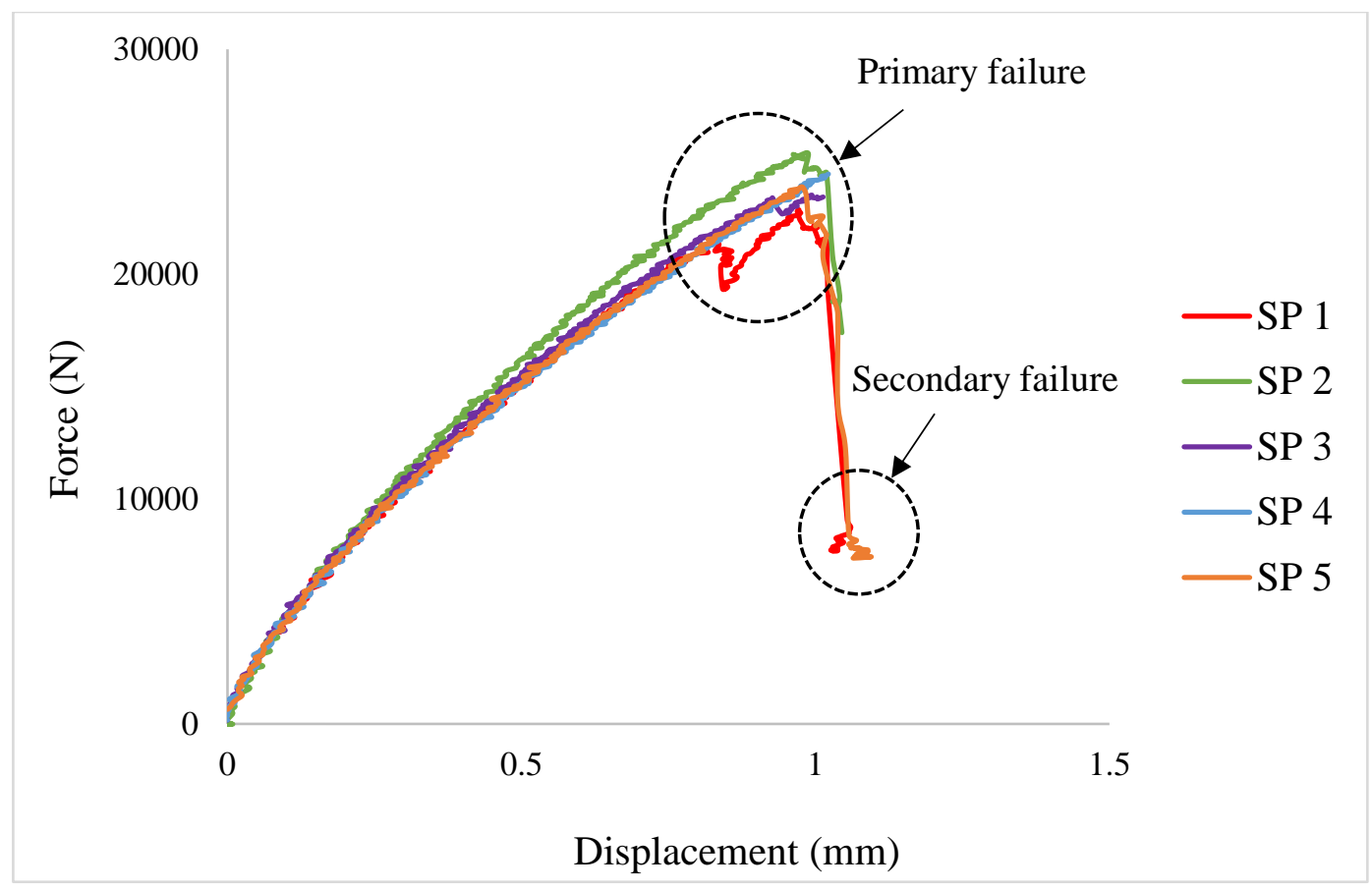

Figure 65: Force vs. displacement of five tested specimens (SP 1 to SP 5) of $\left[0_{G 2} / \pm 45_{F 6}\right]_{S}$ laminates

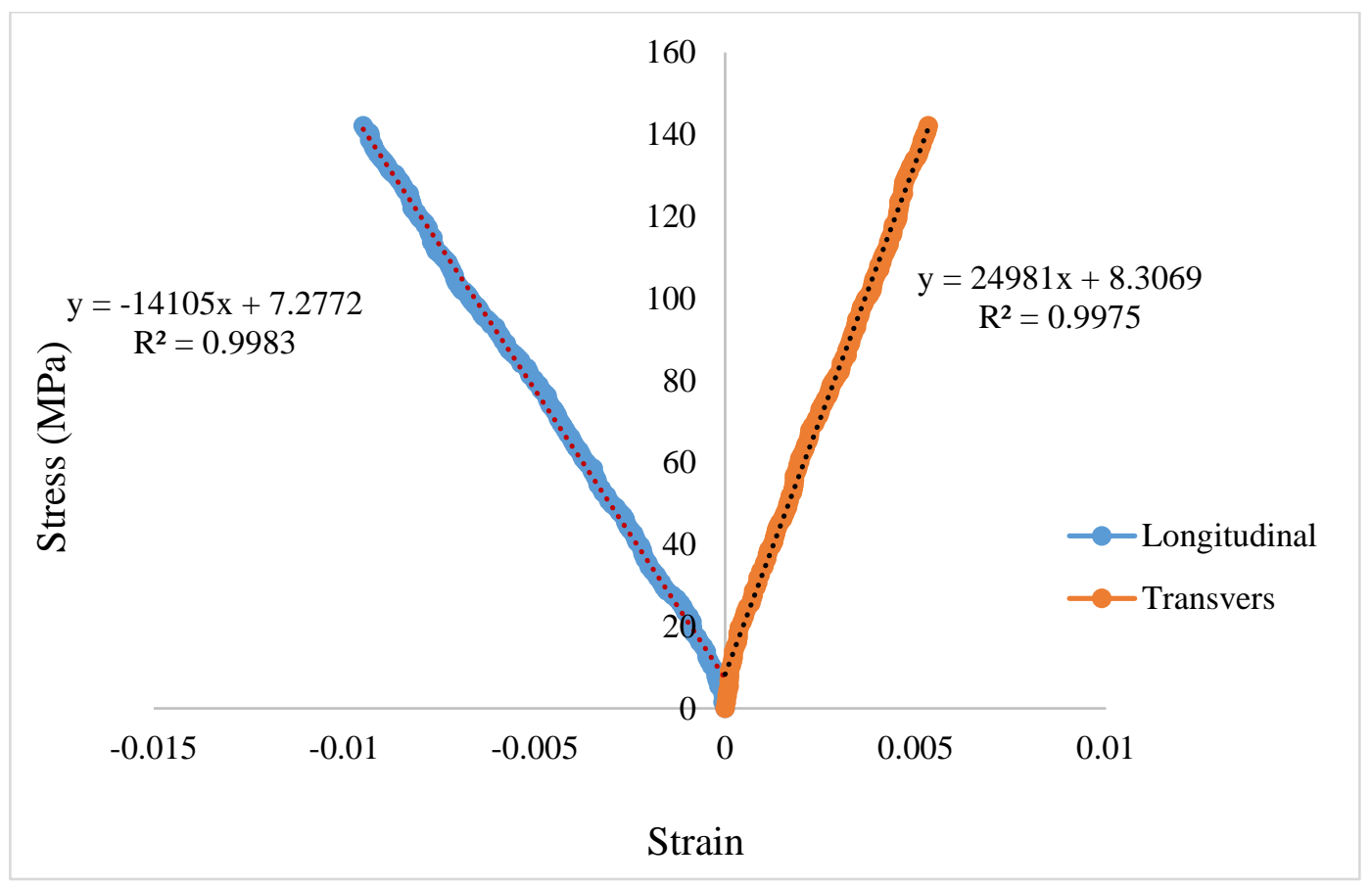

Figure 66: Typical stress vs. strain for curve $\left[0_{\mathrm{G} 2} / \pm 45_{\mathrm{F} 6}\right]_{\mathrm{S}}$ laminates 
Table 15: Overall results of compression test on five specimens of $\left[0_{\mathrm{G} 2} / \pm 45_{\mathrm{F} 6}\right]_{\mathrm{S}}$ laminates

\begin{tabular}{|c|c|c|c|}
\hline Sample \# & ELong. $_{\text {(GPa) }}$ & $\boldsymbol{v}$ & UCS (MPa) \\
\hline SP 1 & 15.046 & 0.57 & 224.76 \\
\hline SP 2 & 16.02 & 0.65 & 244.92 \\
\hline SP 3 & 14.11 & 0.56 & 224.02 \\
\hline SP 4 & 14.48 & 0.59 & 233.62 \\
\hline SP 5 & 13.98 & 0.54 & 232.04 \\
\hline Mean & $\mathbf{1 4 . 7 3}$ & $\mathbf{0 . 5 8}$ & $\mathbf{2 3 1 . 8 7}$ \\
\hline SD & $\mathbf{0 . 7 5}$ & $\mathbf{0 . 0 4}$ & $\mathbf{7 . 5 6}$ \\
\hline CV (\%) & $\mathbf{5 . 0 6}$ & $\mathbf{6 . 4 0}$ & $\mathbf{3 . 2 6}$ \\
\hline
\end{tabular}

Brittle failure due to delamination in the adjacent surface of the glass plies and flax plies accompanied with local compressive barreling of the outermost glass plies were observed in all the specimens. This failure can be referred to as primary failures shown in Figure 63 and Figure 65. The inner flax bundle showed minor delamination but buckled drastically under compressive load. This happened due to crack initiation and propagation in the matrix and fiber interfaces resulting in matrix degradation. It is well known that under compression, the matrix plays a major roll as a load bearing constituent in composite materials. Failure of the matrix resulted in delamination of the flax plies and buckling of the inner flax bundle which can be seen as a secondary failure Figure 63 and Figure 65. Analysing the DIC images reveals that the maximum strain accumulation occurs perpendicular to the $\left[0_{\mathrm{G} 2} / 0_{\mathrm{F} 6}\right]_{\mathrm{S}}$ laminate (Figure 67) ), whereas, it shows a \pm 45 angle in the $\left[0_{\mathrm{G} 2} / \pm 45_{\mathrm{F} 6}\right]_{\mathrm{S}}$ laminate (Figure 68 ). Therefore, it can be concluded that the formation and propagation of micro-damages initiated orthogonally in the matrix, result in a strain profile perpendicular to the fiber direction. The stronger unidirectional glass plies, act like a transparent layer which illuminates the strain profile of the weaker inner flax bundle. In the case of the $\left[0_{\mathrm{G} 2} / \pm 45_{\mathrm{F} 6}\right]_{\mathrm{S}}$ laminate, since the +45 degree plies are perpendicular to -45 degree plies, the maximum strain is accumulated along the structurally weaker plies and failures occur in the \pm 45 degree angle. 


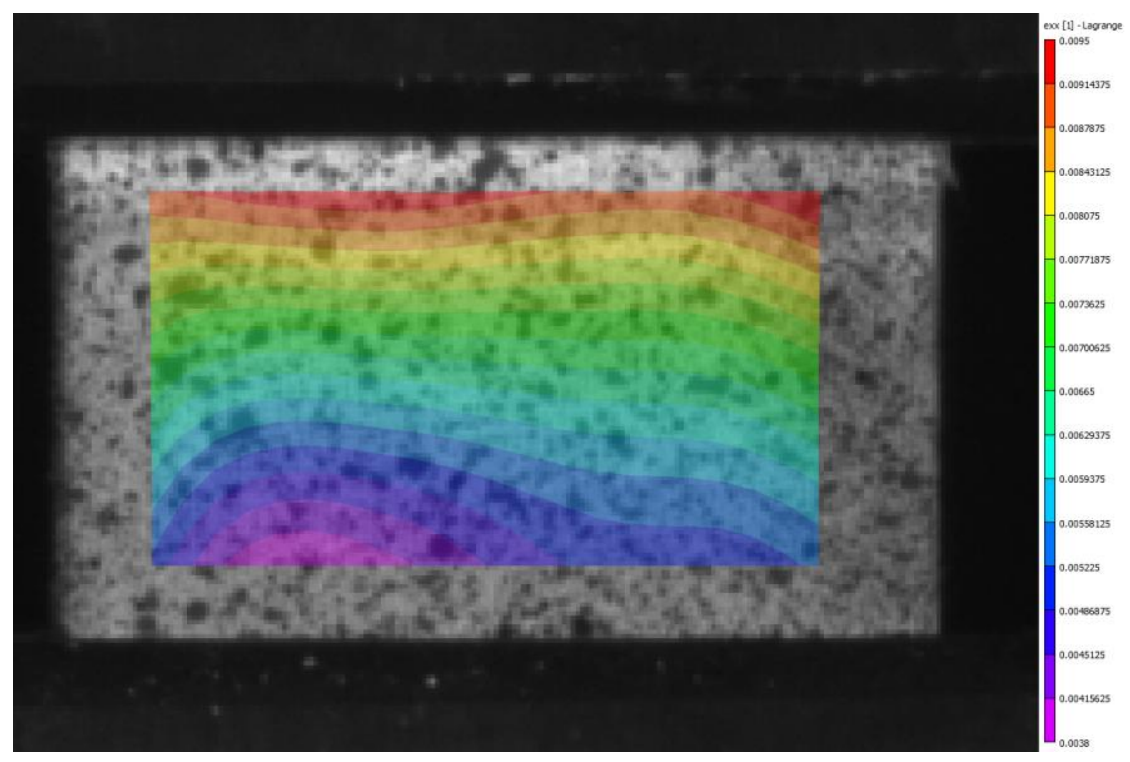

Figure 67: Strain profile $\left(\mathcal{E}_{\mathrm{xx}}\right)$ in longitudinal direction of a DIC image of a $\left[0_{\mathrm{G} 2} / \mathbf{0}_{\mathrm{F} 6}\right]_{\mathrm{S}}$ sample; purple represent lower starin level and red represent a higher starin level.

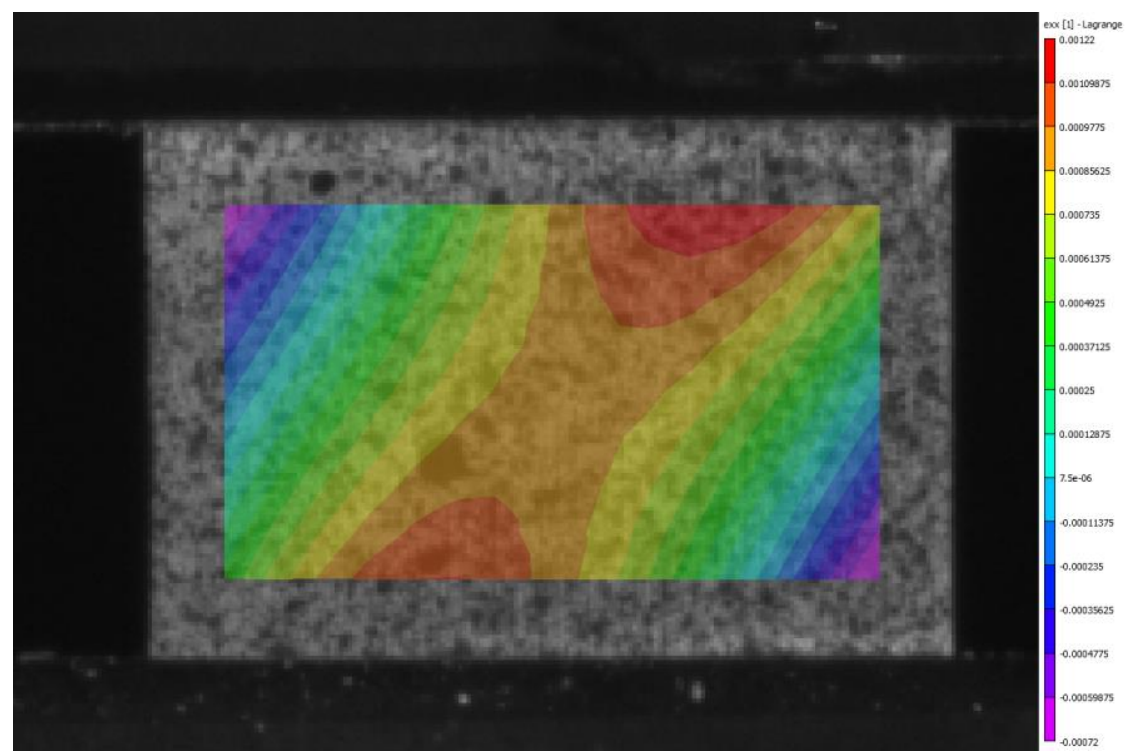

Figure 68: Strain $\left(\mathcal{E}_{\mathrm{xx}}\right)$ profile in \pm 45 direction of a DIC image of a $\left[0_{\mathrm{G} 2} / \pm 45_{\mathrm{F} 6}\right]_{\mathrm{S}}$ sample; purple represent lower starin level and red represent a higher starin level.

\subsubsection{Determination of $\mathrm{S}-\mathrm{N}$ curve and the HCFS using conventional compression- compression fatigue tests}

At first, using the results from quasi static compression test, the average ultimate compression strength (UCS) for each ply configuration were $261.73 \mathrm{MPa}$ for $\left[0_{\mathrm{G} 2} / 0_{\mathrm{F} 6}\right]_{\mathrm{S}}$ and $231.87 \mathrm{MPa}$ for $\left[0_{\mathrm{G} 2} / \pm 45_{\mathrm{F} 6}\right]_{\mathrm{S}}$, respectively. Minimum of three test specimens were used for each applied maximum 
stress amplitude. These stresses were defined as a percentage (60\% to $90 \%$ ) of the average value of the UCS. The S-N curve was generated using fatigue life values versus the different applied stress amplitudes from each experiment.

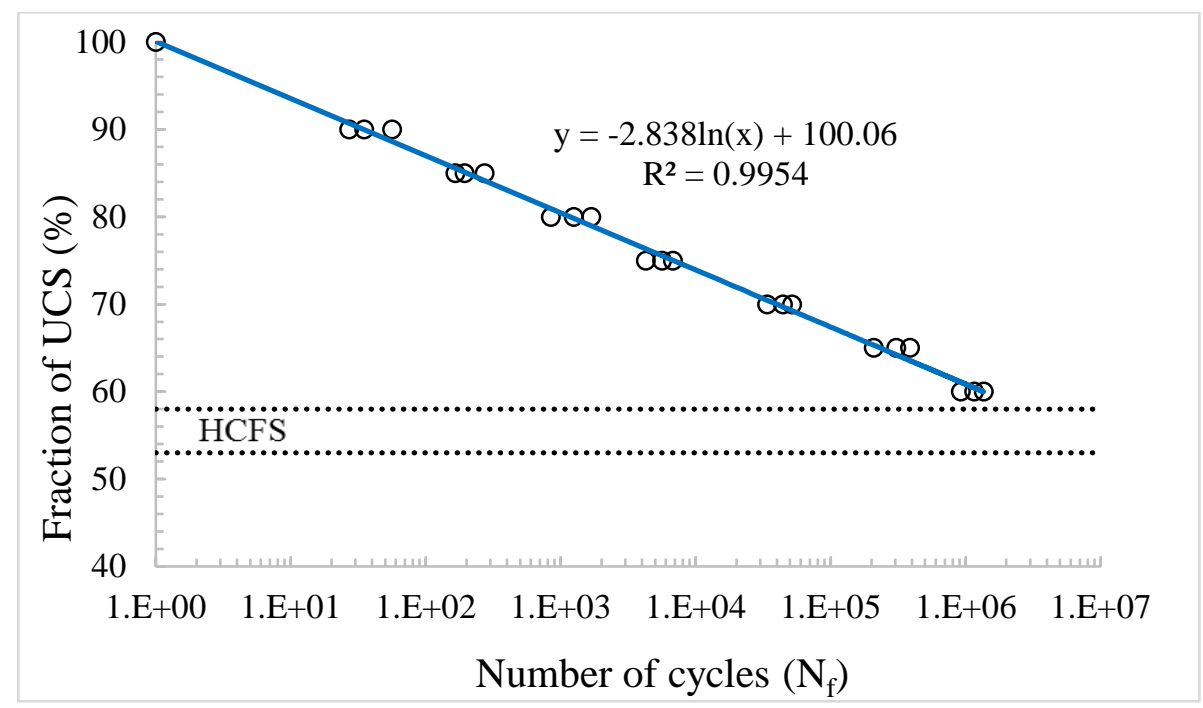

Figure 69: $\mathrm{S}-\mathrm{N}$ curve for the $\left[0_{\mathrm{G} 2} / 0_{\mathrm{F} 6}\right]_{\mathrm{S}}$ laminates; load ratio $\mathrm{R}=0.1$, frequency $=5 \mathrm{~Hz}$, and UCS=261.73 MPa

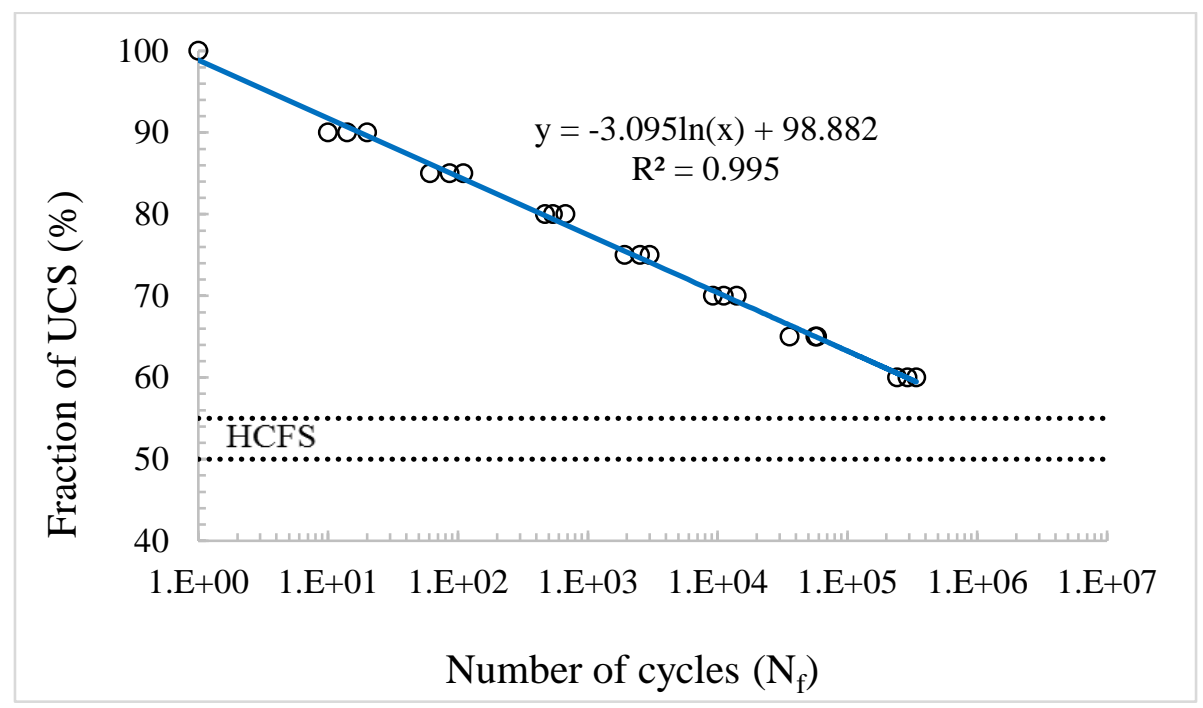

Figure 70: $\mathrm{S}-\mathrm{N}$ curve for the $\left[0_{\mathrm{G} 2} / \pm 45_{\mathrm{F} 6}\right]_{\mathrm{S}}$ laminates; load ratio $\mathrm{R}=0.1$, frequency $=5 \mathrm{~Hz}$, and UCS=231.87 MPa

Both composite laminates exhibit a linear profile when the $\mathrm{S}-\mathrm{N}$ curves are plotted in a semi-log scale. As can be seen in Figure 69 and Figure 70, the current composites do not have a true fatigue limit, since the S-N curves do not become horizontal. Based on the standard ASTM F382 [148], 
one million cycles are considered conservative for evaluating bone plate fatigue strength. Hence, five million cycles were chosen as an upper limit for number of cycles in this study as a more conservative estimate. The high cyclic fatigue strength was found to be in the range of 53-58\% of the UCS for the $\left[0_{\mathrm{G} 2} / 0_{\mathrm{F} 6}\right]_{\mathrm{S}}$ laminate and in the range of $50-55 \%$ for the $\left[0_{\mathrm{G} 2} / \pm 45_{\mathrm{F} 6}\right]_{\mathrm{S}}$ laminate. It is hypothesized that no failure will be observed until 5 million cycles in any plate loaded at an applied stress amplitude smaller than HCFS.

In addition, the pick-valley data set of each load cycle from each fatigue experiment was used to determine the fatigue characteristics of the composites. As an example, the stress-vs-strain behaviour of the composite for a typical test (70\% of UCS) is given in Figure 71 . The slope of each individual line at each cycle was used to calculate the dynamic modulus $\left(\mathrm{E}^{*}\right)$.

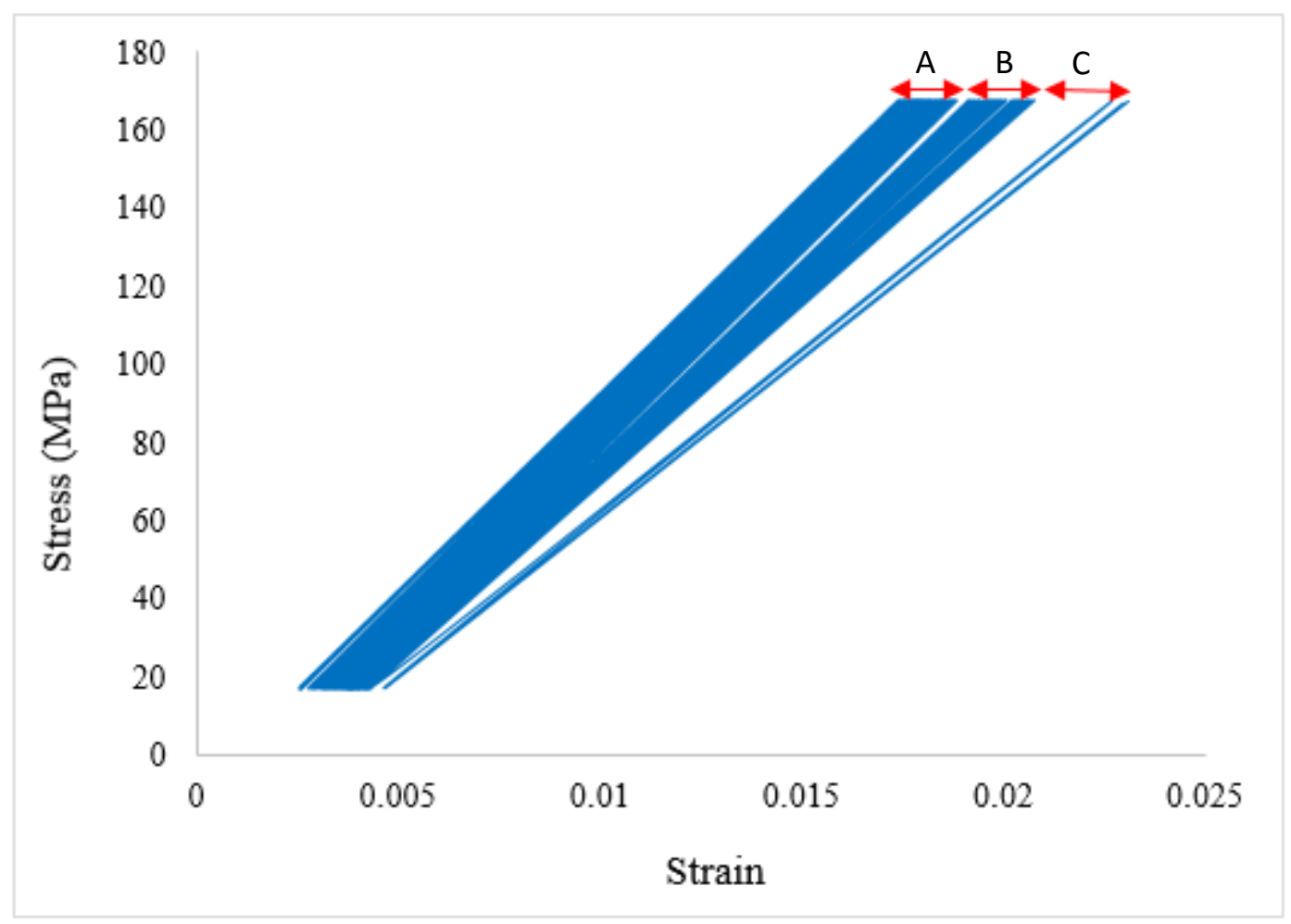

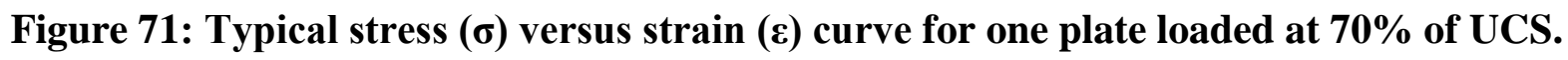

Figure 72 and Figure 73 illustrate that the dynamic modulus of elasticity stayed almost constant with the number of cycles and remained close to its initial value (region B) up until failure, where it drastically decreased (region C). 


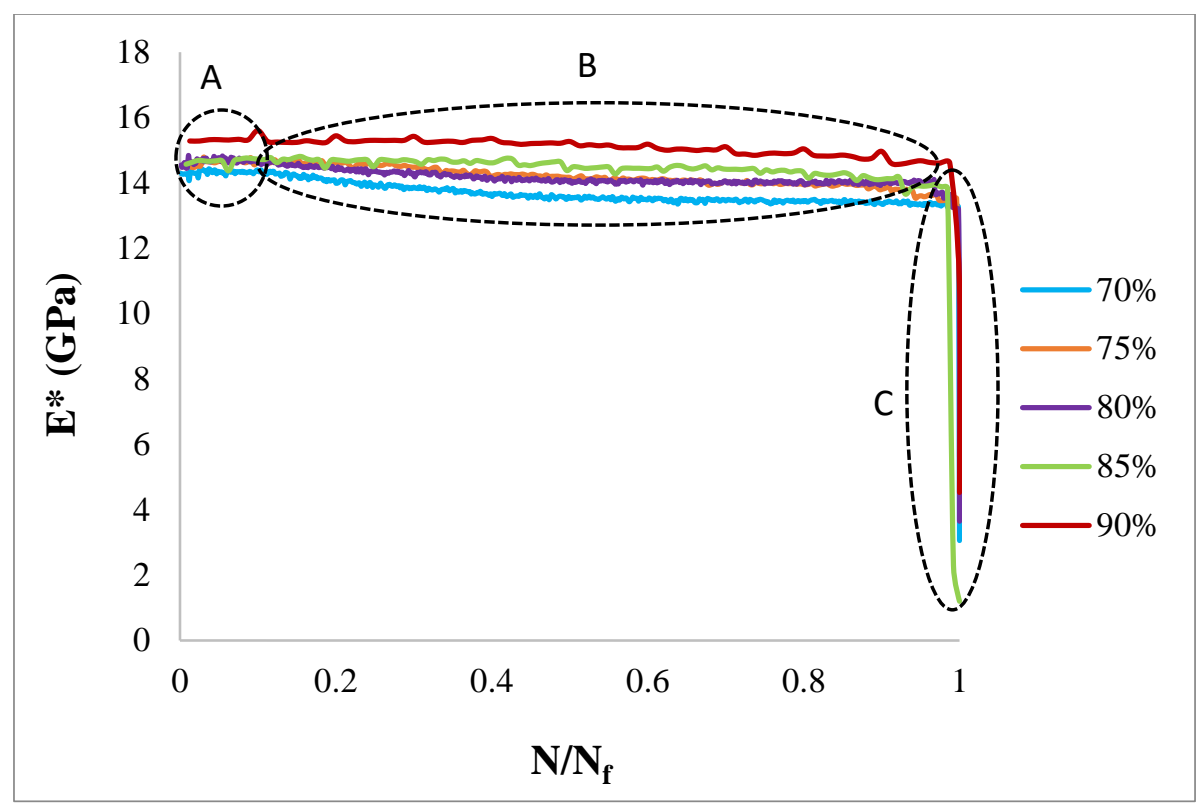

Figure 72: Dynamic elastic modulus $E^{*}$ versus normalized number of cycles $\left(N / N_{f}\right)$ in $\left[0_{G 2} / 0_{F 6}\right]_{S}$ unidirectional laminates. $N=$ number of cycles. $N_{f}=$ number of cycles at failure

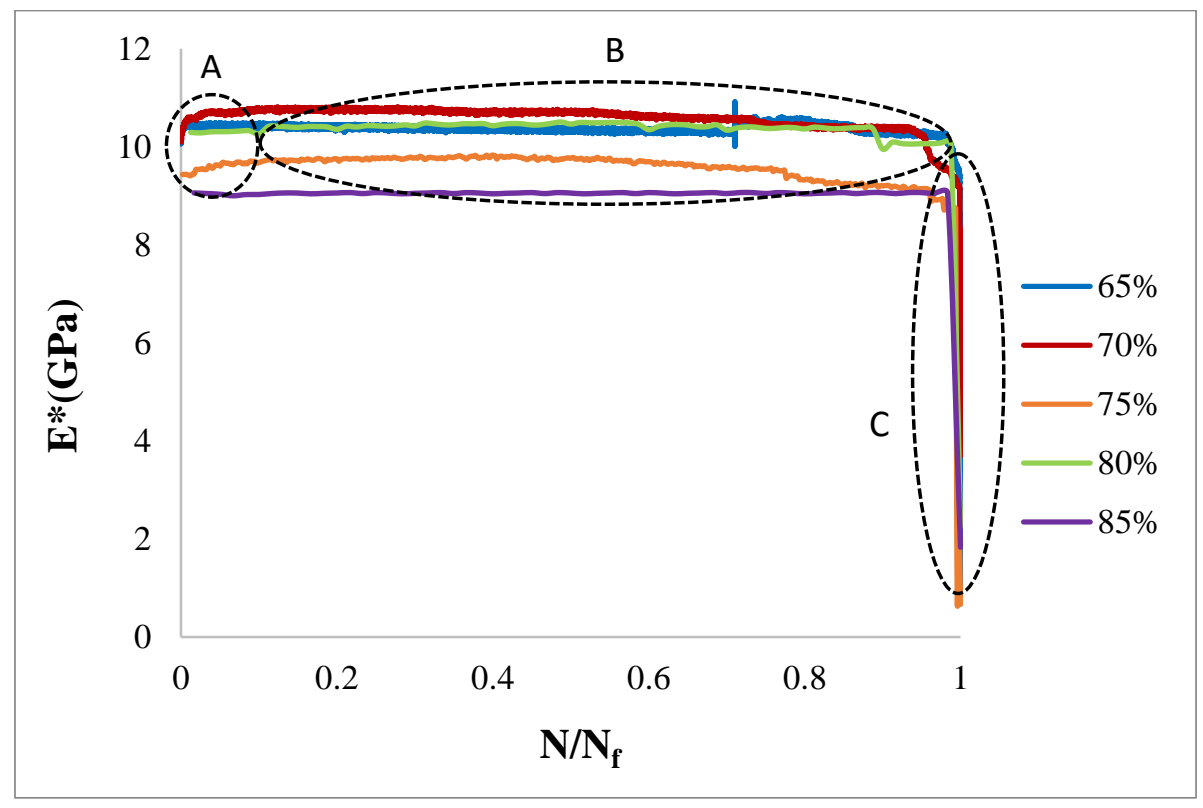

Figure 73: : Dynamic elastic modulus $E^{*}$ versus normalized number of cycles $\left(N / N_{f}\right)$ in $\left[0_{G 2} / \pm 45_{F 6}\right]_{S}$ laminates. $N=$ number of cycles. $N_{f}=$ number of cycles at failure

The corresponding values of the dynamic moduli $\left(\mathrm{E}^{*}\right)$ for each cycle are smaller than the static moduli (E) calculated in the quasi-static compression experiment due to using the pick-valley (maximum and minimum load level) of each load cycle to determine $\mathrm{E}^{*}$. A slight increase (region $\mathrm{A})$ in $\mathrm{E}^{*}$ was observed in Figure 72 and Figure 73 for both $\left[0_{\mathrm{G} 2} / 0_{\mathrm{F} 6}\right]_{\mathrm{S}}$ and $\left[0_{\mathrm{G} 2} / \pm 45_{\mathrm{F} 6}\right]_{\mathrm{S}}$ laminates 
until a specific steady value was reached, prior to sudden decrease due to failure. This increasing behaviour can be described as a hardening phenomenon occurring due to the progressive reorientation of the cellulose micro-fibrils towards the loading direction. Plant-based fibers are known to have such hardening behaviour, for instance, Baley [149], Spatz et al. [150] and Silva et al. [141] have observed an increase in the stiffness of single plant-based fibers (Sisal and Flax) when investigating their behaviour under cyclic loading. Furthermore, similar hardening behaviors were reported by El Sawi et al. [130] and Liang et al. [151] for flax/epoxy composite laminates.

\subsubsection{Thermography tests}

Using the IR camera, the temperature increase of both laminates were recorded during stepwise loading fatigue tests. The applied stress amplitude was incremented stepwise with 5\% load intervals ranging from $20 \%$ to $85 \%$ of UCS and the procedure was continued until failure. Figure 74 shows how each specimen was subjected to cyclic loading for 5000 cycles for each step, in order to reach the steady state temperature.

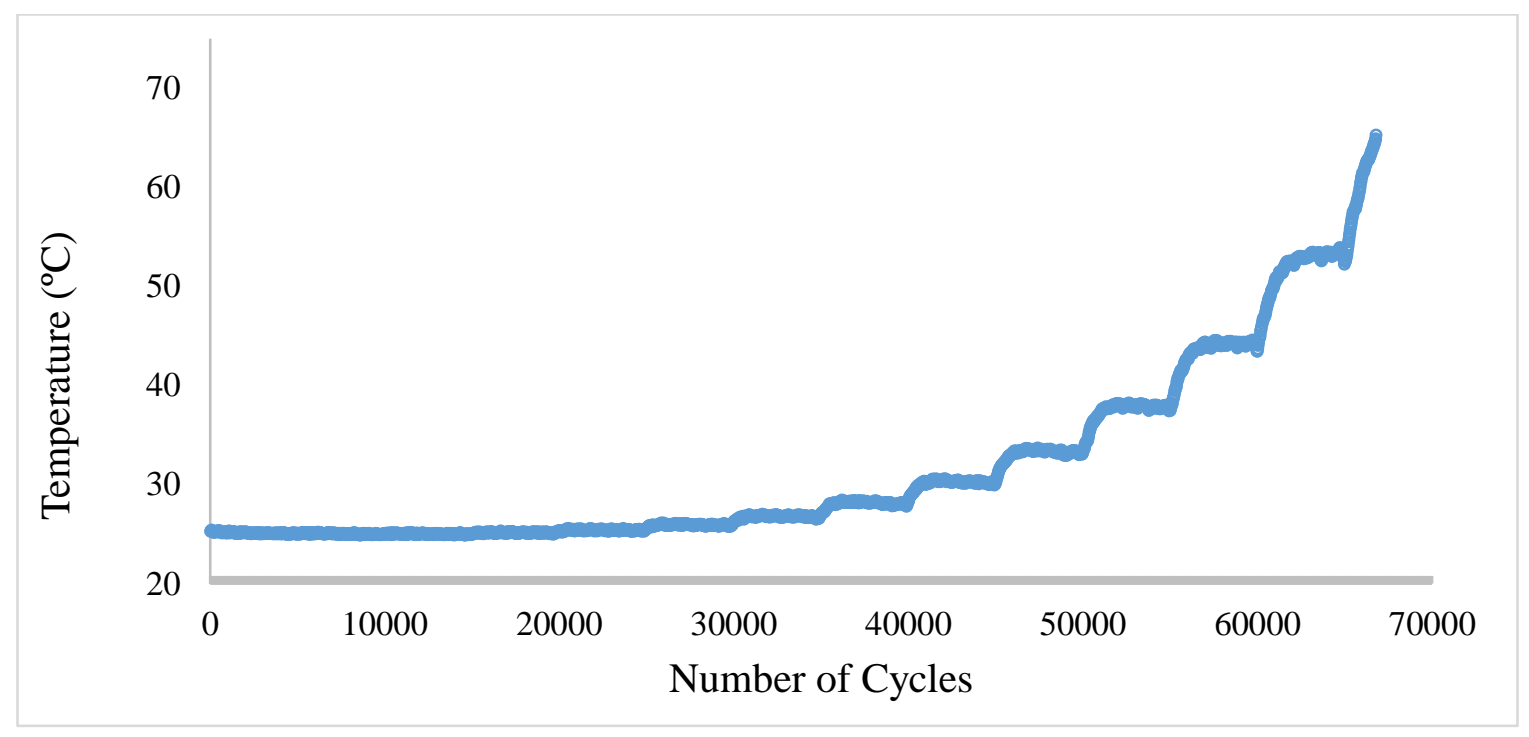

\section{Figure 74: A typical graph of thermal variation vs. number of cycles of a $\left[0_{\mathrm{G} 2} / \mathbf{0}_{\mathrm{F} 6}\right]_{\mathrm{S}}$ plate under stepwise fatigue loading test; every 5000 cycles load increases to next step}

It was observed that the temperature distribution at the surface of the plates was almost uniform and around room temperature $\left(25^{\circ} \mathrm{C}\right)$ until 25000 cycles $(40 \%$ of UCS). However, for stress 
amplitudes above $40 \%$ of UCS, hot zones were spotted and the temperature was no longer uniform across the surface.
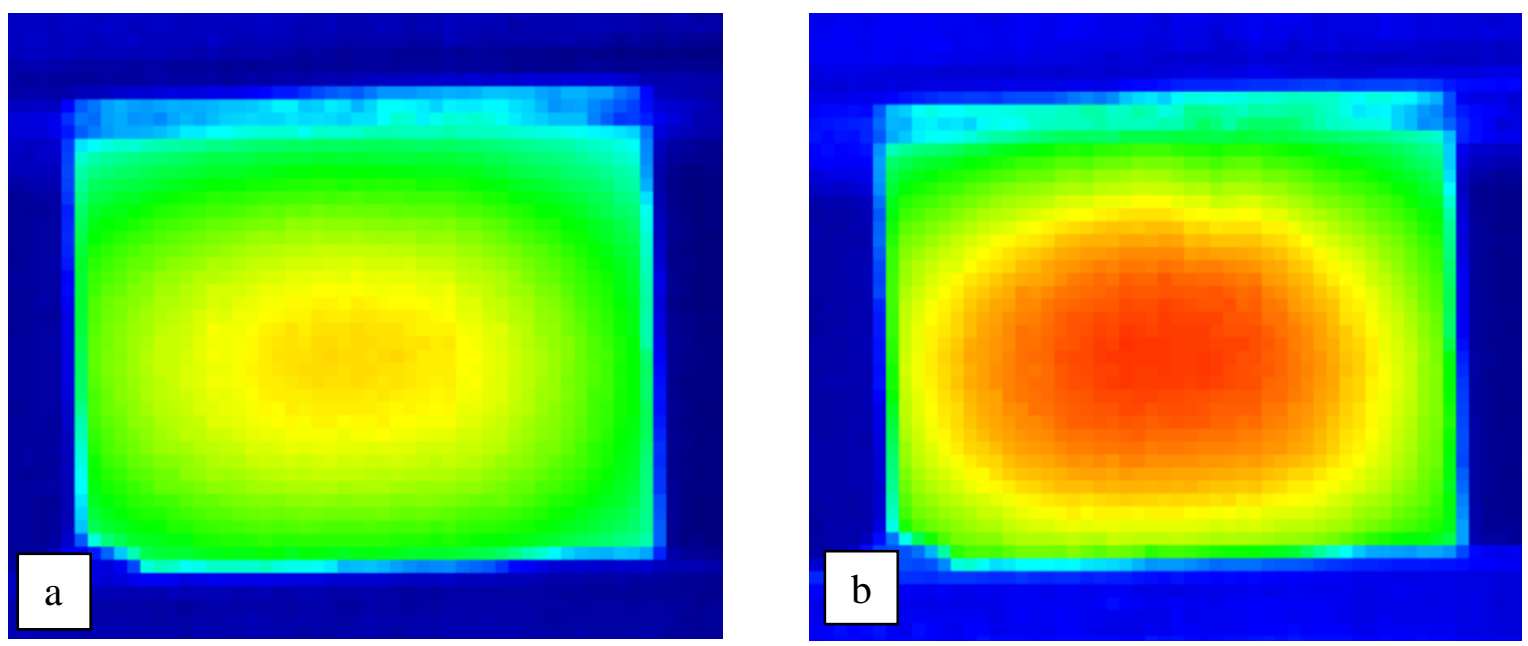

Figure 75: Temperature distributions at the surface of a $\left[0_{\mathrm{G} 2} / \mathbf{0}_{\mathrm{F} 6}\right]_{\mathrm{S}}$ laminate as a function of number of cycles at $75 \%$ of UCS; a) sample at 1000 cycles, b) sample at 2500 cycles an temperature stabilized at $61^{\circ} \mathrm{C}$.
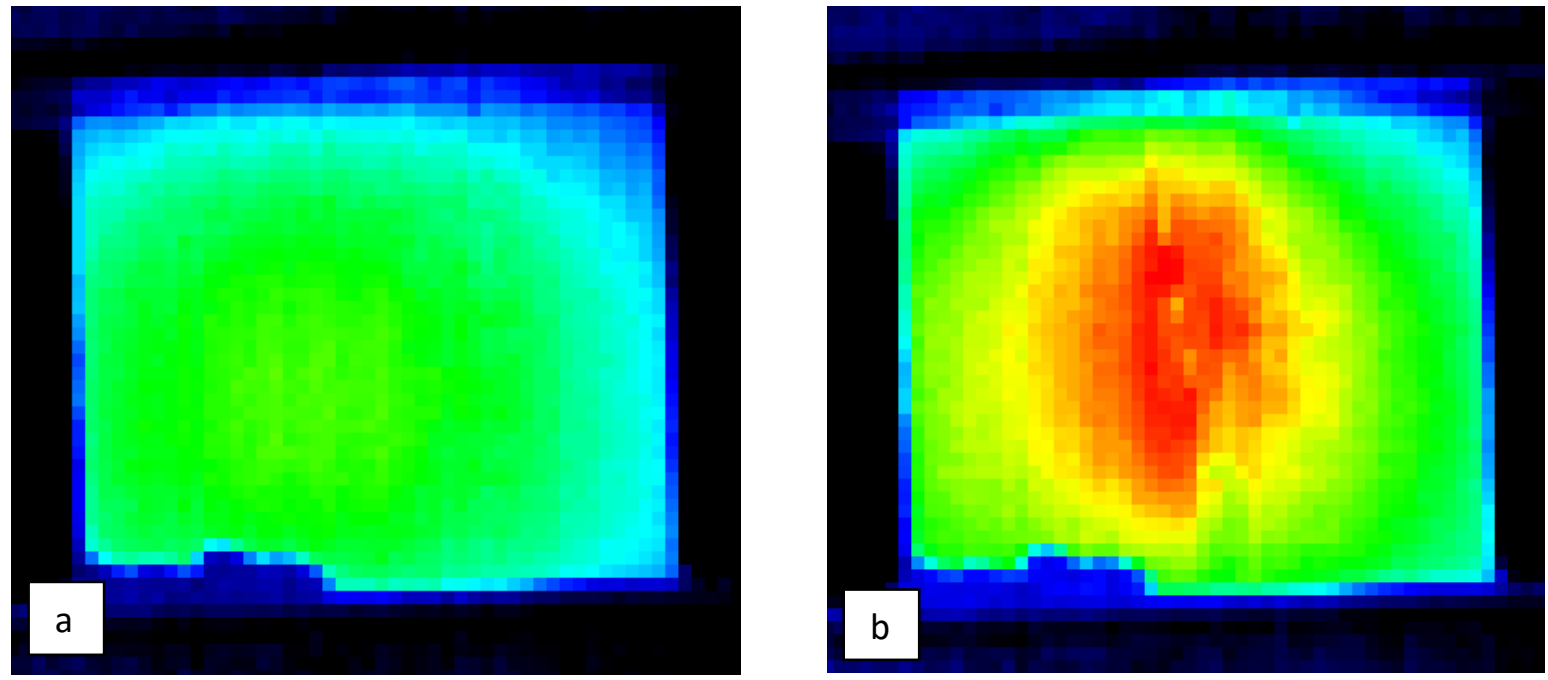

Figure 76: Temperature distributions at the surface of a $\left[0_{\mathrm{G} 2} / \pm 45_{\mathrm{F} 6}\right]_{\mathrm{S}}$ laminate as a function of number of cycles at $75 \%$ of UCS; a) sample at 1000 cycles, b) sample at 2500 cycles an temperature stabilized at $34^{\circ} \mathrm{C}$.

For each stress level, the corresponding temperature variations, as a function of the number of cycles, are plotted in Figure 77 and Figure 78. Furthermore, the temperature versus the applied stress amplitude are also plotted using each matching stabilized temperatures (Figure 79 and Figure 80). 


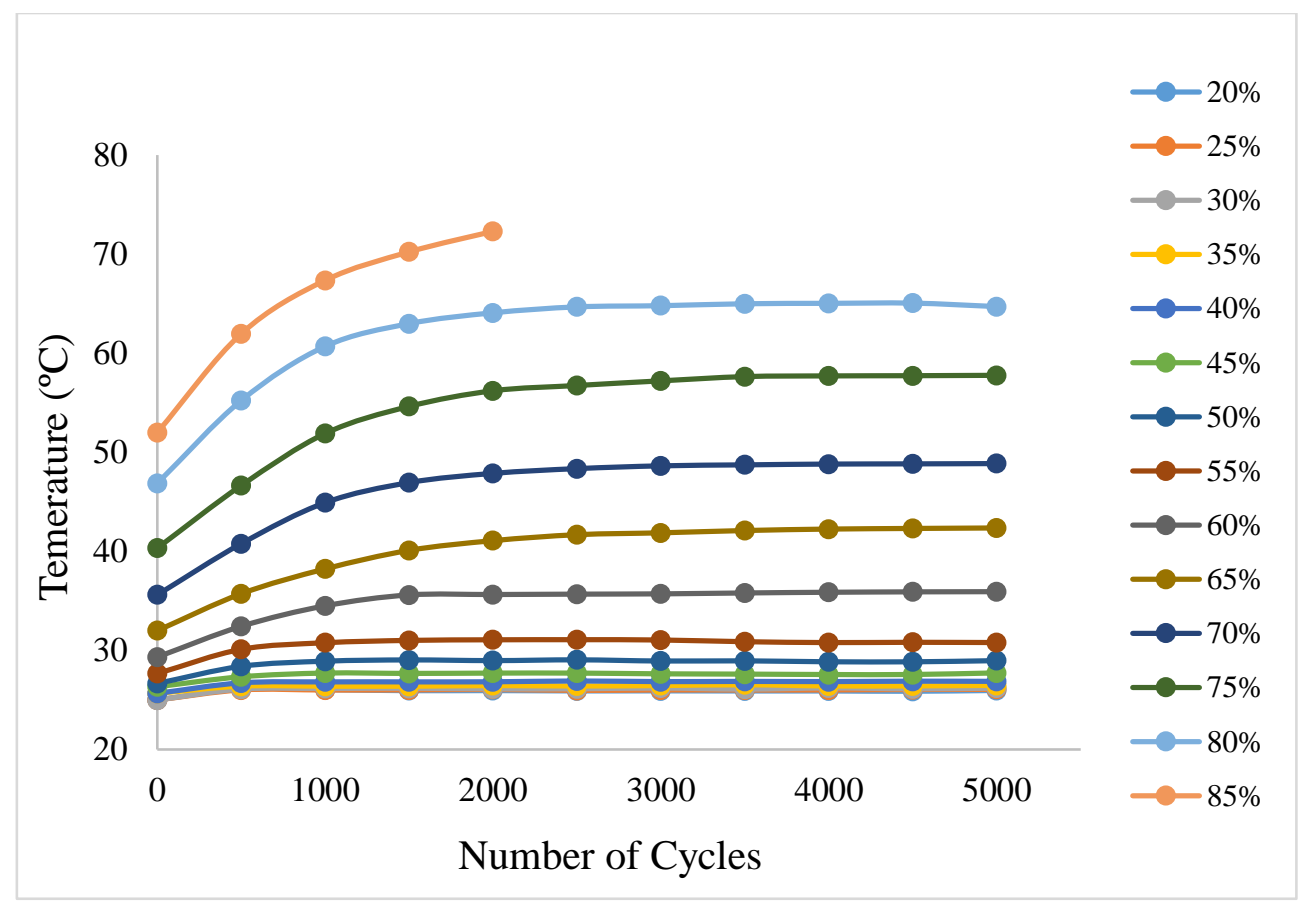

Figure 77: Average thermal variations versus number of cycles for stepwised applied stress as a fraction $(\%)$ of $\mathrm{UCS}$ on the $\left[0_{\mathrm{G} 2} / \mathbf{0}_{\mathrm{F} 6}\right]_{\mathrm{S}}$ laminates

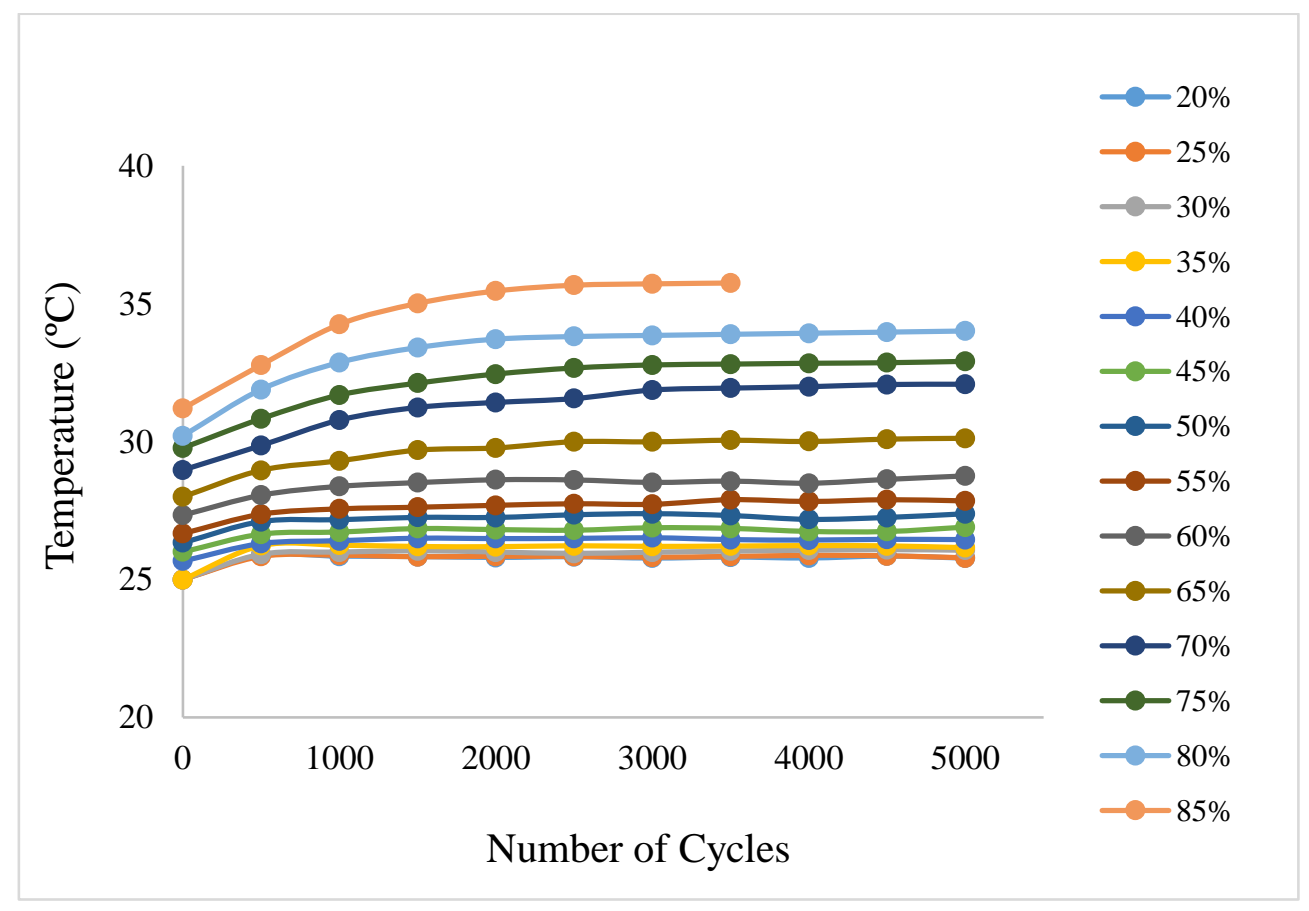

Figure 78: Average thermal variations versus number of cycles for stepwised applied stress as a fraction $(\%)$ of $\mathrm{UCS}$ on the $\left[0_{\mathrm{G} 2} / \pm 45_{\mathrm{F} 6}\right]_{\mathrm{S}}$ laminates 


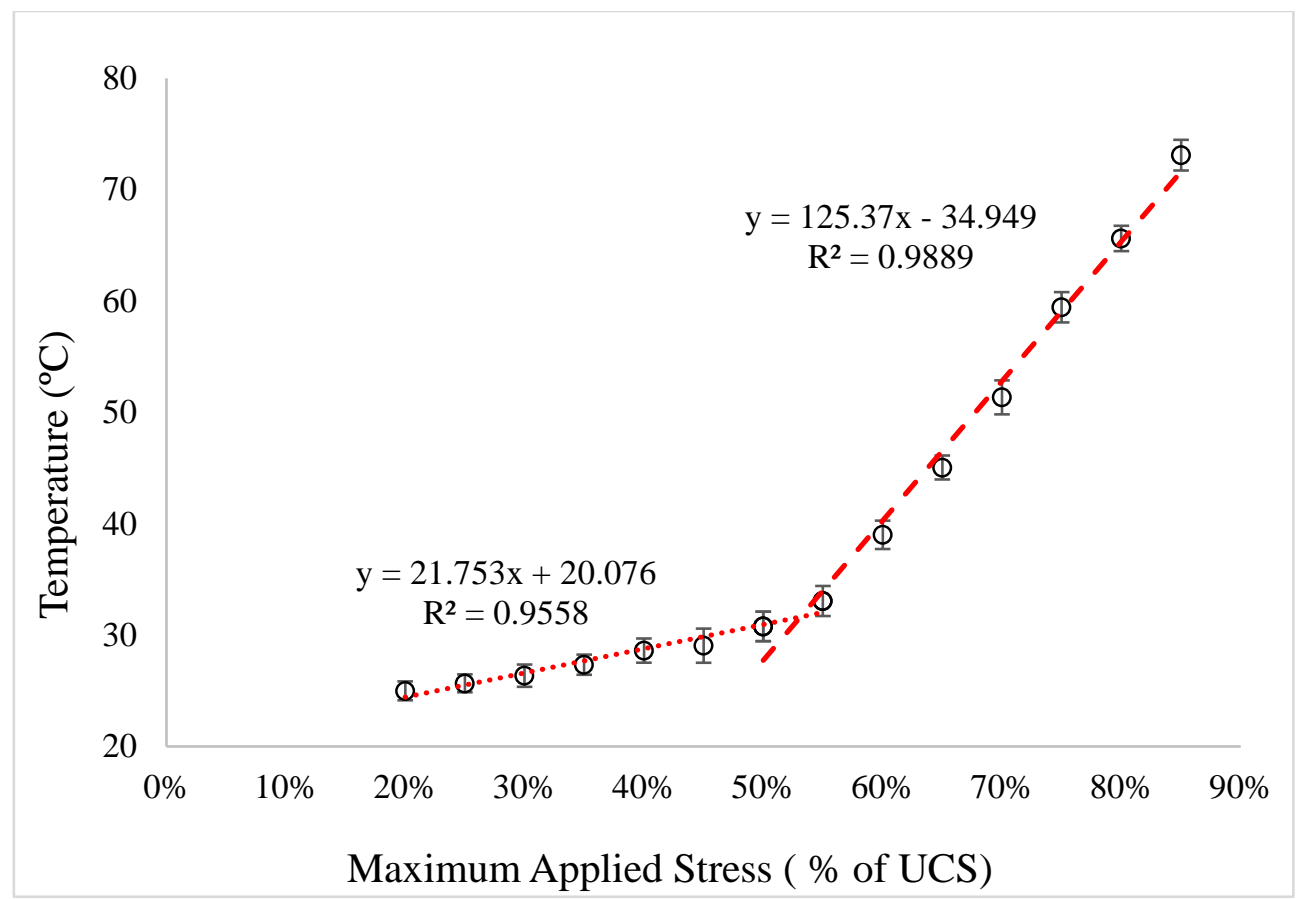

Figure 79: Average stabilized temperature versus the applied stress level of $\left[0_{\mathrm{G} 2} / \mathbf{0}_{\mathrm{F} 6}\right]_{\mathrm{S}}$ laminates

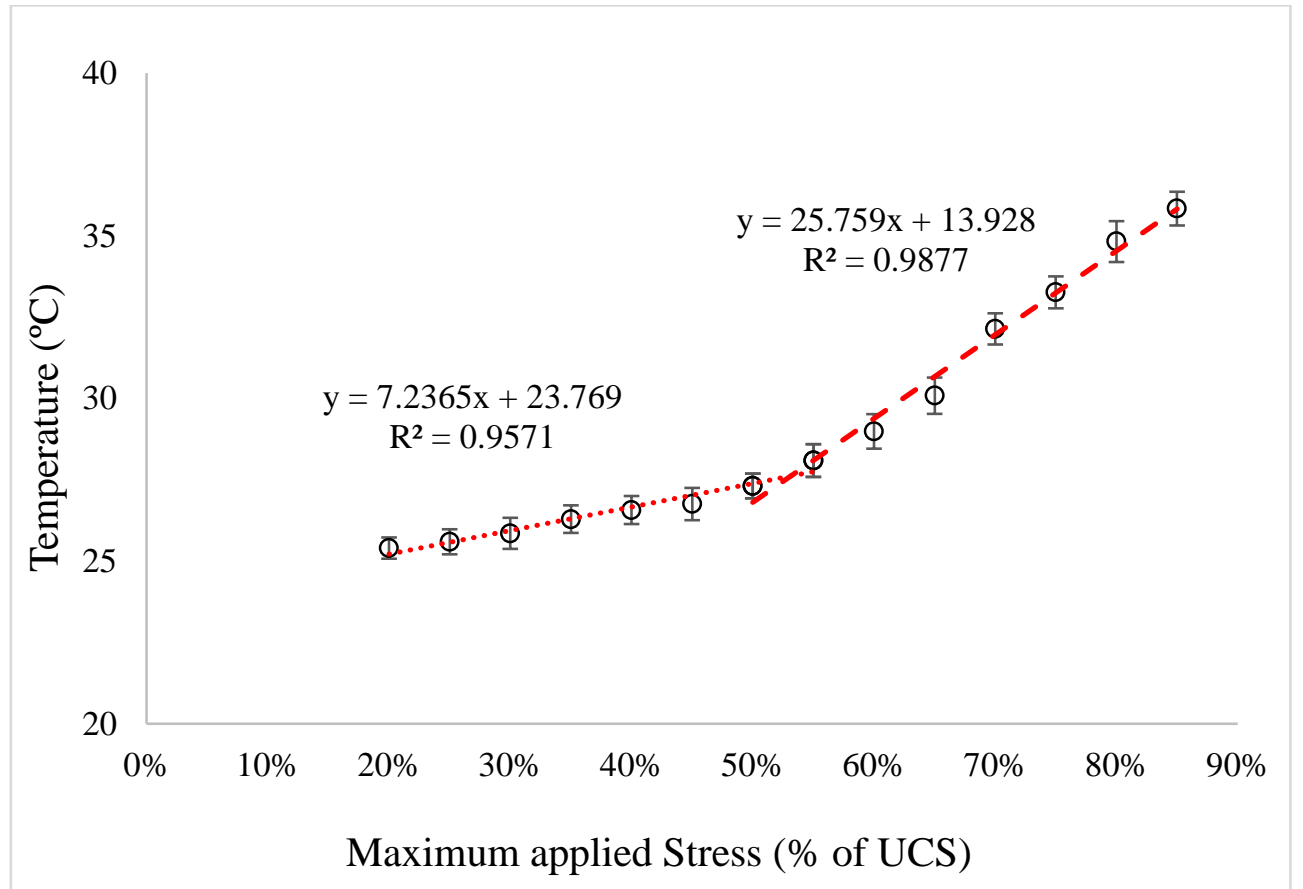

Figure 80: Average stabilized temperature versus the applied stress level of $\left[0_{\mathrm{G} 2} / \pm 45_{\mathrm{F} 6}\right]_{\mathrm{S}}$ laminates 
Figure 79 and Figure 80 display a bilinear behaviour, i.e. the slope of the graph clearly increases at the specific stress amplitude. Applying linear regression for each linear part of the plots, the fatigue strength can be determined at the intersection of the two linear regions. The HCFS determined by the IR thermography method was found to be approximately $53 \%$ of UCS for both $\left[0_{\mathrm{G} 2} / 0_{\mathrm{F} 6}\right]_{\mathrm{S}}$ and $\left[0_{\mathrm{G} 2} / \pm 45_{\mathrm{F} 6}\right]_{\mathrm{S}}$ laminates. These estimated values are in accordance with the HCFS evaluated by the conventional methods which was $56.3 \%$ of UCS for $\left[0_{\mathrm{G} 2} / 0_{\mathrm{F} 6}\right]_{\mathrm{S}}$ laminates and $51.2 \%$ of $\mathrm{UCS}$ for $\left[0_{\mathrm{G} 2} / \pm 45_{\mathrm{F} 6}\right]_{\mathrm{S}}$ laminates corresponding with 5 million cycles before failure $\left(\mathrm{N}_{\mathrm{f}}\right.$ $\left.\geq 5 * 10^{6}\right)$.

The thermal variations data $(\Delta T)$ from thermographic tests and the fatigue data $\left(\mathrm{N}_{\mathrm{f}}\right)$ from conventional fatigue tests for each corresponding stress level was used to calculate the integration parameter $\Phi$ using equation 6 and the results are presented in Table 16.

Table 16: Integration parameter $\Phi$ for the $\left[0_{\mathrm{G} 2} / \mathbf{0}_{\mathrm{F} 6}\right]_{\mathrm{S}}$ and $\left[0_{\mathrm{G} 2} / \pm 45_{\mathrm{F} 6}\right]_{\mathrm{S}}$ laminates

\begin{tabular}{|c|c|c|c|c|c|c|}
\hline \multirow{2}{*}{$\begin{array}{c}\text { Load } \\
(\% \text { of UCS })\end{array}$} & \multicolumn{3}{|c|}{$\left[0_{\mathrm{G} 2} / 0_{\mathrm{F} 6}\right]_{\mathrm{S}}$ samples } & \multicolumn{3}{c|}{$\left[0_{\mathrm{G} 2} / \pm 45_{\mathrm{F} 6}\right]_{\mathrm{S}}$ samples } \\
\cline { 2 - 7 } & $\log \left(\mathrm{N}_{\mathrm{f}}\right)$ & $\Delta T_{i}\left({ }^{\circ} \mathrm{C}\right)$ & $\Phi\left({ }^{\circ} \mathrm{C}\right)$ & $\log \left(\mathrm{N}_{\mathrm{f}}\right)$ & $\Delta T_{i}\left({ }^{\circ} \mathrm{C}\right)$ & $\Phi\left({ }^{\circ} \mathrm{C}\right)$ \\
\hline 85 & 2.281 & 48.09 & 109.69 & 1.934 & 11.83 & 22.88 \\
\hline 80 & 2.848 & 40.61 & 115.66 & 2.758 & 8.82 & 24.33 \\
\hline 75 & 3.631 & 32.43 & 117.75 & 3.396 & 7.56 & 25.67 \\
\hline 70 & 4.527 & 26.34 & 119.24 & 4.066 & 6.63 & 26.96 \\
\hline 65 & 5.318 & 20.05 & 106.63 & 4.761 & 5.08 & 24.19 \\
\hline
\end{tabular}

Table 17: Average, standard deviation and coefficient of variation of $\Phi$

\begin{tabular}{|c|c|c|}
\hline$\Phi\left({ }^{\circ} \mathrm{C}\right)$ & {$\left[0_{\mathrm{G} 2} / 0_{\mathrm{F} 6}\right]_{\mathrm{S}}$ samples } & {$\left[0_{\mathrm{G} 2} / \pm 45_{\mathrm{F} 6}\right]_{\mathrm{S}}$ samples } \\
\hline Average & 113.8 & 24.8 \\
\hline S.D. & 4.8 & 1.4 \\
\hline C.V. $(\%)$ & 4.3 & 5.6 \\
\hline
\end{tabular}

As shown in above tables, the average value of $\Phi \pm$ standard deviation was calculated to be approximately $113.8 \pm 4.8^{\circ} \mathrm{C}$ for the $\left[0_{\mathrm{G} 2} / 0_{\mathrm{F} 6}\right]_{\mathrm{S}}$ laminates and $24.8 \pm 1.4^{\circ} \mathrm{C}$ for the $\left[0_{\mathrm{G} 2} / \pm 45_{\mathrm{F} 6}\right]_{\mathrm{S}}$ laminates. With S.D. $\leq 5$, the integration parameters can be considered constant regardless of the applied maximum stress. Therefore, the number of cycles at failure $\left(N_{f i}\right)$ and the corresponding thermal variation $\left(\Delta \mathrm{T}_{i}\right)$ for a stabilized temperature at a specific stress value is deterministic of the 
integration constant $(\Phi)$, and subsequently, the $\mathrm{S}-\mathrm{N}$ curve. Since the laminates showed bilinear behaviour in both ply configurations, the result of the conventional fatigue tests and the thermography study, conclude that the integration formula is valid only for loads above the fatigue limit. However, below the fatigue limit, the result can not be correlated to the S-N curve determined from conventional fatigue test. For example, in the case of $\left[0_{\mathrm{G} 2} / 0_{\mathrm{F} 6}\right]_{\mathrm{S}}$ at $55 \%$ of UCS, the steady state temperature in stepwise fatigue test, $\Delta \mathrm{T}$ was measured to be $10.9\left({ }^{\circ} \mathrm{C}\right)$ and considering $\Phi=113.8\left({ }^{\circ} \mathrm{C}\right.$ ), using the integration equation (Eq. 6), the corresponding number of cycles to failure is equal to $10^{10}$ cycles. But for the same material at the same load level, the linear interpolation of the $\mathrm{S}-\mathrm{N}$ curve results in $\mathrm{N}_{\mathrm{f}}$ equal to $6.5 * 10^{6}$ cycles, which is not comparable to the results from the integration formula.

\subsection{Discussion}

\subsubsection{General findings}

This is the first study which assessed the fatigue properties of this new Glass/Flax/epoxy composite material using conventional fatigue tests and thermographic analysis. Based on the current preliminarily results, the composite showed fatigue properties that make it a potential candidate for long bone fracture plates, where the cyclic loading would be experienced during daily activities. Furthermore, for both stacking sequences, the laminate was able to retain its mechanical stiffness during its entire fatigue life. The fatigue strength obtained from thermography and conventional fatigue tests were in accordance, suggesting that the thermography technique can be used for rapid determination of HCFS for fiber reinforced polymer composite materials. Finally, the thermography method can be a great non-destructive tool to determine the fatigue life of the polymer composite when the applied load is above the HCFS.

\subsubsection{Comparison to prior studies}

Current data is compared to the results of prior studies on the fatigue properties of carbon fiberbased composites, natural fiber-based composites, and human femoral cortical bone, as displayed in Table 18. 
Table 18: Fatigue properties of the current Glass/Flax/Epoxy materials, human femur cortical bone, carbon fiber composite, and flax fiber composites from prior studies

\begin{tabular}{|c|c|c|c|c|c|}
\hline Materials & $\begin{array}{c}\text { Testing } \\
\text { condition }\end{array}$ & $\begin{array}{c}\text { Applied } \\
\text { Stress } \\
\text { amplitude }\end{array}$ & $\begin{array}{c}\text { Changes in } \\
\text { stiffness } \\
(\%)\end{array}$ & $\begin{array}{c}\text { Type of } \\
\text { loading }\end{array}$ & $\begin{array}{c}\text { Final number of } \\
\text { cycles }\left(\mathrm{N}_{\mathrm{f}}\right)\end{array}$ \\
\hline $\begin{array}{c}\text { Current } \\
\text { Glass/Flax/Epoxy } \\
{\left[0_{\mathrm{G} 2} / 0_{\mathrm{F} 6}\right]_{\mathrm{S}}}\end{array}$ & $\begin{array}{c}\text { Ambient } \\
\text { atmosphere }\end{array}$ & $\begin{array}{c}60-90 \% \\
\mathrm{UCS}\end{array}$ & $10 \%$ rise & Compression & $50-1.35 \times 10^{\wedge} 6$ \\
\hline $\begin{array}{c}\text { Current } \\
\text { Glass/Flax/Epoxy } \\
{\left[0_{\mathrm{G} 2} / \pm 45_{\mathrm{F} 6}\right]_{\mathrm{S}}}\end{array}$ & $\begin{array}{c}\text { Ambient } \\
\text { atmosphere }\end{array}$ & $\begin{array}{c}60-90 \% \\
\mathrm{UCS}\end{array}$ & $13.5 \%$ loss & Compression & $10-3 \times 10^{\wedge} 5$ \\
\hline CF/Flax/Epoxy $[152]$ & $\begin{array}{c}\text { Ambient } \\
\text { atmosphere }\end{array}$ & $50-80 \% \mathrm{UTS}$ & $0 \%$ & Tension & $3 \times 10^{\wedge} 4-6 \times 10^{\wedge} 6$ \\
\hline $\begin{array}{c}\text { Human femur } \\
\text { cortical bone }[153]\end{array}$ & $\begin{array}{c}\text { Physiological } \\
\text { condition }\end{array}$ & $40-80 \mathrm{MPa}$ & - & Tension & $10-10^{6}$ \\
\cline { 5 - 7 } & $60-120 \mathrm{MPa}$ & - & Compression & $100-10^{6}$ \\
\hline CF-PEEK [70] & $\begin{array}{c}\text { Room } \\
\text { Temperature }\end{array}$ & $>60 \% \mathrm{UTS}$ & - & Bending & $10-10^{6}$ \\
\hline Compact Bovine \\
Bone $[154]$
\end{tabular}

While present results are comparable with previous studies, it should be considered that not all of these studies addressed orthopaedic applications. Any differences can be explained by the various composite structures, fiber orientations, fiber/matrix volume fractions, diverse manufacturing processes, and dissimilar tests methods.

\subsubsection{Practical implications}

According to ASTM F382 [148] for evaluating bone plate fatigue strength, 1 million cycles seems to be conservative, as no bone plate is supposed to withstand more than 1 million high stress fatigue cycles in clinical conditions [148]. Considering that an average patient in his post-surgical period with a very conservative assumption walks an average of one-step every second for 4 hours per day, it is reasonable to estimate that this patient with an orthopaedic implant would experience around five million cycles annually. As discussed in previous sections, the current composite showed an HCFS at 5 million cycles around $53 \%$ to $58 \%$ of UCS for $\left[0_{\mathrm{G} 2} / 0_{\mathrm{F} 6}\right]_{\mathrm{S}}$ laminates and between $50 \%$ to $55 \%$ of UCS for $\left[0_{\mathrm{G} 2} / \pm 45_{\mathrm{F} 6}\right]_{\mathrm{S}}$ laminates. These HCFS corresponding to stress 
values ranging from 145 to $155 \mathrm{MPa}$ or $15.5 \mathrm{kN}$ force for $\left[0_{\mathrm{G} 2} / 0_{\mathrm{F} 6}\right]_{\mathrm{S}}$ laminates, and 115 to 130 $\mathrm{MPa}$ or $11.5 \mathrm{kN}$ force for $\left[0_{\mathrm{G} 2} / \pm 45_{\mathrm{F} 6}\right]_{\mathrm{S}}$ laminates. Such load levels are extremely higher compared physiological loads (i.e, 2.5 to 3 times body weight [26]) experienced by human femurs during daily activities. In addition, these stress levels in the hybrid composite laminates are comparable to that of clinical 316L stainless steel (roughly $150 \mathrm{MPa}$ ) [82]. The dynamic modulus $\mathrm{E}^{*}$ obtained for the current Glass/Flax/epoxy composite was almost constant versus the number of cycles and stayed around its initial value for entire of its fatigue life. For most other composites (e.g., $\mathrm{CF} /$ epoxy and glass/epoxy laminates), $\mathrm{E}^{*}$ usually decreases gradually with the number of cycles $[129,151]$. This can be explained by the hardening behaviour of Flax/epoxy laminae caused by progressive reorientation of the cellulose micro-fibrils towards the loading direction. This hardening effect of flax/epoxy composites was reported previously [151]. The contribution of both Flax/Epoxy and Glass/Epoxy laminae of the composite during the fatigue loading helped to maintain an almost constant level of stiffness up until failure.

Moreover, the stiffness degradation during fatigue life is considered as a measure of microscopic fatigue damage even though the polymer matrix composite may appear to be structurally intact physically. For any application and engineering design, estimating the material fatigue life at a given service load is highly essential. Also, one of the main reported complications of using composite biomaterials is the gradual loss of mechanical properties, i.e. stiffness, during cyclic loading caused by fatigue damage. This eventually generates wear debris which requires an immunological response via blood clotting, macrophages, and leukocytes $[10,11,12]$. Hence, the current composite is able to maintain its stiffness constant around its initial value during its entire fatigue life, without any stiffness degradation, its fatigue life can be determined at any given service load and aforementioned biological disorders will not arise since the loss of mechanical properties is not sufficient. This suggests that the current composite may be a potential candidate for fabrication of a long bone fracture plate because it can retain its stiffness for more than 1 million cycles at $50-60 \%$ of UCS with negligible fatigue damage, which is enough time for bone regeneration to produce complete union of fracture site.

Additionally, current thermographic analysis has been shown to be a successful tool for the rapid determination of high cyclic fatigue strength of a composite biomaterial. The HCFS from thermographic analysis was determined by intersecting two linear regions and was in a good 
accordance with the range obtained for the HCFS using the conventional test methods. As illustrated in Figure 79 and Figure 80 the temperature variation versus applied stress graph shows bilinear behaviour. Some microscopic changes may occur in the structure of the specimen during cyclic loading and cause this bilinear behaviour of the graph. Although the plates were loaded in the elastic region, at the microscopic level and in the vicinity of defects, some stress fluctuation may have happened. This may eventually initiate matrix deformation, debonding at matrix and fiber interfaces, and fiber breakage. This microscopic phenomenon can develop and finally cause heat emanation, which can cause temperature rise in a material $[129,155]$. However, when a material reaches its fatigue strength (HCFS) the temperature rises significantly since the microscopic phenomenon could be accelerated in both initiation and growth.

\subsection{Summary}

This chapter confirms that the fatigue behaviour of proposed composite material is suitable for withstanding clinical-type cyclic loads occurring on femoral bone during normal daily activities. Hence, the current composite is able to maintain its stiffness without any degradation. The fatigue life of the material can be determined at any given service load. This suggests that the current composite may be a potential candidate for applications that require specific mechanical properties in a given period of time such as long bone fracture plate fixation. Moreover, thermographic analysis has been shown to be a successful tool for the rapid determination of fatigue strength of a composite biomaterial. 


\section{Conclusions, limitations and future work}

As previously discussed, in this study a new "sandwich structure" of Glass/Flax/Epoxy has been developed and both static and dynamic mechanical properties were characterized. A strong bonding at Glass/Epoxy and Flax/Epoxy laminae interface was observed and the overall proposed composite plate exhibited mechanical properties suitable for bone fracture fixation plates. Although the glass layers at the surfaces of the composite plate reduce the water absorption rate considerably, the exposure of flax fibers at the sides and screw holes may cause moisture uptake as a long-term effect. Therefore, special coating techniques at the edges as well as screw holes with should be considered in future studies.

As per detail discussed in chapter 3, the manufacturing process of the Glass/Flax/Epoxy composite plates used in this study successfully result in an average volume fraction of fiber close to $50 \%$ and void content are in acceptable range of less than 3\%. Moreover, SEM analysis verified that the developed Glass/Flax/epoxy composite material has shown a strong bonding at Glass/Epoxy and Flax/Epoxy layers' interface. Finally, adding the external layers of glass fiber significantly improved the water absorption rate by almost $180 \%$ compared to pure flax/epoxy composite, increasing biocompatibility.

As discussed in chapter 4, the results from the mechanical experiments confirmed that the developed composite material used in this study shows higher mechanical properties compared to the previously studied Flax/Epoxy composites, which means improvement of the structure by adding the layers of the Glass fiber was successful. In addition, the proposed composite structure has higher stiffness in bending compared to tension and compression. This phenomenon can be explained by the so called "sandwich structure effect". In fact, using the stronger Glass/Epoxy laminae as outer layers and more flexible Flax/Epoxy laminae as the inner core of the structure resulted in advanced bending properties. Therefore, the proposed composite in this study represents an ideal candidate for specific applications where selective stress shielding is required such as long bone fracture plates. If the designed implant adequately counters bending, torsional, and shear stresses while only fractionally resisting compressive stress, it can thereby be beneficial in fracture healing and help to better stimulate remodelling of the callus at the fracture site. Moreover, this material has shown high enough ultimate strength in tension, compression and bending to carry clinical-type forces as occur on femur bone during daily normal activities. 
However, more improvement and optimization still is required in order to reach to a confident ground for clinical application of this new hybrid composite.

The fatigue properties of the proposed Glass/Flax/Epoxy composite in this study were evaluated in chapter 5 of this thesis. The determined high cyclic fatigue strength (HCFS) was adequate to withstand clinical-type cyclic loads occurring on femoral bone during normal daily activities. Additionally, the dynamic modulus E* obtained for the current Glass/Flax/epoxy composite was almost constant versus the number of cycles and stayed around its initial value for entire of its fatigue life. Hence, the current composite is able to maintain its stiffness without any degradation, the fatigue life of the material can be determined at any given service load. Furthermore, since the loss of mechanical properties is not significant, it may result in less debris formation and prevent subsequent immune system response due to biological disorders caused by debris formation. This suggests that the current composite may be a potential candidate for applications that require specific mechanical properties in a given period such as long bone fracture plate fixation. As per results obtained in this chapter, the developed structure can retain its stiffness for more than five million cycles at $50-60 \%$ of UCS with negligible fatigue damage, which is enough time for bone remodeling and regeneration to provide a complete union at fracture site. Moreover, thermographic analysis has been shown to be a successful tool for the rapid determination of fatigue strength of a composite biomaterial. The HCFS from thermographic analysis was determined by intersecting two linear regions and was in a good accordance with the range obtained for the HCFS using the conventional test methods.

Although, two Glass/Flax/Epoxy structures used in this study provide enough information which can be used as a base line for future comprehensive studies on this material. However, it is necessary to determine the effect of other variables on mechanical properties, such as fiber volume fraction, fiber orientation, type of resin, and manufacturing process such as curing cycle. The unidirectional fiber orientation was adequate enough to obtain the present material's maximum axial and bending properties. Also, the results of experiments on $\left[0_{\mathrm{G} 2} / \pm 45_{\mathrm{F} 6}\right]_{\mathrm{S}}$ laminate provide good understanding to anticipate the behavior of changing fiber orientation on overall mechanical properties of the overall structure. It has been observed that slanted fiber orientation compromises the axial and bending mechanical properties but possibly, it could enhance the shearing and torsional properties [156]. 
Furthermore, in biomechanical studies the clinical loading regimes include axial compression, flexural bending and torsional dynamic loading in order to simulate a more realistic loading condition for a femur fracture fixation system [157]. For example, physical activities such as stair climbing or raising from a chair induce high torsional and bending loads. Thus, it is recommended for a future investigation to conduct torsion tests. Furthermore, investigating the performance of this composite material under impact, cyclic tension, cyclic bending, and cyclic torsion can further expand the body of knowledge of this material compare to CF/Epoxy or Glass/Epoxy composites , and also will help other industries to adopt it for structural applications confidently [156].

Another limitation of this work is the curvature of the plate which plays an important role in the stabilization of the bone fragments at the fracture site $[158,159,160]$. All specimens used in the current study were straight rather than curved which may affect the overall stiffness and the ultimate strength of the composite plates. For example, the compressive load-to-failure can be reduced due to curvature since the curved specimen will more prone to buckling [24]. Therefore, further mechanical testing is required on curved composite specimens to consider the overall lateral effect of curvature on the mechanical performance.

Finally, one important aspect to be considered in future work is biocompatibility. Bagheri et al. [157], conducted a comparative biocompatibility study including cytotoxicity and osteogenesis tests on a very similar sandwich structure consisting same flax fiber and epoxy hybrid with a layer of carbon fiber ply on each side. The CF/Flax/epoxy specimens showed comparable cell viability with no cytotoxicity at all incubation times to that of medical grade stainless steel. In addition, osteogenesis test results showed that bone formation genes' expression levels induced by $\mathrm{CF} /$ Flax/Epoxy were significantly higher than those induced by the control. This shows the potential of the hybrid structure to promote bone growth. Also, Ballo et al. [18] investigated the bone tissue response to glass fiber reinforced composite implants to evaluate in vivo bone-toimplant contact and the osteoconductive capacity of bioactive fiber-reinforced composite implant (FRC). The results suggested that the FRC implant is biocompatible with bone. The biological behavior of FRC was comparable to that of Ti after 4 and 12 weeks of implantation. Furthermore, the addition of bioactive glass to the FRC implant increased peri-implant osteogenesis and bone maturation $[33,34,161]$. 


\section{References}

[1] A. P. Vassilopoulos and T. Keller, Fatigue of Fiber-reinforced Composites, New York: Springer, 2011.

[2] K. Friedrich, S. Fakirov and Z. Zhang, Polymer Composites: From Nano to Macro Scale, New York: Springer Science \& Business Media, 2005.

[3] M. Ansar, W. Xinwei and Z. Chouwei, "Modeling strategies of 3D woven composites: A review," Journal of Composite Structures, vol. 93, no. 8, pp. 1947-1963, July 2011.

[4] W. H. Akeson, S. WOO, R. D. Coutts, J. V. Matthews, M. Gonsalves and D. Amiel, "Quantitative histological evaluation of early fracture healing of cortical bones immobolized bystainless steel and composite plates," Journal of Calcified Tissue Research, vol. 19, p. 27-37, 1975.

[5] K. Tayton, C. Johnson-Burse, B. Mckibbin, J. Bradleym and G. W. Hastings, "The use of semi-rigid carbon fiber reinforced plastic platess for fixation of human fractures," Journal of Bone and Joint Surgery, vol. 64, no. 1, p. 105-111, 1982.

[6] J. S. Bradley, G. W. Hastings and C. Johnson-Nurse, "Carbon fibre reinforced epoxy as a high strength, low modulus material for internal fixation plates," Journal of Biomaterials, vol. 1, pp. 38-40, 1980.

[7] Z. S. Bagheri, I. El Sawi, E. H. Schemitsch, R. Zdero and H. Bougherara, "Biomechanical properties of an advanced new carbon/flax/epoxy composite material for bone plate application," Journal of Mechanical Behavior of Biomedical Material, vol. 20, p. 398406, 2013.

[8] T. Suchy, K. Balı'k, R. Sedlacek, Z. Sucharda, M. Sochor, J. Benes and J. Krena, "Radiolucent composites providing high resistance against sterilization decomposition," Journal of Ceramics Silikaty, vol. 55, no. 4, p. 401-409, 2011.

[9] J. Chlopek, I. Kotela, P. Rosol and M. Blazewicz, "Mechanical Assessment of Nonmetallic composite materials for bone surgery," Journal of Composite Materials, vol. 43, no. 26, pp. 3265-3274, 2009.

[10] M. S. Ali, T. A. French, G. W. Hastings, T. Rae, N. Rushton, E. R. S. Ross and C. H. Wynn-Jones, "Carbon fibre composite bone plates," Journal of Bone and Joint Surgery, vol. 72, p. 586-591, 1990. 
[11] G. I. Howling, E. Ingham, H. Sakoda, T. D. Stewart, J. Fisher, A. Antonarulrajah, S. Appleyard and B. Rand, "Carbon-carbon composite bearing materials in hip arthroplasty: analysis of wear and biological response to wear debris," Journal of Materials Science Materials in Medicine, vol. 15, pp. 91-98, 2004.

[12] M. Barry, S. M. Thomas, A. Rees, B. Shafighian and M. A. Mowbray, "Histological changes associated with an artificial anterior cruciate ligament," Journal of Clinical Pathology, vol. 48, p. 556-559, 1995.

[13] H. B. Skinner, "Composite technology for total hip arthroplasty," Journal of Clinical orthopaedics and related research, vol. 235, pp. 224-236, 1988.

[14] K. Tayton and J. Bradley, "How stiff should semi-rigid fixation of he human tibia be?," Journal of Bone and Joint Surgery British, vol. 63, no. 3, p. 312-315, 1983.

[15] Z. S. Bagheri, I. El Sawi, H. Bougherara and R. Zdero, "Biomechanical Fatigue Analysis of an Advanced New Carbon Fiber/Flax/Epoxy Plate for Bone Fracture Repair using Conventional Fatigue Tests and Thermography," Journal of the Mechanical Behavior of Biomedical Material, vol. 35, pp. 27-38, 2014.

[16] J. W. Brantigan and A. D. Steffee, "A carbon fiber implant to aid interbody lumbar fusion. Two-year clinical results in the first 26 patients," Journal of Spine, vol. 18, pp. 2106-2107, 1993.

[17] J. W. Brantigan, A. D. Steffee, M. L. Lewis, L. M. Quinn and J. M. Persenaire, "Lumbar interbody fusion using the Brantigan I/F cage for posterior lumbar interbody fusion and the variable pedicle screw placement system: two-year results from a Food and Drug Administration investigational device exemption clinical trial," Spine, vol. 25, pp. 14371446, 2000.

[18] A. M. Ballo, E. A. Akca, T. Ozen, L. Lassila, P. K. Vallittu and T. O. Narhi, "Bone tissue responses to glass fiber-reinforced composite implants; a histomorphometric study," Journal of Clinical Oral Implants Research, vol. 20, pp. 608-615, 2009.

[19] A. M. Ballo, L. V. Lassila, P. K. Vallittu and T. O. Narhi, "Load bearing capacity of bone anchored fiber-reinforced composite device," Journal of Materials Science Materials in Medicine, vol. 18, pp. 2025-2031, 2007.

[20] S. L. Evans and P. J. Gregson, "Composite technology in load-bearing orthopaedic implants," Journal of Biomaterials, vol. 19, pp. 1329-1342, 1998.

[21] R. Sanders, Trauma: Core Knowledge in Orthopaedics, Philadelphia: Mosby, 2008. 
[22] R. M. Deshmukh and S. S. Kulkarni, "Experimental Investigation and Prediction of Mechanical Properties of a Composite Material for Bone Plate Application," International Journal of Science, Engineering and Technology Research, vol. 4, no. 8, pp. 2871-2875, 2015.

[23] C. A. Rockwood, D. P. Green, R. W. Bucholz, C. M. Court-Brown, J. D. Heckman and P. Tornetta, Rockwood and Green's Fractures in Adults, Wolters Kluwer Health/Lippincott Williams \& Wilkins, Philadelphia, 2010.

[24] S. Samiezadeh, P. Tavakkoli Avval, Z. Fawaz and H. Bougherara, "Biomechanical assessment of composite versus metallic intramedullary nailing system in femoral shaft fractures: a finite element study," Journal of Clinical Biomechanics, vol. 29, no. 7, p. 803$810,2014$.

[25] G. Cheung, P. Zalzal, M. Bhandari, J. K. Spelt and M. Papini, "Finite element analysis of a femoral retrograde intramedullary nail subject to gait loading," Journal of Medical Engineering \& Physics, vol. 26, no. 2, p. 93-108, 2004.

[26] D. L. Bartel, D. T. Davy and T. M. Keaveny, Orthopaedic Biomechanics: Mechanics and Design in Musculoskeletal Systems, New Jersey: Pearson Prentice Hall Bioengineering, 2006.

[27] J. A. Buckwalter and A. J. Grodzinsky, "Loading of healing bone, fibrous tissue, and muscle: implications for orthopaedic practice," Journal of American Academy of Orthopaedic Surgeons, vol. 7, no. 5, p. 291-299, 1999.

[28] D. Chandramohan and K. Marimuthu, "Characterization of natrural fibers and their applictaion in bone grafting substitues," Journal of Acta Bioengineering and Biomechanics, vol. 13, p. 77-84, 2011.

[29] M. Jawaid, H. P. S. Abdul Khalil and A. Abu Bakar, "Woven hybrid composites: tensile and flexural properties of oil palm-woven jute fibres based epoxy composites," Journal of Material Science Engineering, vol. 528, p. 5190-5195, 2011.

[30] M. Zimmerman, J. R. Parsons and H. Alexander, "The design and analysis of a laminated partially degradable composite bone plate for fracture fixation," Journal of Biomedical Materials Research, vol. 21, no. 3, p. 345-361, 1987.

[31] N. Gillett, S. A. Brown, J. H. Dumbleton and R. P. Pool, "The use of short carbon fibre reinforced thermoplastic plates for fracture fixation," Journal of Biomaterials, vol. 6, pp. 113-121, 1985.

[32] M. Hautamaki, V. V. Meretoja, R. H. Mattila, A. J. Aho and P. K. Vallittu, "Osteoblast response to polymethyl methacrylate bioactive glass composite," Journal of Materials Science Materials in Medicine, vol. 21, pp. 1685-1692, 2010. 
[33] J. K. Piitulainen, T. Kauko, K. M. J. Aitasalo, V. Vuorinen, P. K. Vallittu and J. P. Posti, "Outcomes of Cranioplasty with Synthetic Materials and Autologous Bone Grafts," Journal of World Neurosurgery, vol. 83, no. 5, p. 708-714, 2015.

[34] J. P. Posti, J. M. Piitulainend, L. Hupaf, S. Fagerlundf, J. Frantzéna, K. M. J. Aitasalod, V. Vuorinena, W. Serlog, S. Syrjänenh and P. K. Vallittu, "A glass fiber-reinforced composite - bioactive glass cranioplasty implant: A case study of an early development stage implant removed due to a late infection," Journal of the Mechanical Behavior of Biomedical Materials, vol. 55, p. 191-200, 2016.

[35] A. M. Hashim, K. Tanner and J. K. Ulaiwe, "Tensile and Fracture Properties of Coir Fiber Green Composites Bone Plate Fixation," in International Conference on Engineering and Innovative Technology, SU-ICEIT 2016, April 12-14, 2016, Salahaddin University, Erbil, Kurdistan, Iraq, 2016.

[36] K. A. Jockisch, S. A. Brown, T. W. Bauer and K. Merritt, "Biological response to choppedcarbon-fiber-reinforced peek," Journal of Biomedial Materials Research, vol. 26, pp. 133146, 1992.

[37] K. Fujihara, Z. M. Huang, S. Ramakrishna, K. Satknanantham and H. Hamada, "Performance study of braided carbon/PEEK composite compression bone plates," Journal of Biomaterials, vol. 24, no. 15, pp. 2661-2667, 2003.

[38] P. N. Khanam, H. P. S. A. Khalil, M. Jawaid, G. R. Reddy, C. S. Narayana and S. V. Naidu, "Sisal/carbon fiber reinforced hybrid composites: tensile/flexural and chemical resistance properties," Journal of Polymers and the Environment, vol. 18, no. 4, p. 723 $733,2010$.

[39] V. K. Ganesh, K. Ramakrishra and D. N. Ghista, "Biomechanics of bone-fracture fixation by stiffness-graded plates in compariosn with stainless-steel plates," Journal of Biomedical Engineering Online, vol. 4, p. 46, 2005.

[40] S. K. Saw, G. Sarkhel and A. Choudhury, "Effect of layering pattern on the physical, mechanical, and thermal properties of jute/bagasse hybrid fiber-reinforced epoxy novolac composites," Journal of Polymer Composites, vol. 33, pp. 1824-1831, 2012.

[41] A. Atiqah, M. Maleque, M. Jawaid and M. Iqbal, "Development of kenaf-glass reinforced unsaturated polyester hybrid composite for structural applications," Journal of Composite Materials Engineering, vol. 56, p. 68-73, 2014.

[42] M. Sayer, N. B. Bektas and O. Sayman, "An experimental investigation on the impact behavior of hybrid composite plates," Journal of Composite Structures, vol. 92, no. 5, p. 1256-1262, 2010. 
[43] R. M. Deshmukh and S. S. Kulkarni, "A Review on Biomaterials in Orthopedic Bone Plate Application," International Journal of Current Engineering and Technology, vol. 5, no. 4, pp. 2587-2591, 2015.

[44] C. Vanputte, J. Regan, R. Seeley, T. Stephens, P. Tate and A. Russo, Seeley's Anatomy \& Physiology, 10 ed., McGraw Hill, 2014, pp. 230-234.

[45] "Illustration of the Normal Left Hip Joint and Bones of the Pelvis, Including the Acetabulum," Nucleus Medical Art, [Online]. Available: http://www.allposters.com/sp/Illustration-of-the-Normal-Left-Hip-Joint-and-Bones-of-the-Pelvis-Including-theAcetabulum-Posters_i9013352_.htm. [Accessed 2016].

[46] "Bone," 2016. [Online]. Available: http://medical-dictionary.thefreedictionary.com/Bone +(Human+Anatomy). [Accessed July 2016].

[47] H. Gray, "The Femur," 2015. [Online]. Available: http://www.bartleby.com/107/59.html. [Accessed 14 July 2016].

[48] "Structure and composition of bone," University of Cambridge, 2015. [Online]. Available: http://www.doitpoms.ac.uk/tlplib/bones/structure.php. [Accessed 2016].

[49] R. L. Buly, Interviewee, Femoral Osteotomy: An Overview. [Interview]. 1 February 2015.

[50] C. Huei-Ming, "Retroversion," 3 May 2005. [Online]. Available: http://www.pt.ntu.edu. tw/hmchai/hGlossary/Retroversion.htm. [Accessed 2016].

[51] Z. Leman, S. M. Sapuan, M. Azwan, M. M. H. M. Ahmad and M. A. Maleque, "The effect of environmental treatments on fiber surface properties and tensile strength of sugar palm fiber-reinforced epoxy composites," Journal of Polymer Plastic Technology Engineering, vol. 47, pp. 606-612, 2008.

[52] American Academy of Orthopedic Surgeons, "Femur Shaft Fractures (Broken Thighbone)," August 2011. [Online]. Available: http://orthoinfo.aaos.org/topic.cfm? topic=A00521. [Accessed July 2016].

[53] E. Raaymakers, I. Schipper, R. Simmermacher and C. Van Der Werken, "Proximal Femur," 14 November 2010. [Online]. Available: https://www2.aofoundation.org $/ \mathrm{wps} /$ portal/surgery?showPage=diagnosis\&bone=Femur\&segment=Proximal. [Accessed 18 July 2016].

[54] M. Laurence, "The Elements of Fracture Fixation," Bone and Joint Journal, vol. 90, no. 7, pp. 980-981, 2008.

[55] Oasis Orthopedics, "Trauma and Fractures," Oasis Orthopedics, 2015. [Online]. Available: http://www.oasisortho.com.au/trauma-fractures.html. [Accessed 2016]. 
[56] B. Link and R. Babst, "Current Concepts in Fractures of the Distal Femur," ACTA CHIRURGIAE ORTHOPAEDICAE ET TRAUMATOLOGIAE ČECHOSL, vol. 79, no. 2012, pp. 11-20, 2012.

[57] " Thighbone (Femur) Fractures in children," American Academy of Orthopaedic Surgeons, 2008. [Online]. Available: HTTP:http://orthoinfo.aaos.org/topic.cfm?topic $=\mathrm{A} 00364$.

[58] F. Gebhard, P. Kregor and C. Oliver, "Temporary long leg splint," AO Foundation, 12008. [Online]. Available: https://www2.aofoundation.org/wps/portal/surgery?showPage $=$ redfix $\&$ bone $=$ Femur\&segment $=$ Distal\&classification $=33-A 2 \&$ treatment $\&$ method $=$ Provisional+treatment\&implantstype=Temporary+long+leg+splint\&redfix_url=128523 8413036. [Accessed 2016].

[59] "Splinting fractured femurs: Then and now," 2006. [Online]. Available: http://www.wildernessemergencycare.com/book/splint_femurs.htm. [Accessed 2016].

[60] N. S. Done and R. Hatwar, "Splint ppt by rupeshkumar," 9 Nov. 2013. [Online]. Available: http://www.slideshare.net/vhjokhi/splint-ppt-by-rupeshkumar. [Accessed Jul. 2016].

[61] "Orthoinfo," AAOS, Feb. 2015. [Online]. Available: http://orthoinfo.aaos.org/topic.cfm? topic $=\mathrm{a} 00424$. [Accessed July 2016].

[62] D. Hak, "Closed Reduction, Traction, and Casting Techniques," October 2008. [Online].

[63] E. K. L. Carroll, "External Fixation and Temporary Stabilization of Femoral and Tibial Trauma," Journal of Surgical Orthopaedic Advances, vol. 20, no. 1, pp. 74-81, 2011.

[64] Midwest Physical Therapy and Sports Center, "Physical Therapy in Lincoln and Ashland for Hip Issues," [Online]. Available: http://loptonline.com/patient-education/injuriesconditions/hip-issues/adult-femur-fractures/. [Accessed 2016].

[65] T. Zgonis, G. Jolly and P. Blume, "A Brief Historical Overview of External Fixation," Podiatry Today, vol. 16, no. 4, April 2003.

[66] G. W. Wood, "Intramedullary nailing of femoral and tibial shaft fractures," Journal of Orthopaedic Science, vol. 11, no. 6, p. 657-669, 2006.

[67] P. Wolinsky, N. Tejwani, J. H. Richmond, K. Egol and D. J. G. Stephan, "Controversies in Intramedullary Nailing of Femoral Shaft Fractures," Journal of Bone and Joint Surgery, vol. 83, no. 9, pp. 1404-1415, September 2001.

[68] N. M. A. Stock, "Distal Femur Fractures with Retrograde Surgical Fixation with Intramedullary Nail," $2012 . \quad$ [Online]. Available: http://doctorstock.photoshelter.com/image/I0000vIg9i_luZvk. [Accessed 2016]. 
[69] A. D. K. Pankovich, Handbook of Fractures: Fractures of the Femoral Shaft, 3rd ed., New York: McGraw-Hill, 2006, pp. 293-303.

[70] A. J. Thakur, The Elements of Fracture Fixation, 2nd ed., New Delhi: Elsevier India, 2007.

[71] R. Soto-Hall and N. P. McCloy, "Problems in Intramedullary Nailing of Femoral Fractures," Western Journal of Medicine, vol. 74, no. 6, pp. 424-428, June 1951.

[72] H. K. Uhthoff, P. Poitras and D. Backman, "Internal Plate Fixation of Fractures: Short History and Recent Developments," Journal of Orthopedic Science, vol. 11, pp. 118-126, 2006.

[73] AO Foundation, "AOFoundation," [Online]. Available: https://www2.aofoundation.org /wps/portal/!ut/p/a0/04_Sj9CPykssy0xPLMnMz0vMAfGjzOKN_A0M3D2DDbz9_UM MDRyDXQ3dw9wMDAx8jfULsh0VAdAsNSU!/?BackMode=true\&bone=CMF\&conte $\mathrm{ntUrl}=\% 2 \mathrm{Fsrg} \% 2$ Fpopup\%2Fadditional_material\%2F91\%2FX40_Lockplate_principles. jsp\&popupStyle=diagnosis\&segment=Mandible \&soloState=true. [Accessed 2016].

[74] M. Nazeer, "Absolute Stability-Plate Fixation," 13 March 2014. [Online]. Available: http://www.slideshare.net/sitanshubarik/absolute-stability-plate-fixfin. [Accessed 2016].

[75] MatWeb, "Overview of Materials for Stainless Steel," 2009. [Online]. [Accessed 2016].

[76] MatWeb, "Titanium, Ti," 2009. [Online]. Available: http://www.matweb.com/search /DataSheet.aspx?MatGUID=66a15d609a3f4c829cb6ad08f0dafc01\&ckck=1.. [Accessed 2016].

[77] MatWeb, "Cobalt Co," 2009. [Online]. Available: http://www.matweb.com/search/ DataSheet.aspx?MatGUID=4602449fc566494ab3efa2 . [Accessed 2016].

[78] D. E. T. Cullinance, Principles of Bone Biology: Biomechanics of Bone, 2nd Edition ed., San Diego: Academic Press, 2000, pp. 17-32.

[79] N. Rucci, "Molecular Biology of Bone Remodelling," Journal of Clinical cases in mineral and bone metabolism, vol. 5, no. 1, pp. 49-56, 2008.

[80] K. Kusunose, "Experimental studies on less rigid polyacetal plates for fracture fixation," Nihon Seikeigeka Gakkai Zasshi, vol. 56, no. 5, pp. 339-414, 1982.

[81] H. P. Brunner and J. Simpson, "Fatigue fracture of bone plates," Journal of Injury, vol. 11, pp. 203-207, 1980.

[82] K. A. Mohammad, A. Aidy, B. B. Sahari and S. Abdullah, "Fatigue behavior of Austenitic Type 316L Stainless Steel," journal of IOP Conference Series: Materials Science and Engineering, vol. 36, pp. 1-9, 2012. 
[83] G. Dominique and D. Poitout, Biomechanics and Biomaterials in Orthopedics, London: Springer, 2004.

[84] S. L. Woo, W. H. Akeson, B. Levenetz, R. D. Coutts, J. V. Matthews and D. Amiel, "Potential application of graphite fiber and methyl methacrylate resin composites as internal fixation plates," Journal of Biomedical Materials Research, vol. 8, pp. 321-338, 1974.

[85] V. Kostopoulos, L. Vellios, A. P. Fortis, E. Panagiotopoulos, Z. Milis and E. Lambiris, "Comparative study of callus performance achieved by rigid and sliding plate osteosynthesis based upon dynamic mechanical analysis," Journal of medical engineering \& technology, vol. 18, pp. 61-66, 1994.

[86] M. S. Jasmine, L. E. Dahners and J. A. Gilbert, "Reduction of stress shielding beneath a bone plate by use of a polymeric underplate. An experimental study in dogs," Journal of Clinical orthopaedics and related research, vol. 246, pp. 293-299, 1989.

[87] D. L. Korvick, J. W. Newbrey, G. W. Bagby, G. D. Pettit and J. D. Lincoln, "Stress shielding reduced by a silicon plate-bone interface. A canine experiment," Journal of Acta orthopaedica Scandinavica, vol. 60, pp. 611-616, 1989.

[88] X. L. Zhang, K. R. Dai and T. T. Tang, "The effect of stress-relaxation plate fixation on the remodeling of the cortex under plate," Zhongguo xiu fu chong jian wai ke za zhi= Zhongguo xiufu chongjian waike zazhi $=$ Chinese journal of reparative and reconstructive surgery, vol. 15, pp. 1-4, 2001.

[89] S. Benli, S. Aksoy, H. Havitcioglu and M. Kucuk, "Evaluation of bone plate with lowstiffness material in terms of stress distribution," Journal of Biomechanics, vol. 41, pp. 3229-3235, 2008.

[90] A. S. Brydone, D. Meek and S. Maclaine, "Bone grafting, orthopaedic biomaterials, and bone engineering. Proceedings of the Institution of Mechanical Engineers, Part H," Journal of Engineering in Medicine, vol. 224, p. 1329-1343, 2010.

[91] A. M. Ballo, T. O. Narhi, E. A. Akca, T. Ozen, S. M. Syrjanen, L. V. Lassila and P. K. Vallittu, "Prepolymerized vs. in situpolymerized fiber-reinforced composite implants-a pilot study.," Journal of Dental Research, vol. 90, pp. 263-267, 2011.

[92] D. S. Zhao, N. Moritz, P. Laurila, R. Mattila, L. V. Lassila and S. N. N., "Development of a multi-component fiber-reinforced composite implant for load-sharing conditions," Journal of Medical engineering \& physics, vol. 31, pp. 461-469, 2009.

[93] S. H. Saidpour, "Assessment of carbon fibre composite fracture fixation plate using finite element analysis," Journal of Annals of biomedical engineering, vol. 34, pp. 1157-1163, 2006. 
[94] M. Dauner, H. Planck, L. Caramaro, Y. Missirlis and E. Panagiotopoulos, "Resorbable continuous-fibre reinforced polymers for osteosynthesis," Journal of Materials Science: Materials in Medicine, vol. 9, pp. 173-179, 1998.

[95] J. San Roman and G. P. Guillen, "Partially biodegradable polyacrylic-polyester composites for internal bone fracture fixation," Biomaterials, vol. 12, pp. 236-241, 1991.

[96] P. Tormala, J. Vasenius, S. Vainionpaa, J. Laiho, T. Pohjonen and P. Rokkanen, "Ultrahigh-strength absorbable self-reinforced polyglycolide (SR-PGA) composite rods for internal fixation of bone fractures: in vitro and in vivo study," Journal of Biomedical Materials Research, vol. 25, pp. 1-22, 1991.

[97] J. Choueka, J. L. Charvet, H. Alexander, O. Y. O., G. Joseph and N. C. Blumenthal, "Effect of annealing temperature on the degradation of reinforcing fibers for absorbable implants," Journal of Biomedical Materials Research, vol. 29, pp. 1309-1315, 1995.

[98] N. R. Boeree, J. Dove, J. J. Cooper, J. Knowles and G. W. Hastings, "Development of a degradable composite for orthopedic use; mechanical evaluation of an hydroxyapatitepolyhydroxybutyrate composite material," Journal of Biomaterials, vol. 14, no. 10, pp. 793-796, 1993.

[99] J. C. Knowles, G. W. Hastings, H. Ohta, S. Niwa and N. Boeree, "Development of a degradable composite for orthopedic use-in vivo biomechanical and histological evaluation of two bioactive degradable composites based on the polyhydroxybutyrate polymer," Journal of Biomaterials, vol. 13, no. 8, pp. 491-496, 1992.

[100] G. A. Edwards, J. A. Werkmeister, J. F. White, F. Casagranda and J. A. M. Ramshaw, "Evaluation of a collagen-based biosynthetic material for the repair of abdominal wall defects.," in 5th World Biomaterials Congress, Toronto, 1996.

[101] M. J. Sundaresan, E. G. Henneke and K. L. Reifsnider, "Prediction of fatigue life of composite femoral prostheses using acoustic emission technique," Journal of Composite, Technology and Research, vol. 16, no. 2, pp. 127-137, 1994.

[102] J. V. Raemdonch, J. V. Acker, N. Defoirdt and H. McKee, "Epoxy/flax fiber prepregs: properties and applications.," Journal of SAMPE, vol. 44, pp. 6-12, 2008.

[103] A. Foux, A. Yeadon and H. K. Uhthoff, "Improved fracture healing with less rigid plate: a biomechanical study in dogs," Journal of Clinical Orthopaedics and Related Research, vol. 339, pp. 232-245, 1995.

[104] A. Skirving, W. MacDonald and R. McLaren, "Carbon fiber reinforced plastic (CFRP) plates versus stainless steel dynamic compression plates in the treatment of fractures of the tibiae in dogs," Journal of Clinical Orthopaedics and Related Research, vol. 224, p. 117-124, 1987. 
[105] S. C. Amico, C. C. Angrizani and M. L. Drummond, "Influence of the stacking sequence on the mechanical properties of glass/sisal hybrid composites," Journal of Reinforced Plastics and Composites, vol. 29, no. 2, p. 179-189, 2010.

[106] Z. Gürdal, A. P. Tomasino and S. B. Biggers, "Effects of processing induced defects on laminate response. Interlaminar tensile strength," Journal of SAMPE, vol. 27, pp. 39-49, 1991.

[107] C. Meola and C. Toscano, "Flash Thermography to Evaluate Porosity in Carbon Fiber Reinforced Polymer (CFRPs)," Journal of Materials, vol. 7, pp. 1483-1501, 2014.

[108] L. Maragoni, P. A. Carraro, A. Dallavia and M. Quaresimin, "Influence of manufacturing induced voids on the mechanical properties of Carbon/Epoxy Laminates," Associazione Italiana per L'Analisi Delle Sollecitazioni, p. 384, 2014.

[109] A. R. Chambers, J. S. Earl, C. A. Squires and M. A. Suhot, "The effect of voids on the flexural fatigue performance of unidirectional carbon fibre composites developed for wind turbine applications," International Journal of Fatigue, vol. 28, no. 10, pp. 1389-1398, 2006.

[110] M. Ricotta, M. Quaresimin and R. Talreja, "Mode I strain energy release rate in composite laminates in the presence of voids," Journal of Composites Science and Technology, vol. 68, no. 13, pp. 2616-2623, 2008.

[111] H. Zhu, B. Wu, D. Li, D. Zhang and Y. Chen, "Influence of Voids on the Tensile Performance of Carbon/epoxy Fabric Laminates," Journal of Material Science Technology, vol. 27, no. 1, pp. 69-73, 2011.

[112] R. Zdero, R. Walker, J. P. Waddell and E. H. Schemitsch, "Biomechanical Evaluation of Periprosthetic Femoral Fracture Fixation," Journal of Bone and Joint Surgery (American), vol. 90, no. 5, p. 1068-1077, 2008.

[113] S. M. Tuusa, L. V. Lassila, J. P. Matinlinna, M. J. Peltola and P. K. Vallittu, "Initial adhesion of glass-fiber-reinforced composite to the surface of porcine calvarial bone," Journal of Biomedial Materials Research Part B Applied Biomaterials, vol. 75, no. 2, p. 334-342, 2005.

[114] S. M. Tuusa, M. J. Peltola, T. Tirri, M. A. Puska, M. Ro“ytta“, H. Aho, J. Sandholm, L. V. Lassila and P. K. Vallittu, "Reconstruction of critical size calvarial bone defects in rabbits with glass-fiber-reinforced composite with bioactive glass granule coating," Journal of Biomedial Materials Research Part B Applied Biomaterials, vol. 84, no. 2, p. 510-519, 2008.

[115] N. Moritz, N. Strandberg, D. S. Zhao, R. Mattila, L. Paracchini, P. Vallittu and H. T. Aro, "Mechanical properties and in vivo performance of load-bearing fiber-reinforced 
compositeintramedullary nails with improved torsional strength.," Journal of Mechanical Behavior of Biomedical Materials, vol. 40, no. 0, p. 127-139, 2014.

[116] ASTM International, "Standard Test Method for Water Absorption of Plastics, ASTM D570-98," ASTM, West Conshohocken, PA., 2010 b.

[117] ASTM International, " Standard Test Method for Tensile Properties of Polymer Matrix Composite Materials, ASTM D3039/D3039M-14," ASTM, West Conshohocken, PA., $2008 b$.

[118] ASTM International, "Standard Test Method for Compressive Properties of Rigid Plastics, ASTM D695-10," ASTM, West Conshohocken, PA, 2010a.

[119] ASTM International, " Standard Test Method for Flexural Properties of Polymer Matrix Composite Materials, ASTM D7264/D7264M—07," ASTM , West Conshohocken, PA., 2015.

[120] ASTM International, " Standard Test Method for Rockwell Hardness of Plastics and Electrical Insulating Materials, ASTM D785-08," ASTM, West Conshohocken, PA., 2008 b.

[121] N. Moritz, N. Strandberg, D. S. Zhao, R. Mattila, L. Paracchini, P. K. Vallittu and H. T. Aro, "Mechanical properties and in vivo performance of load-bearing fiber-reinforced compositeintramedullary nails with improved torsional strength," Journal of Mechanical Behavior of Biomedical Materials, vol. 40, p. 127-139, 2014.

[122] Z. S. Bagheri, I. El Sawi, E. H. Schemitsch, R. Zdero and H. Bougherara, "Biomechanical properties of an advanced new carbon/flax/epoxy composite material for bone plate application," Journal of the Mechanical Behavior of Biomedical Materials, vol. 20, p. 398-406, 2013.

[123] K. Charlet, J. P. Jernot, M. Gomina, L. Bizet and J. Bread, "Mechanical properties of flax fibers and of the derived unidirectional composites," Journal of Composite Materials, vol. 44, pp. 2887-2896, 2010.

[124] C. Baley and B. Lamby, "Stiffness prediction of flax fibers-epoxy composite materials," Journal of Material Science Letters, vol. 19, p. 979-980, 2000.

[125] P. B. Gning, S. Liang and L. Guillaumat, "Influence of process and test parameters on the mechanical properties of flax/epoxy composites using response surface methodology," Journal of Materials Science, vol. 46, no. 21, p. 6801-6811, 2011.

[126] V. Fiore, G. Di Bella and A. Valenza, "Glass-basalt epoxy hybrid composites for marine applications," Journal of Material and Design, vol. 32, no. 4, p. 2091-2099, 2010. 
[127] J. A. Disegi and L. Eschbach, "Stainless steel in bone surgery," Journal of Injury, vol. 4, pp. 2-6, 2000.

[128] O. E. Pohler, "Unalloyed titanium alloys for implants in bone surgery," Journal of Injury, vol. 4, pp. 7-13, 2000.

[129] J. Montesano, Z. Fawaz and H. Bougherara, "Use of infrared thermography to investigate the fatigue behavior of a carbon fiber reinforced polymer composite," Journal of Composite Structures, vol. 97, p. 76-83, 2013.

[130] I. El Sawi, Z. Fawaz, R. Zitoune and H. Bougherara, "An investigation of the damage mechanisms and fatigue life diagrams of flax fiber-reinforced polymer laminates," Journal of Matreial Science, vol. 49, pp. 2338-2346, 2014.

[131] F. C. Campbell, Elements of Metallurgy and Engineering Alloys, ASM International, 2008.

[132] D. R. Askeland, P. Pradeep and W. J. Wright, The Science and Engineering of Materials, 6 ed., Cengage Learning, 2010, p. 896.

[133] H. El Kadi, "Modeling the mechanical behavior of fiber-reinforced polymeric composite materials using artificial neural networks-A review," Journal of Composite Structures, vol. 73, no. 1, pp. 1-23, May 2006.

[134] B. Harris, Fatigue in composites: science and technology of the fatigue response of fibrereinforced plastics, Oxford: Woodhead Publishing Limited, 2003.

[135] J. Montesano, Fatigue Damage Characterization of Braided and Woven Fiber Reinforced Polymer Matrix Composites at Room and Elevated Temperatures, 2012.

[136] G. Pitarresi and E. Patterson, "A review of the general theory of thermoelastic stress analysis.," Journal of Strain Analysis of Engineering Design, vol. 38, pp. 405-417, 2003.

[137] R. Greene, E. Patterson and R. Rowlands, Springer handbook of experimental solid mechanics, S. W.N., Ed., New York: Springer, 2008.

[138] M. Quaresimin and E. Guglielmino, "In: Paolo P (ed) Proceedings of the fifth seminar on experimental techniques and design in composite materials," in Trans tech publications, Cagliari, 2000.

[139] V. Dattoma, R. Marcuccio, C. Pappalettere and G. M. Smith, "Thermographic investigation of sandwich structure made of composite material," Journal of NDT \& International, vol. 34, no. 8, p. 515-520, 2001. 
[140] M. Karama, "Determination of the fatigue limit of a carbon/epoxy composite using thermographic analysis," Journal of Structural Control Health Monitoring, vol. 18, p. 781-789, 2011.

[141] F. D. Silva, N. Chawla and R. D. De Toledo, "An experimental investigation of the fatigue behavior of sisal fibers," Journal of Materials Science and Engineering, vol. 516, no. 1-2, pp. 90-95, 2009.

[142] A. Belaadi, A. Bezazi, M. Bourchak and F. Scarpa, "Tensile static and fatigue behaviour of sisal fibres," Journal of Material Design, vol. 46, p. 76-83, 2013.

[143] D. U. Shah, P. Schubel, M. J. Clifford and P. Licence, "Fatigue life evaluation of aligned plant fibre composites through $\mathrm{S}-\mathrm{N}$ curves and constant-life diagrams," Journal of Composites Science and Technology, vol. 74, p. 139-149, 2013.

[144] M. P. Luong, "Fatigue limit evaluation of metals using an infrared thermographic technique," Journal of Mechanics of Materials, vol. 28, pp. 155-163, 1998.

[145] M. P. Luong, "Infrared thermographic scanning of fatigue in metals," Journal of Nuclear Engineering and Design, vol. 158, pp. 363-376, 1995.

[146] G. Fargione, A. Geraci, G. La Rosa and A. Risitano, "Rapid determination of the fatigue curve by the thermographic method," International Journal of Fatigue, vol. 24, pp. 11-19, 2002.

[147] G. La Rosa and A. Risitano, "Thermographic methodology for rapid determination of the fatigue limit of materials and mechanical components," International Journal of Fatigue, vol. 22, pp. 65-73, 2000.

[148] "ASTMF382. Standard Specification and Test Method for Metallic Bone Plates," in Annual Book of ASTM Standards, 2008.

[149] C. Baley, "Analysis of the flax fibres tensile behaviour and analysis of the tensile stiffness increase," Journal of Composite Part A, vol. 33, pp. 939-948, 2002.

[150] H. Spatz, L. Kohler and K. Niklas, "Mechanical behaviour of plant tissues: composite materials or structures?," Journal of Experimental Biology, vol. 202, pp. 3269-3272, 1999.

[151] S. Liang, P. B. Gning and L. Guillaumat, "A Comparative Study of Fatigue Behaviour of Flax/Epoxy and Glass/Epoxy Composites," Journal of Composite Science Technology, vol. 72, p. 535-543, 2012.

[152] S. Shah, H. Bougherara, E. H. Schemitsch and R. Zdero, "Biomechanical stress maps of an artificial femur obtained using a new infrared thermography technique validated by strain gages," Journal of Medical engineering \& physics, vol. 34, pp. 1496-1502, 2012. 
[153] "Physiotherapy in Waterdown and Flamborough for Pediatric Issues," [Online]. Available: http://waterdownphysiotherapy.com/Injuries-Conditions/Pediatric/PediatricIssues/Guide-for-Rotational-Deformities-in-Children/a 3265/article.html..

[154] D. R. Carter and W. C. Hayes, "Compact bone fatigue damage, Residual strength and stiffness," Journal of Biomechanics, vol. 10, pp. 325-337, 1977.

[155] R. Steinberger, T. Valadas Leitão, E. Ladstätter, G. Pinter, W. Billinger and R. W. Lang, "Infrared thermographic techniques for non-destructive damage characterization of carbon fibre reinforced polymers during tensile fatigue testing," International Journal of Fatigue, vol. 28, pp. 1340-1347, 2006.

[156] R. Yahaya, S. M. Sapuan, M. Jawid, Z. Leman and E. S. Zaynudin, "Effect of fibre orientations on the mechanical properties of kenaf-aramid hybrid composites for spallliner application," Journal of Deffence Technology, vol. 12, pp. 52-58, 2016.

[157] Z. S. Bagheri, E. Giles, I. El Sawi, A. Amleh, E. H. Schemitsch, R. Zdero and H. Bougherara, "Osteogenesis and cytotoxicity of a new carbon fiber/flax/epoxy composite material for bone fracture plate applications," Journal of Materials Science and Engineering, vol. 46, p. 435-442, 2015.

[158] X. Y. Su, Z. Zhao, J. X. Zhao, L. C. Zhang, A. H. Long, L. H. Zhang and P. F. Tang, "Three-Dimensional Analysis of the Curvature of the Femoral Canal in 426 Chinese Femurs," Journal of BioMed Research International, vol. 2015, 2015.

[159] T. D. Stewart, "Anterior femoral curvature: its utility for race identification," in Human Biology, vol. 34, Washington, D.C.: Wayne State University Press, 1962, p. 49-62.

[160] A. Morawska-Chocho'ł, J. Chłopek, B. Szaraniec, P. Domalik-Pyzik, E. Balacha, M. Bogun' and R. Kucharski, "Influence of the intramedullary nail preparation method on nail's mechanical properties and degradation rate," Journal of Material Science and Engineering, vol. 51, p. 99-106, 2015.

[161] P. K. Vallittua, O. T. Närhi and L. Hupa, "Fiber glass-bioactive glass composite for bone replacing and bone anchoring implants," Journal of Dental Materials, vol. 31, no. 4, pp. 371-381, 2015. 